\title{
Einfluss der Helix 1 und des $\beta$-Faltblattes auf die Aggregation des Prionproteins und seine Amyloidstruktur
}

\author{
Dissertation \\ zur Erlangung des Doktorgrades \\ der Mathematisch-Naturwissenschaftlichen Fakultäten \\ der Georg-August-Universität Göttingen
}

\author{
vorgelegt von \\ Jens Watzlawik \\ aus \\ Stadthagen
}

Göttingen, 2006 
D 7

Referent: Prof. Dr. Hans-Joachim Fritz

Koreferent: Prof. Dr. Rüdiger Hardeland

Tag der mündlichen Prüfung: 18.01.2007 


\section{Inhaltsverzeichnis}

$\begin{array}{ll}\text { Abkürzungen } & \text { VI }\end{array}$

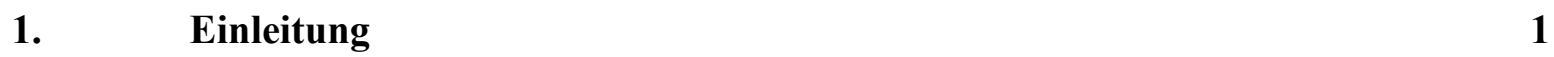

1.1. Die Prionerkrankungen 1

1.2. Das zelluläre Prionprotein $\left(\operatorname{PrP}^{\mathrm{C}}\right) \quad 2$

1.2.1. Struktur des Prionproteins 3

1.2.2. Funktionen des Prionproteins 4

1.3. Die pathologische Form des Prionproteins $\left(\operatorname{PrP}^{\mathrm{Sc}}\right)$

1.3.1. Eigenschaften des pathologischen Prionproteins $\left(\mathrm{PrP}^{\mathrm{Sc}}\right)$

1.3.2. Die Prionhypothese 6

$\begin{array}{lll}\text { 1.3.3. } & \text { Prionerregerstämme und Speziesbarrieren } & 7\end{array}$

1.3.4. Mechanismus der Umfaltung von $\operatorname{PrP}^{\mathrm{C}}$ in $\operatorname{PrP}^{\mathrm{Sc}} \quad 7$

1.3.5. $\quad$ Einfluss des $\mathrm{pH}-$ Wertes auf die Aggregation des Prionproteins 9

$\begin{array}{lll}\text { 1.3.6. } & \mathrm{PrP}^{\mathrm{Sc}} \text {-Strukturmodelle } & 10\end{array}$

$\begin{array}{lll}\text { 1.4. Zielsetzung } & 12\end{array}$

$\begin{array}{ll}\text { 2. } & 14\end{array}$

$\begin{array}{lll}\text { 2.1. } & \text { Material } & 14\end{array}$

2.1.1. Chemikalien 14

2.1.2. Enzyme und Antibiotika 15

2.1.3. „Kits“ zur Behandlung von DNA 15

2.1.4. DNA- und Protein-,,Standards“

2.1.5. Verbrauchsmaterialien zum Arbeiten mit Bakterien 16

2.1.6. Verbrauchsmaterialien für Western Blots 16

2.1.7. Lösungen und Puffer für Arbeiten mit DNA 16 
2.1.8. Lösungen und Puffer für Proteinarbeiten 18

2.1.9. Nährmedien für die Mikrobiologie 20

2.1.10. Escherichia coli-Stämme 21

2.1.11. Oligodesoxyribonukleotide 22

2.1.12. Mutagenese- Oligodesoxyribonukleotide 23

2.1.13. Plasmide 24

2.1.14. Antikörper für die Immunologische Detektion 27

2.2. Mikrobiologische und genetische Arbeitsmethoden 28

2.2.1. Lagerung von Bakterienstämmen 28

2.2.2. Stammhaltung von E. coli-Kulturen 28

2.2.3. Anzuchtbedingungen und Wachstumsmessung 28

2.2.4. Präparation von kompetenten E. coli-Zellen (Nishimura et al., 1990) 28

2.2.5. Transformation von E. coli mit Plasmid-DNA 29

2.2.6. Allgemeine Methoden zum Arbeiten mit DNA 29

2.2.6.1. Fällung von DNA mit Ethanol 29

2.2.6.2. Extraktion von DNA mit Chloroform/Phenol/Isoamylalkohol 30

2.2.6.3. Konzentrationsbestimmung der DNA 30

2.2.6.4. Spaltung von DNA mit Restriktionsendonukleasen 30

2.2.6.5. Isolierung von Plasmid-DNA 31

2.2.7. Agarosegelelektrophorese 32

2.2.8. Präparation von DNA für die Subklonierung von DNA-Fragmenten in Plasmidvektoren 33

2.2.9. Ligation von DNA-Fragmenten in Plasmidvektoren 33

2.2.10. Polymerase-Kettenreaktion (PCR) 34

2.2.11. Einführung von Mutationen durch site directed mutagenesis (Quick change) 35

2.2.12. Einführung von Mutationen durch Polymerase-Kettenreaktion (SOE-PCR) 35

2.2.13. Herstellung der Prnp-Konstrukte im pET27b(+)-Vektor 36 
2.3.1. Proteinkonzentrationsbestimmung

2.3.2. Expression und Aufreinigung von humanem Prionprotein aus zytoplasmatischen Einschlusskörpern (Inclusion bodies) im Vollmedium $\quad 37$

2.3.2.1. Inclusion body-Aufreinigung 38

2.3.2.2. Chromatographische Aufreinigung 39

2.3.3. Expression und Aufreinigung von humanem Prionprotein aus zytoplasmatischen Einschlusskörpern (Inclusion bodies) in M9 Minimalmedium für die NMR-Spektroskopie

2.3.4. Allgemeines Rückfaltungsprotokoll für das Prionprotein 41

2.3.5. Entsalzung und Aufkonzentration $\quad 42$

2.3.6. SDS-Acrylamid-Gelelektrophorese (SDS-PAGE) 43

2.3.7. Immunologischer Nachweis elektrophoretisch aufgetrennter Proteine (Western Blot) 45

2.3.8. Kapillarelektrophorese (CE) 46

2.3.9. Elektronenmikroskopie-Negativkontrastierung 46

2.3.10. Messung der Aggregationsgeschwindigkeit des Prionproteins 47

$\begin{array}{ll}\text { 2.3.10.1. Thioflavin T (ThT)-Assay } & 47\end{array}$

2.3.10.2. Absorptionsspektroskopie $\quad 48$

2.3.11. Proteinase K-Verdau 49

2.3.12. Edman-Sequenzierung 49

2.3.13. Massenspektrometrie (MALDI-MS) 50

2.4. Spektroskopische Verfahren $\quad 51$

2.4.1. FTIR-Spektroskopie 51

2.4.2. CD-Spektroskopie 52

2.4.3. NMR-Spektroskopie von humPrP23-159 und humPrP23-173 $\quad 53$ 
3. Ergebnisse

3.1. Herstellung und Charakterisierung verschiedener

Prionproteinfragmente

3.1.1. Herstellung der verschiedenen Prionproteinfragmente 56

3.1.2. Überprüfung der Reinheit der Prionproteinfragmente 56

3.1.3. Strukturanalyse der Prionproteinfragmente 59

3.2. Einfluss der Helix 1 auf die Aggregation des humanen Prionproteins

3.2.1. Nachweis des monomeren Zustands

von humPrP23-144 und humPrP23-159

3.2.2. Vergleich der spontanen Aggregation von humPrP23-159

mit humPrP23-144

3.2.3. Vergleich der Aggregation von humPrP23-159 mit

humPrP23-144 unter Zugabe von fibrillärem Prionprotein (Seeding)

3.2.4. Morphologie von aggregiertem humPrP23-159 und humPrP23-144 74

3.2.5. Proteinase K-Resistenz der Helix 1 in fibrillärem humPrP23-159 75

3.2.6. FTIR-spektroskopische Untersuchung der fibrillären Aggregate von humPrP23-159 und humPrP23-144

3.2.6.1. Zuordnung der Absorptionsbanden zu spezifischen Strukturelementen in humPrP23-159 und humPrP23-144

3.2.6.2. Quantitative Analyse der FTIR-Spektren von fibrillärem humPrP23-159 und fibrillärem humPrP23-144

3.3. $\quad$ Einfluss des pH-Wertes auf die Aggregation von humPrP23-159 und humPrP23-144

\subsection{Einfluss der N-terminalen Region des humanen Prionproteins} auf seine Aggregation 
3.5.1. Vergleich der Aggregation von humPrP23-173 mit humPrP23-159

3.5.2. Morphologie von aggregiertem humPrP23-173

3.5.3. Proteinase K-Resistenz des $\beta$-Strands S2 und der Helix 1 in fibrillärem humPrP23-173

4. Diskussion

4.1. In vitro Modell zur Simulation konformativer Änderungen

des humanen Prionproteins in seine pathologische Isoform

4.2. $\quad$ Einfluss des $\mathrm{pH}-$ Wertes auf die Bildung des pathologischen Prionproteins

4.3. Einfluss der N-terminalen Domäne, der Helix 1 und des $\beta$-Strands S2 auf den Mechanismus der Aggregation des humanen Prionproteins

4.4. Struktur des pathologischen Prionproteins

5. Ausblick

6. Zusammenfassung

7. Literaturverzeichnis 


\section{ABKÜRZUNGEN}

AA Acrylamid

Abb. Abbildung

AS Aminosäure

APS Ammoniumpersulfat

bp Basenpaare

${ }^{\circ} \mathrm{C}$ Grad Celsius

ca. circa

CD-Spektroskopie Cicular-Dichroismus-Spektroskopie

cDNA komplementäre Desoxyribonukleinsäure

cm Zentimeter

d. h. das heißt

DMF Dimethylformamid

DMSO Dimethylsulfoxid

DNA Desoxyribonukleinsäure

dNTP 2'-Desoxyribonucleosid-5'-triphosphate

DTT Dithiothreitol

EDTA Ethylendiamintetraessigsäure

et al. et alteri, und andere

FTIR-Spektroskopie Fourier-Transformations-Infrarot-Spektroskopie

GPI Phosphatidylinositolglykolipid

h Stunden

hum human

kb Kilobasenpaare

kDa Kilodalton

1 Liter

M molar

$\mathrm{m} \operatorname{Mikro}\left(10^{-6}\right)$

mA Milliampère

MES Morpholinoethansulfonsäure

min Minuten 
ml Milliliter

moPrP murines Prionprotein (Maus)

MOPS Morpholinopropansulfonsäure

n Nano $\left(10^{-9}\right)$

NMR. nuclear magnetic resonance ( kernmagnetische Resonanz)

$\mathrm{OD}_{600}$ optische Dichte bei einer Wellenlänge von $600 \mathrm{~nm}$

ORF offener Leserahmen (Open Reading Frame)

p Pico $\left(10^{-12}\right)$

PAGE Polyacrylamidgelelektrophorese

PK Proteinase $\mathrm{K}$

PMSF Phenylmethylsulfonylfluorid

RNAse Ribonuklease

Prnp für das Prionprotein codierendes Gen

PrP Prionprotein

rpm Umdrehungen pro Minute (revolutions per minute)

RT Raumtemperatur

SDS Natriumdodecylsulfat

SHa Syrischer Hamster

SHaPrP Prionprotein des syrischen Hamsters

TEMED N,N,N',N'-Tetramethylethylendiamin

Tris Trishydroxymethylaminomethan

U Unit(s), Enzymeinheit

u. a. unter anderem, unter anderen

UV Ultraviolett

v/v Volumen pro Volumen

wt Wildtyp

w/v Gewicht pro Volumen

X-Gal 5-Brom-4-chlor-3-indolyl-ß-D-galaktopyranosid 


\section{Einleitung}

\subsection{Die Prionerkrankungen}

Prionerkrankungen repräsentieren eine Gruppe sporadischer, vererbbarer oder erworbener neurodegenerativer Erkrankungen. Sie sind übertragbar und verlaufen immer tödlich. Zusammengefasst werden sie auch unter dem Begriff transmissible spongiforme Enzephalopathien (TSEs, transmissible spongiform encephalopathies) (Creutzfeldt, 1920; Jakob, 1921; Gerstmann et al., 1936; Gajdusek \& Zigas, 1959; Manetto et al., 1992; Medori et al., 1992; Goldfarb et al., 1992).

$\mathrm{Zu}$ den humanen Prionerkrankungen zählen die Creutzfeldt-Jakob-Krankheit (CJD), Kuru, das Gerstmann-Sträussler-Scheinker-Syndrom (GSS) und die tödliche familiäre Schlaflosigkeit (FFI, fatal familial insomnia). Bei den Tieren sind unter anderem die bovine spongiforme Enzephalopathie (BSE) beim Rind, die Traberkrankheit (Scrapie) bei Schaf und Ziege und die chronisch zehrende Erkrankung (CWD, chronic wasting disease) der Hirsche und Hirschartigen bekannt.

Die molekulare Grundlage der bekannten Prionerkrankungen ist die Umfaltung des zellulären Prionproteins $\mathrm{PrP}^{\mathrm{C}}$ in eine pathogene $\mathrm{PrP}^{\mathrm{Sc}}$-Form (Kapitel 1.3.). Neuropathologische Kennzeichen aller TSEs sind Ablagerungen des pathologischen Prionproteins im Gehirn, schwammartige Läsionen mit Vakuolenbildung, massiver Nervenzellverlust und die Aktivierung von astrozytären Gliazellen (Astrogliose). Die Proteinablagerungen können dabei entweder fein granulär oder fibrillärer Natur sein, wobei die fibrillären Strukturen in Form so genannter Plaques organisiert und für die Klassifikation der Erkrankungsform bedeutsam sind (Kretzschmar et al., 2001).

Die häufigste humane Prionerkrankung ist die sporadische Form der Creutzfeldt-JakobKrankheit (sCJD), deren Ursache bislang unbekannt ist. Sie tritt in $90 \%$ aller Fälle auf. Bei etwa zehn Prozent der humanen Prionenerkrankungen konnten Punkt- bzw. Insertionsmutationen im für das Prionprotein codierenden Prnp-Gen für das Auftreten der Krankheit verantwortlich gemacht werden (Abb.1) (Glatzel et al., 2005).

Neben den Punkt- bzw. Insertionsmutationen ist der natürlich vorkommende Methionin/ Valin-Polymorphismus am Codon 129 im humanen Prnp-Gen (Abb. 1) eine entscheidende Determinante, an allen Formen der TSE zu erkranken. Einige der pathogenen Mutationen im 
Prnp-Gen kommen nur mit einem bestimmten Polymorphismus am Codon 129 auf dem gleichen Allel vor (Gambetti et al., 2003; Ironside et al., 2005).

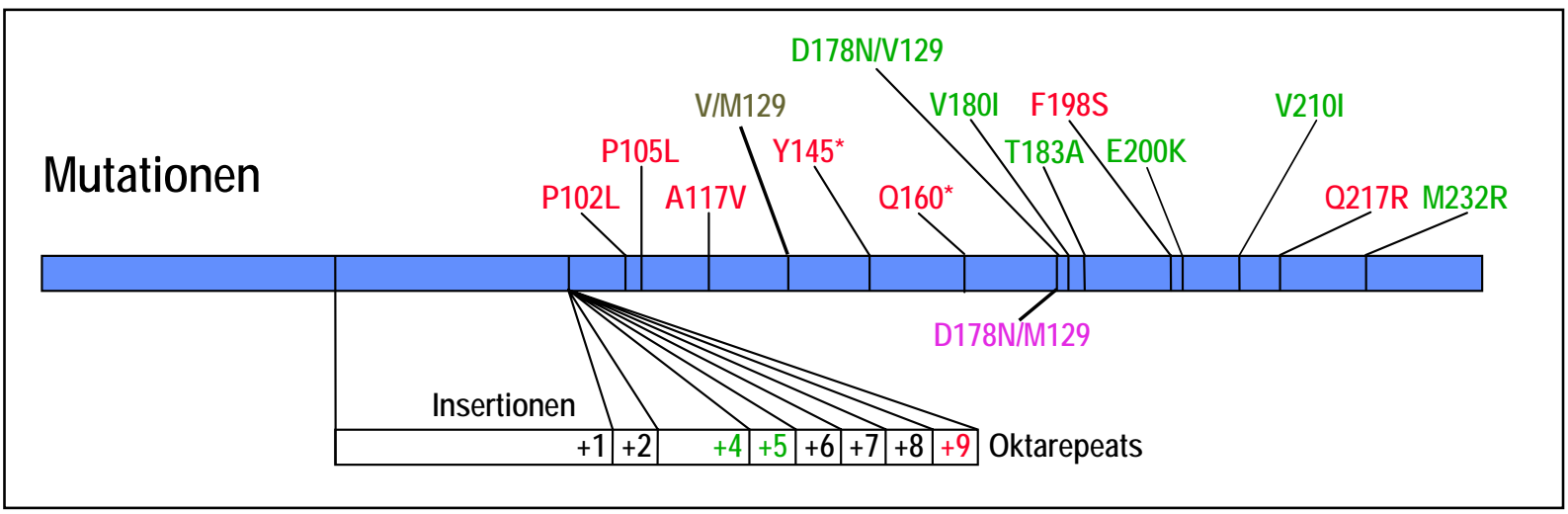

Abb. 1: Polymorphismus 129 und pathogene Mutationen im Prnp-Gen. Dargestellt wurde der für das Prionprotein codierende Bereich auf dem Exon 2 im humanen Prnp-Gen auf dem Chromosom 20. Die mit den verschiedenen Prionerkrankungen assoziierten Mutationen und der Polymorphismus 129 wurden in verschiedenen Farben dargestellt: grün (familiäre Formen der Creutzfeldt-Jakob-Krankheit (fCJD)), rot (GSS), pink (FFI) und braun (V/M-Polymorphismus am Codon 129). Die Insertionsmutationen codieren für zusätzliche Oktarepeats und können mit der GSS (+9 Oktarepeats), der fCJD (+4 bzw. +5 Oktarepeats) oder einer nicht klar definierten Prionerkrankung assoziiert sein (schwarz). Die pathogenen Stopmutanten wurden mit Y145* bzw. Q160* bezeichnet.

Eine besondere Stellung innerhalb der Prionerkrankungen nimmt die Variante der CreuzfeldtJakob-Erkrankung (vCJD) ein, die durch den Verzehr von mit dem BSE-Erreger kontaminierten Schlachtprodukten herrührt und die gleichen Erregerstammkriterien wie die BSE aufweist (Bruce et al., 1997; Hill et al., 1997; Lazmesas et al., 1996; Scott et al., 1999). Sie bildet zusammen mit der Kuru und den iatrogenen Formen der CJD (iCJD) die dritte Gruppe der relativ seltenen erworbenen humanen Prionerkrankungen, die durch ein direktes Einbringen des infektiösen Agens in den Körper übertragen werden.

\subsection{Das zelluläre Prionprotein $\left(\operatorname{PrP}^{\mathrm{C}}\right)$}

Die zelluläre Form des humanen Prionproteins $\left(\operatorname{PrP}^{\mathrm{C}}\right)$ ist ein Sialoglykoprotein von 209 Aminosäuren Länge (humPrP23-231). Das Prionprotein ist extrazellulär vor allem auf der 
Zelloberfläche von Neuronen (Kretzschmar et al., 1986) über einen Glykosylphosphatidylinositol (GPI)- Anker in Detergenz-resistenten, Cholesterol und Sphingolipid reichen Mikrodomänen, den lipid rafts, in der Plasmamembran verankert (Abb. 2) (Vey et al., 1996; Kaneko et al., 1997; Peters et al., 2003). $\operatorname{PrP}^{\mathrm{C}}$ wird konstitutiv internalisiert und zu 90 \% zurück zur Zelloberfläche transportiert (Harris et al., 2003; Prado et al., 2004). Die Halbwertszeit von $\operatorname{PrP}^{\mathrm{C}}$ auf der Zellmembran wurde mit 3-6 h beschrieben (Caughey et al., 1989).

\subsubsection{Struktur des Prionproteins}

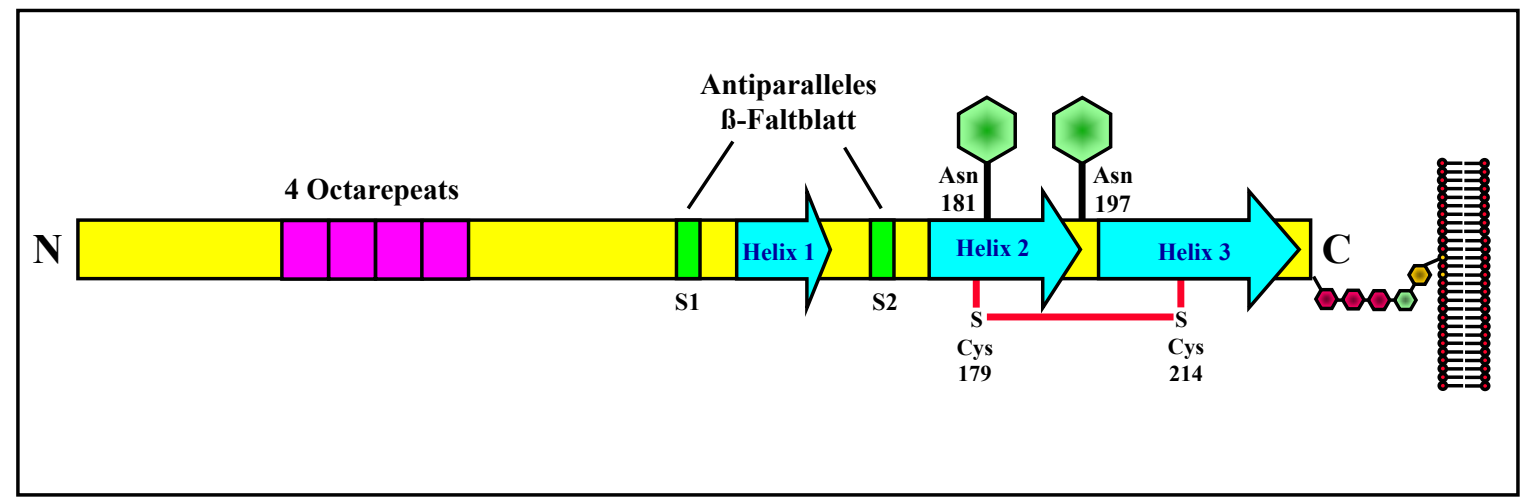

Abb. 2: Schematische Darstellung des humanen Prionproteins. Das Prionprotein ist extrazellulär über den GPI-Anker (kleine Sechsecke) in der Plasmamembran verankert. Die Helices sind in türkis, die beiden NGlykosylierungen in grün, das antiparallele $\beta$-Faltblatt mit den $\beta$-Strands S1 und S2 in grün, die Disulfidbrücke in rot und die Oktarepeatregion in pink dargestellt.

Die Struktur des Prionproteins gliedert sich in eine globuläre, $\alpha$-helikale C-terminale Domäne und eine flexible, unstrukturierte N-terminale Domäne. In der strukturierten C-terminalen Domäne (Aminosäure 121-231) befinden sich drei $\alpha$-Helices (Helix 1: 144-156, Helix 2: 174194, Helix 3: 200-228) und ein kurzes aus acht Aminosäuren bestehendes zweisträngiges antiparalleles $\beta$-Faltblatt (Strand 1 (S1): 128-131, Strand 2 (S2): 161-164) (Zahn et al., 2000; Calzolai \& Zahn, 2003) (Abb. 2).

Die hydrophoben Helices 2 und 3 sind durch einen kurzen Loop miteinander verbunden und bilden ein kompaktes Helix-Bündel, das durch eine Disulfidbrücke zwischen Cystein 179 und Cystein 214 stabilisiert ist. Helix 1 kann aufgrund seiner sehr polaren Aminosäuresequenz kaum stabilisierende hydrophobe Tertiärkontakte ausbilden und ist damit vom Rest des 
Moleküls isoliert (Morissey \& Shakhnovich, 1999). Die Stabilisierung der Helix 1 soll rein intrahelikal durch zwei (Asp-Arg) Salzbrücken erfolgen (Speare et al., 2003).

Die beiden N-Glykosylierungen befinden sich in der C-terminalen Domäne an Asn 181 innerhalb der Helix 2 und an Asn 197 in dem kurzen Loop zwischen Helix 2 und Helix 3. Im Western Blot detektiert man drei Banden für das zelluläre Prionprotein, die die unterschiedlichen Glykosylierungsformen des Proteins repräsentieren (doppelt, einfach und unglykosyliertes Prionprotein).

Der N-terminale Bereich des Prionproteins PrP23-120 stellt eine $\mathrm{Cu}^{2+}$-bindende Domäne mit einem $\mathrm{Cu}^{2+}$-Bindungsmotiv dar, den so genannten Oktarepeats (Hornshaw et al., 1995; Schätzl et al., 1995; Brown et al., 1997; Viles et al., 1999; Wopfner et al., 1999, Kramer et al., 2001). Die Oktarepeats (Aminosäure 60-91) bestehen aus einer hoch konservierten sich viermal wiederholenden Sequenz aus acht Aminosäuren (PHGGGWGQ), in der das Histidin essentiell für die $\mathrm{Cu}^{2+}$-Bindung ist (Riek et al., 1996, 1997; Zahn et al., 2000).

\subsubsection{Funktionen des Prionproteins}

Die genaue Funktion des zellulären Prionproteins ist ungeklärt. Obwohl Prnp ${ }^{0 / 0}$-Mäuse ohne Prionprotein lebensfähig sind (Bühler et al., 1992), zeigt sich bei ischämischen Hirnverletzungen eine verminderte Regenerationsfähigkeit des Gewebes ohne zelluläres Prionprotein, was durch die Inaktivierung einer antiapoptotischen Signalkaskade erklärt werden kann (Weise et al., 2006). Bei Wildtyp-Mäusen konnte nach der Hirnverletzung ein Anstieg der $\operatorname{PrP}^{\mathrm{C}}$-Level beobachtet werden, die sich proportional zum Ausmass der neuronalen Schädigung verhielten (Weise et al., 2004).

$\operatorname{Prnp}^{0 / 0}$-Mäuse zeigten ausserdem eine höhere Empfänglichkeit gegenüber oxidativem Stress (Wong et al., 2001).

Viele Evidenzen deuten darauf hin, dass das Prionprotein in den Kupfertransport oder Kupfermetabolismus der Zelle involviert ist, wobei $\mathrm{Cu}^{2+}$-Ionen die Endozytose des Prionproteins induzieren (Pauly et al., 1998; Watt et al., 2003; Lee et al., 2001; Brown et al., 2001; Kramer et al., 2001; Chiarini et al., 2002).

Andere Arbeiten zeigten, dass das Prionprotein an der Signaltransduktion und der synaptischen Transmission beteiligt sein könnte (Mouillet-Richard et al., 2000; Mallucci et al., 2002; Collinge et al., 1994). 


\subsection{Die pathologische Isoform des Prionproteins $\left(\mathrm{PrP}^{\mathrm{Sc}}\right)$}

\subsubsection{Eigenschaften des pathologischen Prionproteins $\left(\mathrm{PrP}^{\mathrm{Sc}}\right)$}

Im Unterschied zum zellulären Prionprotein $\mathrm{PrP}^{\mathrm{C}}$ kommt das pathologische Prionprotein $\mathrm{PrP}^{\mathrm{Sc}}$ nur in oligomerer oder fibrillärer Form vor (Swietnicki et al., 2000). $\mathrm{PrP}^{\mathrm{Sc}}$ ist unlöslich in nicht-denaturierenden Detergentien und prinzipiell infektiös. Der Nachweis von pathologischem Prionprotein erfolgt durch einen limitierten Proteinase K-Verdau unter Bedingungen, bei denen nur das zelluläre Prionprotein $\operatorname{PrP}^{\mathrm{C}}$ komplett verdaut wird. Das aus dem partiellen Proteinase K-Verdau resultierende $\operatorname{PrP}^{\mathrm{Sc}}$ wird $\mathrm{PrP} 27-30$ genannt, weil sein Laufverhalten in der SDS-PAGE etwa dem eines 27-30 kDa grossen Proteins entspricht. PrP27-30 ist weiterhin infektiös und besteht noch aus den Aminosäuren 90-231.

Auf struktureller Ebene weist $\operatorname{PrP}^{\mathrm{Sc}}$ einen hohen $\beta$-Faltblatt-Anteil von etwa $32-37 \%$ und einen $\alpha$-helikalen Anteil von etwa 12-17\% auf, wohingegen die Struktur des $\operatorname{PrP}^{\mathrm{C}}$ überwiegend von $\alpha$-Helices dominiert wird (Tabelle 1). In den meisten Fällen (Tabelle 1) wurden strukturelle Untersuchungen am $\mathrm{PrP} 27-30$ und nicht am $\mathrm{PrP}^{\mathrm{Sc}}$ durchgeführt, da die $\mathrm{PrP}^{\mathrm{Sc}}$-Präparationen stark mit $\mathrm{PrP}^{\mathrm{C}}$ angereichert sind.

Tabelle 1: Unterscheidungsmerkmale zwischen nativem $\operatorname{PrP}^{\mathrm{C}}$ und pathogenem $\operatorname{PrP}^{\mathrm{Sc}}$

\begin{tabular}{|l|l|}
\hline $\mathbf{P r P}^{\mathbf{C}}$ & $\mathbf{P r P}^{\mathbf{S c}}$ \\
\hline monomer & aggregiert (fibrillär oder oligomer) \\
\hline löslich in Detergentien & unlöslich in nicht-denaturierenden Detergentien \\
\hline nicht infektiös & infektiös \\
\hline $30 \% \alpha$-Helix, $4 \% \beta$-Faltblatt (Zahn et & $12 \% \alpha$-Helix, $32 \% \beta$-Faltblatt (Caughey et al., 1991) $*$ \\
al., 2000) & $17 \% \alpha$-Helix, $37 \% \beta$-Faltblatt (Gasset et al., 1993)* \\
& $14 \% \alpha$-Helix, $37 \% \beta$-Faltblatt (Pan et al., 1993) * \\
\hline Proteinase K sensitiv & partielle Proteinase K-Resistenz \\
\hline
\end{tabular}

* die strukturellen Untersuchungen wurden am PrP27-30 durchgeführt. Die angegebenen Daten wurden zur besseren Vergleichbarkeit mit nativem $\operatorname{PrP}^{\mathrm{C}}$ umgerechnet auf das $\operatorname{PrP}^{\mathrm{Sc}}$ mit 209 Aminosäuren Länge. 


\subsubsection{Prionhypothese}

Entsprechend der „Protein-only“-Hypothese (Prusiner, 1982) soll ein Protein, das Prionprotein, bei der Übertragung der Prionerkrankungen das infektiöse Agens darstellen (prion $=$,proteinacceous infectious particel“"). Dabei soll ein fehlgefaltetes, oligomeres Konformationsisomer $\left(\mathrm{PrP}^{\mathrm{Sc}}\right)$ dem natürlich vorkommenden, monomeren zellulären Protein $\left(\operatorname{PrP}^{\mathrm{C}}\right)$ seine Konformation durch direkten Kontakt aufzwingen. Die Information für die Umfaltung des Proteins $\left(\operatorname{PrP}^{\mathrm{C}}\right)$ wird nur durch die dreidimensionale Struktur des Erregerproteins $\left(\mathrm{PrP}^{\mathrm{Sc}}\right)$ vermittelt.

Ein derartiger Erregertyp ist zuvor noch nicht beschrieben worden. Wegen der geringen Grösse und der langen Inkubationszeit des Erregers wurde zunächst ein langsames Virus vermutet (Alper et al., 1966, 1667; Griffith et al., 1967). Im Gegensatz zu allen bekannten in Frage kommenden Erregern wie Viren, Viroiden oder Bakterien konnte der Erreger nicht durch Nukleinsäure zerstörende Behandlungen wie UV- und ionisierende Strahlung, große Hitze oder durch Gegenwart von Formaldehyd zerstört werden. Ferner konnte die Anwesenheit einer Nukleinsäure von mehr als 100 Basenpaaren Länge im Erreger ausgeschlossen werden (Meyer et al., 1991; Kellings et al., 1992, 1993). Der Erreger konnte aber durch einen vollständigen proteolytischen Verdau mit Proteinase K oder Trypsin oder durch Exposition von Agenzien wie Phenol, SDS, Kaliumthiocyanat und Harnstoff inaktiviert werden, die Proteine modifizierten oder denaturierten (Diener et al., 1982).

Einen wichtigen Beweis für die Prion-Hypothese stellt die Tatsache dar, dass durch homozygote Inaktivierung des Prnp-Genes $\left(\operatorname{Prnp}^{0 / 0}\right)$ Mäuse resistent gegen jede Infektion mit TSE-Erregern werden (Büehler et al., 1993). Diese Resistenz kann durch Implantation von Prnp-überexprimierendem Gewebe in die Gehirne der $\operatorname{Prnp}^{0 / 0}$-Mäusen wieder aufgehoben werden (Brandner et al., 1996a, 1996b). Eine deutliche Verminderung der PrP ${ }^{\mathrm{C}}$-Level konnte in $\mathrm{PrP}^{\mathrm{Sc}}$ infizierten transgenen Mäusen durch homologe Rekombination mit Cre/loxPElementen erreicht werden. Die Erkrankung konnte dadurch in den Tieren nicht nur zum Stillstand gebracht werden, sondern bereits aufgetretene spongiforme Läsionen rückgängig gemacht und einem Verlust an Neuronen vorgebeugt werden (Mallucci et al., 2003). Alle Daten sprechen für die Prionhypothese, wobei der finale Beweis der Hypothese durch eine de novo Generierung von infektiösem $\mathrm{PrP}^{\mathrm{Sc}}$ aus rekombinantem Prionprotein weiterhin aussteht. 


\subsubsection{Prion-Erregerstämme und Speziesbarrieren}

Analog zu anderen Erregern lassen sich bei der TSE sogenannte Prion-Erregerstämme (strains) voneinander unterscheiden (Bruce et al., 1991, 1994, 2003; Bessen et al., 1992, 1994, 1995). In der SDS-PAGE weisen die Erregerstämme nach proteolytischem Verdau durch Proteinase $\mathrm{K}$ ein unterschiedliches Migrationsverhalten mit unterschiedlich starker Glykosylierung auf. Beim Menschen konnten zwei verschiedene $\mathrm{PrP}^{\mathrm{Sc}}$-Typen identifiziert werden, die sich jeweils durch eine unterschiedliche $\mathrm{N}$-terminale $\mathrm{PrP}^{\mathrm{Sc}}$-Degradation durch die Proteinase K unterscheiden. Der PrP ${ }^{\mathrm{Sc}}$-Typ1 wird zwischen den Aminosäuren 82/83 und der PrP $^{\mathrm{Sc}}$-Typ 2 zwischen den Aminosäuren 97/98 durch die Proteinase K gespalten (Parchi et al., 2000).

Die Transmission von Prionenerkrankungen innerhalb der Säuger wird durch eine Speziesbarriere limitiert oder verhindert (Bruce et al., 1994; Dickinson, 1976). Lange Zeit hatte man vermutet, dass ausschliesslich die Primärsequenz des Prionproteins für die Speziesbarriere verantwortlich ist. Seit einiger Zeit geht man aber davon aus, dass neben der Primärsequenz die verschiedenen Prion-Erregerstämme entscheidend für die dreidimensionale Struktur des glykosylierten Prionproteins mitverantwortlich sind und die Effizienz der Protein-Protein-Interaktionen wesentlich beeinflussen (Collinge, 2005).

\subsubsection{Mechanismus der Umfaltung von $\operatorname{PrP}^{\mathrm{C}}$ in $\operatorname{PrP}^{\mathrm{Sc}}$}

Trotz intensiver Forschungen auf dem Gebiet der Prionerkrankungen seit über 35 Jahren ist es weder gelungen den Mechanismus der Umfaltung des Prionproteins aufzuklären noch die Struktur des $\operatorname{PrP}^{\mathrm{Sc}} \mathrm{zu}$ analysieren. Es ist nicht bekannt, warum es zur spontanen Konversion eines zellulären Proteins $\left(\mathrm{PrP}^{\mathrm{C}}\right)$ in eine pathogene Isoform $\left(\mathrm{PrP}^{\mathrm{Sc}}\right)$ kommt.

Obwohl die sekundärstrukturellen Elemente und deren Anteil an der Gesamtstruktur im $\mathrm{PrP}^{\mathrm{Sc}}$ seit über 13 Jahren bekannt sind (Tabelle 1), konnte bislang nicht gezeigt werden, welche Segmente bzw. welche strukturellen Elemente im $\mathrm{PrP}^{\mathrm{C}}$ an der Umfaltung beteiligt sind und welchen Einfluss sie auf die $\mathrm{PrP}^{\mathrm{Sc}}$-Bildung haben. Es ist lediglich bekannt, dass sich der $\alpha$ helikale Anteil von 30 \% (63 AS) im $\operatorname{PrP}^{\mathrm{C}}$ (Zahn et al., 2000; Calzolai \& Zahn, 2003) auf $12-$ 17 \% (25-36 AS) bei der Bildung des $\operatorname{PrP}^{\mathrm{Sc}}$ reduziert, während der $\beta$ - Faltblattanteil von 4 \% (8 AS) im $\operatorname{PrP}^{\mathrm{C}}$ (Zahn et al., 2000; Calzolai \& Zahn, 2003) auf 32-37 \% (67-77 Aminosäuren) 
ansteigt (Tabelle 1). Weiterhin war der N-terminale Bereich des Prionproteins für die Übertragbarkeit der Infektiösität nicht zwingend erforderlich (Rogers et al., 1993; Flechsig et al., 2000).

Die Existenz von Mutationen im proteincodierenden Bereich des Prnp-Gens bei allen vererbbaren Formen von Prionerkrankungen führte zu der Vermutung, dass die veränderten Prionproteine eine geringere thermodynamische Stabilität als das Wildtyp-Prionprotein (wtPrP) aufweisen und somit leichter zur Umfaltung neigen könnten. Bei der Bestimmung der thermodynamischen Stabilität der mit den vererbbaren Formen der Prionerkrankungen assoziierten Prionproteine, wiesen aber nur einige Prionproteine eine deutliche Destabilisierung im Vergleich zum wtPrP auf (Liemann \& Glockshuber, 1999; Swietnicki et al., 1998). Diese Daten implizieren, dass die Destabilisierung des $\operatorname{PrP}^{\mathrm{C}}$ kein genereller Mechanismus ist, mit dem die Bildung des $\operatorname{PrP}^{\mathrm{Sc}}$ erklärt werden könnte (Liemann \& Glockshuber, 1999). Beim Schaf zeigte sich, dass eine Reihe natürlich vorkommender Polymorphismen in der proteincodierenden Region des Prnp-Gens eine entscheidende Determinante für das Risiko darstellen, an Scrapie zu erkranken. In Studien mit rekombinantem Schaf-Prionprotein wiesen aber die Proteine die höchste thermodynamische Stabilität auf, die das höchste Risiko beinhalteten, in die $\mathrm{PrP}^{\mathrm{Sc}}$-Form umzufalten (Rezaei et al., 2000). Untermauert wurden diese Daten durch einen Vergleich der thermodynamischen Stabilität von Prionproteinaggregaten relativ zum monomeren Prionprotein. Zusätzlich wurden die Aktivierungsenergien für die Bildung von monomerem und aggregiertem Prionprotein bestimmt (Abb. 3) (Baskakov et al., 2001). Es zeigte sich, dass vollständig entfaltetes Prionprotein in zwei thermodynamisch erlaubte Zustände falten kann (Abb. 3). Entgegen der Erwartung, dass die native, zelluläre Form eines Proteins stets die thermodynamisch stabilste Konformation darstellt (Anfinsen, 1973), war aggregiertes, $\beta$ Faltblatt-reiches Prionprotein $(\beta$-PrP) thermodynamisch stabiler als $\alpha$-Helix-reiches Prionprotein $(\alpha-\operatorname{PrP})$, das eine zum zellulären Prionprotein $\operatorname{PrP}^{\mathrm{C}}$ analoge Sekundärstruktur aufwies. Die Bildung des $\beta$-PrP war aber im Gegensatz zur Bildung des $\alpha$-PrP durch eine hohe kinetische Barriere gehemmt. Insofern steht die Faltung des Prionproteins unter kinetischer Kontrolle (Abb. 3) (Baskakov et al., 2001). 


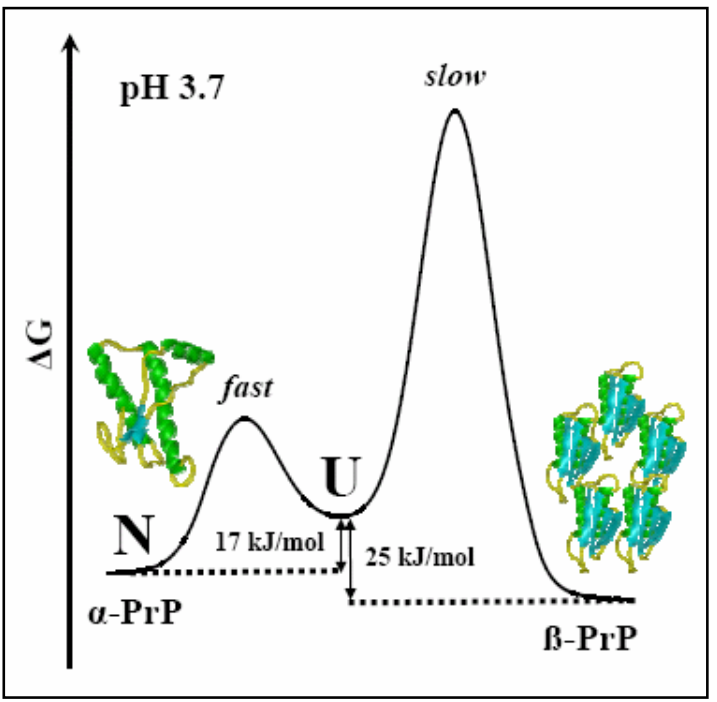

Abb. 3: Die Faltung des Prionproteins ist unter kinetischer Kontrolle (Baskakov et al., 2001) Ausgehend vom vollständig entfalteten Zustand (U) kann rekombinantes moPrP90-231 bei einem pH-Wert von 3.7 in zwei thermodynamisch erlaubte Zustände falten. Oligomeres $\beta$-Faltblatt-reiches Prionprotein ( $\beta$ $\operatorname{PrP}$ ) ist um $8 \mathrm{~kJ} / \mathrm{mol}$ thermodynamisch stabiler als $\alpha$-Helix-reiches Prionprotein ( $\alpha$-PrP). Die Bildung des $\beta$-PrP wird aber durch eine hohe Energiebarriere (Aktivierungsenergie) verhindert.

\subsubsection{Einfluss des pH-Wertes auf die Aggregation des Prionproteins}

Neben dem Konversionsmechanismus und der Struktur des infektiösen Erregers sind auch die zellulären Bedingungen für die $\operatorname{PrP}^{\mathrm{Sc}}$-Bildung nicht hinreichend bekannt.

Einiges deutet auf eine Beteiligung des endozytären Weges bei der Umwandlung des nativen $\operatorname{PrP}^{\mathrm{C}}$ in das pathogene $\operatorname{PrP}^{\mathrm{Sc}}$ hin (Borchelt et al., 1992; Taraboulos et al., 1992). So wurde die $\mathrm{PrP}^{\mathrm{Sc}}$-Bildung durch Erniedrigung der Temperatur verhindert, was die Endozytose und Internalisierung des $\operatorname{PrP}^{\mathrm{C}}$ blockiert (Borchelt et al., 1992). Zusätzlich wurde vorgeschlagen, dass die $\operatorname{PrP}^{\mathrm{Sc}}$-Bildung ohne Oberflächen-Recycling in intrazellulären Kompartimenten ablaufen könnte (Beranger et al., 2002). Da eine Akkumulation des infektiösen $\operatorname{PrP}^{\mathrm{Sc}}$ unter den sauren Bedingungen der späten Endosomen und Lysosomen erfolgte (McKinley et al., 1991; Arnold et al., 1995; Taraboulos et al., 1992), wurde ein saurer pH-Wert für die Umfaltung des Prionproteins in seine pathogene Isoform für notwendig erachtet.

Zur Simulation der $\mathrm{PrP}^{\mathrm{Sc}}$-Bildung mit rekombinantem Prionprotein wurde infolge dessen bevorzugt bei $\mathrm{pH}-$ Werten zwischen 4.0-5.0 gearbeitet. Dabei zeigte sich, dass unter sauren, denaturierenden Bedingungen die Umwandlung einer $\alpha$-helikalen in eine $\beta$-Faltblatt-haltige Isoform parallel zur Oligomerisierung des Prionproteins erfolgt (Swietnicki et al., 1997). Im Gegensatz dazu wurde die Bildung von fibrillären Aggregaten unter neutralen denaturierenden Bedingungen beschrieben (Bocharova et al., 2005a, 2005b; Breydo et al., 2005). 
Unter physiologischen Bedingungen konnte beim Prionprotein dagegen kein Faltungsunterschied zwischen pH-Werten von 2.6-7.2 nachgewiesen werden (Swietnicki et al., 1997), was den für die $\mathrm{PrP}^{\mathrm{Sc}}$-Bildung notwendigen $\mathrm{pH}$-Bereich weiterhin offen lässt.

\subsection{6. $\mathrm{PrP}^{\mathrm{Sc}}$-Strukturmodelle}

Die dreidimensionale Struktur des $\mathrm{PrP}^{\mathrm{Sc}}$-Erregers ist nicht bekannt. Aufgrund der Unlöslichkeit bzw. eines nicht perfekten kristallinen Charakters von fibrillären $\mathrm{PrP}^{\mathrm{Sc}}$ Aggregaten konnte ihre Strukturaufklärung durch klassische NMR-Spektroskopie bzw. Röntgenstrukturanalyse nicht durchgeführt werden.

Um eine Vorstellung von der möglichen Tertiärstruktur eines hypothetischen monomeren Erregers (Swietnicki et al., 2000) zu gewinnen, wurden Strukturmodelle des $\mathrm{PrP}^{\mathrm{Sc}}$-Erregers auf der Basis von Sekundärstrukturanalysen (Tabelle 1) und elektronenkristallographischen Daten (Wille et al., 1996, 2002) entworfen.

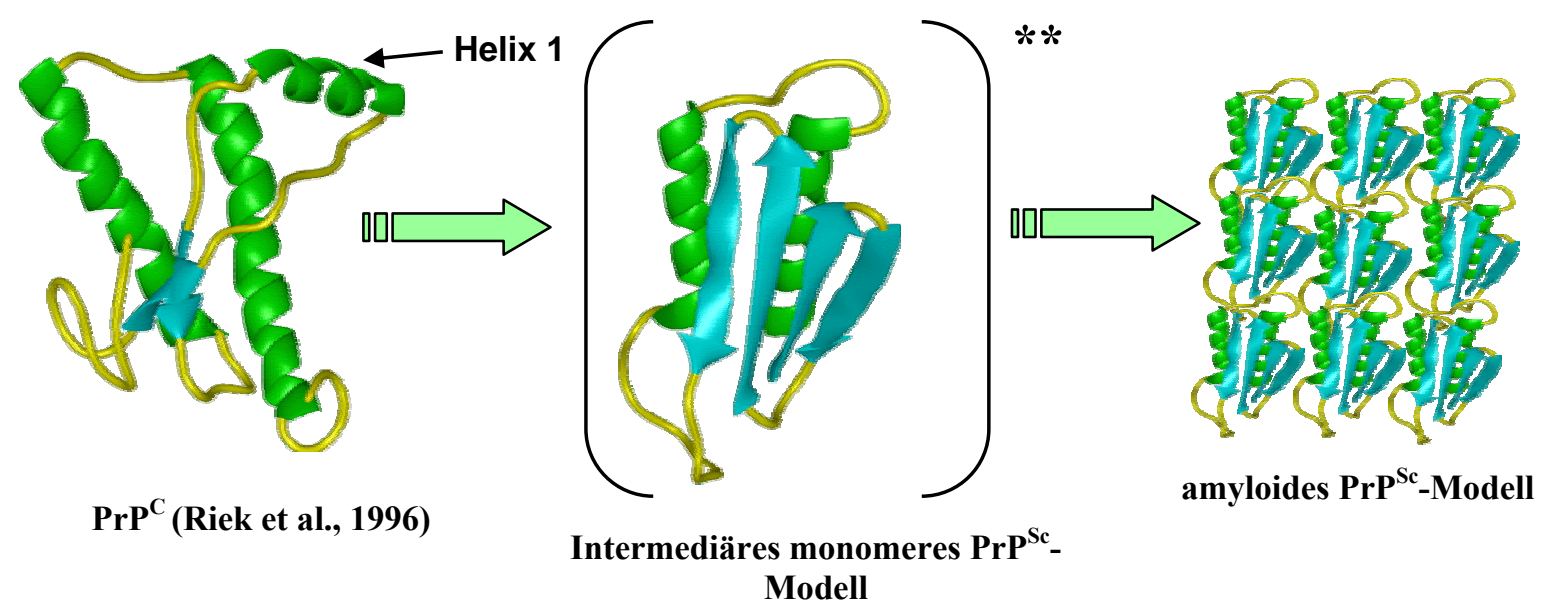

Abb. 4: Erstes $\operatorname{PrP}^{\mathrm{Sc}}$-Strukturmodell (Huang et al., 1996). $\operatorname{PrP}^{\mathrm{C}}$-Modell (links) gemäß der ersten NMRStruktur von rekombinantem moPrP121-231 (Maus) (Riek et al., 1996). Das native Prionprotein wird in diesem Modell intermediär in „monomeres $\mathrm{PrP}^{\mathrm{Sc} ،}$ (mitte) mit antiparallelem $\beta$-Faltblatt (türkis) konvertiert und bildet amyloides (fibrilläres) $\operatorname{PrP}^{\mathrm{Sc}}$ (rechts). ${ }^{* *}$ monomeres $\operatorname{PrP}^{\mathrm{Sc}}$ konnte nicht isoliert werden (Swietnicki et al., 2000). 
Im ersten strukturellen Umfaltungsmodell von $\operatorname{PrP}^{\mathrm{C}}$ in $\operatorname{PrP}^{\mathrm{Sc}}$ (Abb.4) wird die Region um die Helix 1 im Prionprotein in ein viersträngiges antiparalleles $\beta$-Faltblatt im $\operatorname{PrP}^{\mathrm{Sc}}$ konvertiert, während alle anderen Regionen einschließlich der Helix 2 und Helix 3 unverändert vorliegen (Huang et al., 1996; Cohen, 1999). Nach dem Auftreten der ersten NMR-Struktur des Prionproteins erschien es evident, dass die isolierte Helix 1 in ein $\beta$-Faltblatt umfaltet (Riek et al., 1996), während Helix 2 und Helix 3 ein kompaktes Helixbündel bilden, dass zusätzlich durch eine Disulfidbrücke stabilisiert wird.

Auf der Grundlage eines Vergleiches elektronenkristallographischer Daten von fibrillärem, infektiösem PrP27-30 mit einer trunkierten Form des aggregierten PrP90-231 ohne die Region 141-176 wurde ein Nachfolgemodell des $\mathrm{PrP}^{\mathrm{Sc}}$-Erregers entwickelt (Abb.5) (Govaerts et al., 2004).

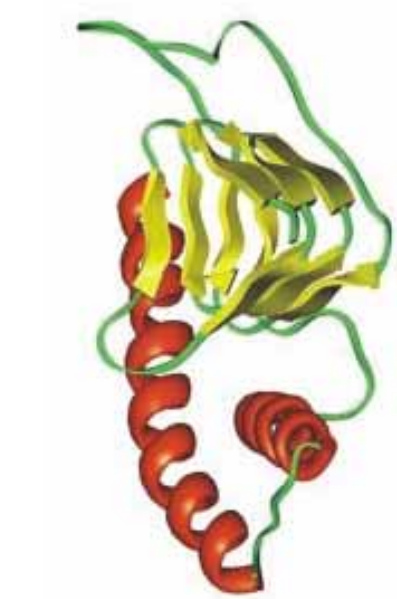

$\beta$-Helix-Modell im PrP ${ }^{\mathrm{Sc}}$

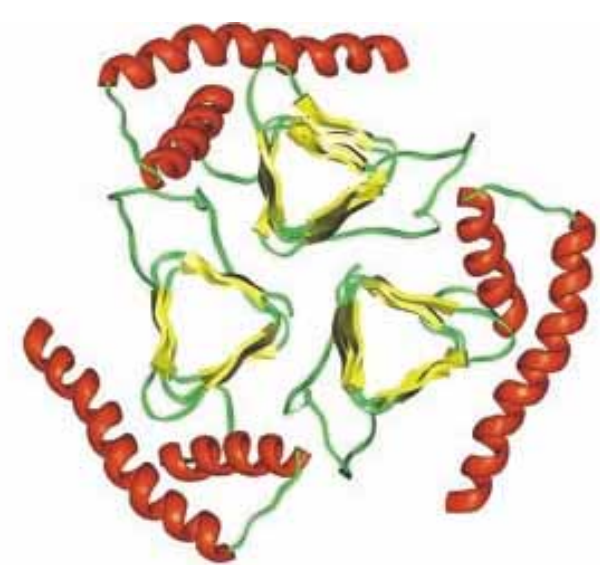

trimere Einheit im $\operatorname{PrP}^{\mathrm{Sc}}$-Modell

Abb. 5: Aktuelles PrP ${ }^{\mathrm{Sc}}$ Strukturmodell (Govaerts et al., 2004). links: Die Region PrP90-175 liegt in einem hypothetischen monomeren $\operatorname{PrP}^{\mathrm{Sc}}$ als $\beta$-Helix (gelb) vor, während Helix 2 und Helix 3 (beide rot) intakt bleiben. rechts: trimere Einheit aus drei Prionproteinen im $\mathrm{PrP}^{\mathrm{Sc}}$-Modell mit interagierenden $\beta$-Helices

Danach faltet der Bereich 90-175 des Prionproteins in eine linksgewundene parallele $\beta$-Helix um. Helix 1, das $\beta$-Faltblatt und die globuläre Region 90-145 werden nach diesem Modell in parallele $\beta$-Strands konvertiert (Abb. 5, gelb), während Helix 2 und Helix 3 (Abb. 5, rot) auch in diesem Modell intakt bleiben (Wille et al., 2002; Govaerts et al., 2004). 


\subsection{Zielsetzung}

Um die spontane Entstehung von infektiösen Prionaggregaten in vivo zu verstehen, sollte die Umfaltung des Prionproteins in vitro unter physiologischen Bedingungen untersucht werden. In der Vergangenheit wurde jedoch fast ausschliesslich unter künstlich denaturierenden Bedingungen gearbeitet (Harnstoff, $\mathrm{GdnHCl}$ ), da das Volllängen-Prionprotein unter nativen Bedingungen keine fibrillären Aggregate bildete. Im Gegensatz zum Volllängen-Prionprotein aggregierte ein mit der GSS-assoziiertes C-terminal trunkiertes pathogenes Prionprotein humPrP23-144 spontan unter physiologischen Bedingungen (Kundu et al., 2003). Anhand von humPrP23-144 konnte die molekulare Ursache von Speziesbarrieren erstmals in vitro aufgezeigt werden, was das enorme Potential physiologischer Bedingungen bei der Untersuchung der Aggregation des humanen Prionproteins zeigt (Jones et al., 2005, Vanik et al., 2004).

Um den Mechanismus der Umfaltung von $\operatorname{PrP}^{\mathrm{C}}$ in $\operatorname{PrP}^{\mathrm{Sc}} \mathrm{zu}$ verstehen, ist es notwendig, die Bereiche innerhalb des Proteinase K resistenten Kerns (90-231) im Prionprotein zu identifizieren, die tatsächlich in $\beta$-Faltblattstruktur umgewandelt werden. Es ist bekannt, dass die Region 90-145 an der Umfaltung des Prionproteins beteiligt ist (Peretz et al., 1997; Kundu et al., 2003). Da die Helices 2 und 3 (Region 174-231) ein kompaktes disulfidverbrücktes Helix-Bündel bilden, scheint eine Umfaltung dieser Region unwahrscheinlich zu sein. Im Gegensatz dazu gibt es keine direkten Evidenzen, die eine Konversion der Region 146-173 belegen.

In allen bisherigen $\mathrm{PrP}^{\mathrm{Sc}}$-Strukturmodellen geht man davon aus, dass die Helix 1 bei der Umfaltung des Prionproteins in ein $\beta$-Faltblatt umgefaltet wird (Govaerts et al., 2004; Wille et al., 2002; Huang et al., 1996). Aufgrund der NMR-Struktur des Prionproteins (Riek et al., 1996) erschien es zunächst plausibel, dass die isolierte Helix 1 in ein $\beta$-Faltblatt umgefaltet wird. Allerdings zeigten andere Arbeiten, dass die Helix 1 eine ungewöhnlich starke Neigung zur Helix-Bildung und somit keine Tendenz zur Ausbildung von $\beta$-Faltblattstruktur besitzt (Ziegler et al., 2003; Jamin et al., 2002, Sharman et al., 1998). Daher soll aufbauend auf den Arbeiten von Kundu et al. (2003) der Einfluss der Helix 1 in einem weiteren GSS-assoziierten Prionprotein humPrP23-159 unter physiologischen Bedingungen in vitro untersucht werden. $\mathrm{Ob}$ die Helix 1 tatsächlich in $\beta$-Faltblattstruktur umgewandelt wird, kann biochemisch nur durch einen direkten Vergleich mit humPrP23-144 ohne Helix 1 untersucht werden. Denn 
in einem so grossen Prionproteinfragment ist auch der mögliche Einfluss der an der Umfaltung beteiligten Region 90-145 auf die Helix 1 gegeben.

Neben der Region 90-145 und der Helix 1 befindet sich der $\beta$-Strand S2 innerhalb der potentiellen Konversionsregion 90-175 im Prionprotein. Ein Fehlen des $\beta$-Strands S2 im Prionprotein führte dazu, dass es nicht mehr in eine infektiöse Form überführt werden kann (Vorberg et al., 2001). In Analogie zu den Helix 1-Experimenten soll deshalb auch der Einfluss des $\beta$-Strands S2 auf die Aggregation des Prionproteins durch einen direkten Vergleich der Prionproteinfragmente humPrP23-173 mit humPrP23-159 untersucht werden.

Der einzige physiologische Parameter, der sich während der Endozytose, die für die Bildung des $\operatorname{PrP}^{\mathrm{Sc}}$ notwendig zu sein scheint (Borchelt et al., 1992), ändert, ist der $\mathrm{pH}-$ Wert. Bislang wurde die pH-Abhängigkeit der Aggregation ausschliesslich unter denaturierenden Bedingungen durchgeführt. Hierbei konnte unter sauren Bedingungen die Bildung von $\beta$ Faltblatt-reichen oligomeren und fibrillären Strukturen des Prionproteins beobachtet werden (Swietnicki et al., 2000; Morillas et al., 2001) In NMR-Untersuchungen des $\operatorname{PrP}^{\mathrm{C}}$ unter nichtdenaturierenden Bedingungen konnte eine Säure-induzierte Destabilisierung der Helix 1Region gezeigt werden (Zahn et al., 2003). Daraus wurde gefolgert, dass die Helix 1 ein potentieller Ausgangspunkt für die Aggregation des Prionproteins sein kann (Zahn et al., 2003). Eine vergleichende pH-Abhängigkeit der Aggregation der Prionproteinfragmente humPrP23-159 mit Helix 1 und humPrP23-144 unter physiologischen, nicht-denaturierenden Bedingungen könnte den Einfluss der Helix 1-Region auf die Aggregation bei verschiedenen $\mathrm{pH}-$ Werten aufzeigen. 


\section{Material und Methoden}

\subsection{Material}

\subsubsection{Chemikalien}

Acrylamid (30 \%; Verhältnis AA/BAA= 37,5:1) Carl Roth GmbH, Karlsruhe, Agar Difco, Detroit

Agarose Bioline, Berlin

APS Sigma, Seelze

Bacto-Hefeextrakt Difco, Detroit

Bacto-Trypton Difco, Detroit

Chloroform, Carl Roth GmbH, Karlsruhe

Desoxyribonukleotide, Bioline, Berlin

DMSO Sigma, Seelze

Guanidiniumhydrochlorid (GdnHCl), Applichem, Darmstadt

Harnstoff, Applichem, Darmstadt

IPTG, Carl Roth GmbH, Karlsruhe

Natriumdeoxycholat, Carl Roth GmbH, Karlsruhe

Nonidet P-40 Sigma, Seelze

Phenol, Carl Roth GmbH, Karlsruhe

Alle weiteren Chemikalien wurden von den Firmen Carl Roth GmbH (Karlsruhe), Applichem (Darmstadt), Merck (Darmstadt), Serva (Heidelberg), Sigma-Aldrich (Seelze) und Bio-Rad (München) bezogen. 


\subsubsection{Enzyme und Antibiotika}

Ampicillin Sigma, Seelze

Immolase DNA Polymerase, Bioline, Berlin

Kanamycin, Carl Roth GmbH, Karlsruhe

Pfu-DNA-Polymerase Stratagene, Amsterdam

Proteinase K (>30u/mg) Sigma, Seelze

Restriktionsendonukleasen: Promega, Heidelberg; MBI Fermentas, St. Leon-Roth

T4-DNA-Ligase, MBI Fermentas, St. Leon-Roth

\subsection{3. „Kits“ zur Behandlung von DNA}

Qiagen Plasmid Midi Kit, Hilden

Qiagen Plasmid Mini Kit, Hilden

QIAquick Gel Extraction Kit (70 bp-10 kb), Hilden

QIAquick PCR Purification Kit (100 bp-10 kb), Hilden

\subsubsection{DNA- und Protein-,,Standards“}

\section{DNA-Längenstandard}

Hyperladder I (Bioline, Berlin) enthält 14 Banden zwischen 200 bp und $10 \mathrm{~kb}$. Fragmentlängen (bp): 10000, 8000, 6000, 5000, 4000, 3000, 2500, 2000, 1500, 1000, 800, 600, 400, 200. Der Hyperladder I ist ein "ready to use" DNA-Längenstandard inklusive DNA-Auftragspuffer. Beim Auftrag von $5 \mu$ l Hyperladder I werden folgende Mengen der DNA-Fragmente aufgetragen: 10000 bp (100 ng), 8000 bp (80 ng), 6000 bp (60 ng), 5000 bp (50 ng), 4000 bp (40 ng), 3000 bp (30 ng), 2500 bp (25 ng), 2000 bp (20 ng), 500 bp (15 ng), 1000 bp (100 ng), 800 bp (80 ng), 600 bp (60 ng), 400 bp (40 ng), 200 bp (20 ng). 


\section{SDS-PAGE Protein-Molekularstandard}

„Broad Range“ (Bio-Rad, München)

Der Protein-Standard lieferte folgende Molekulargrößen:

Myosin, Mr 202000; $\beta$-Galaktosidase, Mr 116000; Rinderserum Albumin, Mr 84000;

Ovalbumin, Mr 50100; Carbonische Anhydrase, Mr 35700; Sojabohnen Trypsininhibitor, Mr 29300; Lysozym, Mr 21200; Aprotinin, Mr 7500

\subsubsection{Verbrauchsmaterialien zum Arbeiten mit Bakterien}

(Steril-)Filter Schleicher \& Schüll, Dassel

Kulturgefäße, Plastikwaren Sarstedt, Braunschweig; Nunc, Wiesbaden;

Greiner, Solingen

Pipetten $2.5 \mathrm{ml} ; 5 \mathrm{ml} ; 10 \mathrm{ml} ; 25 \mathrm{ml}$ Sarstedt, Braunschweig

Reaktionsgefäße $0.5 \mathrm{ml} ; 1.5 \mathrm{ml} ; 2.0 \mathrm{ml}$ Sarstedt, Braunschweig;

Biozym, Hessisch Oldendorf

Zentrifugiergefäße 15 und $50 \mathrm{ml}$ Sarstedt, Braunschweig

\subsubsection{Verbrauchsmaterial für Western blots}

Protran ${ }^{\mathrm{R}}$ Nitrocellulose Transfer Membran, Schleicher \& Schüll, Dassel

Blotpapier, Criterion Size, Bio-Rad, Hercules

Chemilumineszenzreagenzien:

Super Signal West Femto Luminol/Enhancer Solution, Pierce, Bonn

Super Signal West Stable Peroxide Solution, Pierce, Bonn

Hyperfilm ${ }^{\mathrm{TM}}$ ECL, Amersham Biosciences, Buckinghamshire

\subsubsection{Lösungen und Puffer für Arbeiten mit DNA}

\section{6 x DNA-Auftragspuffer}

$0.05 \%$ (w/v) Bromphenolblau, $0.05 \%$ (w/v) Xylencyanol, $30 \%$ (v/v) Glycerin, $100 \mathrm{mM}$ EDTA, pH 8.0 


\section{P1-Puffer (Qiagen)}

200 mM Tris/HCl, pH 8.0, 10 mM EDTA, RNase A (100 $\mu \mathrm{g} / \mathrm{ml})$

\section{P2-Puffer (Qiagen)}

$200 \mathrm{mM} \mathrm{NaOH}, 1 \%(\mathrm{w} / \mathrm{v}) \mathrm{SDS}$

\section{P3-Puffer (Qiagen)}

3.0 M Kaliumacetat, $\mathrm{pH} 4.8$

\section{Phenol/Chloroform/Isoamylalkohol}

1 Vol. Phenol mit 1 Vol. Chloroform/Isoamylalkohol (24:1)

\section{QBT-Puffer (Qiagen)}

$750 \mathrm{mM} \mathrm{NaCl}, 50 \mathrm{mM}$ MOPS, $\mathrm{pH}$ 7.0, 15 \% (v/v) Ethanol, $0.15 \%$ Triton X-100

\section{QC-Puffer (Qiagen)}

$1.0 \mathrm{M} \mathrm{NaCl}, 50 \mathrm{mM}$ MOPS, pH 7.0, $15 \%$ (v/v) Ethanol

\section{QF-Puffer (Qiagen)}

1.25 M NaCl, $50 \mathrm{mM}$ Tris/HCl, pH 8.5, $15 \%$ (v/v) Ethanol

\section{$10 \times$ TBE-Puffer}

0.89 M Tris, 0.89 M Borsäure, 0.025 M EDTA

\section{TE-Puffer}

$10 \mathrm{mM}$ Tris/HCl, $\mathrm{pH}$ 8.0, 0.5 mM EDTA

\section{Tris-Puffer}

Trishydroxymethylaminomethan in bidestilliertem Wasser auflösen und den pH mit Säure einstellen. Für Tris/HCl wurde Salzsäure für Tris/Acetat Essigsäure verwendet. 


\subsubsection{Lösungen und Puffer für Proteinarbeiten}

$10 \%$ APS

$0.1 \mathrm{~g}$ Ammoniumpersulfat mit destilliertem $\mathrm{H}_{2} \mathrm{O}$ auf $1 \mathrm{ml}$ auffüllen.

\section{Blocking-Puffer}

$1 \times$ PBS, $5 \%(w / v)$ Milchpulver (Applichem) in PBS-T, $0.1 \%(v / v)$ Tween 20

\section{Blotting-Puffer}

0.025 M Tris, 0.192 M Glycin, $0.1 \%$ (w/v) SDS, $20 \%$ Methanol

\section{Laufpuffer für SDS-PAGE}

0.025 M Tris, $\mathrm{pH} 8.3,0.192 \mathrm{M}$ Glycin, $0.1 \%$ (w/v) SDS

\section{Anoden-Laufpuffer für SDS-PAGE (Wiltfang)}

$0.2 \mathrm{M}$ Tris $/ \mathrm{H}_{2} \mathrm{SO}_{4}, \mathrm{pH} 8.0$

\section{Kathoden-Laufpuffer für SDS-PAGE (Wiltfang)}

$0.2 \mathrm{M}$ Bicine/ $\mathrm{NaOH}, \mathrm{pH} 8.3,0.25 \%$ SDS

\section{1 x Phosphatgepufferte Saline (PBS)}

9.55 g Instamed PBS Dulbecco (Seromed, Biochrom KG, Berlin)/1 destilliertes $\mathrm{H}_{2} \mathrm{O}$

\section{PBS-Tween}

PBS, $0.05 \%(v / v)$ Tween 20

\section{$2 \times$ Proteinprobenpuffer}

$0.125 \mathrm{M}$ Tris/HCl, pH 6.8, 4 \% (w/v) SDS, $20 \%$ (v/v) Glycerin, 0.2 M DTT, $0.02 \%$ (w/v) Bromphenolblau

\section{5 x Proteinprobenpuffer}

$0.25 \mathrm{M} \mathrm{NaH}_{2} \mathrm{PO}_{4}, 0.16 \mathrm{M}, 10 \%$ SDS, $50 \%$ Glycerol, $75 \%$ Sucrose, 5 mM EDTA, pH 7.0, $0.02 \%$ Bromphenolblau 
$10 \%$ SDS

$1 \mathrm{~g}$ SDS in $9 \mathrm{~g} \mathrm{H}_{2} \mathrm{O}$ lösen.

$4 \times$ Sammelgelpuffer

0.5 M Tris/ $\mathrm{HCl}, \mathrm{pH} 6.8$

$4 \times$ Trenngelpuffer

$1.5 \mathrm{M}$ Tris/ $\mathrm{HCl}, \mathrm{pH} 8.8$

$4 \times$ Sammelgelpuffer (Wiltfang)

$0.8 \mathrm{M}$ BisTris $/ \mathrm{H}_{2} \mathrm{SO}_{4}, \mathrm{pH} 6.5$

$4 \times$ Trenngelpuffer (Wiltfang)

1.6 M Tris $/ \mathrm{H}_{2} \mathrm{SO}_{4}, \mathrm{pH} 8.0$

\section{Lysis-Puffer}

0.1 M Tris/HCl pH 8.0, 1.0 M NaCl, 1 mM EDTA, $1.0 \%$ Triton-X-100,

$1 \mathrm{mM}$ Benzamidine/HCl

\section{Protease-Inhibitor Mix (PI-Mix)}

$0.1 \mathrm{mM}$ PMSF, $10 \mu \mathrm{M}$ TPCK, $10 \mu \mathrm{M}$ TLCK

PI-Mix wird frisch aus den Lösungen hergestellt und in trockenem Methanol gelöst.

\section{IB-Waschpuffer-TX-100}

$50 \mathrm{mM}$ Tris $/ \mathrm{HCl} \mathrm{pH}$ 8.5, $23 \%$ Sucrose, $1 \mathrm{mM}$ EDTA, $1 \mathrm{mM}$ Benzamidine/ $\mathrm{HCl}, 1.0 \%$ Triton-X-100

\section{IB-Waschpuffer-TX-100+ Hochsalz}

$50 \mathrm{mM}$ Tris/ $\mathrm{HCl} \mathrm{pH} \mathrm{8.5,} 23 \%$ Sucrose, $1 \mathrm{mM}$ EDTA, $1 \mathrm{mM}$ Benzamidine/HCl, $1.0 \%$ Triton-X-100, $2 \mathrm{M} \mathrm{NaCl}$ 


\section{IB-Waschpuffer + Detergenz SB14}

$50 \mathrm{mM}$ Tris/HCl, $\mathrm{pH}$ 8.5, $23 \%$ Sucrose, $1 \mathrm{mM}$ EDTA, $1 \mathrm{mM}$ Benzamidine/ $\mathrm{HCl}, 0.5 \%$

Sulfobetaine 14

Rückfaltungspuffer (Zahn et al., 1997):

\section{Puffer A:}

$6 \mathrm{M}$ Guanidiniumhydrochlorid, $100 \mathrm{mM}$ Natriumphosphat, $10 \mathrm{mM}$ Tris, $15 \mathrm{mM} \beta-$ Mercaptoethanol, $\mathrm{pH} 8.0$

\section{Puffer B:}

$100 \mathrm{mM}$ Natrium Phosphat, $10 \mathrm{mM}$ Tris, $\mathrm{pH} 8.0$

\section{Puffer C:}

100 mM Natrium Phosphat, 10 mM Tris, pH 5.8

\section{Puffer E:}

0.5 M Imidazol, $100 \mathrm{mM}$ Natrium Phosphat, $10 \mathrm{mM}$ Tris, $\mathrm{pH} 5.8$

\subsubsection{Nährmedien für die Mikrobiologie}

\section{LB-Medium}

$10 \mathrm{~g}$ Trypton, $5 \mathrm{~g}$ Hefeextrakt, $10 \mathrm{~g} \mathrm{NaCl}, \mathrm{H}_{2} \mathrm{O}$ ad 1 Liter

\section{"Glockshuber-Medium"}

$20 \mathrm{~g}$ Tryptone, $10 \mathrm{~g}$ Hefeextrakt, $5 \mathrm{~g} \mathrm{NaCl}, 25.2 \mathrm{~g}$ Glycerol, $\mathrm{H}_{2} \mathrm{O}$ ad $900 \mathrm{ml}$. Nach dem Autoklavieren Zugabe von $50 \mathrm{ml}$ steriler autoklavierter $1 \mathrm{M} \mathrm{K}_{2} \mathrm{HPO}_{4}$-Lösung, $50 \mathrm{ml}$ autoklavierter $20 \%$ Glucose und $10 \mathrm{ml}$ autoklavierter $1 \mathrm{M} \mathrm{MgCl}_{2}$-Lösung.

\section{TB-Medium}

$1.2 \%$ (w/v) Trypton, $2.4 \%$ (w/v) Hefeextrakt, $0.4 \%$ (v/v) Glycerin, nach dem Autoklavieren

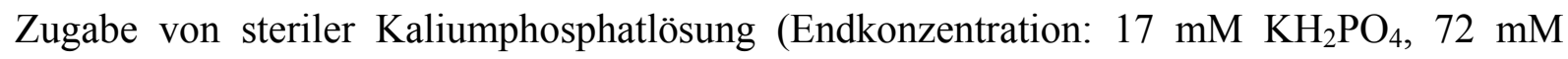
$\left.\mathrm{K}_{2} \mathrm{HPO}_{4}\right)$. 
10 x M9 Salzmedium (1 L) für die NMR-Spektroskopie

$68 \mathrm{~g} \mathrm{Na}_{2} \mathrm{HPO}_{4}$

$30 \mathrm{~g} \mathrm{KH}_{2} \mathrm{PO}_{4}$

$5 \mathrm{~g} \mathrm{NaCl}$

Mit bidestilliertem Wasser auf 1 Liter auffüllen und Autoklavieren.

\section{1 x M9 Minimalmedium (1 L) für die NMR-Spektroskopie}

$100 \mathrm{ml} 10$ x M9 Salzmedium

$1 \mathrm{ml} 1 \mathrm{M} \mathrm{MgSO}_{4}$-Lösung (autoklaviert)

$1 \mathrm{~g} \mathrm{NH}_{4} \mathrm{Cl}$ ( ${ }^{15} \mathrm{~N}$-gelabelt, $99 \%$, Campro Scientific GmbH, Berlin)

3 g D-Glucose $\left({ }^{13} \mathrm{C}_{6}\right.$-gelabelt, $99 \%$, Campro Scientific GmbH, Berlin)

$10 \mathrm{ml} 100$ x MEM Vitamin Solution (Gibco-Invitrogen Cell Culture, Karlsruhe)

1. Mit bidestilliertem Wasser auf 1 Liter auffüllen

2. $\mathrm{pH}-$ Wert kontrollieren (soll zwischen $\mathrm{pH}$ 7.0-7.4 liegen)

3. $0.22 \mu \mathrm{m}$ steril filtrieren

4. $100 \mu 1$ einer $1 \mathrm{M} \mathrm{CaCl}_{2}$-Lösung (autoklaviert) zugeben

\section{LB-Platten}

LB-Medium mit zusätzlich 15 g Agar. Als Antibiotika wurden Ampicillin (final $100 \mu \mathrm{g} / \mathrm{ml}$ ) oder Kanamycin (final $30 \mu \mathrm{g} / \mathrm{ml}$ ) eingesetzt.

\subsubsection{Escherichia coli-Stämme}

\section{DH5a (Hanahan et al., 1983) (Invitrogen, Karlsruhe)}

$\mathrm{F}^{-} \varphi 80$ lacZ $\Delta \mathrm{M} 15 \Delta\left(\right.$ lacZYA-argF)U169 deo $\mathrm{R}$ recA1 endA1 hsdR17( $\left.\mathrm{r}_{\mathrm{k}}{ }^{-}, \mathrm{m}_{\mathrm{k}}{ }^{+}\right)$phoA supE44 thi-1 gyrA96 relA1 $\lambda^{-}$

XL1-Blue (Bullock et al., 1987) (Stratagene, La Jolla, CA, USA) recAl endA1 gyrA96 thi-1 hsdR17 supE44 relA1 lac $\left[\mathrm{F}^{\prime}\right.$ proAB lacl ${ }^{\mathrm{q}} Z \Delta M 15 \operatorname{Tn} 10$ (Tet $\left.\left.^{\mathrm{r}}\right)\right]$. 
Origami 2(DE3) (Novagen, Nottingham, UK)

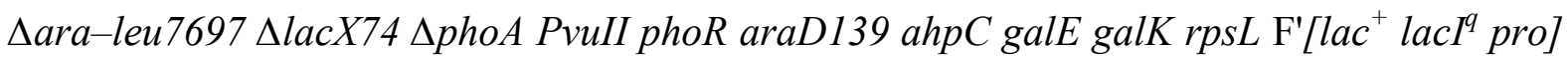
(DE3) gor522: $\operatorname{Tn} 10 \operatorname{trx} B\left(\mathrm{Str}^{\mathrm{R}}, \mathrm{Tet}^{\mathrm{R}}\right)$

B121 (DE3) (Studier and Moffatt, 1986) (Novagen, Nottingham, UK)

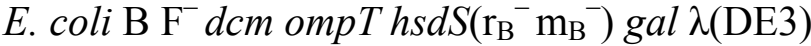

\subsubsection{Oligodesoxyribonukleotide}

\section{humJWforw}

CCTCTCCTCACGAAGCTTGCAGAGCAGTCAT

humJWrev

AAGATGGTGTCTAGAGGAAGACCTTCCTCATCCCA

23MSon

5 CGACGGTAAAGCTTACATATGAGCAAGAAGCGCCCGAAG

231SSon

GCCGCTGTCGACTTACGACGATCCACGCTGGTAATAGGCCT

112rev

GGAGCTCGTCGACTTATCACATGTGCTTCA

144rev

ACGATAGTAGTCGACCTATTAGTCACTGCCGAAATG

159rev

GGGCCTGTAGTCGACTTAGTTGGGGTAACGGTG

173rev

GCAGTCGTGGTCGACCTAGTTCTGGTTGCTGTAC

199rev

ATCATCTTGTCGACTCATTAGGTGAAGTTCTCCCCCT 


\subsubsection{Mutagenese-Oligodesoxyribonukleotide}

humPrP S143C

5’ GGCCCATCATACATTTCGGCTGCGACTATGAGGACCGTT 3’

5`AACGGTCCTCATAGTCGCAGCCGAAATGTATGATGGGCC 3`

\section{humPrP P102L}

5' CACAGTCAGTGGAACAAGCTGAGTAAGCCAAAAACCAAC 3'

5' GTTGGTTTTTGGCTTACTCAGCTTGTTCCACTGACTGTG

\section{humPrP P105L}

5' CAGTGGAACAAGCCGAGTAAGCTGAAAACCAACATGAAGCAC 3'

5' GTGCTTCATGTTGGTTTTCAGCTTACTCGGCTTGTTCCACTG 3'

\section{humPrP G114V}

5' ATGAAGCACATGGCTGTtGCTGCAGCAGCTGGG 3'

5' CCCAGCTGCTGCAGCAACAGCCATGTGCTTCAT 3'

humPrP A117V

5' AtGGCtGGtGCtGCAGTGGCTGGGGCAGTGGTG 3'

5' CACCACTGCCCCAGCCACTGCAGCACCAGCCATG 3'

humPrP M129V

5' GGCCTTGGCGGCTACGTGCTGGGAAGTGCCATG 3'

5' CATGGCACTTCCCAGCACGTAGCCGCCAAGGCC 3'

humPrP V129M

5' GGCCTTGGCGGCTACATGCTGGGAAGTGCCATG 3'

5' CATGGCACTTCCCAGCATGTAGCCGCCAAGGCC 3'

humPrP D178N

5' CAGAACAACTTTGTGCACAACTGCGTCAATATCACAATC 3'

5' GATTGTGATATTGACGCAGTTGTGCACAAAGTTGTTCTG 3'

\section{humPrP E200K}

5' GGGGAGAACTTCACCAAGACCGACGTTAAGATG 3'

5' CATCTTAACGTCGGTCTTGGTGAAGTTCTCCCC 3'

\section{humPrP V210I}

5' GATGATGGAGCGCGTGATCGAGCAGATGTGTATCACC 3'

5' GGTGATACACATCTGCTCGATCACGCGCTCCATCATC 3' 


\section{humPrP Q217R}

5' GAGCAGATGTGTATCACCAGGTACGAGAGGGAATCTCAG 3'

5' CTGAGATTCCCTCTCGTACCTGGTGATACACATCTGCTC 3'

humPrP R220R (Beseitigung des seltenen Arginin-Codons AGA in E. coli)

5' GTATCACCCAGTACGAGCGTGAATCTCAGGCCTATT 3'

5' AATAGGCCTGAGATTCACGCTCGTACTGGGTGATAC 3'

humPrP R228R (Beseitigung des seltenen Arginin-Codons AGA in E. coli)

5' GGACCATGCTCGATCCACGCTGGTAATAGGCCTGAG 3' (rev-Primer)

\subsubsection{Plasmide}

pBluescript ${ }^{\circledR}$ II SK $(+)$ (STRATAGENE, La Jolla, USA), Klonierungsvektor $\left(\right.$ Ap $^{r}$ )

pCIneo (PROMEGA, Heidelberg), Eukariontischer Expressionsvektor ( $\left.\mathrm{Ap}^{\mathrm{r}}, \mathrm{Neo}\right)$

pET27b $(+)$ (NOVAGEN, Madison, USA), Prokaryotischer Expressionsvektor $\left(\operatorname{Kan}^{\mathrm{r}}\right)$

pPeptide (MoBiTec, Göttingen), Prokaryotischer Expressionsvektor (Ap ${ }^{\mathrm{r}}$ )

Tabelle 2: cDNAs in bakteriellen Expressionsvektoren

\begin{tabular}{|c|c|c|}
\hline Name & Expressionsplasmid codiert für: & Herkunft/Relevanz \\
\hline $\mathrm{pET} 27 \mathrm{~b}(+) /$ humPrnp, V129M & $\begin{array}{l}\text { humanes PrP23-231 mit Valin } 129 \text { zu Methionin } \\
\text { (Polymorphismus) }\end{array}$ & diese Arbeit \\
\hline $\begin{array}{l}\text { pET27b(+)/humPrnp, V129M, } \\
\text { P102L }\end{array}$ & humanes PrP23-231 mit Prolin 102 zu Leucin & diese Arbeit \\
\hline $\begin{array}{l}\text { pET27b(+)/humPrnp, V129M, } \\
\text { P105L }\end{array}$ & humanes PrP23-231 mit Prolin 105 zu Leucin & diese Arbeit \\
\hline $\begin{array}{l}\text { pET27b(+)/humPrnp, V129M, } \\
\text { G114V }\end{array}$ & $\begin{array}{l}\text { humanes PrP23-231 mit Glycin } 114 \text { zu Valin } \\
\text { (Polymorphismus) }\end{array}$ & diese Arbeit \\
\hline $\begin{array}{l}\text { pET27b(+)/humPrnp, V129M, } \\
\text { A117V }\end{array}$ & humanes PrP23-231 mit Alanin 117 zu Valin & diese Arbeit \\
\hline
\end{tabular}




\begin{tabular}{|c|c|c|}
\hline Name & Expressionsplasmid codiert für: & Herkunft/Relevanz \\
\hline $\begin{array}{l}\text { pET27b(+)/humPrnp, V129M, } \\
\text { Y145X }\end{array}$ & humanes PrP23-144 mit Tyrosin 145 zu Stop & diese Arbeit \\
\hline $\begin{array}{l}\text { pET27b(+)/humPrnp, V129M, } \\
\text { Q160X }\end{array}$ & humanes PrP23-159 mit Prnp- Glutamin 160 zu Stop & diese Arbeit \\
\hline $\begin{array}{l}\text { pET27b(+)/humPrnp, V129M, } \\
\text { D178N }\end{array}$ & $\begin{array}{l}\text { humanes PrP23-231 mit Asparaginsäure } 178 \mathrm{zu} \\
\text { Asparagin }\end{array}$ & diese Arbeit \\
\hline $\begin{array}{l}\text { pET27b(+)/humPrnp, V129M, } \\
\text { E200K }\end{array}$ & humanes PrP23-231 mit Glutaminsäure 200 zu Lysin & diese Arbeit \\
\hline $\begin{array}{l}\text { pET27b(+)/humPrnp, V129M, } \\
\text { V210I }\end{array}$ & humanes PrP23-231 mit Valin 210 zu Isoleucin & diese Arbeit \\
\hline $\begin{array}{l}\text { pET27b(+)/humPrnp, V129M, } \\
\text { Q217R }\end{array}$ & humanes PrP23-231 mit Glutamat 217 zu Arginin & diese Arbeit \\
\hline $\begin{array}{l}\text { pET27b(+)/humPrnp, V129M, } \\
\Delta 84-91\end{array}$ & $\begin{array}{l}\text { humanes PrP23-231 mit Deletion von einem } \\
\text { Oktarepeat (1 x PHGGGWGQ) }\end{array}$ & diese Arbeit \\
\hline $\begin{array}{l}\text { pET27b(+)/humPrnp, V129M, } \\
\Delta \text { 76-91 }\end{array}$ & $\begin{array}{l}\text { humanes PrP23-231 mit Deletion von zwei } \\
\text { Oktarepeats ( } 2 \text { x PHGGGWGQ) }\end{array}$ & diese Arbeit \\
\hline $\begin{array}{l}\text { pET27b(+)/humPrnp, V129M, } \\
\text { P102L, T188M }\end{array}$ & $\begin{array}{l}\text { humanes PrP23-231 mit Prolin } 102 \text { zu Leucin und } \\
\text { Threonin } 188 \text { zu Methionin }\end{array}$ & diese Arbeit \\
\hline $\begin{array}{l}\text { pET27b(+)/humPrnp, V129M, } \\
\text { Q160X, G114V }\end{array}$ & $\begin{array}{l}\text { humanes PrP23-159 mit Glutamin } 160 \mathrm{zu} \text { Stop und } \\
\text { Glycin } 114 \mathrm{zu} \text { Valin }\end{array}$ & diese Arbeit \\
\hline pET27b(+)/humPrnp, M129V & $\begin{array}{l}\text { humanes PrP23-231 mit Methionin } 129 \mathrm{zu} \text { Valin } \\
\text { (Polymorphismus) }\end{array}$ & diese Arbeit \\
\hline $\begin{array}{l}\text { pET27b(+)/humPrnp, M129V, } \\
\text { P102L }\end{array}$ & humanes PrP23-231 mit Prolin 102 zu Leucin & diese Arbeit \\
\hline $\begin{array}{l}\text { pET27b(+)/humPrnp, M129V, } \\
\text { P105L }\end{array}$ & humanes PrP23-231 mit Prolin 105 zu Leucin & diese Arbeit \\
\hline $\begin{array}{l}\text { pET27b(+)/humPrnp, M129V, } \\
\text { G114V }\end{array}$ & $\begin{array}{l}\text { humanes PrP23-231 mit Glycin } 114 \text { zu Valin } \\
\text { (Polymorphismus) }\end{array}$ & diese Arbeit \\
\hline $\begin{array}{l}\mathrm{pET} 27 \mathrm{~b}(+) / \text { humPrnp, M129V, } \\
\text { A117V }\end{array}$ & humanes PrP23-231 mit Alanin 117 zu Valin & diese Arbeit \\
\hline $\begin{array}{l}\text { pET27b(+)/humPrnp, M129V, } \\
\text { Y145X }\end{array}$ & humanes PrP23-144 mit Tyrosin 145 zu Stop & diese Arbeit \\
\hline $\begin{array}{l}\text { pET27b(+)/humPrnp, M129V, } \\
\text { Q160X }\end{array}$ & humanes PrP23-159 mit Glutamin 160 zu Stop & diese Arbeit \\
\hline
\end{tabular}




\begin{tabular}{|c|c|c|}
\hline Name & Expressionsplasmid codiert für: & Herkunft/Relevanz \\
\hline $\begin{array}{l}\text { pET27b(+)/humPrnp, M129V, } \\
\text { D178N }\end{array}$ & $\begin{array}{l}\text { humanes PrP23-231 mit Asparaginsäure } 178 \mathrm{zu} \\
\text { Asparagin }\end{array}$ & diese Arbeit \\
\hline $\begin{array}{l}\text { pET27b(+)/humPrnp, M129V, } \\
\text { E200K }\end{array}$ & humanes PrP23-231 mit Glutaminsäure 200 zu Lysin & diese Arbeit \\
\hline $\begin{array}{l}\text { pET27b(+)/humPrnp, M129V, } \\
\text { V210I }\end{array}$ & humanes PrP23-231 mit Valin 210 zu Isoleucin & diese Arbeit \\
\hline $\begin{array}{l}\text { pET27b(+)/humPrnp, M129V, } \\
\text { Q217R }\end{array}$ & humanes PrP23-231 mit Glutamat 217 zu Arginin & diese Arbeit \\
\hline $\begin{array}{l}\text { pET27b(+)/humPrnp, V129M, } \\
\Delta 84-91\end{array}$ & $\begin{array}{l}\text { humanes PrP23-231 mit Deletion von einem } \\
\text { Oktarepeat (1 x PHGGGWGQ) }\end{array}$ & diese Arbeit \\
\hline $\begin{array}{l}\mathrm{pET} 27 \mathrm{~b}(+) / \text { humPrnp, V129M, } \\
\Delta 76-91\end{array}$ & $\begin{array}{l}\text { humanes PrP mit Deletion von zwei Oktarepeats } \\
(2 \times \text { PHGGGWGQ) }\end{array}$ & diese Arbeit \\
\hline pET27b(+)/humSynuclein $\alpha$ & Wildtyp Synuclein $\alpha$ & diese Arbeit \\
\hline pPeptide/humAbeta1-40 & Wildtyp A $\beta$ 1-40 Fragment & diese Arbeit \\
\hline pPeptide/humAbetal-42 & Wildtyp $A \beta$ 1-42 Fragment & diese Arbeit \\
\hline pCIneo/humPrnp-EGFP & PrP-GFP Chimäre mit humanem Prionprotein 1254 & diese Arbeit \\
\hline pCIneo/moPrnp $1-254$ & murines PrP1-254 (Maus) & diese Arbeit \\
\hline pCIneo/moPrnp-EGFP & PrP-GFP Chimäre mit murinem Prionprotein 1-254 & diese Arbeit \\
\hline pET27b(+)/humPrnp23-112 & humanes PrP23-112 mit Alanin 113 zu Stop & diese Arbeit \\
\hline
\end{tabular}




\subsubsection{Antikörper für die Immunologische Detektion}

Folgende Antikörper wurden für immunologische Detektionen in der angegebenen Verdünnung im Western blot eingesetzt:

Tabelle 3: Antikörper

\begin{tabular}{|c|c|c|c|}
\hline Bezeichnung & Spezifikation & Verdünnung & Herkunft/Referenz \\
\hline Anti-PrP-Antikörper & Maus, monoklonal & $1: 10000$ & Prionics AG, Basel, Schweiz \\
$6 \mathrm{H} 4$ & Maus, monoklonal & $1: 10000$ & Cell Sciences \\
$1 \mathrm{E} 4$ & Maus, monoklonal & $1: 20000$ & Kascsak et al., 1987 \\
3F4 & Maus, monoklonal & $1: 20000$ & Krasemann et al., 1996 \\
3B5 & Maus, monoklonal & $1: 50000$ & Krasemann et al., 1996 \\
12F10 & & $1: 125000$ & Dako, Hamburg \\
Sekundär-Antikörper & Ziege, polyklonal & & \\
HRP-gekoppelt & & & \\
\hline
\end{tabular}




\subsection{Mikrobiologische und genetische Arbeitsmethoden}

Die folgenden Methoden und Vorschriften wurden, soweit nicht anders angegeben, dem Laborhandbuch „Molecular Cloning“ von Sambrook et al. (1989) entnommen.

\subsubsection{Lagerung von Bakterienstämmen}

Häufig verwendete Bakterienstämme wurden auf LB-Agarplatten mit den entsprechenden Antibiotika über Nacht bei $37{ }^{\circ} \mathrm{C}$ inkubiert und anschließend bei $4{ }^{\circ} \mathrm{C}$ über einen Zeitraum von bis zu drei Wochen gelagert.

\subsubsection{Stammhaltung von E. coli-Kulturen}

Zur Herstellung von E. coli-Stammkulturen wurden jeweils $0.9 \mathrm{ml}$ einer Übernachtkultur mit $0.1 \mathrm{ml}$ Glycerin versetzt und bei $-80^{\circ} \mathrm{C}$ gelagert.

\subsubsection{Anzuchtbedingungen und Wachstumsmessung}

E. coli wurde aerob in Reagenzgläsern oder Erlenmeyerkolben bei $37^{\circ} \mathrm{C}$ in einem Schüttelinkubator bei 180-250 rpm angezogen. Bei der Verwendung von LB-Medium wurde über Nacht inkubiert. Das Wachstum der Zellen wurde durch Trübungsmessung (Ultrospec II, Pharmacia) bei einer Wellenlänge von $600 \mathrm{~nm}$ gegen LB-Medium verfolgt.

\subsubsection{Präparation von kompetenten E. coli-Zellen (Nishimura et al., 1990)}

$50 \mathrm{ml}$ Medium A wurden mit $0.5 \mathrm{ml}$ einer E. coli-Übernachtkultur angeimpft und unter Schütteln bei $37^{\circ} \mathrm{C}$ bis zum Erreichen der mittleren logarithmischen Phase (OD $\left.600=0.4-0.6\right)$ inkubiert. Daraufhin wurden die Zellen für ca. 10 min auf Eis gestellt, anschließend bei 5000 rpm und $4{ }^{\circ} \mathrm{C}$ für 10 min pelletiert und der Überstand verworfen. Die Zellen wurden danach mit $0.5 \mathrm{ml}$ vorgekühltem Medium A resuspendiert und nach Zugabe von $2.5 \mathrm{ml}$ Lösung B gut gemischt. Die kompetenten Zellen wurden in Aliquots von $0.1 \mathrm{ml}$ aufgeteilt und bis zur 
Transformation bei $-80^{\circ} \mathrm{C}$ gelagert.

\subsubsection{Transformation von E. coli mit Plasmid-DNA}

Für die Transformation wurden die Zellen auf Eis aufgetaut, mit der jeweiligen DNA (ca. 100 pg) gemischt und für 15 bis 30 min bei $4{ }^{\circ} \mathrm{C}$ inkubiert. Anschließend wurden sie einem Hitzeschock bei $42{ }^{\circ} \mathrm{C}$ für $45 \mathrm{~s}$ ausgesetzt, für 2 min auf Eis gestellt und dann mit $0.9 \mathrm{ml} \mathrm{LB}$ Medium $\left(42^{\circ} \mathrm{C}\right)$ versetzt. Zur Expression der Antibiotikaresistenz wurden die Zellen für eine Stunde bei $37{ }^{\circ} \mathrm{C}$ inkubiert („Kur“) und daraufhin in geeigneten Volumina (i. d. R. 200-300 $\mu 1)$ auf Selektivplatten ausgesät und bei $37^{\circ} \mathrm{C}$ über Nacht inkubiert.

\subsubsection{Allgemeine Methoden zum Arbeiten mit DNA}

\subsubsection{Fällung von DNA mit Ethanol}

Die Ethanolfällung diente der Konzentrierung von DNA und der teilweisen Entfernung von Proteinen, Salzen und freien Nukleotiden. Dabei wurde die Konzentration monovalenter Kationen erhöht, welches, durch Erhöhung der Dielektrizitätskonstante, die Abstoßung der negativen Ladungen des Phospodiester-Rückgrats vermindert, wodurch bei Lösungsmittelentzug durch Zugabe von Ethanol die DNA-Fällung ermöglicht wird. Das Volumen der DNA-Lösung wurde bestimmt und mit 1/10 Vol. 3 M Na-Acetat- oder $7 \mathrm{M}$ NH4-Acetat-Lösung gemischt. Der Ansatz wurde mit 2-3 Vol. Ethanol versetzt und gründlich gemischt. Die Präzipitation erfolgte für $30 \mathrm{~min}$ bei $-80{ }^{\circ} \mathrm{C}$ oder 60 min bis über Nacht bei -20 ${ }^{\circ} \mathrm{C}$. Die DNA wurde durch Zentrifugation $\left(10 \mathrm{~min}, 14000 \mathrm{rpm}, 4{ }^{\circ} \mathrm{C}\right)$ pelletiert, anschließend einmal mit $200 \mu 170 \%$ igem Ethanol gewaschen und erneut zentrifugiert (5 min, 14000 rpm, RT). Das DNA-Präzipitat wurde im Exsikkator oder bei RT getrocknet und in dem gewünschten Volumen TE-Puffer oder $\mathrm{H}_{2} \mathrm{O}$ aufgenommen. 


\subsubsection{Extraktion von DNA mit Phenol/Chloroform/lsoamylalkohol}

Zur Entfernung von Proteinen, Ethidiumbromid oder Resten anderer hydrophober Kontaminationen diente die Extraktion von DNA mit Phenol/ Chloroform/ Isoamylalkohol. Die DNA-Lösung wurde mit 1 Vol. Phenol/Chloroform/Isoamylalkohol versetzt, gründlich gemischt und zur Beschleunigung der Phasentrennung 5 min zentrifugiert (14000 rpm, RT). Die DNA in der wässrigen Oberphase wurde in ein neues Reaktionsgefäß überführt und bei Bedarf einer Fällung mit Ethanol unterzogen.

\subsubsection{Konzentrationsbestimmung der DNA}

$10 \mu 1$ der DNA-Lösungen wurden auf $0.5 \mathrm{ml}$ mit $\mathrm{H}_{2} \mathrm{O}$ aufgefüllt und die Konzentrationen durch Messung der OD260 in einer Quarzküvette (Schichtdicke: $1 \mathrm{~cm}$ ) gegen $0.5 \mathrm{ml} \mathrm{H}_{2} \mathrm{O}$ bestimmt. Ein OD260-Wert von 1 entsprach einer Konzentration von $50 \mu \mathrm{g}$ dsDNA/ml. Der

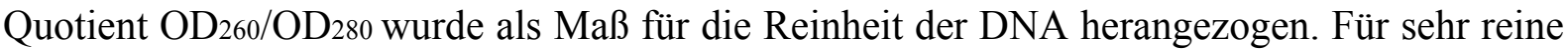
DNA-Lösungen beträgt das Verhältnis 1.8 bis 1.95. Niedrigere Werte sind ein Indiz für die Anwesenheit von Proteinen und Verunreinigungen mit Phenol. Geringe DNA-Mengen wurden nach elektrophoretischer Auftrennung im Agarosegel über ihre Fluoreszenzintensität unter UV-Licht durch Vergleich mit einem DNA-Standard bekannter Konzentration bestimmt.

\subsubsection{Spaltung von DNA mit Restriktionsendonukleasen}

Für Restriktionsspaltungen wurde das Gesamtvolumen des Ansatzes so gewählt, dass die Enzym-Stammlösung wenigstens 1:10 verdünnt wurde, um unspezifische Reaktionen aufgrund zu hoher Glycerinkonzentrationen zu vermeiden. Pro $\mu \mathrm{g}$ DNA wurden etwa 1-2 Einheiten (Units) des Enzyms und 0.1 Vol. des entsprechenden 10 fach Restriktionspuffers zugegeben. Die Inkubation erfolgte i. d. R. bei $37{ }^{\circ} \mathrm{C}$ für eine bis mehrere Stunden. Die Spaltung wurde mittels einer Agarosegelelektrophorese überprüft. 


\subsubsection{Isolierung von Plasmid-DNA}

\section{A. Minipräparation von Plasmid-DNA}

$20 \mathrm{ml}$ LB-Selektionsmedium (LB-Medium $+100 \mu \mathrm{g} / \mathrm{ml}$ Ampicillin) wurden mit dem Plasmid-tragenden E. coli-Stamm beimpft und über Nacht bei $37{ }^{\circ} \mathrm{C}$ geschüttelt. Nach Zentrifugation (1 min, $14000 \mathrm{rpm}, \mathrm{RT}$ ) von $1.5 \mathrm{ml}$ dieser Bakterienkultur wurde das Zellpellet nach Verwerfen des Überstandes in $150 \mu \mathrm{l}$ P1-Puffer resuspendiert. Nach fünfminütiger Inkubation bei RT erfolgte die Lyse durch Zugabe von $150 \mu 1$ P2-Puffer. Das Lysat wurde mehrmals geschüttelt, mit $150 \mu 1$ eiskaltem P3-Puffer neutralisiert und mindestens 5 Minuten auf Eis belassen. Nach zwei Zentrifugationen unter identischen Bedingungen (5 min, 14000 rpm, $4{ }^{\circ} \mathrm{C}$ ) wurde die DNA im Überstand auf eine mit $1 \mathrm{ml}$ QBT-Puffer aequilibrierte Qiagen-20 Säule gegeben und vier mal mit je $1 \mathrm{ml}$ QC Waschpuffer gewaschen. Die Elution der DNA erfolgte mit $0.8 \mathrm{ml}$ QF-Puffer, wobei die DNA mit 0.7 Vol. Isopropanol präzipitiert und für 30 Minuten bei 14000 x g, $4{ }^{\circ} \mathrm{C}$ zentrifugiert wurde. Nachfolgendes Waschen mit 70 \% Ethanol diente der Entfernung von Salzen. Die DNA wurde nach Abtrennung des Ethanols im Exsiccator getrocknet und in einem geeigneten Volumen TE-Puffer oder Wasser gelöst, die Konzentration durch Messung bei $\mathrm{OD}_{260 \mathrm{~nm}}$ bestimmt und bei $-20{ }^{\circ} \mathrm{C}$ gelagert.

\section{B. Midipräparation von Plasmid-DNA}

30-40 ml LB-Medium mit $100 \mu \mathrm{g} / \mathrm{ml}$ Ampicillin wurden mit $0.5 \mathrm{ml}$ Bakterienkulturbeimpft und über Nacht bei $37^{\circ} \mathrm{C}$ im Inkubator geschüttelt. Die Kultur wurde im JA-17-Röhrchen für $3 \mathrm{~min}$ bei $5000 \mathrm{rpm}$ zentrifugiert, der Überstand verworfen und das Bakterienpellet in $4 \mathrm{ml}$ P1-Puffer resuspendiert. Die Suspension wurde mit $4 \mathrm{ml}$ P2-Puffer versetzt, vorsichtig gemischt und 5 min bei RT inkubiert. Anschließend wurde der Ansatz durch Zugabe von $4 \mathrm{ml}$ eiskaltem P3-Puffer neutralisiert und 15 min auf Eis inkubiert. Die Suspension wurde 30 min bei $16000 \mathrm{rpm}$ zentrifugiert $\left(4^{\circ} \mathrm{C}\right)$, der Überstand vorsichtig mit einer Pipette entnommen und auf eine mit $4 \mathrm{ml}$ QBT-Puffer äquilibrierte Qiagen-100-Säule gegeben. Die Säule wurde zweimal mit $10 \mathrm{ml}$ QC-Puffer gewaschen, die Plasmid-DNA anschließend mit $5 \mathrm{ml}$ QFPuffer eluiert und in einem JA-17-Röhrchen aufgefangen. Die DNA wurde mit 0.7 Vol. Isopropanol gefällt (15 min auf Eis) und bei $16000 \mathrm{rpm}$ bei $4{ }^{\circ} \mathrm{C}$ pelletiert. Das Pellet wurde 
mit $70 \%$ igem Ethanol gewaschen, bei RT getrocknet und in einem geeigneten Volumen TEPuffer oder $\mathrm{H}_{2} \mathrm{O}$ aufgenommen. Abschließend wurde die DNA-Konzentration durch eine OD260-Messung bestimmt und Aliquots zur weiteren Verwendung bei $-20{ }^{\circ} \mathrm{C}$ gelagert.

\section{Isolierung von DNA-Fragmenten aus Agarosegelen}

Für die Extraktion von DNA aus Agarosegelen wurde das QIaquick Gel Extraction Kit (Qiagen, Hilden) angewendet. Es wurden die beigefügten Puffer verwendet und die Extraktion anhand des mitgelieferten Protokolls wie folgt durchgeführt. Die DNA-Bande wurde über dem UV-Leuchttisch mit einem Skalpell aus dem Agarosegel herausgeschnitten und in ein Reaktionsgefäß überführt. Etwa 3 Vol. Puffer QG wurden auf das Gelstück gegeben und der Ansatz für 10 min bei $50{ }^{\circ} \mathrm{C}$ inkubiert und dabei alle 2 min kurz gemischt (Vortexgerät) um eine gleichmäßige Verteilung der Suspension zu gewährleisten. Nach Auftrag auf eine QIagen-10-Säule und Zentrifugation für 30 Sekunden, 14000 x g wurde der Durchlauf verworfen und das Pellet zweimal mit Puffer PE gewaschen (jeweils $500 \mu 1$ Puffer, resuspendieren mittels Mischen am Vortexgerät und zentrifugieren für $30 \mathrm{~s}, 14000 \mathrm{rpm}, \mathrm{RT}$ ). Das Pellet wurde an der Luft getrocknet und zur Elution der DNA in $20 \mu_{1} \mathrm{H}_{2} \mathrm{O}$ resuspendiert. Nach Inkubation für 5 min bei der jeweils empfohlenen Temperatur (DNA-Fragmente $\leq 4 \mathrm{~kb}$ bei RT, DNA-Fragment $4-10 \mathrm{~kb}$ bei $50{ }^{\circ} \mathrm{C}$ ) wurde die Suspension zentrifugiert (30 s, 14000 rpm, RT), der Überstand in ein neues Reaktionsgefäß überführt, die Elution mit $10 \mu \mathrm{H} \mathrm{H}_{2} \mathrm{O}$ wiederholt und die DNA-Lösungen vereinigt. Qualität und Konzentration der eluierten DNA wurden im Agarosegel überprüft.

\subsubsection{Agarosegelelektrophorese}

Für die präparative und analytische Auftrennung von DNA-Fragmenten wurden 0.7 bis 1.5 \%ige (w/v) Agarosegele verwendet. Nach dem Kochen der Agarose in 1 x TBE-Puffer wurde 1/2000 Vol. einer Ethidiumbromidlösung (1 mg/ml) zugesetzt, die Agarose in eine Flachbettschale gegossen und mit einem Kamm versehen, welcher für die Ausbildung der Probenauftragstaschen sorgte. Nach dem Erstarren der Agarose wurde das Gel in eine mit $1 \mathrm{x}$ TBE-Puffer gefüllte Flachbettelektrophoresekammer überführt und der Kamm entfernt. Vor 
dem Auftragen der DNA-Proben wurden diese mit 0.1-0.2 Vol. 6 x DNA-Auftragspuffer versetzt. Als Längenstandard diente der Hyperladder I (Bioline, Berlin). Für die Elektrophorese wurden Spannungen von bis zu 120 Volt (Feldstärken 5-15 V/cm) angelegt. Anschließend wurde die DNA durch UV-Licht als fluoreszierende Banden sichtbar gemacht und fotografiert.

\subsubsection{Präparation von DNA für die Subklonierung von DNA-Fragmenten in Plasmidvektoren}

Plasmid-DNA wurde mit Restriktionsendonukleasen verdaut und mittels des QIAquick Gel Extraction Kits (Qiagen, Hilden) aus Agarosegelen extrahiert.

\subsubsection{Ligation von DNA-Fragmenten in Plasmidvektoren}

Die Verknüpfungsreaktion erfolgte unter Einsatz der T4-DNA-Ligase, welche die Bildung einer Phosphodiesterbindung zwischen dem 3'-Hydroxylende und dem 5'-Phosphatende von DNA-Molekülen katalysiert.

\section{Reaktionsmix:}

Vektor-DNA nach Restriktionsverdau (50-200 ng)

DNA-Fragment (5-10 facher molarer Überschuß)

1 x T4-DNA-Ligase-Puffer

T4-DNA-Ligase (1-2 U)

i. d. $\mathrm{R} . \mathrm{H}_{2} \mathrm{O}$ ad $10 \mu \mathrm{l}$

Die Reaktionen wurden entweder bei $22{ }^{\circ} \mathrm{C}$ für 2 Stunden oder bei $16{ }^{\circ} \mathrm{C}$ über Nacht durchgeführt. Anschließend wurden E. coli-Zellen mit der DNA der Ligationsansätze transformiert, eine Minipräparation von den auf Selektivplatten gewachsenen Kolonien durchgeführt und die Konstrukte durch Restriktionsanalysen und DNA-Sequenzanalyse überprüft. 


\subsubsection{Polymerase-Kettenreaktion (PCR)}

PCR (Mullis \& Faloona, 1987, Saiki et al., 1988) wurden i. d. R. mit einem Volumen von 50 $\mu 1$ in 0.5 ml-PCR-Reaktionsgefäßen (Biozym, Hess. Oldendorf) in einem Thermoblock (Biometra, Göttingen; Eppendorf, Hamburg) durchgeführt. Um einen Fehleinbau von Nukleotiden bei der Enzymreaktion weitestgehend $\mathrm{zu}$ vermeiden wurde $P f u$-DNAPolymerase verwendet, die eine deutlich bessere Fehlerkorrekturrate aufweist als z.B. TaqDNA-Polymerase. Zum Screenen wurde eine modifizierte Taq-Polymerase Immolase-DNAPolymerase verwendet (Bioline, Berlin).

Tabelle 4: PCR-Ansätze für verschiedene DNA-Polymerasen

\begin{tabular}{|c|c|c|}
\hline & $\begin{array}{c}\text { Pfu-Turbo Hotstart DNA- } \\
\text { Polymerase (Stratagene, } \\
\text { Amsterdam) }\end{array}$ & $\begin{array}{c}\text { Immolase-DNA- } \\
\text { Polymerase (Bioline, } \\
\text { Berlin) }\end{array}$ \\
\hline DNA & $50-500 \mathrm{ng}$ & $50-500 \mathrm{ng}$ \\
\hline „Primer“ & je 50 pmol & je 50 pmol \\
\hline dNTP-Mix & je $10 \mathrm{mM}$ & je $10 \mathrm{mM}$ \\
\hline Polymerase & $1-2.5 \mathrm{U}$ & $1-2,5 \mathrm{U}$ \\
\hline $10 \times$ Reaktionspuffer & $5 \mu \mathrm{l}$ & $5 \mu \mathrm{l}$ \\
\hline $\mathrm{MgCl}_{2}$ & - & $1.5 \mathrm{mM}$ \\
\hline $\mathrm{H}_{2} \mathrm{O}$ & auf $50 \mu \mathrm{l}$ auffüllen & auf $50 \mu \mathrm{l}$ auffüllen \\
\hline
\end{tabular}

Zum Schutz vor Verdunstung wurden die Ansätze mit sterilem Mineralöl (Sigma, Seelze) überschichtet. Die Denaturierung erfolgte im ersten Zyklus bei $94{ }^{\circ} \mathrm{C}$ für 2 min beim Arbeiten mit $P f u$-Turbo Hotstart DNA- Polymerase und für 7 min beim Arbeiten mit Immolase-DNAPolymerase, danach bei jedem Zyklus bei $94{ }^{\circ} \mathrm{C}$ für 30 Sekunden. Die Anlagerungstemperatur wurde ausgehend von der errechneten Schmelztemperatur der „Primer“ empirisch optimiert und die Kettenverlängerung erfolgte jeweils bei $72{ }^{\circ} \mathrm{C}$ für $2.5 \mathrm{~min} / \mathrm{kb}(P f u$-Turbo Hotstart DNA- Polymerase) bzw. 45 Sekunden/kb (Immolase-DNA-Polymerase). Nach Abschluss von 30 Temperaturzyklen wurden die PCR-Produkte mittels Agarosegelelektrophorese analysiert und für ihre Weiterverwendung präpariert. 


\subsubsection{Einführung von Mutationen durch site directed mutagenesis (Quick change)}

Das Quick Change Site Directed Mutagenesis-Protokoll nutzt komplementäre Primer, welche beide die Mutation enthalten. Sie binden an die wt-DNA und mittels PCR (2.3.3) wird das vollständige Plasmid amplifiziert. Die parentale DNA wird unter Zuhilfenahme von Dpn I verdaut, welches nur methylierte und hemimethylierte DNA erkennt. Die mutierte DNA wird in E. coli XL1 blue transformiert. Die Bakterien ligieren die Strangenden und mutierte Plasmide können präpariert werden. Die Oligonukleotide wurden nach Herstellerangaben konstruiert. Die Punktmutanten wurde noch in den Vektor pET27b(+) über die Restriktionsschnittstellen Nde I und Sal I umkloniert. Die Inserts aller Punktmutanten wurden durch Sequenzierung überprüft. Tabelle 2 gibt eine Übersicht über die hergestellten Punktmutanten.

\subsubsection{Einführung von Mutationen durch Polymerase-Kettenreaktion (SOE- PCR)}

Eine zweite angewendete Methode zur Einführung von Punktmutanten ist die SOE-PCR (splicing by overlap extension). Diese Methode wurde immer dann angewendet, wenn eine Mutagenese über Quick change nicht möglich war. Bei dieser Technik werden zum einen sogenannte äußere PCR Primer eingesetzt, die entgegengesetzt die Zielregion in einer Duplex-DNA flankieren und zusätzlich sogenannte überlappende innere Primer, die die einzuführende Mutation tragen. Zunächst wird in zwei getrennten Reaktionen die 3' und die 5' Hälfte der Zielsequenz mit je einem inneren und einem äußeren Primer wie oben beschrieben amplifiziert. Zur Berechnung der Annealing-Temperatur mußten jeweilige Fehlpaarungen beachtet werden. Nach Entfernung der Primer durch Aufreinigung der PCR-Produkte über Agarosegelelektrophorese (Absatz 5.1.6.2) wurden jeweils etwa $50 \mathrm{ng}$ der 3'- und 5'-PCRProdukte gemischt und einer PCR-Reaktion mit den äußeren Primern unterworfen (SOEPCR). Bei der auf die Denaturierung folgenden Renaturierung während der Annealing-Phase kommt es über deren komplementäre Regionen zur Hybridisierung der beiden unterschiedlichen PCR-Produkte miteinander. Die 3' Enden werden dann während der Elongation verlängert, so daß die mutagenisierte Zielsequenz als Produkt entsteht. Diese mutagenisierte Zielsequenz wird dann ausgehend von den beiden äußeren Primern in den 
folgenden PCR-Zyklen amplifiziert.

\subsubsection{Herstellung der Prnp-Konstrukte im pET27b(+)-Vektor}

Der für das humane Prionprotein humPrP23-231, V129M codierende open reading frame (ORF) des Prnp-Gens wurde aus menschlichem Hirngewebe durch PCR mit den Primern humJWforw und humJWrev (2.1.11) amplifiziert und nach Verdau des entstandenen PCRFragmentes durch die Restriktionsendonukleasen HindIII und SalI in den Kloniervektor pBluescript II $\mathrm{SK}(+)$ ligiert. Aus dem entstandenen Konstrukt pBluescript II $\mathrm{SK}(+) /$ humPrnp23-231,V129M wurden die für die Prionproteine humPrP23-112, humPrP23144, humPrP23-159, humPrP23-173 und humPrP23-199 codierenden ORFs durch PCR mit den Primerpaaren 23MSon (jeweils) und 112rev, 144rev, 159rev, 173rev und 199rev amplifiziert und nach Restriktionsverdau der PCR-Fragmente mit den Endonukleasen HindIII und SalI ebenfalls in den Vektor pBluescript II SK(+) ligiert. Durch Verwendung des 23MSon-Primers wurde im amplifizierten PCR-Fragment eine neue NdeI-Schnittstelle generiert und die für die Aminosäuren Methionin (ATG) und Serin (AGC) codierende Sequenz ATGAGC gemäss der „N-end-rule“ in Bakterien in die Konstrukte im pBluescript II SK(+)-Vektor eingefügt (Tobias et al., 1991). Die resultierende Startsequenz im Prionprotein lautet MSKKRPK, wobei das erste Lysin dieser Sequenz der ersten Aminosäure in der reifen Sequenz des zellulären Prionproteins humPrP23-231 entspricht.

Die für die verschiedenen trunkierten Prionproteine codierenden ORFs wurden durch Restriktionsverdau mit den Restiktionsendonukleasen NdeI und SalI aus den Konstrukten im pBluescript II SK(+)-Vektor ausgeschnitten und über die gleichen Schnittstellen in den prokaryotischen Expressionsvektor pET27b(+) ligiert.

Das in E. coli seltene Arginin-Codon AGA musste am Codon 228 des für das VolllängenPrionprotein humPrP23-231,V129M codierenden Konstruktes pBluescript II $\mathrm{SK}(+)$ /humPrnp23-231,V129M durch das in E. coli häufiger vorkommende Arginin-Codon CGT durch eine PCR mit den Primern 23MSon und 231SSon ausgetauscht werden. Das resultierende PCR-Fragment wurde mit den Restriktionsendonukleasen HindIII und SalI verdaut und in den pBluescript II SK(+)-Vektor ligiert. Die Bezeichnung des Konstruktes lautet pBluescript II SK(+)/humPrnp23-231, V129M, R228R. Dieses Konstrukt wurde mit 
den Restriktionsendonukleasen NdeI und SalI verdaut und für die nachfolgende Proteinsynthese in den Expressionsvektor pET27b(+) ligiert.

\subsection{Methoden für Proteinarbeiten}

\subsubsection{Proteinkonzentrationsbestimmung}

Die Proteinkonzentrationen wurden bei einer $\mathrm{OD}_{280}$ in $6 \mathrm{M} \mathrm{GdnHCl}$ über die Bestimmung der spezifischen Extinktionskoeffizienten bestimmt (Gill, von Hippel,. (1989). Die spezifischen Extinktionskoeffizienten wurden für alle Prionproteine berechnet und für die Konzentrationsbestimmung benutzt.

Tabelle 5: Spezifische molare Extinktionskoeffizienten und Molekulargewichte der untersuchten Prionproteine

\begin{tabular}{|l|c|c|}
\hline \multicolumn{1}{|c|}{ Konstrukt } & $\begin{array}{c}\text { spezifischer molarer } \\
\text { Extinktionskoeffizient } \\
(\mathrm{mg} / \mathrm{ml}) * \mathrm{~cm}^{-1}\end{array}$ & $\begin{array}{c}\text { berechnetes } \\
\text { Molekulargewicht (g/mol) }\end{array}$ \\
\hline 1. humPrP23-112 & 4.553 & 9310.1 \\
\hline 2. humPrP23-144 & 3.564 & 12254.5 \\
\hline 3. humPrP23-159 & 3.402 & 14342.7 \\
\hline 4. humPrP23-173 & 3.270 & 19069.5 \\
\hline 5. humPrP23-199 & 2.761 & 22921.2 \\
\hline 6. humPrP23-231, V129M & 2.469 & 23147.4 \\
\hline 7. SHaPrP23-232 (Hamster) & 2.635 & \\
\hline
\end{tabular}

\subsubsection{Expression und Aufreinigung von humanem Prionprotein} (zytoplasmatische Einschlusskörper (Inclusion Bodies)) aus Vollmedium

Ausgehend von einer frischen LB-Agar Platte $(30 \mu \mathrm{g} / \mathrm{ml}$ Kanamycin) wurde eine einzelne Kolonie von BL21 (DE3) mit pET27b/humPrP gepickt und damit eine Über-Nacht-Kultur aus 
$10 \mathrm{ml} \mathrm{LB}-$ Medium und $10 \mu \mathrm{l}$ einer Kanamycin-Stocklösung $(30 \mathrm{mg} / \mathrm{ml})$ angeimpft. Am nächsten Morgen wurde $1 \mathrm{ml}$ der Über-Nacht-Kultur mit einem Liter „Glockshuber“-Medium und $30 \mu \mathrm{g} / \mathrm{ml}$ (finale Konzentration) Kanamycin verdünnt und etwa $6 \mathrm{~h}$ lang bei $37{ }^{\circ} \mathrm{C}, 250$ rpm im Bakterienschüttler inkubiert. Bei einer $\mathrm{OD}_{600}=1.5$ wurde die Expression der für die verschiedenen Prionproteine codierenden Konstrukte mit IPTG (1 mM Endkonzentration) induziert und über Nacht bei $37^{\circ} \mathrm{C}, 250 \mathrm{rpm}$ im Schüttler inkubiert. Die Bakteriensuspension wurde für $10 \mathrm{~min}$ bei $4{ }^{\circ} \mathrm{C}$ temperiert und für $12 \mathrm{~min}$ bei $4400 \mathrm{xg}$ (Kendro, Multifuge 3R) zentrifugiert. Das entstandene Bakterienpellet wurde in $30 \mathrm{ml}$ Lysispuffer plus $300 \mu 1$ Protease Inhibitor (PI)-Mix, $3 \mathrm{mg}$ DNase I, $3 \mathrm{mg}$ RNase A, $10 \mathrm{mM} \mathrm{CaCl}_{2}$ und $10 \mathrm{mM} \mathrm{MgCl} 2$ (pro Liter Kulturmedium) resuspendiert. Durch dreimalige Einfrier/Auftau-Zyklen mit flüssigem Stickstoff wurden die Bakterien aufgebrochen und auf Eis vorsichtig sonifiziert (Branson Sonifier B 12, „Micro Tip Limit“ =7).

\subsubsection{Inclusion Body-Aufreinigung}

Die zytoplasmatisch entstandenen Inclusion Bodies (IBs) wurden bei 30000 x g (Beckman, JA 17), $4{ }^{\circ} \mathrm{C}$ für 30 min zentrifugiert, wobei von allen löslichen Bestandteilen (Überstand) abgetrennt wurde. Die Inclusion Bodies wurden mit Triton-X-100 und NaCl-haltigem IBWaschpuffer in einem Handhomogenisator gewaschen, bis der Überstand nicht mehr gelblich erschien (2-3 x) und anschliessend bei $30000 \mathrm{x}$ g (Beckman, JA 17), $4{ }^{\circ} \mathrm{C}$ für $30 \mathrm{~min}$ zentrifugiert. Abschliessend wurde noch einmal mit SB14-haltigem IB-Waschpuffer gewaschen. Die gereinigten Inclusion Bodies wurden in $6 \mathrm{M}$ Guanidiniumhydrochlorid, 100 $\mathrm{mM}$ Natriumphosphat, $10 \mathrm{mM}$ Tris, $15 \mathrm{mM} \quad \beta$-Mercaptoethanol, $\mathrm{pH} \quad 8.0 \quad \mathrm{im}$ Handhomogenisator resuspendiert und zur Abtrennung von DNA und Zelltrümmern zwei mal bei $30000 \mathrm{x} \mathrm{g}$ (Beckman, JA 17), $4{ }^{\circ} \mathrm{C}$ für $30 \mathrm{~min}$ zentrifugiert, wobei der Überstand abgenommen wurde und einem erneuten Zentrifugationsschritt unterworfen wurde. Das Prionprotein befand sich vollständig denaturiert im Überstand. 


\subsubsection{Chromatographische Aufreinigung}

\section{A. Metallaffinitätschromatographie:}

Die Ni-NTA Agarose (Qiagen) wurde für $30 \mathrm{~min}$ im Solubilisierungspuffer (Puffer A: $6 \mathrm{M}$ GdnHCl, $100 \mathrm{mM}$ Natrium Phosphat, $10 \mathrm{mM}$ Tris, $15 \mathrm{mM} \beta$-Mercaptoethanol, $\mathrm{pH}$ 8.0) inkubiert. Die im gleichen Puffer gelösten PrP Inclusion Bodies wurden bei pH 8.0 zur NiNTA Agarose gegeben und bei $4{ }^{\circ} \mathrm{C}$ im Kühlraum für 30 min inkubiert. In einem ersten Schritt wurde N-terminal fragmentiertes PrP ohne die für die Bindung an die Ni-NTA Agarose verantwortliche Oktarepeatregion des Prionproteins, membranständige Proteine sowie Nukleinsäuren und Zellbestandteile durch Waschen mit Puffer A und $10 \mathrm{mM}$ Imidazol entfernt. Die Elution des Prionproteins erfolgte durch $3 \mathrm{M} \mathrm{GdnHCl}$ mit $0.5 \mathrm{M}$ Imidazol, pH 7.5. Die Präzipitation des Prionproteins erfolgte durch Methanol-Fällung (Zugabe von 4 Volumen Methanol) für $2 \mathrm{~h}$ bei $-20{ }^{\circ} \mathrm{C}$. Nach sorgfältiger Abtrennung des Methanols wurde das Prionprotein in $8 \mathrm{M}$ Harnstoff, $20 \mathrm{mM}$ Natriumphosphat, $10 \mathrm{mM} \beta$-Mercaptoethanol, $\mathrm{pH}$ 8.0 resolubilisiert und von im Harnstoff unlöslichen Bestandteilen bei $4{ }^{\circ} \mathrm{C}, 7800 \mathrm{x} \mathrm{g} 10 \mathrm{~min}$ lang abzentrifugiert (Multifuge 3R, Kendro).

\section{B. Anionaustauschchromatographie}

Bakterielle Proteine mit negativer Gesamtladung oder hoher lokaler negativer Ladung und Reste von Nukleinsäuren wurden über eine Anionaustauschersäule (EMD-TMAE (Trimethylaminoethyl-) Fractogel, Merck, Darmstadt) abgetrennt. Aufgrund des basischen Charakters des Prionproteins fand keine Wechselwirkung mit der Matrix des Anionaustauschers statt.

\section{Kationaustauschchromatographie}

Das im Durchlauf des Anionaustauschers befindliche Prionprotein wurde zur Abtrennung des Harnstoffs und N-terminal trunkierter PrP-Fragmente ohne die stark basische N-terminale Region direkt weiter durch Kationaustauschchromatographie (EMD-COO-Fractogel, Merck, Darmstadt) aufgereinigt. In einem ersten Waschschritt wurde mit 20 mM Phosphatpuffer, 10 
mM $\beta$-Mercaptoethanol, pH 6.0 gewaschen. Nachfolgend wurde mit steigender Guanidiniumhydrochlorid-Konzentration (0.5-6.0 M), $10 \mathrm{mM} \beta$-Mercaptoethanol, $20 \mathrm{mM}$ Phosphatpuffer pH 6.0 gewaschen bzw. eluiert. Prionproteinhaltige Fraktionen wurden gesammelt und vereinigt. Der das Prionprotein enthaltende Puffer wurde auf $\mathrm{pH} 8.0$ gebracht und mit festem $\mathrm{GdnHCl}$ eine $6 \mathrm{M}$ Konzentration eingestellt.

\subsubsection{Expression und Aufreinigung von humanem Prionprotein (zytoplasmatische Inclusion Bodies) in M9 Minimalmedium für die NMR- Spektroskopie}

Analog zur Expression im Vollmedium wurde ausgehend von einer frischen Retransformation des Expressionsvektors in BL21 (DE3) auf LB-Platten mit $30 \mu \mathrm{g} / \mathrm{ml}$ Kanamycin eine einzelne Kolonie gepickt und damit eine Über-Nacht Kultur in $10 \mathrm{ml}$ LB-Medium $+10 \mu 1$ Kanamycin (Stock: $30 \mathrm{mg} / \mathrm{ml}$ ) angeimpft. Am nächsten Morgen wurden die Bakterien für 10 min bei $4{ }^{\circ} \mathrm{C}$ temperiert und bei $4{ }^{\circ} \mathrm{C}, 5000 \mathrm{x}$ g (JA 17, Beckman) für 5 min zentrifugiert. Es wurde sorgfältig vom Überstand abgetrennt und das $10 \mathrm{ml}$ Pellet ohne LB-Medium (1:100Verdünnung) sofort in 1 Liter M9-Minimalmedium durch vorsichtiges Auf-und Abpipettieren resuspendiert. Das M9-Minimalmedium enthielt als Stickstoffquelle immer ${ }^{15} \mathrm{~N}$ Ammoniumchlorid (99\%) und als Kohlenstoffquelle „normale“ ${ }^{12} \mathrm{C}$-D-Glucose oder gelabelte ${ }^{13}$ C6-D-Glucose (99 \%). Induktion der Bakterien erfolgte nach $~ 8-9 \mathrm{~h}$ Wachstum im Bakterienschüttler $\left(250 \mathrm{rpm}, 37{ }^{\circ} \mathrm{C}\right)$ bei einer $\mathrm{OD}_{600}=0.65-0.7$. Die finale IPTGKonzentration betrug $1 \mathrm{mM}$. Die Ernte und Lyse der Zellen erfolgte analog zur Expression im Vollmedium am nächsten Morgen. Auf eine Inclusion Body Reinigung wurde verzichtet. Die Aufreinigung und Rückfaltung der gelabelten Proteine war identisch zum nicht-gelabelten Prionprotein. Pro Liter Minimalmedium konnten nach Aufreinigung und Rückfaltung etwa 30 $m g{ }^{15} \mathrm{~N} /{ }^{13} \mathrm{C}$-gelabeltes Prionprotein gewonnen werden. 


\subsubsection{Allgemeines Rückfaltungsprotokoll für das Prionprotein}

Die oxidative Rückfaltung des full-lenght Prionproteins PrP23-231 bzw. die Rückfaltungen der Fragmente ohne Disulfidbrücke erfolgte mittels Metallaffinitätschromatographie. Das unter 2.3.2.C aufgereinigte Prionprotein in $6 \mathrm{M} \mathrm{GdnHCl}, 20 \mathrm{mM}$ Phosphat, $\mathrm{pH}$ 8.0, $10 \mathrm{mM}$ $\beta$-Mercaptoethanol wurde analog zu 2.3.2. A an Ni-NTA Agarose gebunden. Zunächst wurde mit $50 \mathrm{ml}$ Puffer A gewaschen. Im Batch-Verfahren wurde Puffer A durch steigende Konzentrationen von Puffer B ersetzt. Damit enthielt jeder Waschpuffer neben sinkenden Konzentrationen von $\mathrm{GdnHCl}(5 \mathrm{M}, 4 \mathrm{M}, 3 \mathrm{M}, 2 \mathrm{M}$, und $1 \mathrm{M}$ ) immer $100 \mathrm{mM}$ NatriumPhosphat und $10 \mathrm{mM}$ Tris, $\mathrm{pH}$ 8.0. Final wurde durch Waschen mit $50 \mathrm{ml}$ reinem Puffer B und $50 \mathrm{ml}$ Puffer $\mathrm{C}$ vom Denaturierungsmittel entfernt. Die Elution des rückgefalteten Prionproteins erfolgte durch $50 \mathrm{ml}$ Puffer E. Ungefaltetes, reduziertes oder aggregiertes Prionprotein konnte unter diesen Bedingungen nicht eluiert werden.

\section{Oxidative Rückfaltung}

Die oxidativen Rückfaltungsbedingungen für das Volllängen-Prionprotein PrP23-231 wichen nur leicht von obigem allgemeinem Rückfaltungsprotokoll ab. Die Rückfaltungspuffer enthielten kein Reduktionsmittel mehr. Nach der Bindung des Prionproteins an Ni-NTAAgarose wurde mit $100 \mathrm{ml}$ Puffer A gewaschen und für $3 \mathrm{~h}$ auf einem „Rollinkubator“ bei RT inkubiert. Anschließend wurde mit dem allgemeinen Rückfaltungsprotokoll fortgefahren. Die Ausbeuten der Rückfaltung betrugen bei PrP-Fragmenten ohne Disulfidbrücke $70 \%$, beim full-length Prionprotein PrP23-231 15-25\% bezogen auf den letzten Aufreinigungsschritt (Kationaustauscher).

\section{Alternatives Rückfaltungsprotokoll}

Die Prionproteine humPrP23-112, humPrP23-144 und humPrP23-159 konnten auch nach dem letzten Aufreinigungsschritt, der Kationaustauschchromatographie, über eine Reversed Phase Chromatographie (C4-Material, Vydac) entsalzt werden. Die C-terminal verkürzten Fragmente eluierten zwischen 20-30 \% Acetonitril und 0.1 \% Trifluoressigsäure und konnten 
nach Lyophyllisation problemlos in $\mathrm{ddH}_{2} \mathrm{O}$ solubilisiert werden. Auch nach Ultrazentrifugation bei $4{ }^{\circ} \mathrm{C}, 15 \mathrm{~h}, 218000 \mathrm{x}$ g waren keine sichtbaren Aggregate vorhanden, was durch Kapillare Zonenektrophorese (CZE) und Absorptionsmessungen bei $350 \mathrm{~nm}$ bestätigt werden konnte. Im Kontrast zu obigen Fragmenten (113stop-, 145stop-, 160stopMutanten) lösten sich humPrP23-173 und längere Fragmente nach Reversed Phase Chromatographie mit nachfolgender Lyophyllisation nicht oder nur sehr unvollständig in destilliertem Wasser auf.

\subsubsection{Entsalzung und Aufkonzentration}

\section{Entsalzung}

Nach der Rückfaltung lag das Prionprotein in einem 100 mM Phosphatpuffer, $10 \mathrm{mM}$ Tris und $0.5 \mathrm{M}$ Imidazol bei einem $\mathrm{pH}$-Wert von 5.8 vor. Die Abtrennung des aggregationsinduzierenden Phosphatpuffers war zwingend notwendig und erfolgte durch Dialyse gegen 10 $\mathrm{mM}$ Natriumacetat Puffer, $\mathrm{pH}$ 4.5, $0.1 \%$ Benzamidinhydrochlorid und $0.1 \%$ Natriumazid (Slide-A-Lyzer Dialysis Cassetes, Pierce, Bonn). Dabei wurde zweimal gegen je 5 Liter Acetatpuffer für je $2 \mathrm{~h}$ bei RT und final gegen 5 Liter Acetatpuffer über Nacht bei RT dialysiert.

\section{Aufkonzentration}

Die Proteinkonzentration betrug nach der Dialyse zwischen $0.5-1 \mathrm{mg} / \mathrm{ml}$. Sofern eine höhere Konzentration für nachfolgende Versuche notwendig war, fand eine Aufkonzentrierung über Centricons statt (Centicon Plus-70, Ultracel-PL, Millipore). Diese Centricons haben ein Fassungsvermögen von $70 \mathrm{ml}$ und weisen ein finales Volumen nach der Aufkonzentration von $350 \mu 1$ auf. 


\subsubsection{SDS-Polyacrylamid-Gelelektrophorese (SDS-PAGE)}

Die analytische Trennung von Proteinen nach ihrem Molekulargewicht erfolgte durch diskontinuierliche, denaturierende SDS-Polyacrylamid-Gelelektrophorese (Laemmli, 1970). Das Gel bestand zu etwa 1/4 seiner Länge aus dem Sammelgel und zu 3/4 aus dem Trenngel. Verwendet wurden Minigele (100 x 80 x 1.5 mm; Bio-Rad, München).

\section{A. Gelzusammensetzung der SDS-PAGE:}

Tabelle 6: Trenngel ( 2 x 1.5 mm) für MiniProtean III:

\begin{tabular}{|c|c|c|c|c|c|}
\hline Acrylamidkonzentration & $5 \%$ & $7.5 \%$ & $10 \%$ & $12.5 \%$ & $15 \%$ \\
\hline $30 \%$ Acrylamid & $2.5 \mathrm{ml}$ & $3.75 \mathrm{ml}$ & $5.0 \mathrm{ml}$ & $6.125 \mathrm{ml}$ & $7.5 \mathrm{ml}$ \\
\hline $1.5 \mathrm{M}$ Tris/HCl pH 8.9 & $3.75 \mathrm{ml}$ & $3.75 \mathrm{ml}$ & $3.75 \mathrm{ml}$ & $3.75 \mathrm{ml}$ & $3.75 \mathrm{ml}$ \\
\hline $10 \%$ SDS & $150 \mu \mathrm{l}$ & $150 \mu \mathrm{l}$ & $150 \mu \mathrm{l}$ & $150 \mu \mathrm{l}$ & $150 \mu \mathrm{l}$ \\
\hline TEMED & $15 \mu \mathrm{l}$ & $15 \mu \mathrm{l}$ & $15 \mu \mathrm{l}$ & $15 \mu \mathrm{l}$ & $15 \mu \mathrm{l}$ \\
\hline $\mathrm{H}_{2} \mathrm{O}$ & $8.51 \mathrm{ml}$ & $7.26 \mathrm{ml}$ & $5.01 \mathrm{ml}$ & $4.98 \mathrm{ml}$ & $3.51 \mathrm{ml}$ \\
\hline $10 \%$ APS & $75 \mu \mathrm{l}$ & $75 \mu \mathrm{l}$ & $75 \mu \mathrm{l}$ & $75 \mu \mathrm{l}$ & $75 \mu \mathrm{l}$ \\
\hline
\end{tabular}

Tabelle 7: Sammelgel (2 x $1.5 \mathrm{~mm})$ für MiniProtean III:

\begin{tabular}{|c|c|c|}
\hline Acrylamidkonzentration & $1 \times 5 \%$ iges Gel & $2 \times 5 \%$ iges Gel \\
\hline $30 \%$ Acrylamid & $0.75 \mathrm{ml}$ & $1.5 \mathrm{ml}$ \\
\hline $0.5 \mathrm{M}$ Tris/HCl $\mathrm{pH} 6.8$ & $0.94 \mathrm{ml}$ & $1.88 \mathrm{ml}$ \\
\hline $10 \% \mathrm{SDS}$ & $37.5 \mu \mathrm{l}$ & $75 \mu \mathrm{l}$ \\
\hline TEMED & $15 \mu \mathrm{l}$ & $15 \mu \mathrm{l}$ \\
\hline $\mathrm{H}_{2} \mathrm{O}$ & $2.12 \mathrm{ml}$ & $4.24 \mathrm{ml}$ \\
\hline $10 \%$ APS & $37.5 \mu \mathrm{l}$ & $37.5 \mu \mathrm{l}$ \\
\hline
\end{tabular}




\section{B. Wiltfang-SDS-Page (Wiltfang et al., 1991)}

Tabelle 8: Trenngel ( 2 x 1.5 mm) für MiniProtean III:

\begin{tabular}{|c|c|c|c|c|c|}
\hline Acrylamidkonzentration & $5 \%$ & $7.5 \%$ & $10 \%$ & $12.5 \%$ & $15 \%$ \\
\hline 8 M Harnstoff & $7.2 \mathrm{~g}$ & $7.2 \mathrm{~g}$ & $7.2 \mathrm{~g}$ & $7.2 \mathrm{~g}$ & $7.2 \mathrm{~g}$ \\
\hline $\begin{array}{c}30 \% \text { Acrylamid }(5 \% \mathrm{w} / \mathrm{v} \\
\text { Bis })\end{array}$ & $2.55 \mathrm{ml}$ & $3.75 \mathrm{ml}$ & $4.95 \mathrm{ml}$ & $6.3 \mathrm{ml}$ & $7.5 \mathrm{ml}$ \\
\hline $1.6 \mathrm{M}$ Tris $/ \mathrm{H}_{2} \mathrm{SO}_{4}, \mathrm{pH} 8.0$ & $3.75 \mathrm{ml}$ & $3.75 \mathrm{ml}$ & $3.75 \mathrm{ml}$ & $3.75 \mathrm{ml}$ & $3.75 \mathrm{ml}$ \\
\hline $10 \% \mathrm{SDS}$ & $150 \mu 1$ & $150 \mu 1$ & $150 \mu 1$ & $150 \mu 1$ & $150 \mu 1$ \\
\hline TEMED & $15 \mu l$ & $15 \mu 1$ & $15 \mu 1$ & $15 \mu 1$ & $15 \mu 1$ \\
\hline $\mathrm{H}_{2} \mathrm{O}$ & \multicolumn{5}{|c|}{ auf $15 \mathrm{ml} \mathrm{mit} \mathrm{H}_{2} \mathrm{O}$ auffüllen } \\
\hline $10 \%$ APS & $75 \mu 1$ & $75 \mu 1$ & $75 \mu 1$ & $75 \mu 1$ & $75 \mu 1$ \\
\hline
\end{tabular}

Tabelle 9: Sammelgel ( 2 x 1.5 mm) für MiniProtean III:

\begin{tabular}{|l|l|l|}
\hline Acrylamidkonzentration & $1 \times 5 \%$ iges Gel & $2 \times 5 \%$ iges Gel \\
\hline $30 \%$ Acrylamid (5\% Bis) & $0.75 \mathrm{ml}$ & $1.5 \mathrm{ml}$ \\
\hline $\begin{array}{l}0.8 \mathrm{M} \text { BisTris/ } \mathrm{H}_{2} \mathrm{SO}_{4} \\
\text { pH } 6.4\end{array}$ & $1.88 \mathrm{ml}$ & $3.75 \mathrm{ml}$ \\
\hline $10 \%$ SDS & $37.5 \mu \mathrm{l}$ & $75 \mu \mathrm{l}$ \\
\hline TEMED & $15 \mu \mathrm{l}$ & $15 \mu \mathrm{l}$ \\
\hline $\mathrm{H}_{2} \mathrm{O}$ & $1175 \mu \mathrm{l}$ & $2350 \mu \mathrm{l}$ \\
\hline $10 \%$ APS & $37.5 \mu \mathrm{l}$ & $37.5 \mu \mathrm{l}$ \\
\hline
\end{tabular}

Nach dem Gießen des Trenngels wurde die Gellösung mit Isopropanol überschichtet, um einen geraden Abschluss zu erzeugen. Nach dem Polymerisieren des Trenngels wurde das Isopropanol entfernt, die Sammelgellösung zugegeben und der Kamm positioniert. Die Proteinproben wurden mit Proteinprobenpuffer versetzt, 10 Minuten in kochendem Wasser denaturiert und zusammen mit dem vorgefärbten SDS-PAGE Protein-Molekularstandard 
„Broad Range“ (Bio-Rad) auf das Gel aufgetragen. Die elektrophoretische Auftrennung der Proteine erfolgte im Laufpuffer für SDS-PAGE bei einer Stromstärke von $30 \mathrm{~mA}$ pro Minigel.

\subsubsection{Immunologischer Nachweis elektrophoretisch aufgetrennter Proteine (,Western blot")}

Für immunochemische Nachweise wurden Proteine nach ihrer Auftrennung in Polyacrylamidgelen über Elektroelution mit Hilfe des „semi-dry“-Verfahrens (Towbin et al., 1979; Kyhse-Andersen, 1984; Towbin \& Gordon, 1984; Bjerrum \& Nielsen, 1986) auf immobilisierende Membranen übertragen. Die Proteine wurden auf eine Nitrocellulosemembran (Protran, Schleicher \& Schüll, Dassel) mit $0.1 \mu \mathrm{m}$ Porendurchmesser transferiert. Dazu wurden auf einen Stapel aus drei mit Blotting-Puffer getränkten Filterpapieren (Whatman-Papier, Bio-Rad) die Membran und das SDS-Polyacrylamidgel gelegt und mit weiteren drei Lagen Filterpapier (Whatman-Papier) bedeckt. Der gesamte Stapel wurde so zwischen die Elektrodenplatten einer Blot-Apparatur positioniert, dass die Nitrocellulose-Membran in Richtung Anode lag. Der Transfer wurde für 1-2 Stunden bei einer Stromstärke von $0.8 \mathrm{~mA} / \mathrm{cm}^{2}$ Gelfläche durchgeführt. Nach dem Western Blot wurde die Nitrocellulosemembran-Membran mit den immobilisierten Proteinen einmal in PBS gewaschen und anschließend für 60 min bei RT oder über Nacht bei $4{ }^{\circ} \mathrm{C}$ in Blocking-Puffer zum Absättigen unspezifischer Bindungsstellen gelagert. Anschließend wurde der PrimärAntikörper (s. 2.1.14) in Blocking-Puffer verdünnt und die Membran für 1 Stunde bei RT inkubiert. Die Membran wurde 2 x 5 min in Blocking-Puffer gewaschen und für 60 min bei RT mit der Sekundär-Antikörperlösung (s. 2.1.14) inkubiert und erneut $3 \times 5 \mathrm{~min}$ in Blocking-Puffer gewaschen.

Die Chemilumineszenzreaktion erfolgte durch Inkubation des Western Blots mit $2 \mathrm{ml}$ einer 1:1-Mischung aus Super Signal West Femto Luminol/Enhancer Solution mit Super Signal West Stable Peroxide Solution für $5 \mathrm{~min}$ bei RT unter Lichtausschluss. Die Detektion der Chemilumineszenz erfolgte auf einem Hyperfilm ${ }^{\mathrm{TM}}$ ECL (Amersham Biosciences, Buckinghamshire). 


\subsubsection{Kapillarelektrophorese (CE)}

Die Kapillarelektrophorese wurde an einem Beckman P/ACE MDQ Kapillarelektrophoresegerät durchgeführt, gesteuert durch die Karat 7.0 Software von Beckman Instruments. Zur Detektion der Proben wurde bei $214 \mathrm{~nm}$ mit einem UV-Detektor gearbeitet. Die elektrophoretische Auftrennung der Proben erfolgte in einer $75 \mu \mathrm{m}$ I.D. $\times 57$ $\mathrm{cm}$ (50 cm Effektive Länge) bare fused-silica Kapillare (Beckman Instruments) bei $12.5 \mathrm{kV}$ und $25^{\circ} \mathrm{C}$. Neue Kapillaren wurden durch jeweils 10 minütiges Spülen mit $0.1 \mathrm{M} \mathrm{HCl,} 0.1 \mathrm{M}$ $\mathrm{NaOH}, \mathrm{H}_{2} \mathrm{O}$ und Laufpuffer äquilibriert. Vor jedem Probendurchlauf wurde die Kapillare für 5 Minuten mit einer $1 \%(\mathrm{w} / \mathrm{v})$ Polyvinylpyrrolidon (K90)-Lösung zur Unterdrückung von Wandeffekten gespült. Weiterhin wurde zur Unterdrückung von Adsorptionseffekten an die Kapillarinnenwand bei einem pH-Wert von 2.77 gearbeitet. Der im Laufpuffer enthaltene Polyvinylalkohol $(0.5 \%(\mathrm{w} / \mathrm{v}))$ sollte ebenfalls die Adsorption von basischen Proteinen an die Kapillarwand verhindern. Alle Lösungen inklusive der Proteinlösungen und des Laufpuffers (50 mM Aspartat, $0.5 \%$ Polyvinylalkohol (PVA) bei pH 2.77) wurden direkt vor Gebrauch $0.2 \mu \mathrm{m}$ filtriert. Die hydrodynamische Injektion erfolgte bei 0.5 psi für 10 Sekunden. Die Proteinproben wurden vor dem Gebrauch für die CE nur in Wasser gelöst, $0.2 \mu \mathrm{m}$ filtriert und in einer Konzentration von $0.15 \mathrm{mg} / \mathrm{ml}$ eingesetzt.

\subsubsection{Elektronenmikroskopie - Negativkontrastierung}

Die Negativkontrastierung mit Schwermetallsalzen erlaubt die Darstellung von Proteinen und Proteinaggregaten mit einer Auflösung von 1.0-1.5 nm. Das entspricht Proteindomänen mit ca. 5-15 Aminosäuren. Dazu wurden mit amorpher Kohlefolie bedampfte Kupfernetzchen (Grids) verwendet. Diese hydrophoben Objektträger wurden vor dem Aufbringen der wässrigen Probe durch das Beglimmen unter Hochvakuum bei hoher Spannung benetzbar gemacht. Dabei werden Ladungen auf die Kohlefolie gebracht, so dass sie vorübergehend einen hydrophilen Charakter erhält. Dies ermöglicht die Adsorption von partiell geladenen Makromolekülen auf dem Träger. Anschließend wurden $5 \mu$ l Aliquots (600-800 ng Protein) der zu untersuchenden Probe auf die Kupfer-Grids aufgebracht und maximal 1 Minute inkubiert. Der Flüssigkeitsüberstand wurde mittels eines Filterpapiers abgezogen, wobei das 
Präparat nicht eintrocknen durfte und mit einer $2 \%$ igen, wässrigen Uranylacetat-Lösung (pH 3.5-4.5) oder einer $0.75 \%$ Uranylformiat-Lösung ( $\mathrm{pH} 4.0-4.5)$ negativ kontrastiert wurde.

Elektronenmikroskopische Bilder wurden bei einer Anodenspannung von $60 \mathrm{kV}$ und einer Vergrößerung von 5000x-100000x mit einem Zeiss 10B-Transmissions-Elektronenmikroskop aufgenommen. Die Aufnahmen wurden durch digitale Bildverarbeitung dokumentiert.

Für die Elektronenmikroskopie wurden nur aggregierte Proteinproben benutzt. Die Proben wurden für mindestens 3 Wochen bei Raumtemperatur in $20 \mathrm{mM}$ Natriumphosphat, $20 \mathrm{mM}$ Natriumacetat bei pH 6.5 in Glasgefäßen mit Schraubverschluss (2 ml Shorty vials, Neolab, Heidelberg) inkubiert. Die Proben wurden niemals eingefroren. Mehrfaches Einfrieren/Auftauen der Proben veränderte die Morphologie der Proteinaggregate vollständig. Die Uranylacetatlösung musste stets frisch angesetzt und $0.2 \mu \mathrm{m}$ filtriert werden. Überschüssiges Uranylacetat wurde durch vorsichtiges Schwenken der Grids in Wasser entfernt.

\subsubsection{Messung der Aggregationsgeschwindigkeit des Prionproteins}

\subsubsection{Thioflavin T-Assay}

Die aufgereigten und (oxidativ) rückgefalteten Proteine wurden direkt vor Gebrauch aufgetaut und $0.2 \mu \mathrm{m}$ filtriert (Millipore). Bei den Reaktionsgefäßen handelte es sich um $2 \mathrm{ml}$ Shorty vials aus Borosilikatglas mit Schraubdeckelverschluss (Neolab, Heidelberg). Das Reaktionsvolumen betrug $1 \mathrm{ml}$ und die Reaktionstemperatur $25{ }^{\circ} \mathrm{C}$. Startpunkt der Aggregation war die Zugabe eines 10 fach Acetat-/Phosphatpuffer (200 mM Acetat, $200 \mathrm{mM}$ Phosphat, pH 6.5). Die Reaktionslösungen wurden während der Aggregation weder gerührt oder geschüttelt. Die Proteinkonzentrationen betrugen $340 \mu \mathrm{M}, 200 \mu \mathrm{M}$ und $80 \mu \mathrm{M}$ bei humPrP23-144 und humPrP23-159 und $200 \mu \mathrm{M}, 80 \mu \mathrm{M}, 40 \mu \mathrm{M}$ und $10 \mu \mathrm{M}$ bei humPrP23173. Bei externer Zugabe von Aggregationskeimen $\mathrm{zu}$ den monomeren Prionproteinen (Seeding-Experimente) wurden $200 \mu \mathrm{M}$ Proteinkonzentrationen eingesetzt, zu denen $1 \%$ (v/v) der Aggregationskeime (Seeds) zugegeben wurde. Die Aggregationskeime wurden direkt vor Gebrauch für 10 min mit Ultraschall behandelt. Die Auswertung der erhaltenen Daten erfolgte durch eine mathematische Kurvenanpassung für sigmoidale Kurvenverläufe an die experimentell bestimmten Daten durch das Programm „SigmaPlot“. 
Die Thioflavin T Fluoreszenz (ThT, Sigma-Aldrich) der Proben wurde mit einem Titerplattenlesegerät Safire ${ }^{\mathrm{TM}}$ (Tecan, Crailsheim) bestimmt. Zur Bestimmung der optimalen Thioflavin T Fluoreszenzen wurden Thioflavin T Fluoreszenzanregungsspektren von 350-470 nm und Fluoreszenzemissionsspektren von 450-600 nm aufgenommen. Die Messtemperatur betrug immer $30{ }^{\circ} \mathrm{C}$. Die Thioflavin T Fluoreszenzmessungen wurden in 384 well UV-Star Titerplatten (Greiner Bio-one) mit einem Reaktionsvolumen von $100 \quad \mu 1$ durch Mehrfachbestimmungen mit Mittelwertbildung durchgeführt. Vor jeder Messung wurde die Reaktionslösung mit monomerem oder aggregiertem Prionprotein, Puffer und Thioflavin T für 5 min bei $30{ }^{\circ} \mathrm{C}$ im temperierten Titerplattenlesegerät inkubiert. Der Gain betrug bei allen Thioflavin T Fluoreszenzbestimmungen $100 \%$. Die Anregungsbandbreite betrug $5 \mathrm{~nm}$, die Emissionsbandbreite $7.5 \mathrm{~nm}$. Der Integrationszeitraum bei den Fluoreszenzmessungen betrug 100 ms. Zur Messung der Thioflavin $\mathrm{T}$ Fluoreszenz wurden Aliquots aus den Aggregationsassays mit $50 \mathrm{mM}$ BisTris, pH 6.7 auf eine Proteinkonzentration von $6 \mu \mathrm{M}$ verdünnt und mit Thioflavin $\mathrm{T}(10 \mu \mathrm{M}$ final) versetzt

\subsubsection{Absorptionsspektroskopie}

Der Einfluss des pH-Wertes auf die Aggregation von humPrP23-144 und humPrP23-159 wurde kontinuierlich durch Bestimmung der Absorption verfolgt.

Die Absorptionsmessungen der Proteinlösungen wurden bei $400 \mathrm{~nm}$ mit $200 \mu \mathrm{M}$ Proteinkonzentration von humPrP23-159 und humPrP23-144 in unterschiedlichen Puffersystemen bei verschiedenen $\mathrm{pH}$-Werten und $30{ }^{\circ} \mathrm{C}$ in einem Titerplattenlesegerät Safire $^{\mathrm{TM}}$ (Tecan, Crailsheim) durchgeführt. Jede Messung wurde durch 10 Scans bestimmt und gemittelt. Die Messung wurde in einer Hellma 96 well-Quarztiterplatte durchgeführt. Die Quarztiterplatte wurde mit einer UV-transparenten Abdeckfolie (,viewseal“, Greiner Bio-one) versiegelt. Das Probenvolumen betrug jeweils $250 \mu 1$ pro well. Die Bestimmung der Aggregationsgeschwindigkeit der Proteinlösungen erfolgte durch Absorptionsmessungen im Abstand von 15 Minuten. Nach 16 Tagen wurden die Messungen beendet und die Morphologie der aggregierten Proteine elektronenmikroskopisch bestimmt. Die pHAbhängigkeit der Aggregation der Prionproteine humPrP23-144 und humPrP23-159 wurde dreimal wiederholt. Als Puffersysteme wurden verwendet: $\mathrm{pH}$ 4.0: 50 mM Natriumacetat; $\mathrm{pH}$ 
5.0: 50 mM Natriumacetat; $\mathrm{pH}$ 6.2: $50 \mathrm{mM}$ MES; pH 7.2: $50 \mathrm{mM}$ MOPS; $\mathrm{pH}$ 8.1: $50 \mathrm{mM}$ Tris. Die pH-Abhängigkeit der Aggregation von humPrP23-112 wurde mit $250 \mu \mathrm{M}$ und 400 $\mu \mathrm{M}$ Proteinkonzentrationen unter den gleichen Pufferbedingungen und $\mathrm{pH}-$ Werten wie bei humPrP23-159 und humPrP23-144 durchgeführt. Zusätzlich wurden noch $200 \mathrm{mM}$ Natriumchlorid verwendet.

\subsubsection{Proteinase K-Verdau}

Die Proteinfibrillen wurden mit Proteinase K (PK) (Sigma-Aldrich, >30units pro mg) bei 37 ${ }^{\circ} \mathrm{C}$ für $1 \mathrm{~h}$ und $1400 \mathrm{rpm}$ ( Eppendorf Thermomixer) in $2 \mathrm{ml}$ Eppendorfgefäßen in $100 \mathrm{mM}$ Tris/ $\mathrm{HCl}$ pH 8.0, $100 \mathrm{mM} \mathrm{NaCl}, 0.1 \%$ Brij, $0.5 \%$ Nonidet P40 und $0.5 \%$ Deoxycholate verdaut, wobei das molare Verhältnis von PrP-Fibrillen zur Proteinase K 104:1 (50 $\mu \mathrm{g} / \mathrm{ml}$ PK) und 52:1 $(100 \mu \mathrm{g} / \mathrm{ml} \mathrm{PK})$ betrug. Der Verdau wurde duch Zugabe von $1 \mathrm{mM}$ (finale Konzentration) PMSF und Kochen bei $100{ }^{\circ} \mathrm{C}$ für $10 \mathrm{~min}$ in SDS-Probenpuffer gestoppt. Die Proben wurden sofort über eine $15 \% \mathrm{H}_{2} \mathrm{SO}_{4} /$ Bicine SDS-Page (Wiltfang et al., 1991) mit nachfolgender Coomassie-Färbung bzw. Western Blot analysiert. Bei den Western Blots mit Proteinase K verdautem aggregiertem Prionprotein wurden die Antikörper 6H4 (Prionics, Basel) (1:10000), 1E4 (Cell Sciences) (1:10000), 12F10 (1:50000) und 3B5 (1:5000) verwendet. Als zweiter Antikörper diente jeweils HRP-gekoppelter Goat-anti-Mouse Antikörper (GaM-HRP) in einer Verdünnung von 1:125000 (Dako).

\subsubsection{Edman-Sequenzierung}

\section{Vorbereiten der Proteine für die Sequenzierung}

Nach Beendigung des Western-Transfers wurde die Position des Gels auf der Membran markiert. Um die Proteinbanden aus der PVDF-Membran ausschneiden zu können, mussten diese durch Anfärben mit Coomassie-Blau sichtbar gemacht werden. Die teilweise Entfärbung der Membran erfolgte durch 7 \% Essigsäure in einem Methanol/Wasser-Gemisch (43\% Methanol). Nach dem Ausschneiden der Banden mit einem sauberen Skalpell mussten diese 
drei mal 10 min in 11 destilliertem $\mathrm{H}_{2} \mathrm{O}$ gründlich gewässert und bis zur Sequenzierung feucht in einem Reaktionsgefäß bei $-20^{\circ} \mathrm{C}$ gelagert werden.

Die Edman-Sequenzierung der Proteinase K verdauten Proteinfragmente von humPrP23-159 und humPrP23-144 erfolgte an einem Procise cLC Proteinsequenziergerät (Applied Biosystems, Weiterstadt) gemäß Standard-Protokollen des Herstellers und wurde von Dr. Bernhard Schmidt und Klaus Neifer, Abteilung für Biochemie II, Universität Göttingen durchgeführt.

\subsubsection{Massenspektrometrie (MALDI-MS)}

Die Matrix-unterstützte Laserdesorptions-Ionisations-Massenspektrometrie (MALDI-MS) ist ein massenspektrometrisches Verfahren, mit dem die Massen von Substanzen auch bei geringer Konzentration $\left(10^{-5}-10^{-6} \mathrm{~mol} / \mathrm{l}\right)$ bestimmbar sind. Die Probe wird mit einer Matrix vermischt und anschließend getrocknet. Im Vakuum des Massenspektrometers wird das Matrix-Probengemisch einem intensiven Impuls kurzwelliger Laserstrahlung ausgesetzt. Die Anregung der Matrixmoleküle führt zu einer Aufweitung des Matrixgerüstes. Bei diesem Vorgang werden sowohl Probenmoleküle, als auch Matrixmoleküle aus der Gitterstruktur der Matrix freigesetzt und ionisiert. Mit Hilfe eines elektrostatischen Feldes von einigen $\mathrm{keV} / \mathrm{mm}$ werden die geladenen Probenmoleküle in Richtung eines Analysators beschleunigt. Die Probenmoleküle haben jetzt annähernd die gleiche kinetische Energie. Nach der Beschleunigung der Ionen durchlaufen diese eine feldfreie Driftstrecke, die typischerweise 0,5 bis 2 Meter lang ist. Die Massenbestimmung erfolgt über die Messung der Flugzeit, die die Ionen für das Durchfliegen der freien Driftstrecke benötigen. Bei gleicher kinetischer Energie haben Ionen unterschiedlicher Massen gemäß der Beziehung $E=1 / 2 \mathrm{mv}^{2}$ unterschiedliche Flugzeiten. Die Flugzeit wird von einem Detektor registriert. Aus der Flugzeit wird dann die Masse der Substanz ermittelt. Die Kalibrierung erfolgt über Referenzmassen.

Die Bestimmung der Massen von humPrP23-112, humPrP23-144, humPrP23-159 und humPrP23-173 wurde bei einer Proteinkonzentration von $100 \mu \mathrm{M}$ in $5 \mathrm{mM}$ Natriumacetatpuffer, $\mathrm{pH} 4.5$ von Dr. Hartmut Kratzin am Max-Planck-Institut für Experimentelle Medizin, Göttingen durchgeführt. 


\subsection{Spektroskopische Verfahren}

\subsubsection{FTIR-Spektroskopie}

FTIR (Fourier-Transformations-Infrarot)-Spektren von aggregiertem und löslichem humPrP23-144 und humPrP23-159 wurden an einem Nicolet 6700 FTIR Spektrometer mit freundlicher Genehmigung der Thermo Electro Corporation, Frankfurt durchgeführt. Es wurden jeweils 64 Messungen gemittelt, um das Signal-Rausch-Verhältnis zu verbessern. Die Spektren sind in ihrer zweiten Ableitung dargestellt.

Da Protein-FTIR-Spektren wegen der störenden anregbaren Schwingungen des Wassers (insbesondere der symmetrischen Deformationsschwingung $\delta$ bei $1595 \mathrm{~cm}^{-1}$ ) im interessierenden Wellenlängenbereich (Wellenzahlen zwischen 1700 und $1600 \mathrm{~cm}^{-1}$ ) nur in $\mathrm{D}_{2} \mathrm{O}$ meßbar sind, mußten die Proben vorher in $\mathrm{D}_{2} \mathrm{O}$ überführt werden.

Die Suspension wurde in eine IR-Küvette mit $\mathrm{CaF}_{2}$-Fenstern gefüllt, die mit Dichtungsringen auf eine Schichtdicke von $50 \mu \mathrm{m}$ zusammengepreßt wird. Gemessen wurde bei Raumtemperatur. Vor der Messung wurde die Probenkammer ausreichend (mindestens 20 Minuten) mit getrockneter Luft gespült, um den störenden Einfluß von Wasserdampf auf die Spektren zu minimieren.

Wichtiger Bestandteil der Probenvorbereitung war die Entfernung der Trifluoressigsäure aus den lyophyllisierten Proben, da die Carboxyl-Gruppe der Trifluoressigsäure in der Amid IRegion des FTIR-Spektrums zwischen Wellenzahlen von $1600 \mathrm{~cm}^{-1}$ bis $1700 \mathrm{~cm}^{-1}$ absorbiert. Dazu wurden die monomeren Proteine 3 x mit $50 \mathrm{mM} \mathrm{HCl}$ in destilliertem Wasser behandelt und sofort wieder lyophyllisiert. Anschließend wurden alle ${ }^{1} \mathrm{H}$-Protonen durch dreimaliges solvatisieren des Proteins in $\mathrm{D}_{2} \mathrm{O}$ und nachfolgender Lyophyllisation entfernt und durch ${ }^{2} \mathrm{H}$ (D)-Protonen ersetzt. In gleicher Weise wurde mit dem Phosphatpuffer und den Aggregationskeimen für die Seeding-Experimente verfahren. Der Phosphat-Puffer wurde vor dem $\mathrm{D}_{2} \mathrm{O}$-Labeling mit $\mathrm{NaOD}$ auf pD 6.5 eingestellt. Die Aggregation der $\mathrm{D}_{2} \mathrm{O}$ gelabelten Proteine erfolgte unter Standard-Aggregationsbedingungen in BorosilikatSchraubdeckelgefäßen bei Raumtemperatur in $50 \mathrm{mM}$ Natriumphosphat-Puffer $\mathrm{pH} 6.5$ unter Verwendung von $200 \mu \mathrm{M}$ Proteinkonzentrationen. 1\% (v/v) Seeds wurden bei geseedeten Aggregationen verwendet, wobei die Aggregationskeime ebenfalls unter Standard- 
Aggregationsbedingungen in $\mathrm{D}_{2} \mathrm{O}$ entstanden sind. Die monomeren Proteine wurden bei einer Konzentration von $800 \mu \mathrm{M}$ vermessen.

\subsubsection{Circulardichroismus (CD)-Spektroskopie}

Circulardichroismus ist die Eigenschaft optisch aktiver Moleküle, links und rechtspolarisiertes Licht gleicher Wellenlänge unterschiedlich stark zu absorbieren. Die optische Aktivität von Proteinen tritt in Form von asymmetrischen Kohlenstoffatomen und/oder aromatischen Aminosäuren auf. Proteine, die sich aus einer großen Anzahl von optisch aktiven Aminosäuren zusammensetzen und Sekundärstruktur besitzen, die auch zur dichroitischen Absorption beiträgt, weisen Circulardichroismus auf.

In der CD-Spektroskopie unterscheidet man je nach Wellenlängenbereich zwei Regionen. Die Nah-UV-Region umfaßt den Bereich zwischen $250 \mathrm{~nm}$ und $350 \mathrm{~nm}$. In diesem Bereich sind asymmetrisch angeordnete aromatische Aminosäuren für das Signal verantwortlich. Die Umgebung dieser Aminosäuren ist von der Tertiärstruktur des Proteins abhängig. Ein Signal in diesem Bereich dient als „Fingerabdruck" des Proteins. Denaturierte Proteine weisen in diesem Bereich kein Signal auf, da ihre aromatischen Aminosäuren nicht mehr in asymmetrischer Umgebung vorliegen. Änderungen bei 285 und $275 \mathrm{~nm}$ reflektieren Beiträge sowohl von Tryptophanen als auch von Tyrosinen, während im Bereich von $295 \mathrm{~nm}$ nur Tryptophane für das Signal verantwortlich sind. Änderungen im Bereich von $259 \mathrm{~nm}$ und 264 nm resultieren aus Änderungen der Phenylalanin-Umgebung. In der Fern-UV-Region (170$250 \mathrm{~nm}$; Amidregion) erzeugt die Konformation der Polypeptidkette ein charakteristisches CD-Signal. $\alpha$-Helices ergeben zwei benachbarte Minima bei $208 \mathrm{~nm}$ und $222 \mathrm{~nm}$. $\beta$ Faltblattstrukturen zeigen ein weniger deutlich ausgeprägtes Signal mit einem einzigen Minimum bei $215 \mathrm{~nm}$. Das Fern-UV-CD-Signal liefert daher Informationen über die Sekundärstruktur der untersuchten Proteine. Die Elliptizität $\Theta$ (in Grad) wird als quantitatives Maß für die Ausprägung an Struktur verwendet. Die Berechnung der molaren Elliptizität, d.h. der Elliptizität bezogen auf das durchschnittliche Molekulargewicht von Aminosäuren, erfolgt nach folgender Formel (Schmid F.X., 1989): 
$\Theta_{\mathrm{MRW}}=\Theta * 100 * \mathrm{MRW} / \mathrm{c} * \mathrm{~d}=\Theta * 100 * \mathrm{M}_{\mathrm{r}} / \mathrm{c}^{*} \mathrm{~d} * \mathrm{~N}_{\mathrm{A}}$

$\Theta_{\mathrm{MRW}}$ Elliptizität der Aminosäuren $\left(\mathrm{Grad} * \mathrm{~cm}^{2} * \mathrm{dmol}^{-1}\right)$

$\Theta$ gemessene Elliptizität

MRW mittleres Molekulargewicht der Aminosäuren

c Konzentration der Proteinlösung (mg/ml)

d Schichtdicke der Küvette

$\mathrm{M}_{\mathrm{r}}$ Molekulargewicht (g/mol)

$\mathrm{N}_{\mathrm{A}}$ Anzahl der Aminosäuren

Die CD-spektroskopischen Messungen wurden an einem J-810 CD-Spektrometer (Jasco) bei $20{ }^{\circ} \mathrm{C}$ durchgeführt. Die Schichtdicke der Küvette betrug $0.1 \mathrm{~cm}$. Alle Spektren wurden in 10 $\mathrm{mM}$ Natriumacetat, $\mathrm{pH} 4.0$ mit jeweils $50 \mu \mathrm{M}$ Proteinkonzentrationen aufgenommen. Der Probenraum wurde kontinuierlich mit trockenem Stickstoff gespült. Die Spektren repräsentieren Mittelwerte aus 10 Scans zwischen 180-300 nm. Die Datenerfassung erfolgte im Abstand von $0.1 \mathrm{~nm}$ mit einer Geschwindigkeit von $100 \mathrm{~nm}$ pro Minute. Alle Spektren wurden durch Subtraktion der Puffer-Spektren korrigiert.

Die Dekonvolution der Spektren erfolgte mit dem Programm CDNN, das mit Hilfe eines neuronalen Netzwerks und eines Basisspektrensatzes die Sekundärstrukturgehalte berechnet (Böhm et al., 1992).

\subsubsection{NMR-Spektroskopie von humPrP23-159 und humPrP23-173}

Alle NMR-Spektroskopischen Messungen und Auswertungen wurden am MPI für Biophysikalische Chemie, Göttingen von Lukasz Skora und Dr. Markus Zweckstetter in der Abteilung von Prof. Dr. Griesinger durchgeführt.

Die NMR-Spektroskopie von ${ }^{13} \mathrm{C}$ und ${ }^{15} \mathrm{~N}$ gelabeltem humPrP23-159 erfolgte bei $293 \mathrm{~K}$ an einem Bruker Avance $900 \mathrm{MHz}$ Spektrometer mit einem Kryo-Sondenkopf. Die NMRProben enthielten $1 \mathrm{mM}{ }^{15} \mathrm{~N} /{ }^{13} \mathrm{C}$-gelabeltes humPrP23-159 und humPrP23-173 in $93 \% \mathrm{H}_{2} \mathrm{O}$, $7 \% \mathrm{D}_{2} \mathrm{O}, 10 \mathrm{mM}$ Natriumacetat, $\mathrm{pH} 4.5$ und $\mathrm{pH}$ 6.5. Die NMR-Daten wurden mit nmr-Pipe (Delaglio et al., 1995) und Sparky aquiriert und analysiert. Dreidimensionale HACANNH-, 
HNCO- und HNN-Experimente (Bax et al., 1993) führten zu einer sequenzspezifischen Anordnung des Peptidrückgrates im Prionprotein. Sekundäre chemische Verschiebungen wurden als Differenzen zwischen den $\mathrm{C} \alpha / \mathrm{C}^{\prime}$-chemischen Verschiebungen und empirischen random coil-Daten bei pH 3.0 berechnet (Schwarzinger et al., 2001). Random coil-Daten von Prolinen und Aspartaten wurden bei Wishart et al. (Wishart et al., 1994) entnommen. 


\section{Ergebnisse}

\subsection{Herstellung und Charakterisierung verschiedener Prionprotein- fragmente}

Nach den $\mathrm{PrP}^{\mathrm{Sc}}$-Strukturmodellen (Govaerts et al., 2004; DeMarco \& Daggett, 2004) wird die Region 90-175 des humanen Prionproteins als alleiniger Konversionsbereich für die Bildung des infektiösen Prionproteins angesehen, wohingegen die Helices 2 und 3 innerhalb der Region 174-231 im $\operatorname{PrP}^{\mathrm{Sc}}$ unverändert vorliegen sollen. Um den Einfluss des $\beta$-Strand S1, der Helix 1 und des $\beta$-Strand S2 innerhalb des Konversionsbereiches 90-175 auf die Aggregation des Prionproteins zu untersuchen und eine Aussage über ihre Struktur im aggregierten Zustand zu treffen, wurden zunächst verschiedene Prionproteinfragmente hergestellt, die um jeweils eines der drei genannten Sekundärstrukturelemente variieren (Abb. 5)

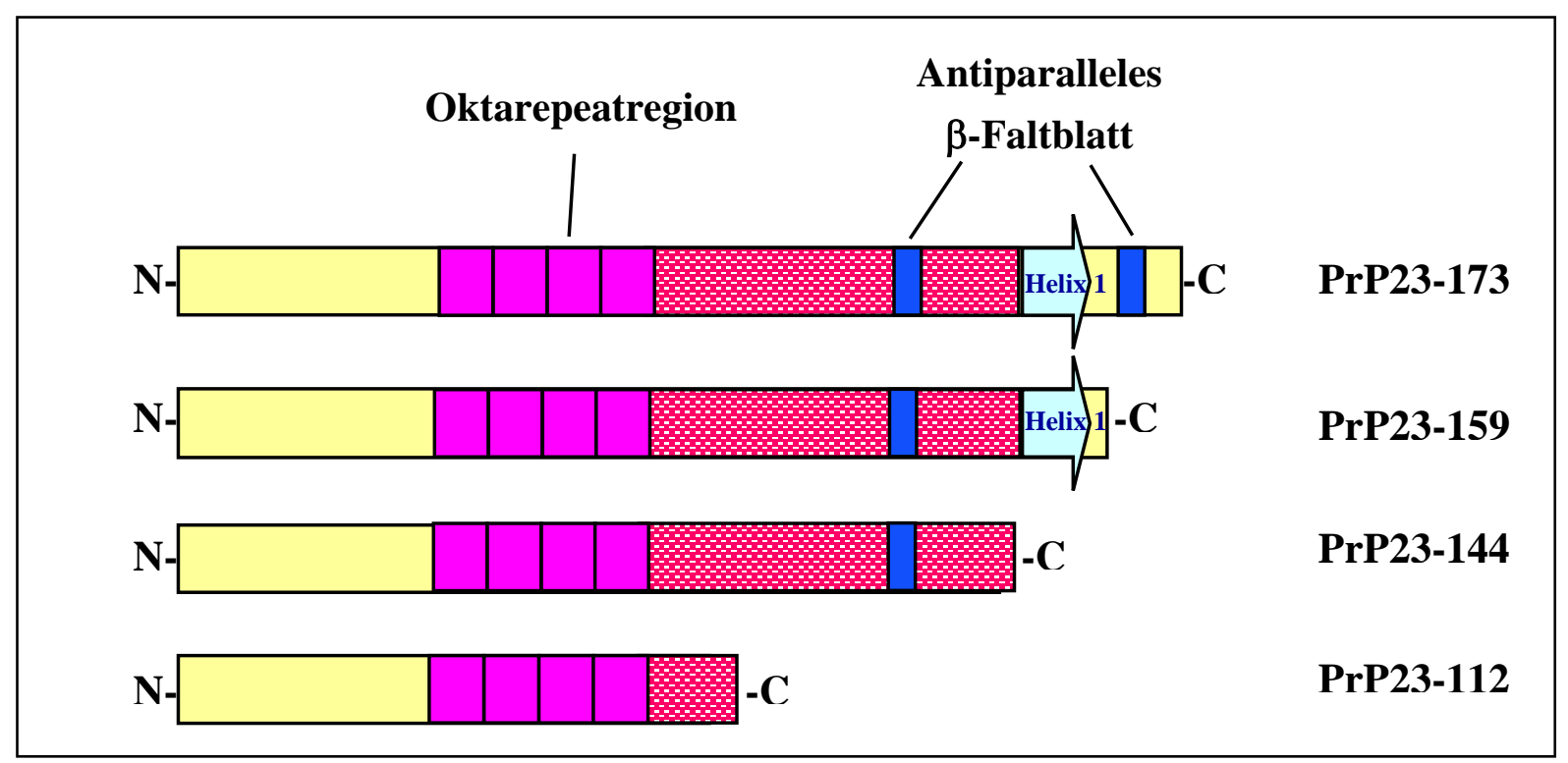

Abb. 5: Schematische Darstellung der untersuchten Prionproteinfragmente mit den erwarteten Sekundärstrukturelementen. Dargestellt sind die Prionproteinfragmente humPrP23-173, humPrP23-159, humPrP23-144 und humPrP23-112. Die Oktarepeatregion wurde in pink, die im PrP ${ }^{\mathrm{Sc}}$ umgefaltete Region 90145 in rot (Peretz et al., 1997), das antiparallele $\beta$-Faltblatt in dunkelblau und die Helix 1 in hellblau dargestellt.

Diese Fragmente waren humPrP23-112, humPrP23-144, humPrP23-159 und humPrP23-173 (Abb. 5). Das kleinste Fragment humPrP23-112 umfasste den unstrukturierten und flexiblen N-terminalen Bereich des Prionproteins inklusive der Oktarepeat-Region. Das zweite 
untersuchte Fragment humPrP23-144 wies zusätzlich zu humPrP23-112 die Proteinsequenz für den $\beta$-Strand S1 auf. Damit enthielt es nach Peretz et al. (1997) auch den im $\operatorname{PrP}^{\mathrm{Sc}}$ umgefalteten Bereich 90-145.

Das dritte untersuchte Fragment humPrP23-159 war um das sehr polaren Helix 1-Segment relativ zu humPrP23-144 verlängert, dessen Einfluss auf die Aggregation des Prionproteins durch einen direkten Vergleich der beiden Fragmente untersucht werden sollte. Analog dazu sollte der Einfluss des $\beta$-Strands S2 auf die Aggregation des Prionproteins durch einen Vergleich der Prionproteinfragmente humPrP23-159 mit humPrP23-173 untersucht werden. Das Fragment humPrP23-173 war relativ zu humPrP23-159 um den zweiten $\beta$-Strand S2 verlängert und umfasste den vermuteten Konversionsbereich in den $\operatorname{PrP}^{\mathrm{Sc}}$-Strukturmodellen (Govaerts et al., 2004; Wille et al., 2002; DeMarco \& Daggett, 2004).

\subsubsection{Herstellung der verschiedenen Prionproteinfragmente}

Die Beschreibung der Herstellung der verschiedenen Prnp-Konstrukte erfolgt in Kapitel 2.2.13.

Die Expression der für die verschiedenen Prionproteinfragmente codierenden Konstrukte wurde in E. coli BL21 (DE3) unter Bildung zytoplasmatischer Einschlusskörper (Inclusion Bodies) durchgeführt. Nach Reinigung der Inclusion Bodies wurde die chromatographische Aufreinigung der Prionproteinfragmente unter vollständig denaturierenden Bedingungen durchgeführt (Kapitel 2.3.2.).

\subsection{2. Überprüfung der Reinheit der Prionproteinfragmente}

Die Reinheit der Prionproteinfragmente wurde zunächst in der SDS-Page (Abb. 6) überprüft. Nach Coomassie-Färbung wurde jeweils nur eine Bande für jedes Prionproteinfragment erhalten (Abb. 6). Aus einem Vergleich des Migrationsverhaltens der Prionproteinfragmente mit den Markerproteinen konnte das ungefähre Molekulargewicht der Fragmente abgeschätzt werden. Es stimmte jeweils gut mit den aus der Proteinsequenz berechneten Molmassen (Tabelle 5, Kapitel 2.3.1) überein. 


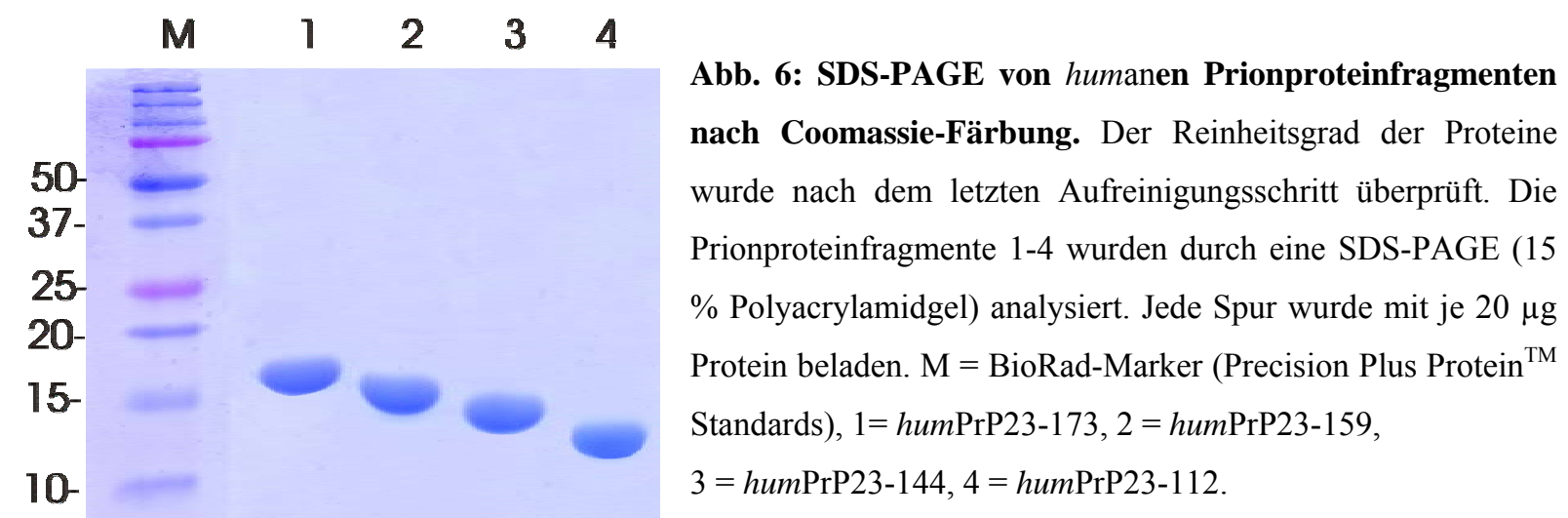

Zur exakten Reinheitsbestimmung und zum Ausschluss von Modifikationen der Proteinsequenz wurde eine massenspektrometrische Analyse (MALDI-MS) der Prionproteinfragmente durchgeführt (Abb. 7).

In den Massenspektrogrammen der Prionproteinfragmente (Abb.7) wurden jeweils nur zwei Peaks mit unterschiedlichem Masse/Ladungs-Quotienten $(\mathrm{m} / \mathrm{z})$ detektiert, die beide dem gleichen Prionproteinfragment bei unterschiedlicher positiver Ladung $(+1,+2)$ zugeordnet werden konnten, was für eine sehr hohe Reinheit der rekombinanten Proteine spricht.

Zum Nachweis von Modifikationen der Prionproteinfragmente wurden die experimentell bestimmten Massen der Prionproteinfragmente mit aus der Proteinsequenz berechneten Massen verglichen (Tabelle 11). Eine mögliche Erklärung für die Abweichungen zwischen experimentell bestimmten und theoretisch berechneten Masse war eine Hydrolyse von Asparaginen zu Aspartaten. Diese Modifikation würde in einer Massendifferenz von +1 Dalton resultieren. Als besonders hydrolyseempfindlich haben sich die Asparaginsequenzen NG/ SN/ NS/ TN/ NT/ KN/ LN/ VN herausgestellt (Wright et al., 1991, Robinson et al., 1974). Das humane Prionprotein humPrP23-231 weist elf Asparagine in seiner Proteinsequenz auf, von denen vier (Aminosäuren 32, 108, 173, 181) als besonders hydrolyseempfindlich eingestuft wurden (Wright et al., 1991).

Bei humPrP23-173 wurde eine Massendifferenz von 34 Dalton zwischen experimentell bestimmter und theoretisch berechneter Masse festgestellt, die aus einer Oxidation eines Methionin-Schwefels in eine Sulfon-Gruppe (32 Dalton) und einer Hydrolyse von ein bis zwei Asparaginen in Aspartate resultieren könnte (Tabelle 11). 

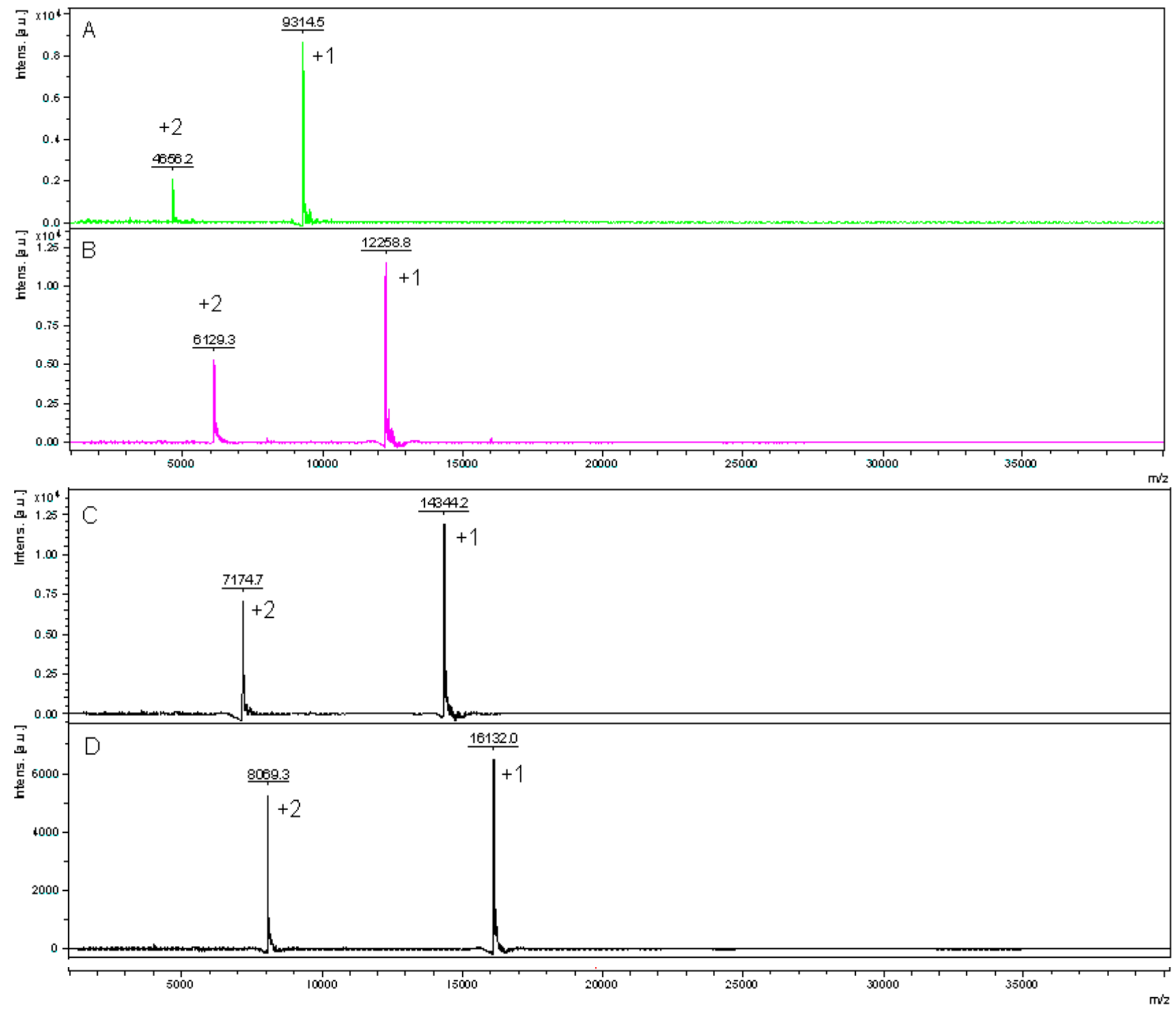

Abb. 7: Massenspektrometrische Analyse (Maldi-MS) der humanen Prionproteine. Maldi-TOF von (A) PrP23-112, (B) PrP23-144, (C) PrP23-159, (D) PrP23-173. Alle Proteine wurden nach Rückfaltung in 10 mM Natriumacetat-Puffer, $\mathrm{pH} 4.5$ vermessen. Die neben den Peaks aufgeführten Zahlenwerte +1 und +2 geben die jeweilige positive Ladung (z) des zu jedem Signal korrespondierenden Fragmentes wider. Die unterstrichenen Zahlenwerte oberhalb der Signale geben das jeweilige Masse/Ladungsverhältnis $(\mathrm{m} / \mathrm{z}) \mathrm{der}$ detektierten Fragmente wider. Die Bestimmung der Massen wurde von Dr. Hartmut Kratzin am MaxPlanck-Institut für Experimentelle Medizin in Göttingen durchgeführt. 
Tabelle 11: Vergleich der experimentell bestimmten Massen mit theoretisch berechneten Massen der humanen Prionproteinfragmente

\begin{tabular}{|c|c|c|c|c|c|c|}
\hline \multirow{2}{*}{ Protein } & \multicolumn{2}{|c|}{$\begin{array}{c}\text { experimentell } \\
\text { bestimmte } \\
\text { Massen (Dalton) }\end{array}$} & \multirow{2}{*}{$\begin{array}{c}\text { theoretisch } \\
\text { berechnete } \\
\text { Massen } \\
\text { (Dalton) }\end{array}$} & \multirow{2}{*}{$\begin{array}{c}\text { Massendifferenz } \\
\text { (gemittelte } \\
\text { experimentelle } \\
\text { minus theoretische } \\
\text { Masse) } \\
\text { (Dalton) }\end{array}$} & \multirow{2}{*}{$\begin{array}{c}\text { Apparativer } \\
\text { Fehler von } \\
\text { MALDI- } \\
\text { TOF } \\
\text { (Dalton) }\end{array}$} & \multirow{2}{*}{$\begin{array}{c}\text { Erklärung der } \\
\text { Abweichung zum } \\
\text { apparativen } \\
\text { Fehler }\end{array}$} \\
\hline & $\begin{array}{c}+1 \\
(\mathrm{~m} / \mathrm{z})\end{array}$ & $\begin{array}{c}+2 \\
(\mathrm{~m} / \mathrm{z})\end{array}$ & & & & \\
\hline humPrP23-112 & 9313.5 & 9308.4 & 9310.1 & +0.9 & $+/-0.9$ & $\begin{array}{c}\text { sehr gute } \\
\text { Übereinstimmung }\end{array}$ \\
\hline humPrP23-144 & 12257.8 & 12254.6 & 12254.5 & +1.7 & $+/-1.2$ & $\begin{array}{c}\text { Asn-->Asp } \\
(\text { eventuell 1x) }\end{array}$ \\
\hline humPrP23-159 & 14343.2 & 14345.4 & 14342.7 & +1.6 & $+/-1.4$ & $\begin{array}{c}\text { Asn-->Asp } \\
(\text { eventuell 1x) }\end{array}$ \\
\hline humPrP23-173 & 16133.0 & 16134.6 & 16099.5 & +34.3 & $+/-1.6$ & $\begin{array}{c}\text { Oxidation des } \\
\text { Schwefels in eine } \\
\mathrm{SO}_{2} \text {-Gruppe, } \\
\text { Asn-->Asp }(1-2 \mathrm{x})\end{array}$ \\
\hline
\end{tabular}

Tabelle 11 gibt eine Übersicht über die nach der Formel: $(\mathrm{m}-\mathrm{z})^{*} \mathrm{z}$ umgerechneten Massen aus den experimentell bestimmten Masse/Ladungs-Quotienten (m/z) der untersuchten Prionproteine wider (Abb. 7). Zum Vergleich wurden die theoretisch berechneten Massen der Prionproteinfragmente angeführt. Die Differenz aus den beiden gemittelten experimentell bestimmten Massen mit Ladungszahlen von +1 und +2 und theoretisch berechneten Massen sind mit dem maximalen apparativen Fehler von MALDI-TOF Messungen (0.01 \%) (Vorm \& Mann, 1994) zu vergleichen.

Zusammen mit einem in der Messmethodik begründeten Fehler der MALDI-TOF-Messungen von $0.01 \%$ oder 100 ppm (Vorm \& Mann, 1994) lassen sich die Abweichungen zwischen experimentell bestimmter und theoretisch berechneter Masse sehr gut erklären und unterstreichen die hohe Qualität der rekombinant hergestellten Prionproteine.

\subsubsection{Strukturanalyse der Prionproteinfragmente}

Eine Strukturanalyse der humanen Prionproteinfragmente war zwingend erforderlich, da die Aufreinigung der Proteine aus Inclusion Bodies unter vollständig denaturierenden Bedingungen durchgeführt wurde.

Ein Nachweis der in den Prionproteinfragmenten vorhandenen Sekundärstrukturelemente war 
insofern erforderlich, als ein Einfluss dieser Elemente auf das Aggregationsverhalten des Prionproteins untersucht werden sollte. Die gemäss dem Volllängen-Prionprotein zu erwartenden Sekundärstrukturen in den Prionproteinfragmenten sind in Abbildung 5 zusammengefasst.

Vor der strukturellen Analyse mussten die Prionproteinfragmente zunächst rückgefaltet werden. Dabei zeigt sich dass die drei kürzeren Fragmente humPrP23-112, humPrP23-144 und humPrP23-159 nach Austausch des Denaturierungsmittels problemlos in Wasser gelöst werden konnten, während humPrP23-173 erst durch ein spezielles Rückfaltungsprotokoll in Lösung gebracht werden konnte (Kapitel 2.3.4) (Zahn et al., 1997). Um eine Vergleichbarkeit der verschiedenen Prionproteinfragmente $\mathrm{zu}$ gewährleisten, wurde dieses Rückfaltungsprotokoll auf alle Fragmente angewendet.

Die strukturelle Analyse der Prionproteinfragmente wurde zunächst mit Circulardichroismus (CD)-Spektroskopie durchgeführt (Abb.8).

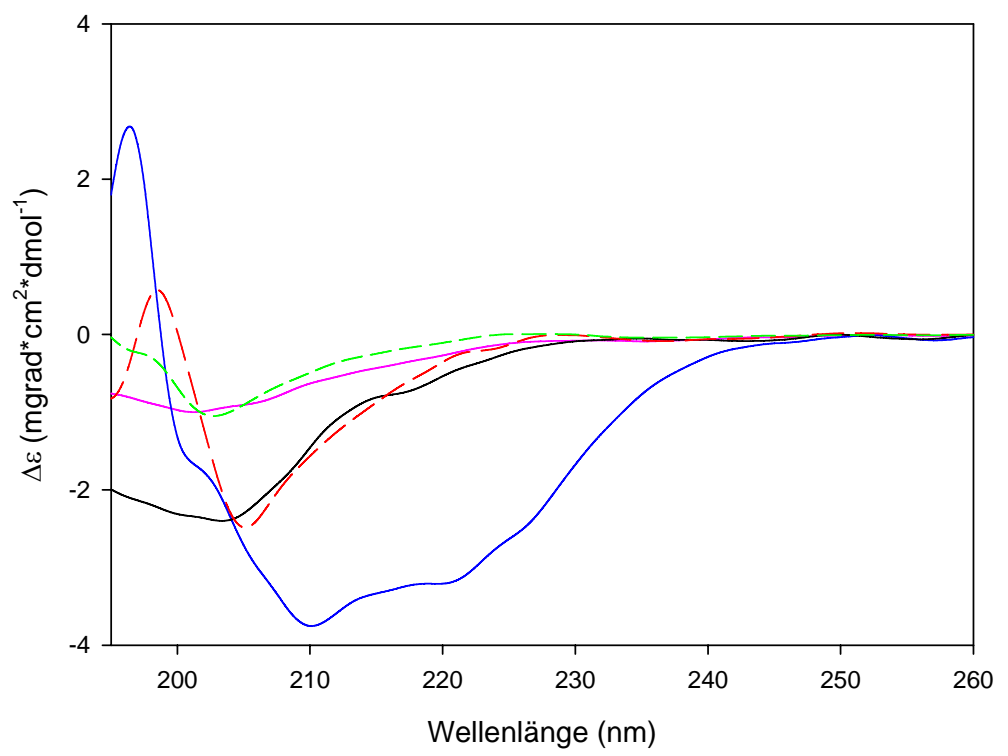

Abb. 8: CD-Spektren der fernen UV-Region der Prionproteinfragmente. Die CD-spektroskopischen Messungen wurden bei $20{ }^{\circ} \mathrm{C}$ an einem J-810 CD-Spektrometer (Jasco) durchgeführt. Die Schichtdicke der Küvette betrug $0.1 \mathrm{~cm}$. Alle Spektren wurden in $10 \mathrm{mM}$ Natriumacetat, $\mathrm{pH} 4.0$ mit jeweils $50 \mu \mathrm{M}$ Proteinkonzentrationen aufgenommen. Jedes CD-Spektrum repräsentiert Mittelwerte aus 10 Messungen. Die Datenerfassung erfolgte im Abstand von $0.1 \mathrm{~nm}$ mit einer Geschwindigkeit von $100 \mathrm{~nm}$ pro Minute. Das CDSpektrum von humPrP23-173 wurde in schwarz (durchgezogene Linie), das von humPrP23-159 in rot (gestrichelte Linie), von humPrP23-144 in grün (gestrichelte Linie) und von humPrP23-112 in pink (durchgezogene Linie) dargestellt. Zum Vergleich wurde das CD-Spektrum von humPrP23-231 beigefügt (blaue durchgezogene Linie) (Hornemann et al., 1997). 
CD-spektroskopische Untersuchungen der fernen UV-Region von humPrP23-159 und humPrP23-173 führten zu sehr ähnlichen Spektren (Abb. 8). Die für $\alpha$-Helices typischen Minima bei $208 \mathrm{~nm}$ und $222 \mathrm{~nm}$, wie sie für das Volllängen-Prionprotein beschrieben werden (Hornemann et al., 1997), konnten jeweils nicht nachgewiesen werden. Stattdessen lagen die Minima bei 205 nm für humPrP23-159 bzw. 203 nm für humPrP23-173, was auf einen noch beträchtlichen unstrukturierten Anteil hindeutete (Abb. 8). Die CD-spektroskopischen Untersuchungen von humPrP23-144 und humPrP23-112 führten ebenfalls zu vergleichbaren Spektren innerhalb der fernen UV-Region. Die Minima lagen in den CD-Spektren bei $203 \mathrm{~nm}$ für humPrP23-144 bzw. $201 \mathrm{~nm}$ für humPrP23-112, was auf einen sehr hohen unstrukturierten Anteil in den Prionproteinfragmenten hindeutete (Kundu et al., 2003) (Abb. 8).

Tabelle 12: Dekonvolution der CD-Spektren der Prionproteinfragmente durch das Programm CDNN (Böhm et al., 1992)

\begin{tabular}{|c|c|c|c|c|c|}
\hline untersuchte Prionproteine & $\begin{array}{c}\alpha \text {-Helix } \\
(\%)\end{array}$ & $\begin{array}{c}\text { Antiparalleles } \beta- \\
\text { Faltblatt }(\%)\end{array}$ & $\begin{array}{c}\text { Paralleles } \beta- \\
\text { Faltblatt (\%) }\end{array}$ & $\begin{array}{c}\beta \text {-Turn } \\
(\%)\end{array}$ & $\begin{array}{c}\text { Random } \\
\text { coil (\%) }\end{array}$ \\
\hline humPrP23-173 & 13.5 & 14.0 & 13.7 & 18.1 & 40.7 \\
\hline humPrP23-159 & 12.7 & 14.0 & 14.0 & 17.9 & 41.4 \\
\hline humPrP23-144 & 10.1 & 14.9 & 15.0 & 17.6 & 42.4 \\
\hline humPrP23-112 & 10.0 & 14.1 & 14.0 & 17.9 & 44.0 \\
\hline
\end{tabular}

Eine Dekonvolution der CD-Spektren durch das Programm CDNN (Böhm et al., 1992) führte für die Prionproteinfragmente zu sehr ähnlichen Sekundärstrukturgehalten mit insgesamt sehr hohen random coil-Gehalten (Tabelle 12). Die $\alpha$-helikalen Werte für die Prionproteinfragmente lagen zwischen 10.0-13.5 \%, wobei humPrP23-112 und humPrP23144 gemäss der NMR-Struktur des Volllängen-Prionproteins keine Helices beinhalten sollten (Zahn et al., 2000). Bei einer zum Volllängen-Prionprotein vergleichbaren Länge der Helix 1 sollte der $\alpha$-helikale Gehalt von humPrP23-173 $9 \%$ und der von humPrP23-159 $10 \%$ betragen.

Der $\beta$-Faltblatt-Gehalt (antiparallel) war für alle Prionproteinfragmente ebenfalls sehr ähnlich 
und lag mit 14.0-14.9\% ebenfalls deutlich zu hoch. humPrP23-112 sollte in Anlehnung an die NMR-Struktur des Volllängen-Prionproteins keinerlei $\beta$-Faltblatt-Struktur aufweisen.

Die Anwesenheit einer Helix 1 in humPrP23-159 und humPrP23-173 und des $\beta$-Faltblattes in humPrP23-173 konnte aus der quantitativen Analyse der CD-Spektren (Tabelle 12) nicht eindeutig bestimmt werden. Da auch FTIR-spektroskopische Messungen (Daten nicht abgebildet) keinen eindeutigen Nachweis der Helix 1 in humPrP23-159 erbringen konnten, wurden humPrP23-159 und humPrP23-173 NMR-spektroskopisch zum Nachweis von Helix 1 bzw. des $\beta$-Faltblattes untersucht.

Die NMR-spektroskopische Untersuchung von humPrP23-159 (Abb. 9 A, B) diente in erster Linie dem Nachweis der Helix 1 bei pH 6.5 und $\mathrm{pH} 4.5$.

Die Zuordnung der Signale zu den Aminosäuren der Helix 1-Region erfolgte im zweidimensionalen ${ }^{1} \mathrm{H}_{-}{ }^{15} \mathrm{~N}$ HSQC-Spektrum (Abb. 9 A). Aminosäuren in Helices resonieren üblicherweise in der ${ }^{1} \mathrm{H}$-Dimension zwischen 7.8-8.8 ppm, was allerdings auch für Aminosäuren in unstrukturierten Bereichen des Proteins gilt. Die ${ }^{15} \mathrm{~N}$-chemischen Verschiebungen in der zweiten Dimension sind stärker von der jeweiligen Aminosäure als von der sie umgebenden Struktur abhängig. Aminosäuren in $\beta$-Faltblättern resonieren üblicherweise zwischen 7-10 ppm in der ${ }^{1} \mathrm{H}$-Dimension und zwischen 105-135 ppm in der ${ }^{15} \mathrm{~N}$-Dimension. Insofern konnte als direkte strukturelle Information aus dem ${ }^{1} \mathrm{H}-{ }^{15} \mathrm{~N}$ HSQCSpektrum (Abb. 9 A) nur abgeleitet werden, dass die Region zwischen den Aminosäuren 135159 kein eindeutiges $\beta$-Faltblatt-Spektrum aufweist. Auf der Grundlage der Zuordung der gemessenen Signale zu den Aminosäuren des Prionproteins humPrP23-159 im ${ }^{1} \mathrm{H}-{ }^{15} \mathrm{~N}$ HSQCSpektrum konnte eine sekundärstrukturelle Zuordnung der Aminosäuren zu $\alpha$-Helices oder $\beta$ Faltblätter vorgenommen werden (Abb. 9 B).

Aminosäuren mit Tendenz zur Ausbildung von $\beta$-Faltblattstruktur in humPrP23-159 weisen negative $\Delta \delta C^{\prime}$ '-Werte auf (Abb. 9 B), während Aminosäuren mit Tendenz zur Ausbildung von Helices positive $\Delta \delta C^{\prime}$ '-Werte besitzen. Insofern konnte die Region 144-152 eindeutig einer $\alpha$ Helix zugeordnet werden. Im Vergleich zum Volllängen-Prionprotein humPrP23-230 (Zahn et al., 2000; Calzolai \& Zahn, 2003) war die Helix 1 in humPrP23-159 um vier Aminosäuren verkürzt. Die Tendenz zur Ausbildung helikaler Strukturen innerhalb der Helix 1-Region in humPrP23-159 ( $\Delta \delta \mathrm{C}^{\prime}$-Werte in Abb. 9 B) war im Vergleich zum Volllängen-Prionprotein um einen Faktor 3-4 reduziert, was auf einen dynamischeren Charakter der Helix 1 in humPrP23159 hindeutete. 
A

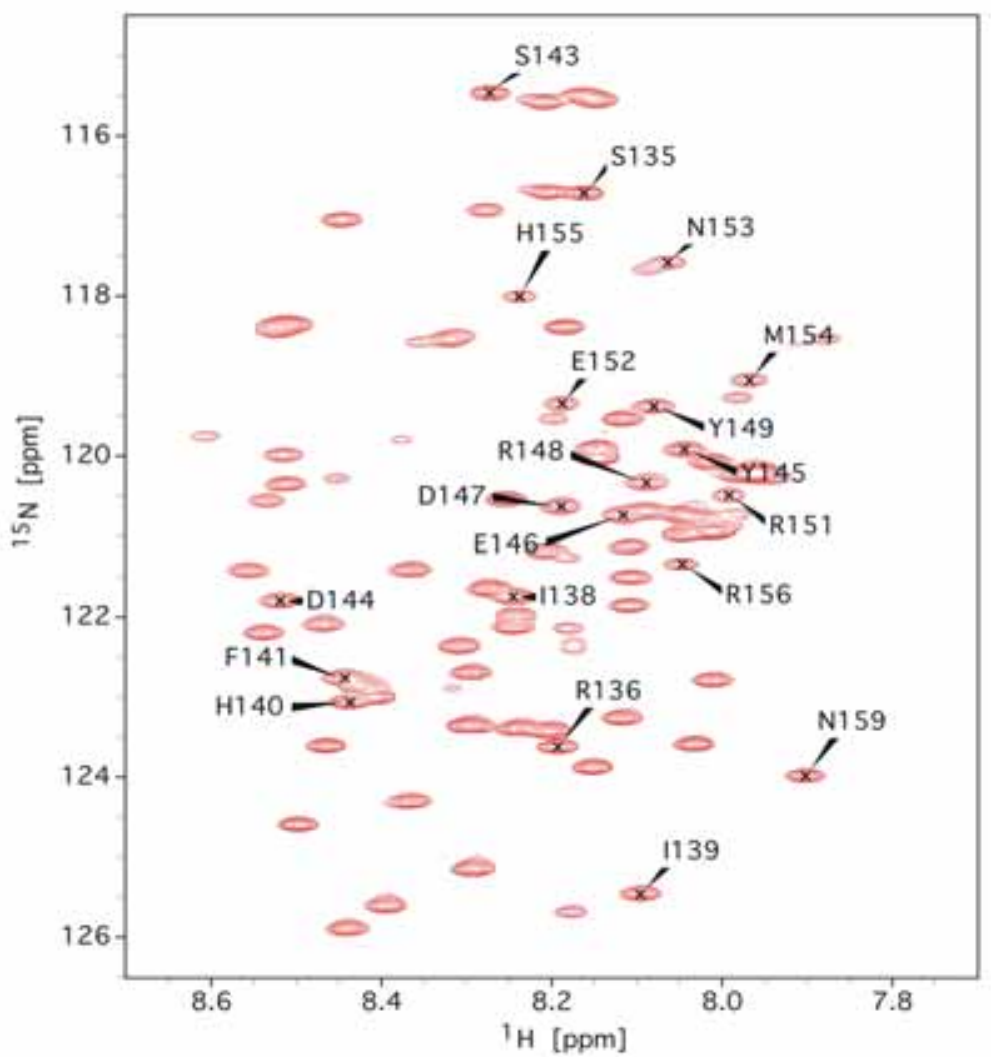

B

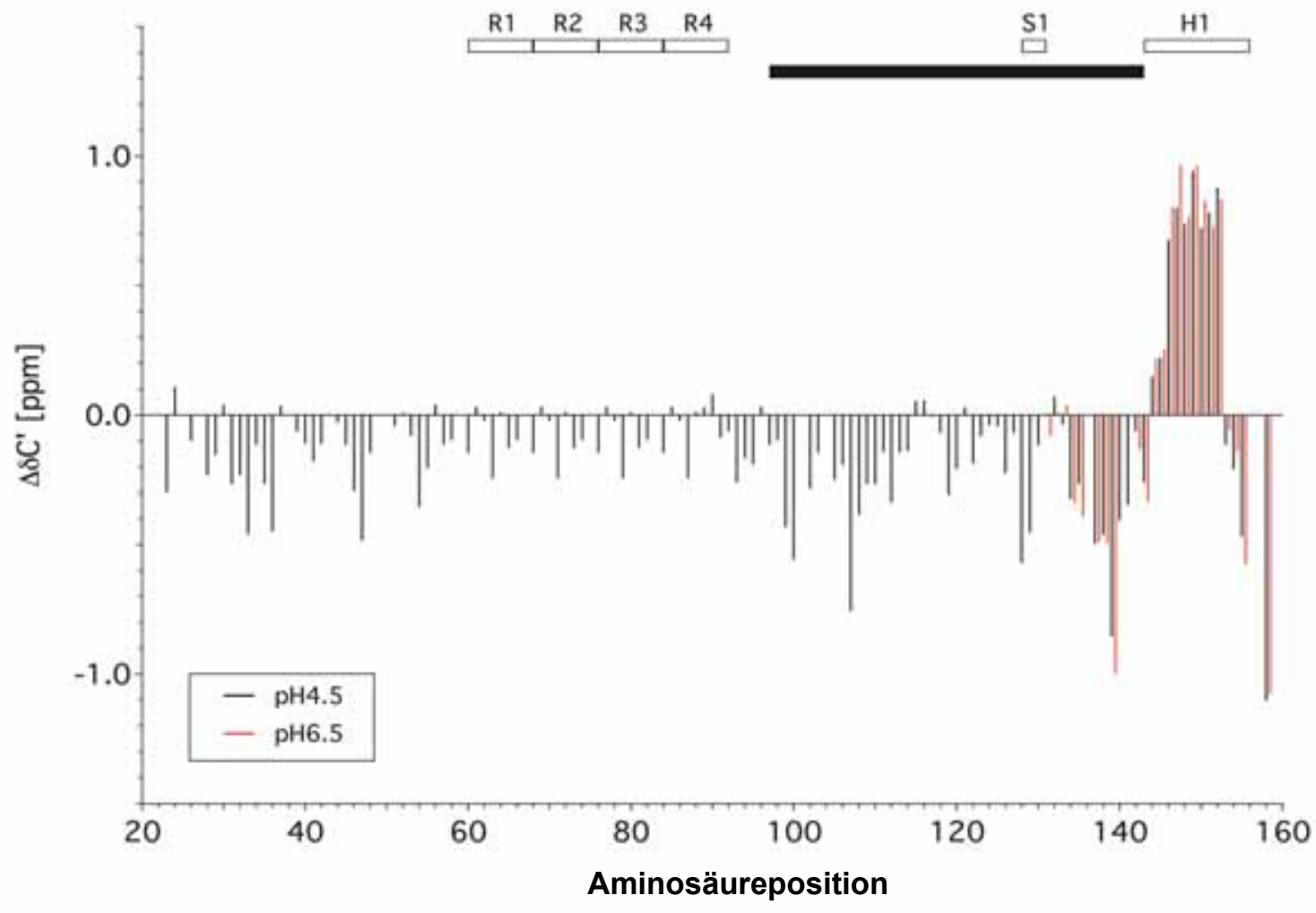


Abb. 9: NMR-Spektroskopie von monomerem humPrP23-159 zum Nachweis der Helix 1 bei verschiedenen pH-Werten. (A) ${ }^{1} \mathrm{H}_{-}{ }^{15} \mathrm{~N}$ HSQC-Spektrum von humPrP23-159 bei $\mathrm{pH} 4.5$ in $10 \mathrm{mM}$ Natriumacetat. Die Zuordnung der Aminosäuren der Helix 1-Region zwischen Aminosäure 135-159 ist durch Pfeile gekennzeichnet. (B) Gemittelte ${ }^{13} \mathrm{C}$-chemische Verschiebungen von humPrP23-159 bei pH 4.5 (schwarz) in $10 \mathrm{mM}$ Natriumacetat und pH 6.5 (rot) in $10 \mathrm{mM}$ MES-Puffer. Die gemittelten Verschiebungen wurden berechnet gemäß $\left[\Delta \delta(\mathrm{C} \alpha)+\Delta \delta\left(\mathrm{C}^{\prime}\right)\right] / 2$. Jeder $\Delta \delta$-Wert entspricht der Differenz aus der chemischen Verschiebung von Ca bzw. dem Carbonyl-Kohlenstoffatom C' in humPrP23-159 und empirischen Werten für Ca bzw. C' der gleichen Aminosäure in random coils (Schwarzinger et al., 2001; Wishart et al., 1994). Die offenen Balken zeigen die Position der Oktarepeat-Region (R1-R4), des $\beta$-Strand S1 (S1) und der Helix 1 (H1) an. Der ausgefüllte Balken markiert die Region PrP90-145 mit erwarteter hoher Umfaltungstendenz im $\operatorname{PrP}^{\mathrm{C}} \mathrm{zu} \operatorname{PrP}^{\mathrm{Sc}}$ (Peretz et al., 1997). Die NMR-spektroskopische Vermessung und Analytik der Proteine wurde von Lukasz Skora und Dr. Markus Zweckstetter am Max-Planck-Institut für Biophysikalische Chemie in Göttingen durchgeführt.

Zwischen den beiden pH-Werten 6.5 und 4.5 konnte keine wesentliche Veränderung der Sekundärstruktur in humPrP23-159 detektiert werden.

Die hohe Umfaltungstendenz der Region 90-145 in ein $\beta$-Faltblatt (Peretz et al., 1997) im Volllängen-Prionprotein konnte durch die negativen $\Delta \delta C^{\prime}$ '-Werte dieser Region in humPrP23159 bestätigt werden (Abb. 9 B).

Interessanterweise wies das Isoleucin 139 die höchste $\beta$-Faltblatt-Tendenz in humPrP23-159 auf. In einem Modellsystem mit rekombinantem Prionproteinen zur Simulation von Speziesbarrieren konnten die Aminosäuren 138 und 139 in der humanen, murinen und Hamster-Prionproteinsequenz als entscheidende Determinante für die Ausbildung einer Speziesbarriere ausgemacht werden (Jones et al., 2005; Vanik et al., 2004).

Das wichtigste Resultat der NMR-spektroskopischen Untersuchung von humPrP23-159 war der Nachweis der Helix 1 bei pH-Werten von 6.5 und 4.5.

Die NMR-Struktur von löslichem humPrP23-173 wurde in erster Linie zum Nachweis des $\beta$ Faltblattes und der Helix 1 angefertigt, sowie um strukturelle Unterschiede zu humPrP23-159 aufzuzeigen.

Die Zuordnung der gemessenen Signale zu den Aminosäuren des Segmentes 135-173 erfolgte im zweidimensionalen ${ }^{1} \mathrm{H}_{-}{ }^{15} \mathrm{~N}$ HSQC-Spektrum (Abb. $10 \mathrm{~A}$ ). Die chemische Verschiebung der Aminosäuren 135-159 in der ${ }^{1} \mathrm{H}$ - und ${ }^{15} \mathrm{~N}$-Dimension war für humPrP23-173 (Abb. $10 \mathrm{~A}$ ) fast identisch zu humPrP23-159 (Abb. 9 A). Eine eindeutige Zuordnung der Region 161-164 zu einem $\beta$-Faltblatt war aus dem ${ }^{1} \mathrm{H}_{-}{ }^{15} \mathrm{~N}$ HSQC-Spektrum nicht möglich. 
A

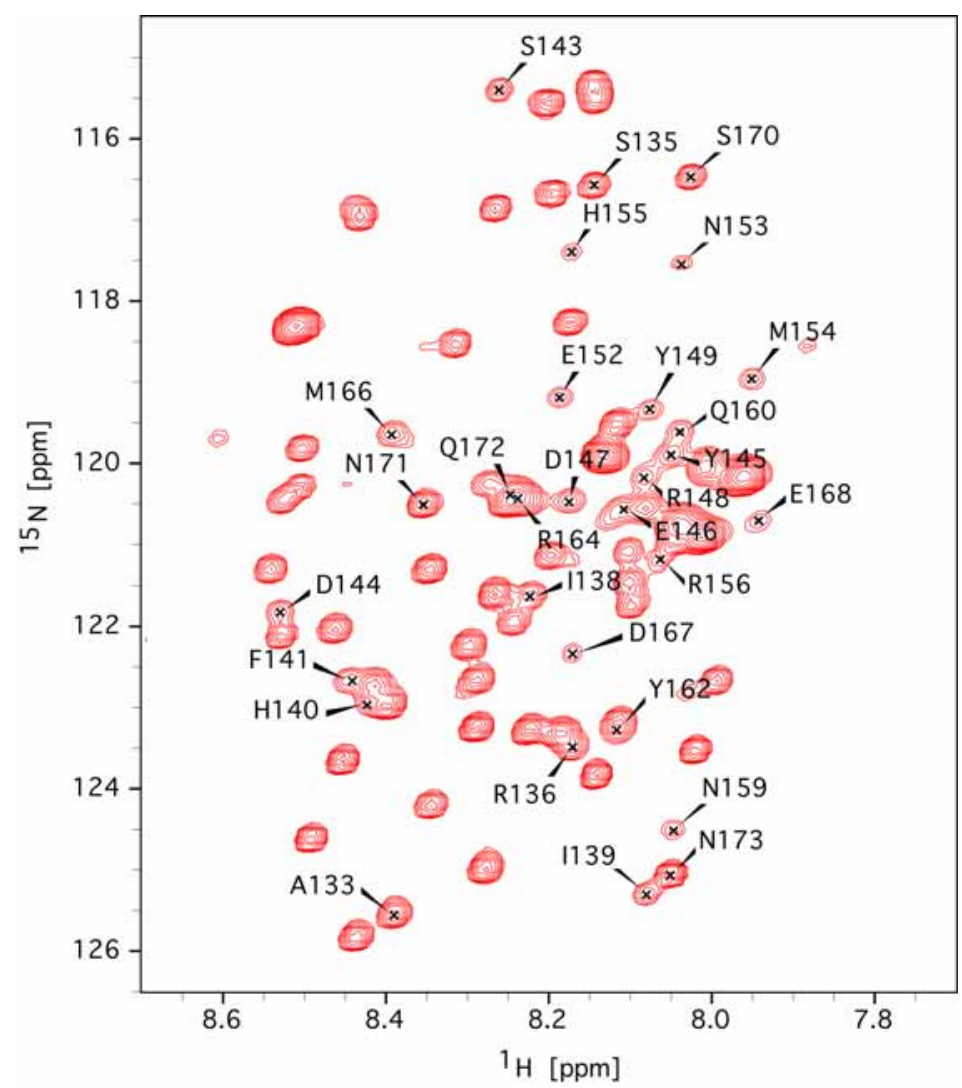

B

PrP23-159 aull length a PrP23-173

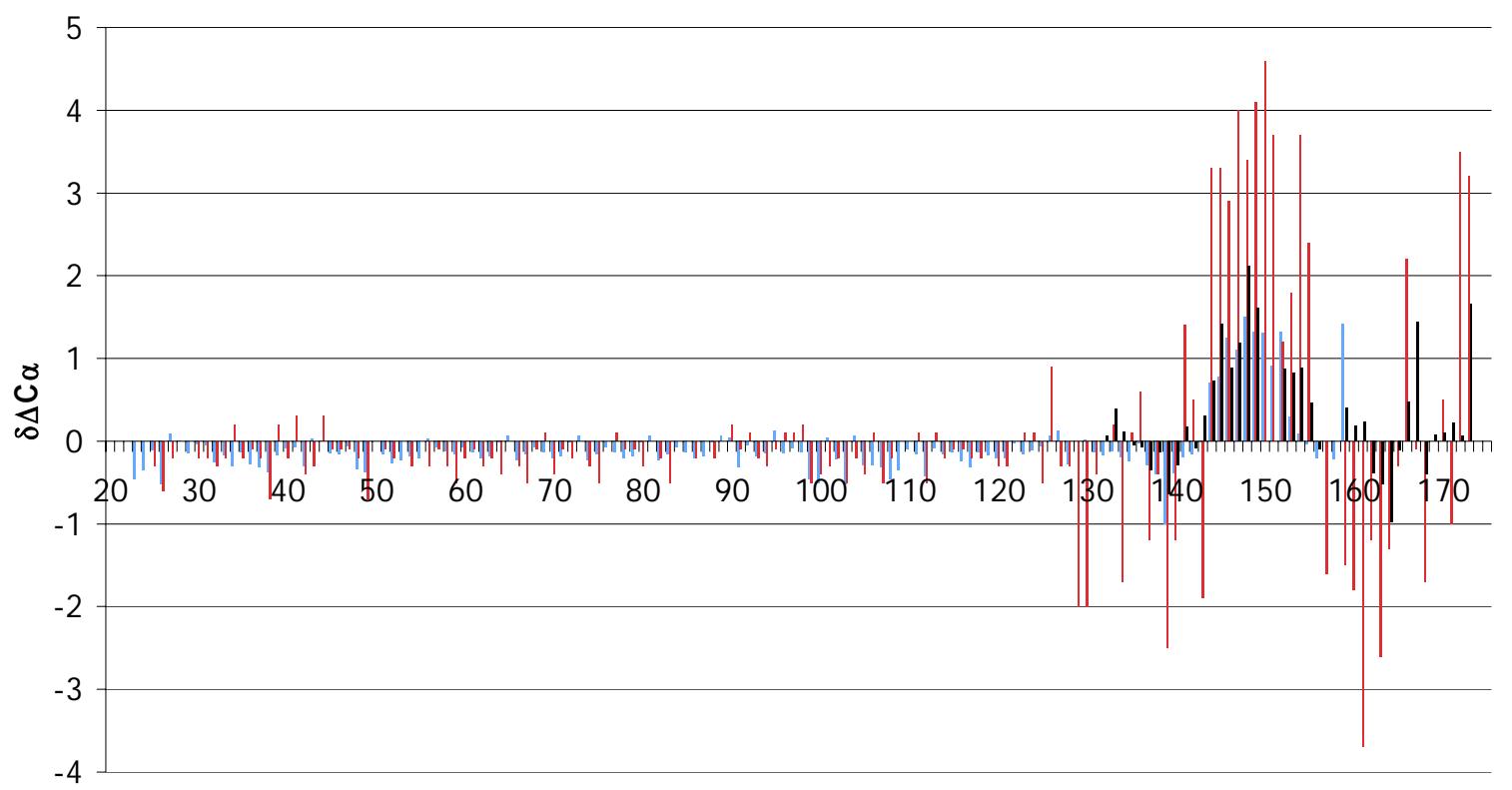

Aminosäureposition 
Abb. 10: NMR-Spektroskopie von humPrP23-173 im Vergleich zu humPrP23-159 und humPrP23-230. (A) ${ }^{1} \mathrm{H}-{ }^{15} \mathrm{~N}$ HSQC-Spektrum von humPrP23-173 bei $\mathrm{pH} 4.5$ in $10 \mathrm{mM}$ Natriumacetat. Die Zuordnung der Aminosäuren der Region 135-173 ist durch Pfeile gekennzeichnet. (B) ${ }^{13} \mathrm{C}$-chemische Verschiebungen der $\mathrm{C} \alpha$ Kohlenstoffatome in humPrP23-173 (schwarz), humPrP23-159 (blau) und humPrP23-230 (rot) bei pH 4.5 (schwarz) in $10 \mathrm{mM}$ Natriumacetat im Vergleich. Die NMR-Struktur von humPrP23-230 war nicht Teil dieser Arbeit und wurde zum Vergleich beigefügt (Zahn et al., 2000). Die Differenz der chemischen Verschiebung für die $\mathrm{C} \alpha$-Kohlenstoffatome in humPrP23-173 $(\Delta \delta \mathrm{C} \alpha)$ wurde mit empirischen Werten von C $\alpha$-Kohlenstoffatomen aus random coils berechnet (Wishart et al., 1994). Die $\Delta \delta C \alpha$-Werte der Aminosäuren 23-130 in humPrP23-173 waren identisch zu den Werten in humPrP23-159 (blau) und wurden deshalb nicht doppelt abgebildet. Die NMRspektroskopische Vermessung und Analytik der Proteine humPrP23-159 und humPrP23-173 wurde von Lukasz Skora und Dr. Markus Zweckstetter am Max-Planck-Institut für Biophysikalische Chemie in Göttingen durchgeführt.

Aus der Differenz der chemischen Verschiebungen der $\mathrm{C} \alpha$-Kohlenstoffatome in humPrP23$173 \mathrm{zu}$ empirischen chemischen Verschiebungen der $\mathrm{C} \alpha$-Atome $(\Delta \delta \mathrm{C} \alpha$-Werte) in random coils (Wishart et al., 1994) konnte gezeigt werden, dass die Region 162-164 die stärkste Tendenz zur Ausbildung von $\beta$-Faltblattstruktur in humPrP23-173 besitzt (Abb. $10 \mathrm{~B}$ ). Im Vergleich zur NMR-Struktur von humPrP23-230 (Zahn et al., 2000) war die Tendenz der Aminosäuren 162-164 zur Ausbildung von $\beta$-Faltblattstruktur in humPrP23-173 durchschnittlich um einen Faktor 3.5 vermindert. Die Tendenz zur Ausbildung helikaler Strukturen in den Helix 1-Segmenten von humPrP23-173 und humPrP23-159 war dagegen nahezu identisch (Abb. 10 B, $\Delta \delta C \alpha$-Werte). Die Länge der Helix 1 (143-154) in humPrP23173 war mit zwölf Aminosäuren um eine Aminosäure zur Helix 1 im Volllängen-Prionprotein verkürzt und um drei Aminosäuren gegenüber der Helix 1 in humPrP23-159 verlängert.

Die Charakterisierung der Prionproteinfragmente zu folgenden Ergebnissen:

Alle Prionproteinfragmente konnten in ausgezeichneter Reinheit hergestellt werden, wobei lediglich humPrP23-173 eine Modifikation seiner Proteinsequenz durch eine mögliche Oxidation aufwies.

Strukturell konnte die Existenz der Helix 1 sowohl in humPrP23-159 als auch in humPrP23173 bewiesen werden. Ebenso konnte der $\beta$-Strand S2 in humPrP23-173 nachgewiesen werden. 


\subsection{Einfluss der Helix 1 auf die Aggregation des humanen Prionproteins}

Nachdem die Reinheit der Prionproteinfragmente und ihre korrekte Faltung sichergestellt waren, sollte der Einfluss der Helix 1 auf die Aggregation des Prionproteins untersucht werden. Dazu sollte die Aggregation der humanen Prionproteinfragmente humPrP23-144 und humPrP23-159 direkt miteinander verglichen werden.

\subsubsection{Nachweis von monomerem humPrP23-144 und humPrP23-159}

Auf Präparationsartefakten beruhende bereits vorhandene oligomere oder fibrilläre Formen der Prionproteinfragmente mussten vor dem Start der Aggregation ausgeschlossen werden. Deshalb konnten nur Proteine im monomeren Zustand untersucht und ihre Eigenschaften miteinander verglichen werden.

In dieser Arbeit wurde die kapillare Zonenelektrophorese (CZE) genutzt, um oligomere oder aggregierte Formen der Prionproteinfragmente nachzuweisen. Bei der CZE werden geladene Moleküle auf Grund unterschiedlicher Ladungszahl und Mobilität in einer englumigen Kapillare durch Anlegen einer Hochspannung voneinander getrennt. Neben der Gesamtladung des Moleküls sind die angelegte Feldstärke, die Viskosität des Mediums und der Radius des Moleküls für seine Wanderungsgeschwindigkeit im elektrischen Feld entscheidend.

Da bei der CZE von humPrP23-159 (Abb. 11 A) und humPrP23-144 (Abb. 11 B) jeweils nur ein einzelner Peak in den Spektren zu sehen war, konnten sowohl oligomere als auch multimere Formen der Prionproteine ausgeschlossen werden. Die Retentionszeiten von humPrP23-159 (A) und humPrP23-144 (B) bei der CZE betrugen 13.9 Minuten bzw. 15.2 Minuten. Oligomere oder aggregierte Proteine wurden bei der CZE als Spezies von geringerer elektrophoretischer Mobilität beschrieben, denen oftmals ein ungewöhnliches negatives Signal vorangeht. Die negative Peakform kann mit einer starken Adsorption von Ionen aus dem umgebenen Milieu an die Aggregate begründet werden, da es in der Umgebung der Aggregate zu einer kurzfristigen Verarmung an Ionen kommen kann (Righetti et al., 2001).

Durch dynamische Lichtstreuungsexperimente (Dynamic Light Scattering) wurde der monomere Charakter der Proteine humPrP23-144 und humPrP23-159 bei pH 4.5 zusätzlich bestätigt (Daten nicht abgebildet). 

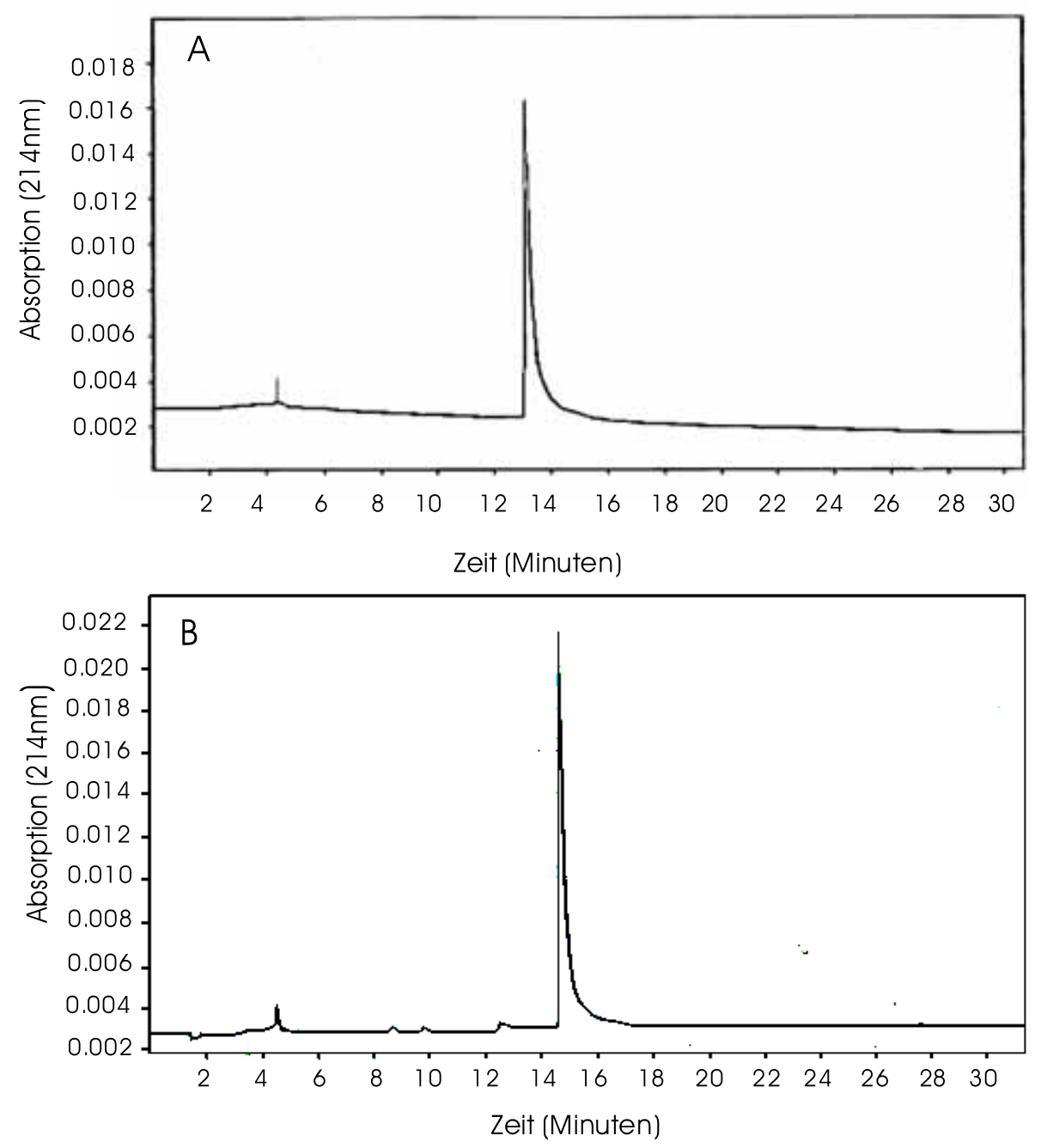

Abb. 11: Kapillare Zonenelektrophorese (CZE) von humPrP23-144 und humPrP23-159 als Nachweis des monomeren Zustandes. (A) humPrP23-159 und (B) humPrP23-144 wurden in destilliertem Wasser in einer Konzentration von jeweils $0.15 \mathrm{mg} / \mathrm{ml}$ gelöst und mittels $\mathrm{CZE}$ bei $12.5 \mathrm{kV}$ und $25{ }^{\circ} \mathrm{C}$ in bare fused silica Kapillaren untersucht. Zur Unterdrückung von Adsorptionseffekten an die Kapillarinnenwand wurde bei einem pH-Wert von 2.77 in einem $50 \mathrm{mM}$ Aspartat-Puffer gearbeitet. Die Absorption der Proteine wurde mit einem UV-Detektor bei $214 \mathrm{~nm}$ verfolgt.

\subsubsection{Vergleich der spontanen Aggregation von humPrP23-159 mit humPrP23-} 144

Die Helix 1 des humanen Prionproteins ist eine der polarsten Helices, die innerhalb der Protein Data Base (RCSB-PDB) (Morrissey \& Shakhnovich, 1999) gefunden wurde. Folglich 
sollte das Helix 1-Segment in humPrP23-159 die Löslichkeit des Prionproteinfragmentes erhöhen.

Um den Einfluss der Helix 1 auf die Aggregation des humanen Prionproteins zu verstehen, wurde die Aggregation von humPrP23-159 mit Helix 1 und humPrP23-144 ohne Helix 1 in Parallelversuchen miteinander verglichen (Abb. 12). humPrP23-159 war das bislang längste unter physiologischen, nicht-denaturierenden Bedingungen untersuchte Prionproteinfragment, bei dem eine Bestimmung der Aggregationsgeschwindigkeit durchgeführt wurde. Der pHWert der Aggregationsversuche wurde analog zu Kundu et al. (2003) gewählt, der die Aggregation von humPrP23-144 in einem physiologischen System beschrieben hatte. humPrP23-159 und humPrP23-144 waren in der Lage unter physiologischen Bedingungen zu aggregieren. Entgegen der Erwartung aggegierte humPrP23-159 bei gleicher Proteinkonzentration schneller als humPrP23-144. Auch wiederholte Messungen bei unterschiedlichen Proteinkonzentrationen (Abb. 12 A-C) führten zum gleichen Ergebnis. Eine Abhängigkeit der Aggregationsgeschwindigkeit von der eingesetzten Proteinkonzentration wurde auch durchgeführt, um ionische oder polare Wechselwirkungen mit der Reaktionsgefässwandung (Borosilikatglass) unter Bildung von Aggregationskeimen als Ursache für das unterschiedliche Aggregationsverhalten der beiden Proteinfragmente auszuschliessen. In diesem Fall sollte die Aggregation des Prionproteins bei unterschiedlicher Proteinkonzentration durch die gebildeten Aggregationskeime nahezu gleich schnell ablaufen. Der zeitliche Unterschied der Halbwertsaggregation war bei hohen und sehr unphysiologischen Proteinkonzentrationen am geringsten ausgeprägt. Je niedriger die Proteinkonzentrationen waren, desto grösser wurde der Unterschied der Aggregationsgeschwindigkeit zwischen humPrP23-159 und humPrP23-144. Bei $200 \mu \mathrm{M}$ und $80 \mu \mathrm{M}$ Proteinkonzentrationen betrug der zeitliche Unterschied der Halbwertsaggregation zwischen beiden Prionproteinfragmenten jeweils etwa $70 \quad \mathrm{~h}$. Bei $340 \quad \mu \mathrm{M}$ Proteinkonzentrationen betrug der zeitliche Unterschied der Halbwertsaggregation zwischen beiden Prionproteinfagmenten dagegen nur $12 \mathrm{~h}$ (Tabelle 14). 

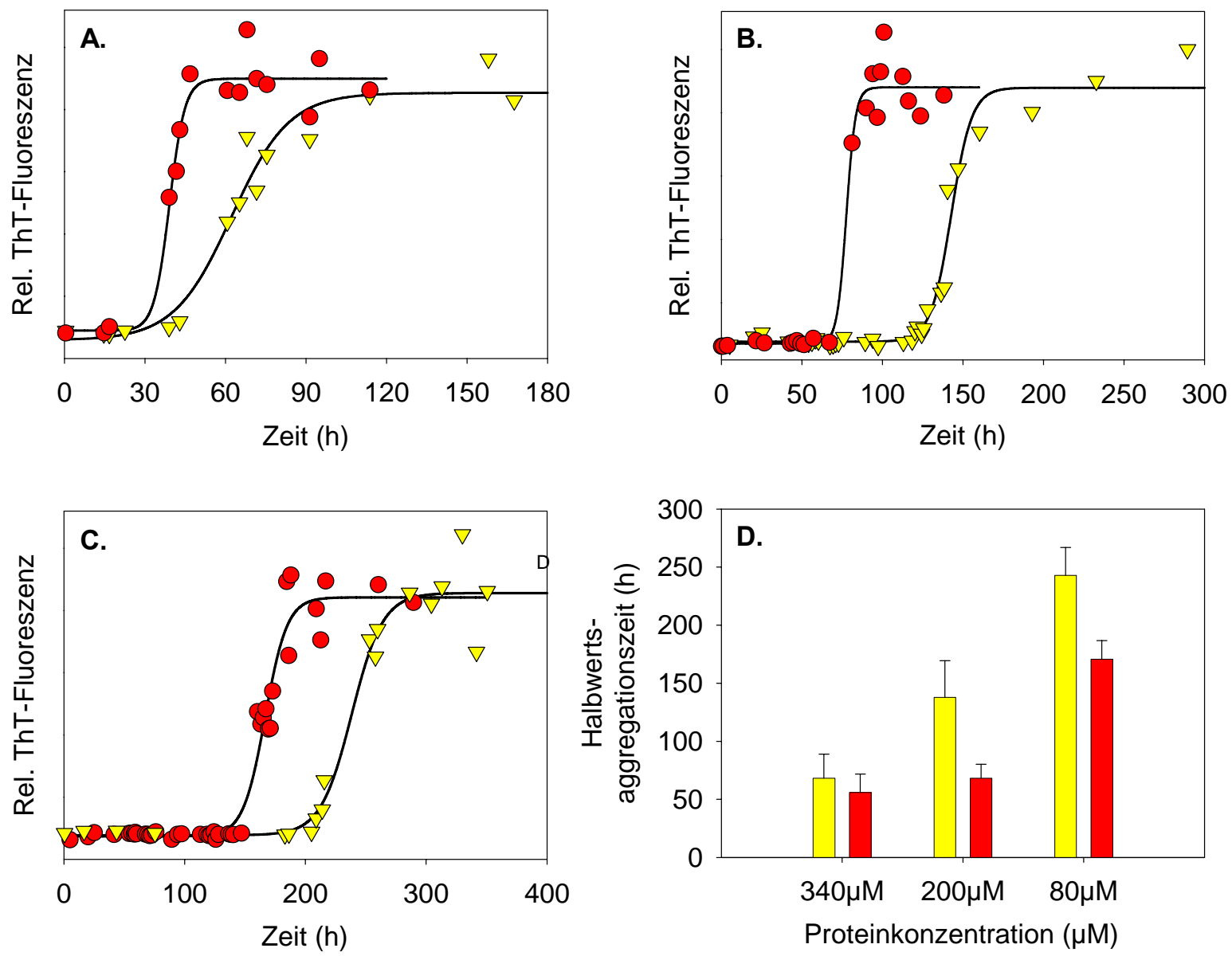

Abb. 12: humPrP23-159 aggregiert signifikant schneller als humPrP23-144. Vergleich der Aggregationsgeschwindigkeiten von humPrP23-144 (gelbe Dreiecke) und humPrP23-159 (rote Kreise) durch Bestimmung der Thioflavin T (ThT)-Fluoreszenz in $20 \mathrm{mM}$ Natriumacetat- und $20 \mathrm{mM}$ Natriumphosphat-

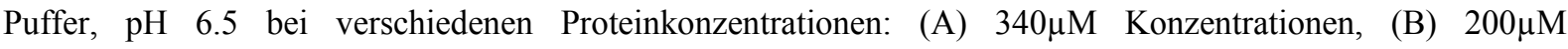

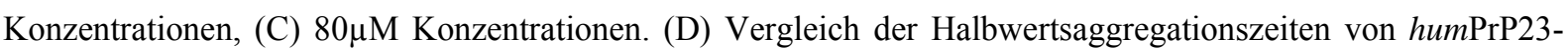
144 (gelbe Balken) mit humPrP23-159 (rote Balken) aus neun unabhängigen Experimenten. Die Fehlerbalken geben die Standardabweichung an. Zur besseren Vergleichbarkeit wurden bei deutlich unterschiedlicher ThTFluoreszenz von humPrP23-144 und humPrP23-159 in A-C die relativen ThT-Fluoreszenzwerte angegeben.

Da die Helix 1 neun der fünfzehn Aminosäuren Differenz zwischen humPrP23-159 und humPrP23-144 ausmachte und das einzige nachweisbare strukturelle Element dieses Segmentes war (Abb. 9 B), lässt sich zusammenfassend sagen, dass die polare Helix 1 einen aggregationsbeschleunigenden Effekt auf das humane Prionprotein ausübt. 
Tabelle 14: Halbwertsaggregationszeiten von humPrP23-159 und humPrP23-144 bei verschiedenen Proteinkonzentrationen unter physiologischen Bedingungen

\begin{tabular}{|c|c|c|}
\hline \multirow{2}{*}{ Proteinkonzentration $(\mu \mathrm{M})$} & $\begin{array}{c}\text { humPrP23-159 } \\
\text { gemittelte Halbwertsaggregationszeit } \\
\text { (h) aus neun Experimenten plus } \\
\text { Standardabweichung }\end{array}$ & $\begin{array}{c}\text { humPrP23-144 } \\
\text { gemittelte Halbwertsaggregationszeit } \\
\text { (h) aus neun Experimenten plus } \\
\text { Standardabweichung }\end{array}$ \\
\hline $340 \mu \mathrm{M}$ & $56 \pm 16$ & $68 \pm 21$ \\
\hline $200 \mu \mathrm{M}$ & $68 \pm 12$ & $138 \pm 32$ \\
\hline $80 \mu \mathrm{M}$ & $171 \pm 16$ & $243 \pm 24$ \\
\hline
\end{tabular}

\subsubsection{Vergleich der Aggregation von humPrP23-159 mit humPrP23-144 unter Zugabe von fibrillärem Prionprotein (,Seeding“)}

In den Experimenten unter Zugabe von fibrillärem Prionprotein hängt der Verlauf der Aggregation nicht nur von den Eigenschaften der monomeren Proteine, sondern auch von den Eigenschaften der Aggregationskeime ab.

Ein zusätzlicher Beleg einer Beteiligung der Helix 1 an der Aggregation von humPrP23-159 könnte erbracht werden, wenn sich der aggregationsfördernde Effekt der Helix 1 gegen die Beschleunigung der Aggregation durch die Nukleationskeime durchsetzt (Abb. 13).

Die Aggregationskeime bestanden aus jeweils fibrillärem humPrP23-144, humPrP23-159 und humPrP106-126. Interessanterweise erfolgte die Aggregation von monomerem humPrP23-159 mit fibrillärem humPrP23-144 und fibrillärem humPrP23-159 jeweils deutlich schneller als die Aggregation von monomerem humPrP23-144 unter Verwendung der gleichen Aggregationskeime (Abb. 13 und 14). Die Halbwertsaggregationszeiten von monomerem humPrP23-159 betrugen bei Zugabe von fibrillärem humPrP23-159 bzw. fibrillärem humPrP23-144 $4.3 \pm 0.7 \mathrm{~h}$ bzw. $4.7 \pm 0.9 \mathrm{~h}$ und waren damit in beiden Fällen nahezu identisch. Die Aggregation von humPrP23-144 zeigte bei Zugabe von fibrillärem humPrP23159 und fibrillärem humPrP23-144 einen ungewöhnlichen biphasischen Verlauf. Die erste Phase bei Zugabe von fibrillärem humPrP23-159 wies eine Halbwertsaggregationszeit von $10.9 \pm 3.0$ h, die Hauptphase eine Halbwertsaggregationszeit von $47.8 \pm 9.5$ h auf. Fibrilläres humPrP23-144 war im Vergleich zu fibrillärem humPrP23-159 der effizientere Nukleationskeim bei der Aggregation von monomerem humPrP23-144. Die Halbwertsaggregationszeit der Vorhase bei Zugabe von fibrillärem humPrP23-144 betrug 2.7 \pm 0.7 h, die der Hauptphase $10.4 \pm 1.5$ h (Abb. $13+14)$. 

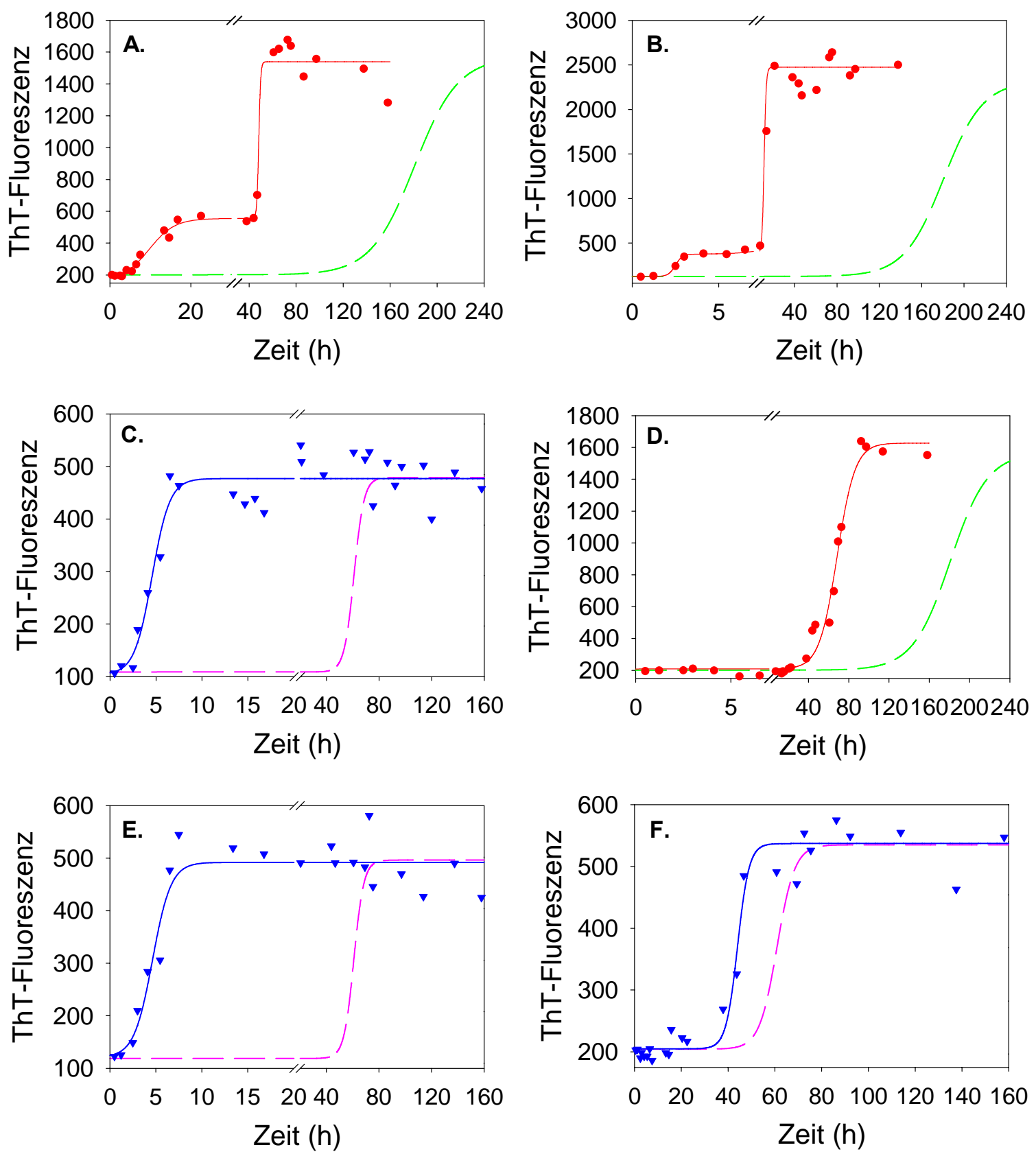

Abb. 13: Vergleich der Aggregationkinetiken von humPrP23-159 und humPrP23-144 bei Zugabe von fibrillärem Prionprotein (Seeding). Bestimmung der Aggregationsgeschwindigkeiten von je $200 \mu \mathrm{M}$ Proteinkonzentrationen von humPrP23-144 (A, B, D) und humPrP23-159 (C, E, F) bei Zugabe von fibrillärem Prionprotein. Die monomeren Proteine wurden in einem $20 \mathrm{mM}$ Natriumacetat- und $20 \mathrm{mM}$ NatriumphosphatPuffer bei einem pH-Wert von 6.5 eingesetzt. Als Aggregationskeime (Seed) wurden jeweils 1\% (v/v) fibrilläres humPrP23-159 (A, C), fibrilläres humPrP23-144 (B, E) oder fibrilläres humPrP106-126 (D, F) eingesetzt. Die Zeitabhängigkeit der Aggregation des Prionproteins bei Zugabe von fibrillärem Prionprotein wurde als durchgezogene Linie bei humPrP23-144 (rot) bzw. humPrP23-159 (blau) dargestellt. Als direkter Vergleich wurde jeweils die Zeitabhängigkeit der Aggregation des Prionproteins ohne externe Zugabe von fibrillärem Prionprotein von humPrP23-144 (grün) bzw. humPrP23-159 (pink) gegenübergestellt. 
Im Gegensatz zur Literatur (Kundu et al., 2003) konnte gezeigt werden, dass fibrilläres humPrP106-126 sowohl die Aggregation von monomerem humPrP23-159 als auch von monomerem humPrP23-144 beschleunigt. Die Halbwertsaggregationszeiten bei Aggregation von monomerem humPrP23-144 und monomerem humPrP23-159 mit fibrillärem PrP106-126 als Aggregationskeim betrugen $71 \pm 14$ h bzw. $42 \pm 6.3$ h. Die Halbwertsaggregationszeiten von monomerem humPrP23-144 und monomerem humPrP23-159 ohne Zugabe von Aggregationskeimen lagen im Vergleich dazu bei $138 \pm 32$ h bzw. $68 \pm 12$ h (Abb. 14)

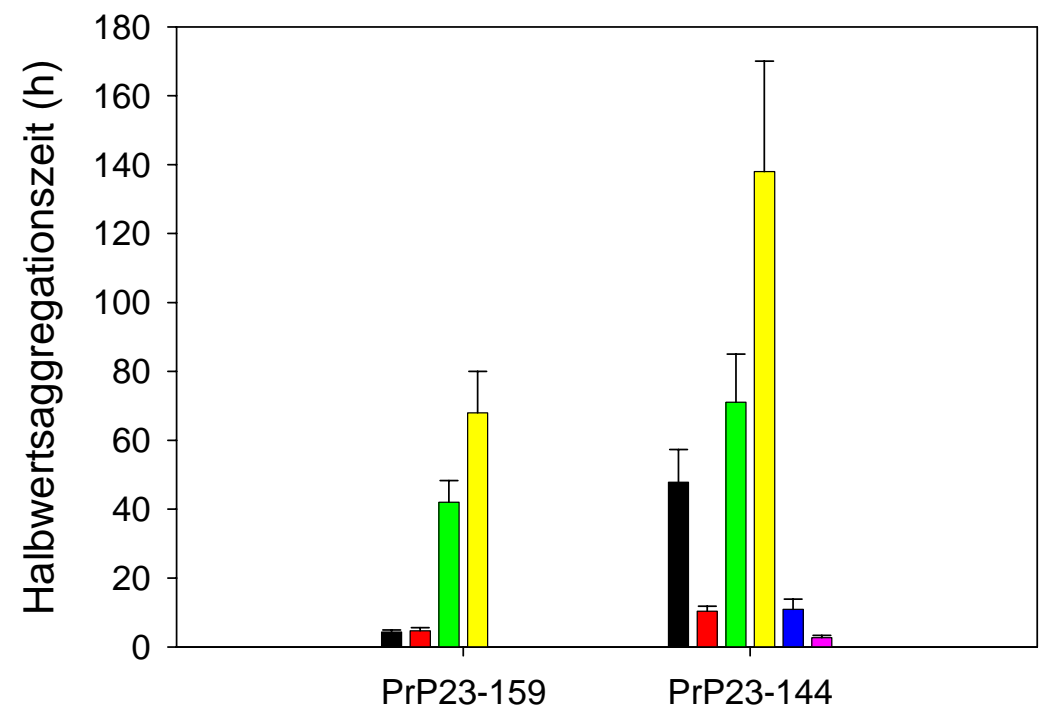

\section{Eingesetzte monomere Proteine}

Abb. 14: Vergleich der Halbwertsaggregationszeiten von humPrP23-159 (links) und humPrP23-144 (rechts) bei Zugabe von fibrillären Prionproteinen (Seeding). Die Bestimmung der Halbwertsaggregation erfolgte jeweils aus drei unabhängigen Experimenten. Als monomere Proteine wurden humPrP23-159 und humPrP23- eingesetzt. Als Aggregationskeime wurden 1\% (v/v) fibrilläres humPrP23-159 (schwarze Balken, Hauptphase), fibrilläres humPrP23-144 (rote Balken, Hauptphase) und fibrilläres humPrP106-126 (grüne Balken) eingesetzt. Zum Vergleich sind die Halbwertsaggregationszeiten ohne Zugabe von Aggregationskeimen abgebildet (gelbe Balken). humPrP23-144 zeigte bei Zugabe von fibrillärem humPrP23-144 und fibrillärem humPrP23-159 eine Vorphase und eine Hauptphase. Die Halbwertsaggregationszeit der Vorphase von humPrP23-144 bei Zugabe von fibrillärem humPrP23-159 ist als blauer Balken, die Halbwertsaggregationszeit der Vorphase von humPrP23-144 bei Zugabe von fibrillärem humPrP23-144 ist als pinker Balken dargestellt. Die Fehlerbalken geben die Standardabweichung an.

Zusätzlich zu dem aggregationsfördernden Effekt der Helix 1 bei der spontanen Aggregation des Prionproteinfragmentes humPrP23-159, aggregierte humPrP23-159 auch unter Zugabe 
von Aggregationskeimen (Seeding) schneller als humPrP23-144, was den aggregationsfördernden Effekt der Helix 1 im humanen Prionprotein unterstützend belegte.

\subsubsection{Morphologie von aggregiertem humPrP23-159}

Elektronenmikroskopische Aufnahmen zeigten, dass humPrP23-144 und humPrP23-159 unter Zugabe von Phosphatpuffer bei einem pH-Wert von 6.5 fibrilläre Aggregate bildeten (Abb. 15). Dabei konnten keine signifikanten morphologischen Unterschiede für die Prionproteine humPrP23-144 und humPrP23-159 gezeigt werden.

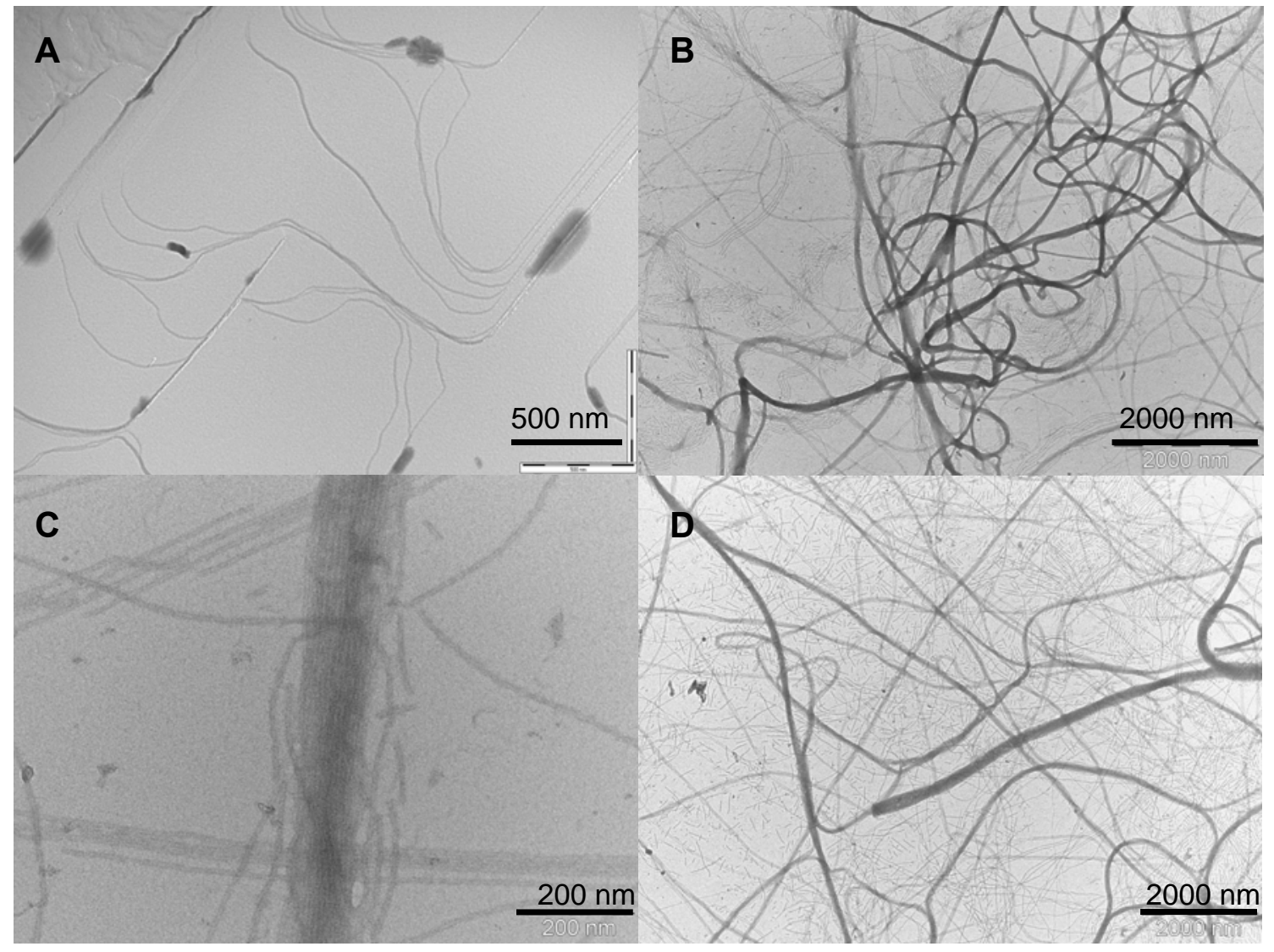

Abbildung 15: Elektronenmikroskopische Darstellung von fibrillärem humPrP23-159 und fibrillärem humPrP23-144. Je $200 \mu \mathrm{M}$ humPrP23-159 (C, D) und humPrP23-144 (A, B) wurden in $20 \mathrm{mM}$ Natriumphosphat und $20 \mathrm{mM}$ Natriumacetat bei $\mathrm{pH} 6.5$ und $25{ }^{\circ} \mathrm{C}$ zur Aggregation gebracht und nach drei Wochen elektronenmikroskopisch untersucht. Alle Proteinlösungen enthielten $0.1 \%$ (w/v) Natriumazid. Die Kontrastierung der Aggregate erfolgte nach 20 facher Verdünnung im gleichen Puffer und Auftrag auf Carbon coated Copper Grids durch $2 \%(w / v)$ Uranylacetat. Die Aufnahmen B und D wurden bei 12500 facher Vergrösserung, die Aufnahmen A und C bei 50000 facher bzw. 100000 facher Vergrösserung aufgenommen. 
Beide aggregierten Prionproteinfragmente bildeten ein Netzwerk aus stark gebündelten Fibrillen mit einem durchschnittlichen Durchmesser von 50-70 nm, der bis auf $350 \mathrm{~nm}$ ansteigen konnte. Die Länge der ungerührten Aggregate betrug jeweils mehrere Mikrometer. Die einzelnen Fibrillen der Bündel wiesen für beide Proteine einen Durchmesser von 8-12 nm auf. Dieses Ergebnis steht im Einklang mit der literaturbeschriebenen Morphologie von fibrillärem humPrP23-144 (Kundu et al., 2003). Auffällig bei beiden Prionproteinfragmenten war die starke Neigung der Fibrillen zur parallelen Anordnung in Bündel (laterale Aggregation).

\subsubsection{Proteinase K Resistenz der Helix 1 in fibrillärem humPrP23-159}

Eine plausible Erklärung für den aggregationsbeschleunigenden Effekt von humPrP23-159 wäre, dass Helix 1 einen fühen Kontakt zwischen PrP-Molekülen herstellt und selbst in ein $\beta$ Faltblatt umgefaltet wird. Ein Beleg für diese Hypothese wäre eine Resistenz des Helix 1Segmentes im fibrillären humPrP23-159 gegenüben proteolytischem Verdau durch die Proteinase $\mathrm{K}$. Im infektiösen $\mathrm{PrP}^{\mathrm{Sc}}$ geht man davon aus, dass alle $\beta$-Faltblatt-haltigen Strukturen durch ihre kompakte Struktur partiell resistent gegenüber proteolytischem Abbau durch die Proteinase $\mathrm{K}$ werden. Der im $\mathrm{PrP}^{\mathrm{Sc}}$ unstrukturierte Bereich 23-89 ist dagegen nicht vor einem Angriff durch Proteinase K geschützt (Rogers et al., 1993, Flechsig et al., 2000). Insofern sollte auch die Helix 1 im fibrillären humPrP23-159 eine partielle Resistenz gegenüber Proteinase $\mathrm{K}$ aufweisen, falls eine Umfaltung des Helix 1-Segmentes in ein $\beta$ Faltblatt stattgefunden hat. Andernfalls würde das Helix 1-Segment durch die Proteinase K abgedaut werden.

In den fibrillären Aggregaten von humPrP23-144 und humPrP23-159 wurde ein proteolytischer Verdau durch die Proteinase $\mathrm{K}$ durchgeführt, wobei die Grösse der entstandenen Fragmente durch eine SDS-PAGE analysiert wurde. Die Resistenz bestimmter Regionen des aggregierten Prionproteins gegenüber proteolytischem Abbau wurde durch ein Epitop-Mapping im Western Blot überprüft (Abb. 16).

Aufgrund eines starken Schmier-Effektes der Proteinase K verdauten Prionproteinfragmente in der klassischen SDS-PAGE (Lämmli et al., 1970) wurde ein spezielles SDS-PAGE System benutzt, das zur Auftrennung von $A \beta$-Peptiden mit nur einer Aminosäure Unterschied entwickelt wurde (Wiltfang et al., 2001). Fibrilläre Aggregate von humPrP23-144 und 
humPrP23-159 waren selbst bei Proteinase K Konzentrationen von $100 \mu \mathrm{g} / \mathrm{ml}$ und einer Verdauzeit von $1 \mathrm{~h}$ noch resistent gegenüber proteolytischem Abbau (Abb. 16 A). Das Migrationsverhalten des Proteinase K resistenten Fragmentes von fibrillärem humPrP23-144 in der SDS-PAGE entsprach etwa dem eines $7 \mathrm{kDa}$-Fragmentes und verhielt sich damit identisch zur Literatur (Ghetti et al., 1996). Durch Vergleich mit den Markerproteinen konnte die Grösse des Proteinase K verdauten Fragmentes von fibrillärem humPrP23-159 auf $\sim 8$ $\mathrm{kDa}$ abgeschätzt werden. Eine Erklärung für den Grössenunterschied zwischen beiden Proteinase $\mathrm{K}$ verdauten Fragmenten könnte in einer unterschiedlichen N- oder C-terminalen Spaltstelle der Proteinase $\mathrm{K}$ in den fibrillären Prionproteinen analog $\mathrm{zu}$ den beiden $\operatorname{PrP}^{\mathrm{Sc}}$ Spaltungstypen des infektiösen Erregers ( $\operatorname{PrP}^{\mathrm{Sc}}-\mathrm{Typ} 1$ und $\operatorname{PrP}^{\mathrm{Sc}}-\mathrm{Typ} 2$, Kapitel 1.3.3.) begründet sein. Fibrilläres humPrP23-159 könnte demnach eine $\operatorname{PrP}^{\mathrm{Sc}}$-Typ-1 Spaltstelle und fibrilläres humPrP23-144 eine $\mathrm{PrP}^{\mathrm{Sc}}$-Typ-2 Spaltstelle aufweisen.

Um das zu überprüfen wurden Western Blots der Proteinase K resistenten Fragmente von aggregiertem humPrP23-144 und humPrP23-159 mit den Antikörpern 3B5 (Abb. 16 E) und 1E4 (Abb. 16 C) durchgeführt. Der Antikörper 3B5 erkennt die Aminosäuren 59-89 im Prionprotein (PrP $\mathrm{P}^{\mathrm{Sc}}$-Typ 1), während der 1E4-Antikörper an das Motiv 98-109 ( $\mathrm{PrP}^{\mathrm{Sc}}$-Typ 2) bindet.

Beide Proteinase K verdauten Fragmente wurden vom 3B5-Antikörper nicht erkannt, was einen $\operatorname{PrP}^{\mathrm{Sc}}$-Typ 1 ausschloss. Der 1E4-Antikörper erkannte dagegen beide Proteinase $\mathrm{K}$ verdauten Fragmente im Western Blot (Abb. $16 \mathrm{C}$ ), was einem $\mathrm{PrP}^{\mathrm{Sc}}$-Typ2 entsprechen könnte. Eine Edman-Sequenzierung der Proteinase K verdauten Aggregate von humPrP23144 und humPrP23-159 konnte diese Annahme bestätigen (Abb. 16 B). Beide Fragmente starteten mit der Aminosäure 97, was exakt dem $\mathrm{PrP}^{\mathrm{Sc}}$-Typ2 entsprach. Infolge dessen sollte der beobachtete Grössenunterschied zwischen den Proteinase K verdauten Fragmenten durch einen C-terminalen Grössenunterschied zu erklären sein, welcher der Helix 1 entsprechen könnte. Zur Überprüfung dieser Hypothese wurden spezifisch gegen das Helix 1-Motiv gerichtete monoklonale Antikörper 6H4 (Motiv: 144-152) und 12F10 (Motiv: 144-152) im Western Blot verwendet (Abb. 16 D). Monomeres humPrP23-159 aber nicht die Proteinase K verdauten Prionproteinfragmente von fibrillärem humPrP23-159 konnten durch die 


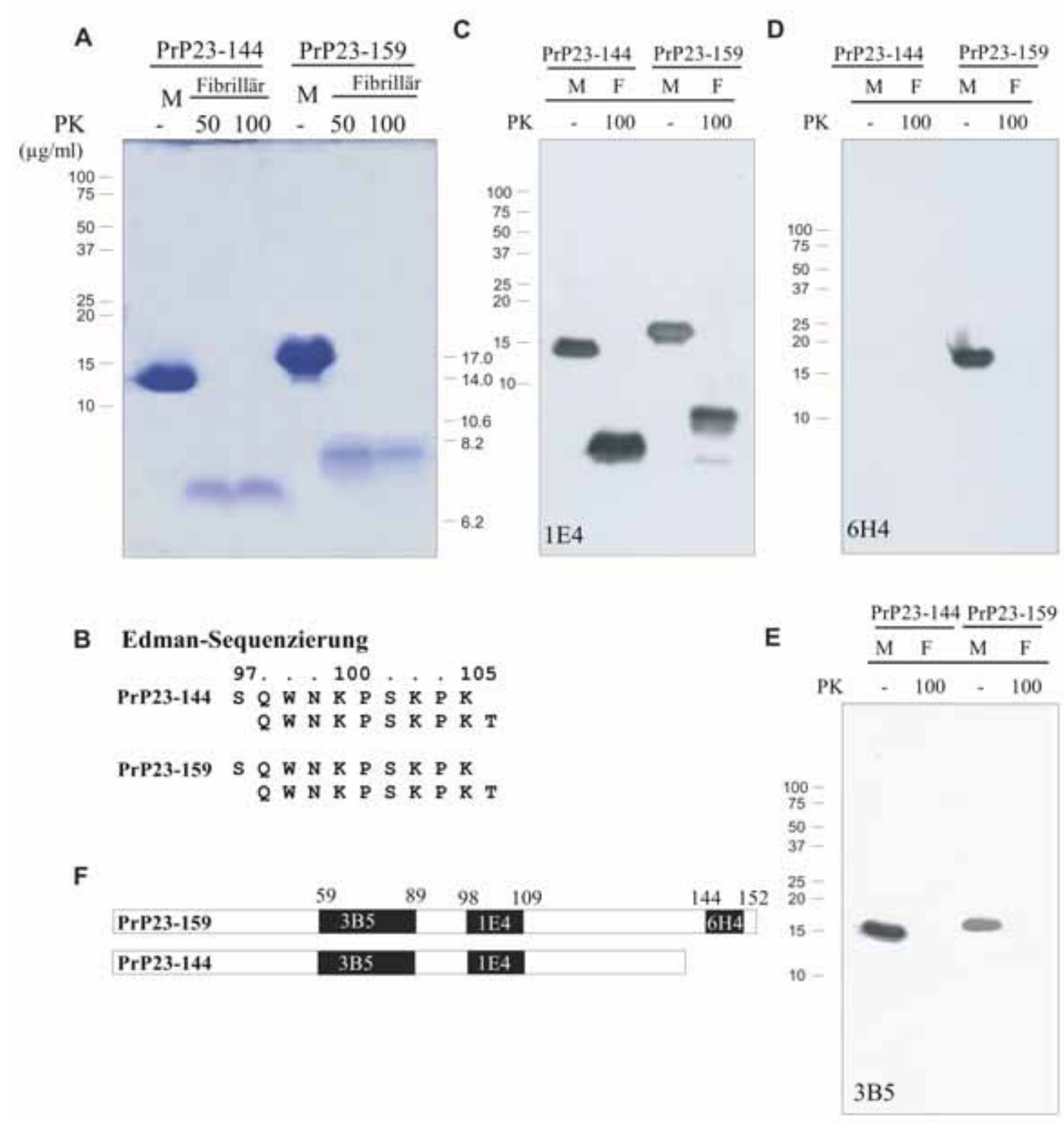

Abb. 16: Helix 1 in fibrillärem humPrP23-159 ist nicht Proteinase $\mathbf{K}$ resistent. (A) SDS-PAGE von monomerem (M) und Proteinase K verdautem fibrillärem (Fibrillär) humPrP23-144 und humPrP23-159 bei Proteinase K Konzentrationen von $50 \mu \mathrm{g} / \mathrm{ml}$ und $100 \mu \mathrm{g} / \mathrm{ml}$. Es wurden pro Spur je $5 \mu \mathrm{g}$ der monomeren Proteine und je $30 \mu \mathrm{g}$ der Proteinase K verdauten fibrillären Prionaggregate aufgetragen. (B) EdmanSequenzierung von fibrillärem humPrP23-144 und fibrillärem humPrP23-159 nach Proteinase K-Verdau (1 h, 37 ${ }^{\circ} \mathrm{C}, 100 \mu \mathrm{g} / \mathrm{ml}$ Proteinase K). Die N-terminale Startsequenz der PK resistenten Fragmente von humPrP23-159 und humPrP23-144 war jeweils identisch und startete mit Aminosäure 97 bzw. 98. (C) Western Blot von monomerem (M) und fibrillärem (F) Proteinase K verdautem (100 $\mu \mathrm{g} / \mathrm{ml}$ Proteinase K, $\left.37{ }^{\circ} \mathrm{C}, 1 \mathrm{~h}\right)$ humPrP23144 und humPrP23-159 mit dem Antikörper 1E4. (D) Western Blot von monomerem (M) und fibrillärem (F) Proteinase K verdautem humPrP23-159 und humPrP23-144 mit dem Antikörper 6H4. (E) Western Blot von monomerem (M) und fibrillärem (F) Proteinase $\mathrm{K}$ verdautem humPrP23-144 und humPrP23-159 mit dem Antikörper 3B5. (F) Schematische Übersicht über die Antikörperbindungsstellen in humPrP23-159 und humPrP23-144 durch die verwendeten Antikörper. 
Antikörper 6H4 und 12F10 detektiert werden. Die Helix 1 war demnach nicht Proteinase K resistent. Eine Konversion der Helix 1 in ein $\beta$-Faltblatt erschien damit sehr unwahrscheinlich.

Die unterschiedliche Grösse der beiden Proteinase K verdauten Fragmente von fibrillärem humPrP23-144 und humPrP23-159 in der SDS-PAGE (Abb. 16 A) könnte demnach das Resultat einer C-terminalen Trunkierung von nur 1-2 Aminosäuren sein, was bereits bei A $\beta$ Fragmenten mit ähnlich differierendem Migrationsverhalten gezeigt werden konnte (Wiltfang et al., 2001).

\subsubsection{FTIR-spektroskopische Untersuchung der fibrillären Aggregate von humPrP23-159 und humPrP23-144}

Da die fehlende Proteinase K Resistenz der Helix 1 im fibrillären Prionprotein gegen eine Umfaltung des Segmentes in ein $\beta$-Faltblatt sprach, wurde eine zweite Methode zur Überprüfung der Faltung des Helix 1-Segmentes in fibrillärem humPrP23-159 herangezogen. Eine quantitative Analyse der FTIR-Spektren (Kapitel 3.2.6.2.) von unverdauten fibrillären Aggregaten von humPrP23-159 und humPrP23-144 sollte Aufschluss darüber geben, ob die aus neun Aminosäuren bestehende Helix 1 (Abb. 9) in humPrP23-159 komplett in ein $\beta$ Faltblatt umgewandelt worden ist (Abb. 17, Tabelle 15).

\subsubsection{Zuordnung der Absorptionsbanden zu spezifischen Strukturelementen in humPrP23-159 und humPrP23-144}

Eine qualitative Zuordnung von FTIR-Signalen zu spezifischen Sekundärstrukturelementen im rekombinantem Prionprotein ist bereits mehrfach durchgeführt worden (Sokolowski et al., 2003; Torrent et al., 2004; Cordeiro et al., 2005).

Die qualitative Analyse der FTIR-Spektren (Abb. 17, Tabelle 15) resultierte für humPrP23144 und humPrP23-159 in Absorptionsbanden bei Wellenzahlen von $1627 \mathrm{~cm}^{-1}, 1640 \mathrm{~cm}^{-1}$, $1652 \mathrm{~cm}^{-1}$ und $1664 \mathrm{~cm}^{-1}$, die nahezu identisch $\mathrm{zu}$ Literatur beschriebenen Daten von fibrillärem humPrP23-144 waren (Tabelle 15) (Kundu et al., 2003). Absorptionsbanden 
zwischen Wellenzahlen von $1611 \mathrm{~cm}^{-1}$ bis $1620 \mathrm{~cm}^{-1}$ in der Amid I-Region sind charakteristisch für $\beta$-Faltblätter in amyloiden Fibrillen, während Absorptionsbanden zwischen Wellenzahlen von $1630 \mathrm{~cm}^{-1}$ bis $1643 \mathrm{~cm}^{-1}$ charakteristisch für „native“ $\beta$ Faltblätter sind (Zandomeneghi et al., 2004). Insofern zeigten die Absorptionsbanden (Abb. 17 A-H, Tabelle 15) zwischen $1615 \mathrm{~cm}^{-1}$ und $1627 \mathrm{~cm}^{-1}$ die Anwesenheit von amyloiden $\beta$ Faltblättern in den fibrillären Proteinen an. Eine starke Absorptionsbande bei einer Wellenzahl von $1640 \mathrm{~cm}^{-1}$ wurde random coil bei $1642 \mathrm{~cm}^{-1}$ zugeordnet (Torrent et al., 2004, Cordeiro et al., 2005). Da die Region 23-96 im monomeren Prionprotein vollständig unstrukturiert ist und auch in fibrillären Prionproteinfragmenten Proteinase K-sensitiv war (Abb. 16), sollte diese Region auch im aggregierten Prionprotein noch einen sehr hohen random coil-Gehalt aufweisen, der in Bezug zur Länge dieser Region mehr als $50 \%$ der Proteinsequenz in humPrP23-159 und humPrP23-144 ausmachte.

Ein Signal bei einer Wellenzahl von $1652 \mathrm{~cm}^{-1}$ wurde ebenfalls random coil zugeordnet, das eigentlich charakteristisch für eine $\alpha$-Helix ist (Cordeiro et al., 2005). Allerdings gab es in den FTIR-Spektren von monomerem humPrP23-159 und monomerem humPrP23-144 (Daten nicht abgebildet) jeweils keine Evidenz für die Anwesenheit einer $\alpha$-Helix. Insofern wurde die Bildung $\alpha$-helikaler Strukturen in den fibrillären Proteinen als sehr unwahrscheinlich angesehen. Die Summe der Absorptionsbanden für random coils bei $1640 \mathrm{~cm}^{-1}$ und $1652 \mathrm{~cm}^{-1}$ betrug $42 \%$ für humPrP23-144 bzw. $46 \%$ für humPrP23-159 (Tabelle 15), womit auch die fibrillären Proteine noch einen sehr hohen unstrukturierten Anteil aufwiesen.

Die bei Wellenzahlen von $1664 \mathrm{~cm}^{-1}$ und $1675 \mathrm{~cm}^{-1}$ berechneten Absorptionsbanden sind charakteristisch für Loops und Turns im Prionprotein (Bocharova et al., 2005a). Eine bei 1684 $\mathrm{cm}^{-1}$ absorbierende Molekülschwingung wurde einer hochfrequenten Komponente eines amyloiden $\beta$-Faltblattes zugeordnet (Cordeiro et al., 2005).

\subsubsection{Quantitative Analyse der FTIR-Spektren von fibrillärem humPrP23-159 und fibrillärem humPrP23-144}

Die quantitative Analyse der FTIR-Daten wurde vor allem deshalb durchgeführt, um eine Aussage über die Sekundärstruktur des Helix 1-Segmentes in fibrillärem humPrP23-159 treffen zu können. Dazu wurden beide Prionproteinfragmente humPrP23-144 und humPrP23159 formal in verschiedene Sekundärstrukturbereiche eingeteilt, denen aus den FTIR-Daten 
eine bestimmte Anzahl an Aminosäuren zugeteilt wurde. Wenn die Helix 1 aus neun Aminosäuren oder das ganze Helix 1-Segment aus 15 Aminosäuren, das den Unterschied zwischen humPrP23-144 und humPrP23-159 ausmacht, in ein $\beta$-Faltblatt umgewandelt worden wäre, sollte in beiden Fällen eine Erhöhung des $\beta$-Faltblatt-Gehaltes im Vergleich zu humPrP23-144 zu erwarten sein. Aus der quantitativen Analyse der FTIR-Daten von fibrillärem humPrP23-144 wurde ein Gesamtgehalt an $\beta$-Faltblatt-Struktur von $34.7 \%$ ermittelt (Tabelle 15, Abb. 17 A), was umgerechnet 42 Aminosäuren entspricht. Wenn zusätzlich zu diesen 42 Aminosäuren in humPrP23-159 weitere neun Aminosäuren aus der Helix 1 bzw. fünfzehn Aminosäuren des ganzen Helix 1-Segmentes in $\beta$-Faltblatt-Struktur umgewandelt worden wären, sollte ein $\beta$-Faltblatt-Gehalt von $37.3 \%$ bzw. $41.7 \%$ in fibrillärem humPrP23-159 zu erwarten sein.

Tatsächlich konnte aber nur ein $\beta$-Faltblatt-Gehalt von $30.7 \%$ in humPrP23-159 ermittelt werden, was einer Beteiligung von ebenfalls 42 Aminosäuren an $\beta$-Faltblatt-Strukturen entspricht (Tabelle 15, Abb. 17 E). Damit war kein Unterschied an $\beta$-Faltblatt-Struktur zwischen humPrP23-144 und humPrP23-159 zu detektieren und eine Umfaltung der Helix 1 in ein $\beta$-Faltblatt war damit sehr unwahrscheinlich.. Umgekehrt konnten aber annähernd 63 Aminosäuren in humPrP23-159 und nur 51 Aminosäuren in humPrP23-144 random coil zugeordnet werden. Die resultierende Differenz aus zwölf Aminosäuren stimmt gut mit der aus neun Aminosäuren bestehenden Helix 1 bzw. dem Helix 1-Segment aus fünfzehn Aminosäuren überein, was als zusätzliches Indiz gewertet werden kann, dass die Helix 1 nicht in ein $\beta$-Faltblatt konvertiert worden ist.

Interessanterweise variierten die $\beta$-Faltblattgehalte von fibrillärem humPrP23-144 stark in Abhängigkeit zum eingesetzten Aggregationskeim. Fibrilläres humPrP23-144 war bezogen auf die Induktion von amyloiden $\beta$-Faltblättern in monomerem humPrP23-144 der einzige effektive Aggregationskeim, während fibrilläres humPrP23-159 und fibrilläres humPrP106$126 \mathrm{zu}$ keiner Zunahme des amyloiden $\beta$-Faltblattgehaltes verglichen mit der Aggregationen ohne Aggregationskeim führten. Dieser Effekt konnte mit monomerem humPrP23-159 nicht gezeigt werden. Für die Plausibilität der FTIR-Daten spricht, dass die Zunahme des $\beta$ Faltblattgehaltes stets mit einer Abnahme des random coil-Gehaltes korrelierte.

Fibrilläres humPrP106-126 konnte als Aggregationskeim keine „native“ $\beta$-Faltblattstruktur in humPrP23-144 erzeugen (Abb, 17 C). Das Signal für amyloide $\beta$-Faltblattstruktur“ bei 1620 $\mathrm{cm}^{-1}$ war dagegen deutlich erhöht, was auf andere Eigenschaften der so entstandenen Fibrillen hindeutete. 

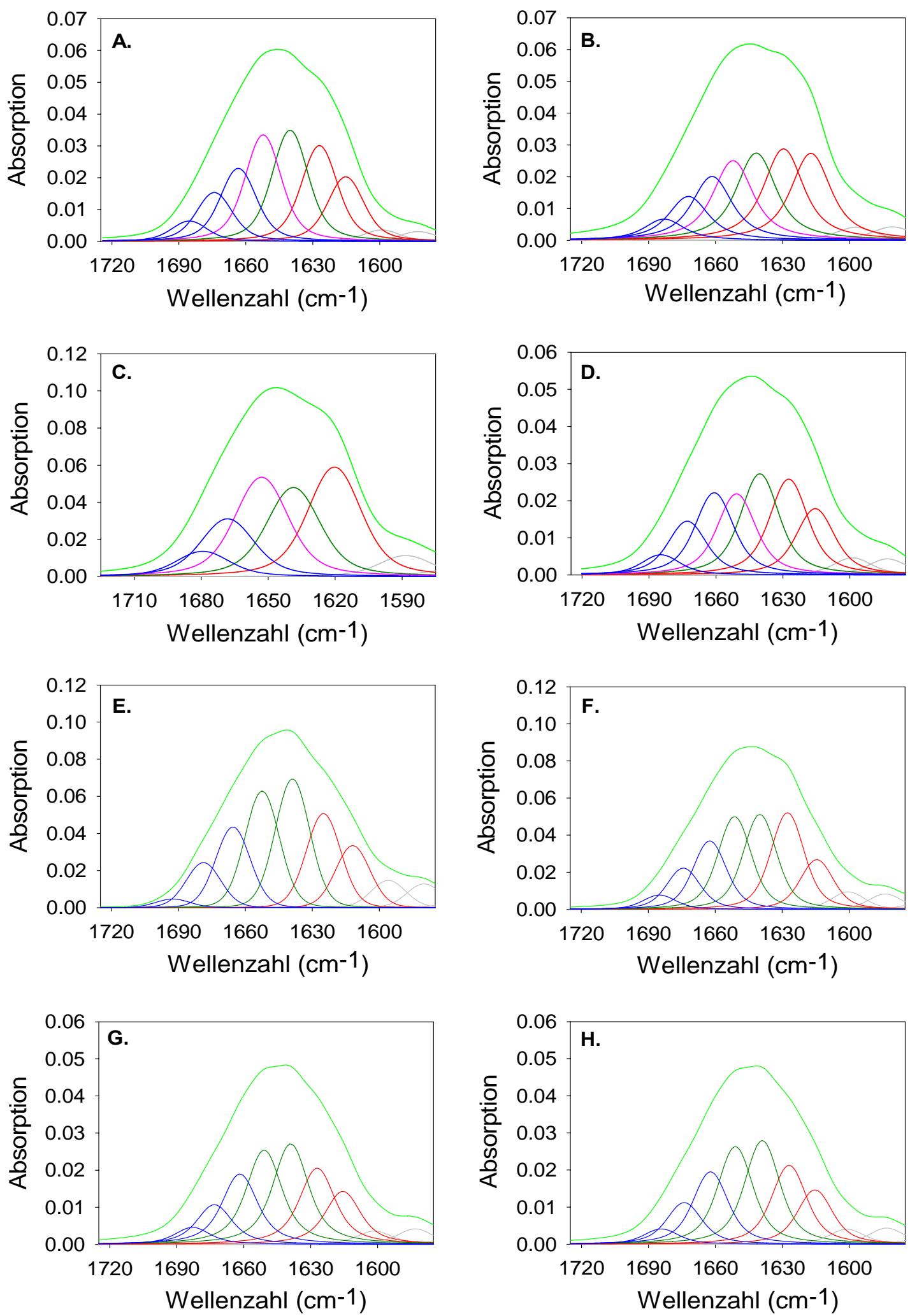

Abb. 17: FTIR-Spektroskopie von fibrillärem humPrP23-144 (A, B, C, D) und fibrillärem humPrP23-159

(E, F, G, H). Monomeres humPrP23-159, monomeres humPrP23-144 und Natriumhydrogenphosphat, pD 6.5 
wurden je dreimal aus $\mathrm{D}_{2} \mathrm{O}$ lyophyllisiert. Die Proteinaggregation erfolgte in $\mathrm{D}_{2} \mathrm{O}$ mit $50 \mathrm{mM}$ deuteriertem Natriumphosphat bei einem pD-Wert von 6.5 und $340 \mu \mathrm{M}$ Proteinkonzentrationen innerhalb von 3 Wochen bei $25^{\circ} \mathrm{C}$. Fibrilläres humPrP23-144 (A, B, C, D) und fibrilläres humPrP23-159 (E, F, G, H) wurden durch Analyse der Amide I-Region (1600-1700 $\mathrm{cm}^{-1}$ ) in $\mathrm{D}_{2} \mathrm{O}$ mittels FTIR-Spektroskopie untersucht. Die erhaltenen Rohdaten (hellgrüne übergeordnete Linie) wurden durch das Programm „PeakFit“ in einzelne unter den Rohdaten abgebildete Absorptionsbanden (Peaks) (dunkelgrüne, rote, blaue und graue Linien) untergliedert. Die Aggreagtion von humPrP23-159 in (E) und von humPrP23-144 in (A) erfolgte ohne Zugabe von Aggregationskeimen. Jeweils 1\% (v/v) fibrilläres humPrP23-144 (B, F), fibrilläres humPrP106-126 (C, $G$ ) oder fibrilläres humPrP23-159 $(D, H)$ wurden als Aggregationskeim zur den monomeren Proteinen gegeben. Die verwendeten Aggregationskeime wurden eebenfalls in $\mathrm{D}_{2} \mathrm{O}$ hergestellt. Die Zuordnung der Absorptionsbanden zu bestimmten Sekundärstrukturelementen wurde durch Verwendung unterschiedlicher Farben verdeutlicht: $\beta$ Faltblätter wurden in rot, random coils in grün, Helices bzw. „helixartige“ Strukturen in rosa, Loops und Turns in blau, eine hochfrequente Schwingungen eines amyloiden $\beta$-Faltblattes in orange und Aminosäurenseitenketten in grau dargestellt.

Elektronenmikroskopische Daten liessen dagegen keine unterschiedliche Morphologie der Proteinfibrillen im Vergleich zu fibrillären Strukturen von humPrP23-144 erkennen, die ohne zugeführten Aggregationskeim entstanden sind.

Das wichtigste Resultat aus den FTIR-spektroskopischen Daten von fibrillärem humPrP23159 und fibrillärem humPrP23-144 war, dass unter der Annahme einer vergleichbaren Struktur im fibrillären humPrP23-144 und fibrillärem humPrP23-159 keine der 9 Aminosäuren der Helix 1 in ein $\beta$-Faltblatt konvertiert worden sein sollte, was sehr gut mit der vergleichbaren Zunahme des random coil-Gehaltes in humPrP23-159 im Vergleich zu humPrP23-144 korrelierte. 
Tabelle 15: Quantitative Analyse der FTIR-Spektren von fibrillärem Prionprotein

\begin{tabular}{|c|c|c|c|c|c|}
\hline \multirow[b]{3}{*}{$\begin{array}{l}\text { Sekundärstruktur- } \\
\text { element }\end{array}$} & \multirow[b]{3}{*}{ Wellenzahl $\left(\mathrm{cm}^{-1}\right)$} & \multicolumn{4}{|c|}{ Prozentualer Anteil des Sekundärstrukturelementes } \\
\hline & & \multirow[t]{2}{*}{ ungeseedet } & \multicolumn{3}{|c|}{ geseedet mit } \\
\hline & & & $\operatorname{PrP}_{23-159}$ & $\operatorname{PrP}_{23^{-} 144}$ & $\operatorname{PrP}_{106-126}$ \\
\hline \multicolumn{6}{|c|}{ humPrP $23-159$} \\
\hline Amyloides $\beta$-Faltblatt (LF) & 1615 & 11.6 & 11.8 & 10.8 & 11.7 \\
\hline „natives“ $\beta$-Faltblatt & 1627 & 17.5 & 17.1 & 21.1 & 17.0 \\
\hline random coil & 1640 & 24.1 & 22.4 & 20.7 & 22.4 \\
\hline$\alpha$-Helix* & 1652 & 21.8 & 21.1 & 20.3 & 20.9 \\
\hline Turn/Loop & 1664 & 15.1 & 15.6 & 15.0 & 15.6 \\
\hline Turn/Loop & 1675 & 8.4 & 9.0 & 9.0 & 8.7 \\
\hline Amyloides $\beta$-Faltblatt (HF) & 1684 & 1.6 & 3.2 & 3.1 & 3.7 \\
\hline \multicolumn{6}{|c|}{ humPrP $23-144$} \\
\hline Amyloides $\beta$-Faltblatt (LF) & 1615 & 12.4 & 13.1 & 18.1 & 28.8 \\
\hline „natives“ $\beta$-Faltblatt & 1627 & 18.4 & 19.0 & 19.1 & $\left(1620 \mathrm{~cm}^{-1}\right)$ \\
\hline random coil & 1640 & 21.4 & 20.0 & 17.9 & 23.4 \\
\hline$\alpha$-Helix* & 1652 & 20.5 & 16.4 & 16.7 & 26.1 \\
\hline Turn/Loop & 1664 & 14.0 & 16.7 & 14.1 & 15.1 \\
\hline Turn/Loop & 1675 & 9.4 & 10.7 & 9.5 & - \\
\hline Amyloides $\beta$-Faltblatt (HF) & 1684 & 3.9 & 4.0 & 4.5 & 6.5 \\
\hline
\end{tabular}

*die Helix-artige Struktur wurde hauptsächlich dem N-terminus des Prionproteins und damit einem random coil zugeordnet;

(LF) niederfrequente Schwingung, (HF) hochfrequente Schwingung in amyloiden $\beta$-Faltblättern 


\subsection{Einfluss des pH-Wertes auf die Aggregation von humPrP23-144 und humPrP23-159}

In den in dieser Arbeit durchgeführten Aggregationsstudien mit rekombinanten Prionproteinfragmenten und bei Kundu et al. (2003) wurde bei einem pH-Wert von 6.5 unter nicht-denaturierenden Bedingungen gearbeitet. Die Struktur der Aggregate war jeweils fibrillärer Natur.

Unter denaturierenden Bedingungen wurden dagegen bei sauren $\mathrm{pH}-\mathrm{Werten}$ von 4.0-5.0 fibrilläre und amorphe Aggregate des Prionproteins detektiert, während bei neutralen $\mathrm{pH}-$ Werten keine bzw. eine stark verlangsamte Aggregation beobachtet wurde (Morillas et al., 2001; Swietnicki et al., 2000).

Um diesen Widerspruch aufzuklären wurde die pH-Abhängigkeit der Aggregation von humPrP23-144 und humPrP23-159 innerhalb eines $\mathrm{pH}$-Bereiches von 4.0-8.1 unter physiologischen, nicht-denaturierenden Bedingungen untersucht.

Bei der Aggregation der Prionproteine humPrP23-144 und humPrP23-159 zeigte sich in verschiedenen Puffersystemen mit unterschiedlichen $\mathrm{pH}$-Werten, dass beide Proteine zwischen $\mathrm{pH}-$ Werten von 4.0-5.0 keine Aggregationsneigung unter physiologischen, nicht denaturierenden Bedingungen aufweisen. Erst bei einem pH-Wert von 6.2 konnte für beide Proteine eine geringe Erhöhung der Absorptionswerte $\left(\Delta \mathrm{A}_{400}\right)$ unter Ausbildung von fibrillären Strukturen gemessen werden (Abb. 18 C + F; Abb. 19 C + F, Abb. 21 A+B). Unter neutralen Bedingungen bei $\mathrm{pH} 7.2$ zeigte humPrP23-159 nach vergleichbarer Zeit eine deutliche verstärkte Absorption $\left(\Delta \mathrm{A}_{400}\right)$ im Vergleich zur Aggregation bei pH 6.2. Nach 16 Tagen konnten bei pH-Werten von 7.2 und 8.1 in der stationären Phase der Aggregation von humPrP23-159 ähnliche Absorptionswerte von 0.11 bzw. 0.13 gemessen werden (Abb. $19 \mathrm{D}$ + E). Im Vergleich dazu wurde bei humPrP23-144 nach 16 Tagen in der stationären Phase der Aggregation ein Absorptionswert $\left(\Delta \mathrm{A}_{400}\right)$ von 0.14 bei einem $\mathrm{pH}$-Wert von 8.1 detektiert (Abb. 18 E), während die Absorptionswerte bei pH-Werten von 7.2 und 6.2 nach 16 Tagen noch um einen Faktor 3.2 bzw. 3.8 reduziert waren (Abb. 18 D bzw. C). 

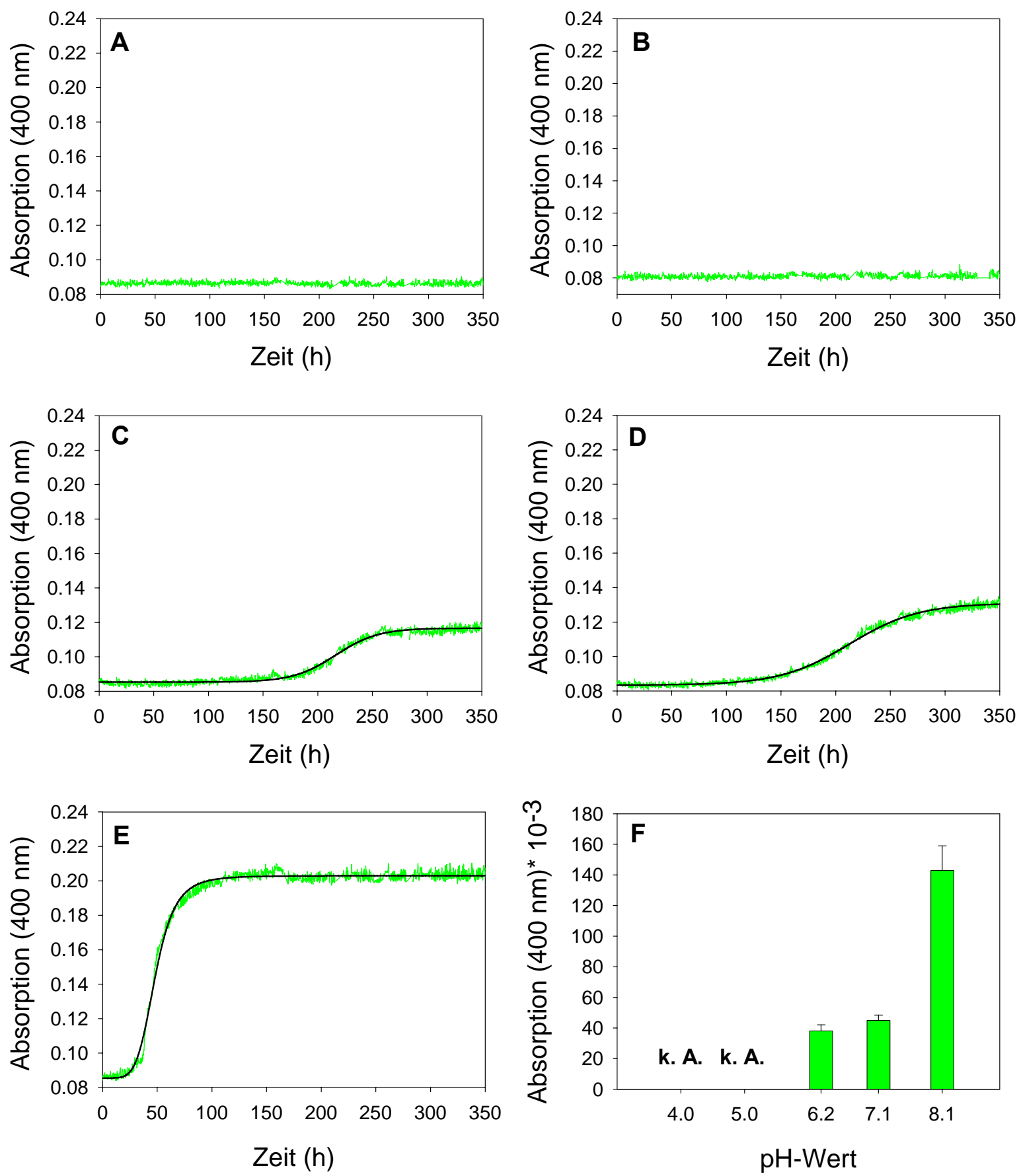

Abb. 18: Bestimmung der pH-Abhängigkeit der Aggregation von humPrP23-144. Die Geschwindigkeit der Aggregation von humPrP23-144 wurde kontinuierlich alle 10 Minuten durch Messung der Absorption bei 400 $\mathrm{nm}$ bei $30^{\circ} \mathrm{C}$ im Titerplattenlesegerät Tecan Safire bestimmt. Die Proteinkonzentration betrug jeweils $200 \mu \mathrm{M}$. Alle Versuche wurden dreifach durchgeführt und die gemittelten Werte abgebildet. Als Puffersubstanzen dienten in (A) $50 \mathrm{mM}$ Natriumacetat, $\mathrm{pH} 4.0$; in (B) $50 \mathrm{mM}$ Natriumacetat, $\mathrm{pH} 5.0$; in (C) $50 \mathrm{mM}$ MES pH 6.2; in (D) $50 \mathrm{mM}$ MOPS pH 7.2 und in (E) $50 \mathrm{mM}$ Tris pH 8.1. Alle Lösungen enthielten $0.1 \%$ (w/v) Natriumazid. Ein Vergleich der Endpunkte der Absorption von humPrP23-144 bei unterschiedlichen pH-Werten ist in (F) abgebildet. k. A. = keine detektierbaren Aggregate. 

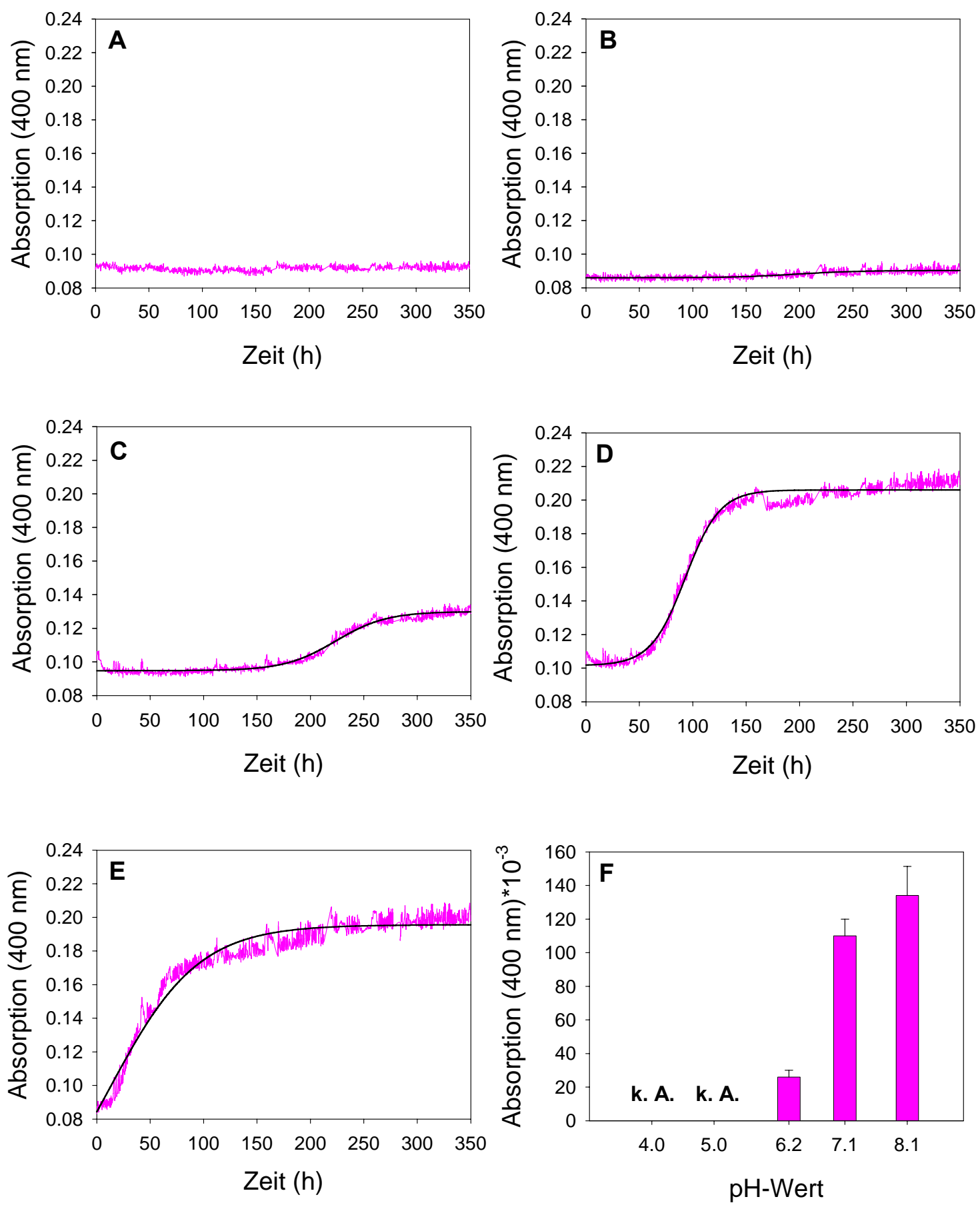

Abb. 19: Bestimmung der pH-Abhängigkeit der Aggregation von humPrP23-159 (pink). Die Geschwindigkeit der Aggregation von humPrP23-159 wurde kontinuierlich alle 10 Minuten durch Messung der Absorption bei $400 \mathrm{~nm}$ bei $30^{\circ} \mathrm{C}$ im Titerplattenlesegerät Tecan Safire bestimmt. Die Versuche wurden dreifach durchgeführt und die gemittelten Werte abgebildet. Die Proteinkonzentrationen betrugen jeweils $200 \mu \mathrm{M}$. Als Puffersubstanzen dienten in (A) $50 \mathrm{mM}$ Natriumacetat, $\mathrm{pH} 4.0$; in (B) $50 \mathrm{mM}$ Natriumacetat, $\mathrm{pH}$ 5.0; in (C) 50 $\mathrm{mM}$ MES pH 6.2; in (D) $50 \mathrm{mM}$ MOPS pH 7.2; in (E) $50 \mathrm{mM}$ Tris pH 8.1. Alle Lösungen enthielten $0.1 \%$ (w/v) Natriumazid Ein Vergleich der Endpunkte der Absorption von humPrP23-159 bei unterschiedlichen pHWerten ist in (F) abgebildet. k. A. = keine detektierbaren Aggregate. 


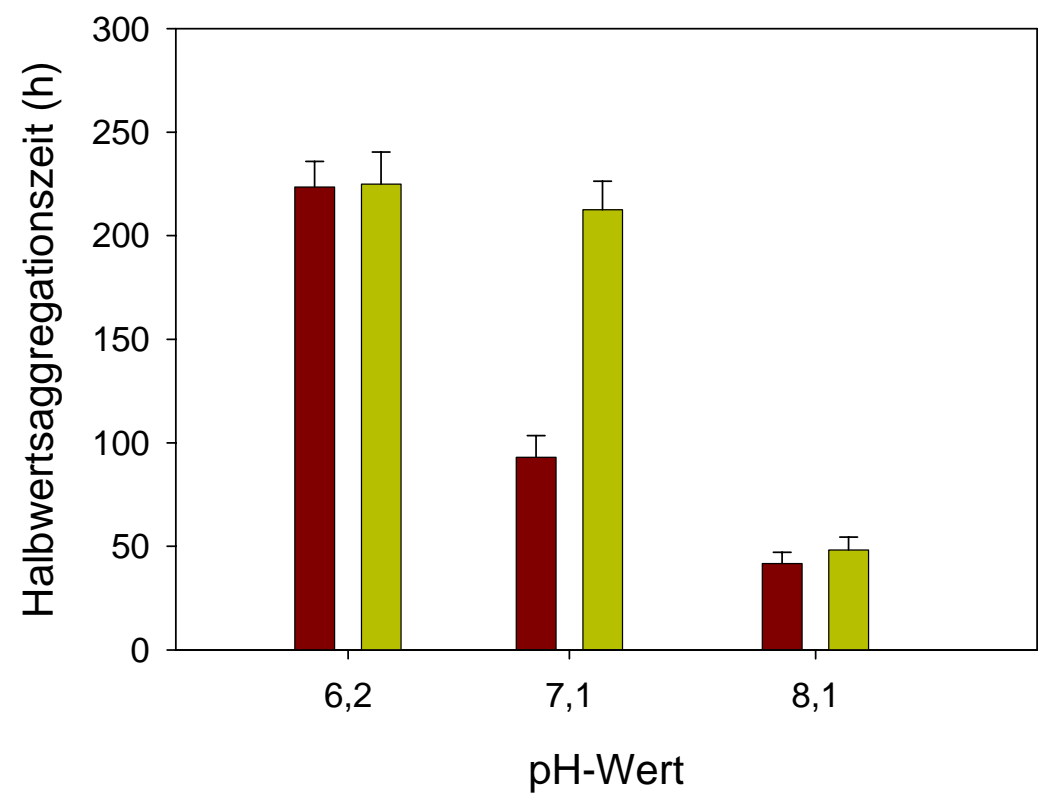

Abb. 20: Abhängigkeit der Halbwertsaggregationszeiten vom pH-Wert: humPrP23-159 (braune Balken) und humPrP23-144 (grüne Balken) aggregieren analog zur Veränderung der Absorption bei unterschiedlichen pHWerten unterschiedlich schnell bei neutralem $\mathrm{pH}-$ Wert.

Interessanterweise korrelierten die Veränderungen der Absorptionswerte $\left(\mathrm{A}_{400 \mathrm{~nm}}\right)(\mathrm{Abb} .18 \mathrm{~F}$ und $19 \mathrm{~F}$ ) bei der Aggregation von humPrP23-144 und humPrP23-159 bei verschiedenen $\mathrm{pH}$ Werten mit den entsprechenden Halbwertsaggregationszeiten (Abb. 20).

So konnte eine deutliche Veränderung der Halbwertsaggregationszeit um einen Faktor 4.4 bei humPrP23-144 analog zur stärksten Veränderung der Absorptionswerte erst beim Übergang des $\mathrm{pH}$-Wertes von 7.2 auf 8.1 gemessen werden, während sich die Halbwertsaggregationszeiten von humPrP23-159 kontinuierlich bei beiden pH-Änderungen um einen Faktor 2.3 voneinander unterschieden.

Der wesentliche Unterschied der pH-Abhängigkeit der Aggregation von humPrP23-144 und humPrP23-159 war, dass bereits ein neutraler pH-Wert einen deutlichen Beschleunigungseffekt auf die Aggregation von humPrP23-159 verglichen mit der Aggregation bei pH 6.2 ausübte, während erst ein $\mathrm{pH}$-Wert von 8.1 einen vergleichbaren Effekt auf die Aggregation von humPrP23-144 hatte (Abb. 20). 


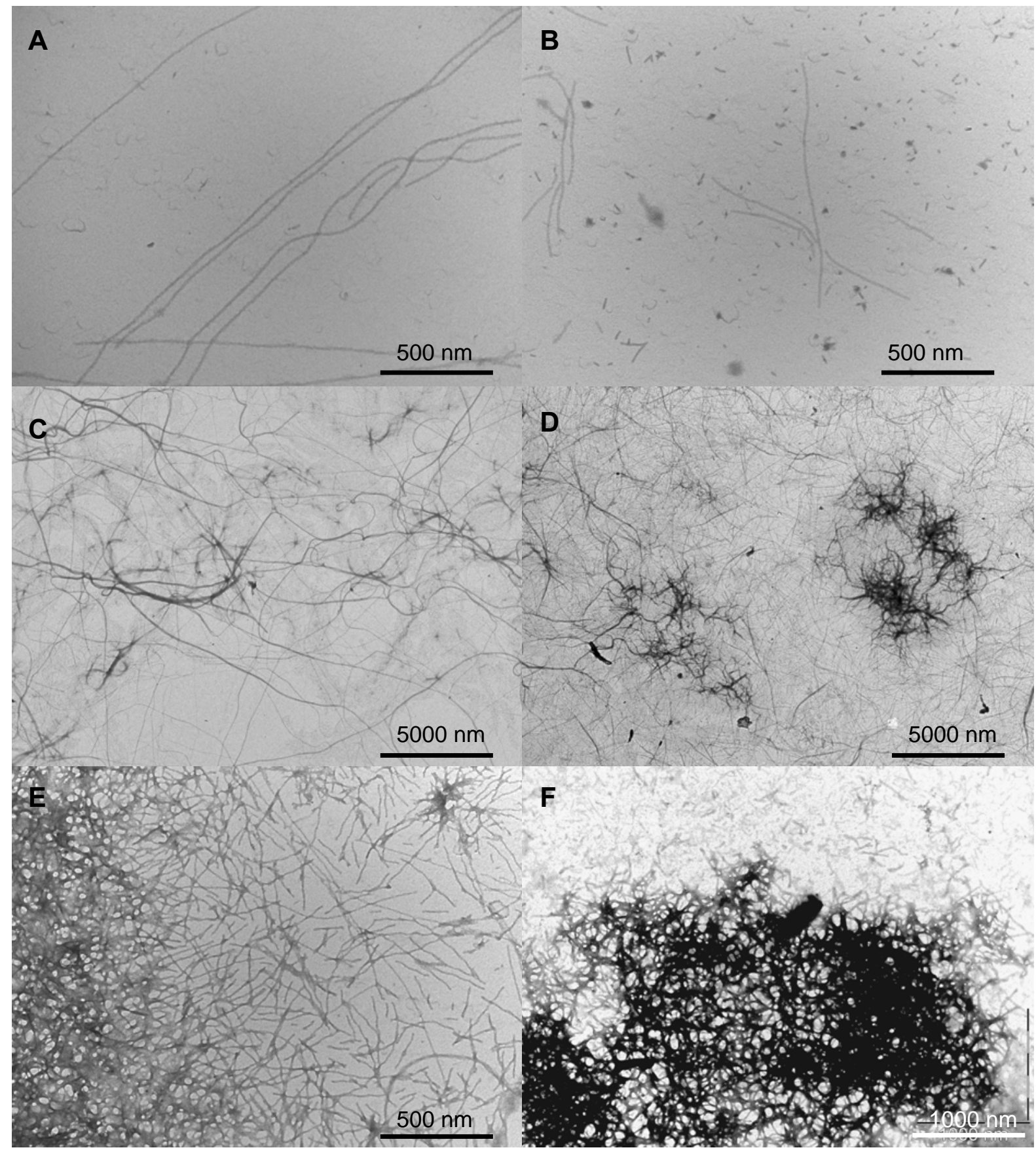

Abb. 21: Elektronenmikroskopische Darstellung von aggregiertem humPrP23-159 und humPrP23-144 bei unterschiedlichen pH-Werten. humPrP23-144 (A, C, E) und humPrP23-159 (B, D, F) wurden in einer Konzentration von je $200 \mu \mathrm{M}$ für 16 Tage in unterschiedlichen Puffer-Systemen bei verschiedenen pH-Werten in einer Helma 96-well Quarzplatte in einem Reaktionsvolumen von $250 \mu$ l bei $30{ }^{\circ} \mathrm{C}$ inkubiert. Alle Lösungen enthielten $0.1 \%(\mathrm{w} / \mathrm{v})$ Natriumazid. Als Puffersystem wurden verwendet: A+B: $50 \mathrm{mM} \mathrm{MES,} \mathrm{pH} \mathrm{6.2;} \mathrm{C+D:} 50$ mM MOPS, pH 7.2; E+F: 50 mM TRIS, pH 8.1. Die Kontrastierung der Aggregate erfolgte nach 20 facher Verdünnung im gleichen Puffer und Auftrag auf Carbon coated Copper Grids (Plano GmbH, Wetzlar) durch 2 \% (w/v) Uranylacetat. Die Aufnahmen A, B und E wurden bei 50000 facher Vergrösserung, die Aufnahmen C und D bei 5000 facher Vergrösserung und die Aufnahme F bei 25000 facher Vergrösserung aufgenommen 
Mit einer zweiten unabhängigen Methode sollten die Ergebnisse zur pH-Abhängigkeit der Aggregation (Abb. 18, 19, 20) des Prionproteins bestätigt werden. Durch elektronenmikroskopische Untersuchungen (Abb. 21) sollte geklärt werden, ob sich die Morphologie der Aggregate bei Variation des pH-Wertes verändert, was als Ursache für die verschiedenen Absorptionswerte bei unterschiedlichen $\mathrm{pH}$-Werten herangezogen werden könnte.

Die Auswertung der elektronenmikroskopischen Aufnahmen von humPrP23-159 und humPrP23-144 innerhalb des pH-Bereiches von 6.2-8.1 führte zu folgenden Ergebnissen:

1. Die Morphologie der Aggregate von humPrP23-144 und humPrP23-159 war unter gleichen äusseren Bedingungen nahezu identisch. Einzelne PrP-Fibrillen wiesen jeweils unabhängig vom untersuchten Protein und pH-Wert einen Durchmesser von 8-12 nm auf, wobei die Länge der Fibrillen jeweils mehrere Mikrometer betragen konnte

2. pH-Wert-Änderungen von 6.2 auf 7.2 führten nicht zu einer veränderten Morphologie der Aggregate, sondern lediglich zu einer deulichen Zunahme von fibrillären Strukturen. Bei pHWerten von 8.1 schienen insbesondere bei humPrP23-159 grössere Aggregate gebildet zu werden, die nur zum Teil noch eine fibrilläre Struktur aufwiesen, aber auch nicht deutlich amorpher Natur waren.

3. Die Zunahme an fibrillären Strukturen bei Zunahme des $\mathrm{pH}-$ Wertes korrelierte zum grössten Teil mit der Veränderung der Absorptionswerte in der stationären Phase der Aggregation bei unterschiedlichen $\mathrm{pH}-$ Werten. Lediglich die relativ grosse Anzahl an fibrillären Strukturen bei humPrP23-144 bei einem pH-Wert von $7.2 \mathrm{im}$ Vergleich zu pH 6.2 (Abb. $21 \mathrm{C}$ ) war nicht gut mit den annähernd gleichen, niedrigen Absorptionswerten nach 16 Tagen bei pH-Werten von 7.2 bzw. 6.2 zu vereinbaren.

Insgesamt konnte bei der Bestimmung der pH-Abhängigkeit der Aggregation von humPrP23144 und humPrP23-159 unter nicht-denaturierenden Bedingungen durch zwei verschiedene Methoden gezeigt werden, dass im Gegensatz zur pH-Abhängigkeit der Aggregation unter denaturierenden Bedingungen keine Aggregation des Prionproteins bei sauren $\mathrm{pH}-$ Werten von 4.0-5.0 erfolgt. Mit zunehmendem $\mathrm{pH}-$ Wert wurden immer mehr fibrilläre und keine amorphen Aggregate gebildet. Bereits neutralen $\mathrm{pH}-$ Werte führten $\mathrm{zu}$ einer deutlichen Beschleunigung der Aggregation von humPrP23-159, während humPrP23-144 einen 
vergleichbaren Effekt erst bei einem pH-Wert von 8.1 zeigte. Daraus kann geschlossen werden, dass die Helix 1 die Aggregation des Prionproteins bei neutralem pH-Wert beschleunigt.

\subsection{Einfluss der $\mathbf{N}$-terminalen Region des Prionproteins auf seine Aggregation}

Der für die Aggregation des humanen Prionproteinfragmentes humPrP23-159 entscheidende $\mathrm{pH}-$ Bereich lag im neutralen Bereich zwischen $\mathrm{pH}-$ Werten von 6.2-7.2. Die einzige Aminosäure mit einem $\mathrm{pK}_{\mathrm{s}}$-Wert der Seitenkette in der Nähe dieses $\mathrm{pH}$-Bereiches war das Histidin, dessen saures N-H-Proton im Imidazolring bei einem $\mathrm{pH}-$ Wert von 6.0 und $25{ }^{\circ} \mathrm{C} \mathrm{zu}$ $50 \%$ protoniert und zu $50 \%$ unprotoniert vorliegt.

Der N-terminale Bereich des Prionproteins 23-112 enthielt sechs von acht Histidinen bezogen auf die untersuchte Proteinsequenz in humPrP23-159. Deshalb wurde angenommen, dass die pH-Abhängigkeit der Aggregation des Proteinfragmentes humPrP23-112 am stärksten ausgeprägt sein sollte. humPrP23-112 besitzt nur positiv geladene und keine negativ geladenen Aminosäuren. Seine Nettoladung bei pH-Werten von 5.0 bzw. 7.0 beträgt +16 bzw. +10 .

Analog zu humPrP23-159 und humPrP23-144 wurde die pH-Abhängigkeit der Aggregation von humPrP23-112 innerhalb eines $\mathrm{pH}$-Bereiches von $\mathrm{pH}$ 4.0-8.0 untersucht. In allen in dieser Arbeit durchgeführten Aggregationsstudien mit rekombinantem humPrP23-112 konnte innerhalb eines $\mathrm{pH}-$ Bereiches von 4.0-8.1 auch unter Zugabe von $200 \mathrm{mM} \mathrm{NaCl}$ und bis zu $400 \mu \mathrm{M}$ Proteinkonzentrationen keine Aggregation des Proteins innerhalb von sechs Monaten erreicht werden (Daten nicht abgebildet). Üblicherweise führte eine Agitation der Proteinlösung zu einer bis zu zehnfachen Beschleunigung der Aggregation des Prionproteins (Kundu et al., 2003). Auch eine für drei Wochen durchgeführte Agitation der Proteinlösungen bei unterschiedlichen Temperaturen von 25-37 ${ }^{\circ} \mathrm{C}$ führte $\mathrm{zu}$ keiner nachweisbaren Aggregation von humPrP23-112. Es konnte weder ein Anstieg der Thioflavin T-Fluoreszenz als Nachweis für $\beta$-Faltblatt-Strukturen noch eine Erhöhung der Absorption bei $400 \mathrm{~nm}$ durch gebildete lichtstreuende Aggregate festgestellt werden. Auch elektronenmikroskopisch konnten keine Aggregate von humPrP23-112 detektiert werden.

Daraus liess sich folgern, dass der N-terminale Bereich des humanen Prionproteins ohne weitere interagierende Regionen des Prionproteins keine Aggregationsneigung aufweist. 


\subsection{Einfluss des $\beta$-Strands $\mathbf{S 2}$ auf die Aggregation des humanen Prionproteins}

\subsubsection{Vergleich der Aggregation von humPrP23-173 mit humPrP23-159}

Um die Bedeutung des $\beta$-Strands S2 für die Aggregation des humanen Prionproteins zu klären, wurde das Prionprotein humPrP23-159 C-terminal formal um 14 Aminosäuren (Sequenz: QVYYRPMDEYSNQN) verlängert. Das resultierende Protein humPrP23-173 wies neben der Proteinsequenz für den ersten $\beta$-Strand S1 (PrP128-131) auch die Proteinsequenz für den zweiten $\beta$-Strand S2 (PrP161-164) zur Vervollständigung des antiparallelen $\beta$ Faltblattes auf (Abb. 10). humPrP23-173 war rückgefaltet nach Zahn et al. (1997) über Wochen stabil. Unter den Pufferbedingungen des Aggregationsassays analog zu humPrP23144 und humPrP23-159 zeigte humPrP23-173 die deutlich stärkste Aggregationsneigung von allen untersuchten Prionproteinen (Abb. 22 A+B).
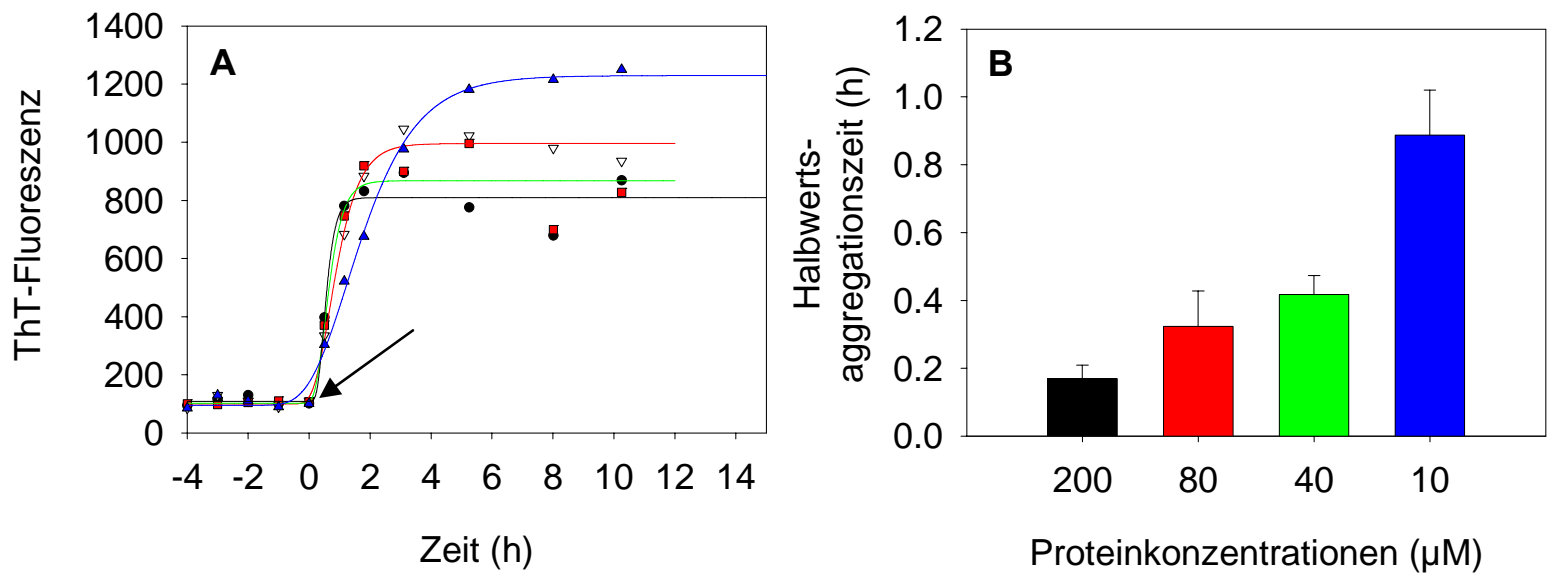

Abb. 22: Beschleunigung der Aggregation in humPrP23-173 durch das Segment 160-173. (A) Thioflavin T Fluoreszenzassay zur Detektion von aggregiertem humPrP23-173. Eingesetzt wurden $200 \mu \mathrm{M}$ (schwarze Kreise), $80 \mu \mathrm{M}$ (rote Dreiecke), $40 \mu \mathrm{M}$ (grüne Quadrate) und $10 \mu \mathrm{M}$ (blaue Dreiecke) Proteinkonzentrationen in $20 \mathrm{mM}$ Natriumacetet, $20 \mathrm{mM}$ Natriumphosphat, $\mathrm{pH} 6.5$ bei $25{ }^{\circ} \mathrm{C}$ in Borosilikatgefässen mit Schraubverschluss. Die Zugabe des 10fach Puffers aus $100 \mathrm{mM}$ Natriumacetat und $200 \mathrm{mM}$ Natriumphosphat, pH 6.5 erfolgte zum Zeitpunkt „,0“ (Pfeil). humPrP23-173 war bis dahin über $24 \mathrm{~h}$ in $10 \mathrm{mM}$ Natriumacetat, $\mathrm{pH}$ 6.5 stabil. (B) Vergleich der Halbwertsaggregationszeiten von humPrP23-173 aus sechs Experimenten bei unterschiedlicher Proteinkonzentration (farbliche Zuordnung analog $\mathrm{zu}$ A). Die Fehlerbalken geben die Standardabweichung an. 
Die Halbwertsaggregationszeiten für die eingesetzten Proteinkonzentrationen lagen alle unter einer Stunde und wiesen nur geringe Differenzen zueinander auf. Die Konzentrationsabhängigkeit der Aggregation war trotz der nur geringen zeitlichen Unterschiede weiterhin gegeben (Abb. 22 B). Die Halbwertsaggregationszeiten lagen für 200 $\mu \mathrm{M}, 80 \mu \mathrm{M}, 40 \mu \mathrm{M}$ und $10 \mu \mathrm{M}$ Proteinkonzentrationen bei $0.17 \mathrm{~h} \pm 0.04 \mathrm{~h}, 0.32 \mathrm{~h} \pm 0.10 \mathrm{~h}$, $0.42 \mathrm{~h} \pm 0.06 \mathrm{~h}$ und $0.89 \mathrm{~h} \pm 0.13 \mathrm{~h}$.

humPrP23-173 aggregierte bei identisch eingesetzten Proteinkonzentrationen von $200 \mu \mathrm{M}$ bzw. $80 \mu \mathrm{M}$ und identischen Pufferbedingungen im Vergleich zu humPrP23-159 400fach bzw. 812fach schneller. Das Segment 160-173 mit dem $\beta$-Strand S2 wies damit den stärksten aggregationsbeschleunigenden Effekt innerhalb der untersuchten Segmente bis PrP23-173 des humanen Prionproteins auf.

\subsubsection{Morphologie von aggregiertem humPrP23-173}

Elektronenmikroskopische Aufnahmen zeigten in Analogie zu humPrP23-144 und humPrP23159, dass auch humPrP23-173 bei der Aggregation fibrilläre Strukturen ausbildet (Abb. 23).

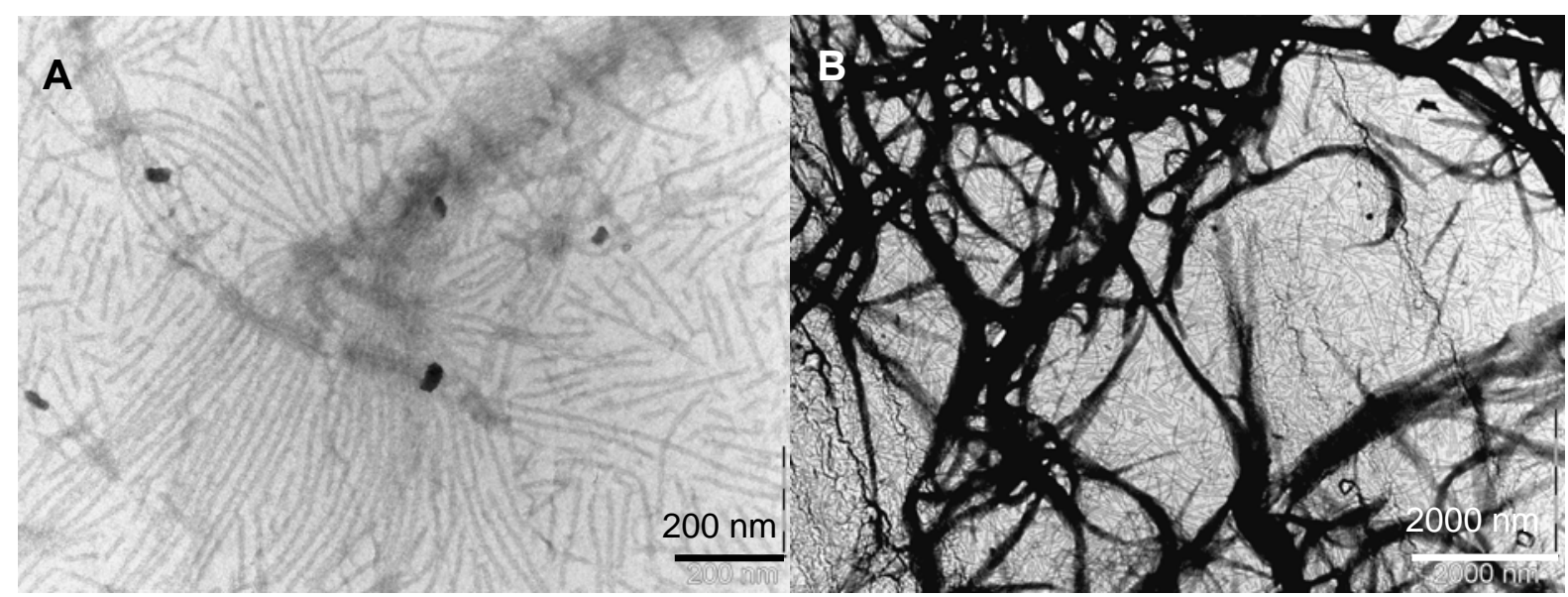

Abb. 23: Elektronenmikroskopische Darstellung von fibrillärem humPrP23-173. (A) $80 \mu \mathrm{M}$ Konzentrationen von humPrP23-173 wurden in $20 \mathrm{mM}$ Natriumphosphat und $20 \mathrm{mM}$ Natriumacetat bei pH 6.5 und $25^{\circ} \mathrm{C}$ zur Aggregation gebracht. Die Kontrastierung der drei Wochen alten Aggregate erfolgte nach 8 facher Verdünnung im gleichen Puffer und Auftrag auf Carbon coated Copper Grids durch 2 \% (w/v) Uranylacetat. Die Aufnahme A wurde bei 80000 facher Vergrösserung Aufnahme B bei 10000 facher Vergrösserung aufgenommen. 
Dabei wies aggregiertes humPrP23-173 keine signifikanten morphologischen Unterschiede zu humPrP23-144 und humPrP23-159 auf. Auch humPrP23-173 bildete ein Netzwerk aus stark gebündelten Fibrillen mit einem durchschnittlichen Durchmesser von 50-70 nm aus, das bis auf $300 \mathrm{~nm}$ ansteigen konnte. Die Länge der Aggregate konnte bis auf mehrere Mikrometer ansteigen. Die einzelnen Fibrillen der Bündel wiesen einen Durchmesser von 8-12 nm auf. Auch humPrP23-173 zeigte eine auffällige Tendenz zur lateralen Aggregation zu grossen Bündelstrukturen.

\subsubsection{Proteinase K Resistenz des $\beta$-Strands $S 2$ und der Helix 1 in fibrillärem humPrP23-173}

Das Segment 160-173 des humanen Prionproteinfragmentes humPrP23-173 mit dem $\beta$-Strand S2 führte zu einer sehr starken Beschleunigung der Aggregation des Proteins. Damit war annähernd das komplette im $\operatorname{PrP}^{\mathrm{Sc}}$-Strukturmodell umfaltende Segment 90-175 in humPrP23173 enthalten (Govaerts et al., 2004). Nach dem Modell wäre zu erwarten, dass die Region 90-173 in eine linksgewundene parallele $\beta$-Helix umfaltet, die relativ stabil gegenüber proteolytischem Verdau durch die Proteinase K sein sollte. Die Helices 2 und 3 sind gemäss der bekannten $\mathrm{PrP}^{\mathrm{Sc}}$-Strukturmodelle für die Konversion des Prionproteins nicht bedeutsam (Govaerts et al., 2004; Huang et al., 1996; DeMarco \& Daggett, 2004). Durch einen Proteinase K-Verdau von fibrillärem humPrP23-173 sollte das $\operatorname{PrP}^{\mathrm{Sc}}$-Strukturmodell überprüft werden. Falls nur die Region 90-175 für die Umfaltung des zellulären Prionproteins in die Proteinase K-resistente $\mathrm{PrP}^{\mathrm{Sc}}$-Form verantwortlich sein sollte, dann würde das rekombinante fibrilläre PrP23-173 zumindest eine deutlich höhere Proteinase K Resistenz als das fibrilläre humPrP23-144 und humPrP23-159 aufweisen.

In der SDS-PAGE von Proteinase K verdautem fibrillärem humPrP23-173 wurden zwei Fragmente mit einem Molekulargewicht von etwa 8 kDa bzw. 6-7 kDa sichtbar, die eine Grösse vergleichbar zu Proteinase $\mathrm{K}$ verdautem humPrP23-159 bzw. humPrP23-144 aufwiesen (Abb. 24 A). 

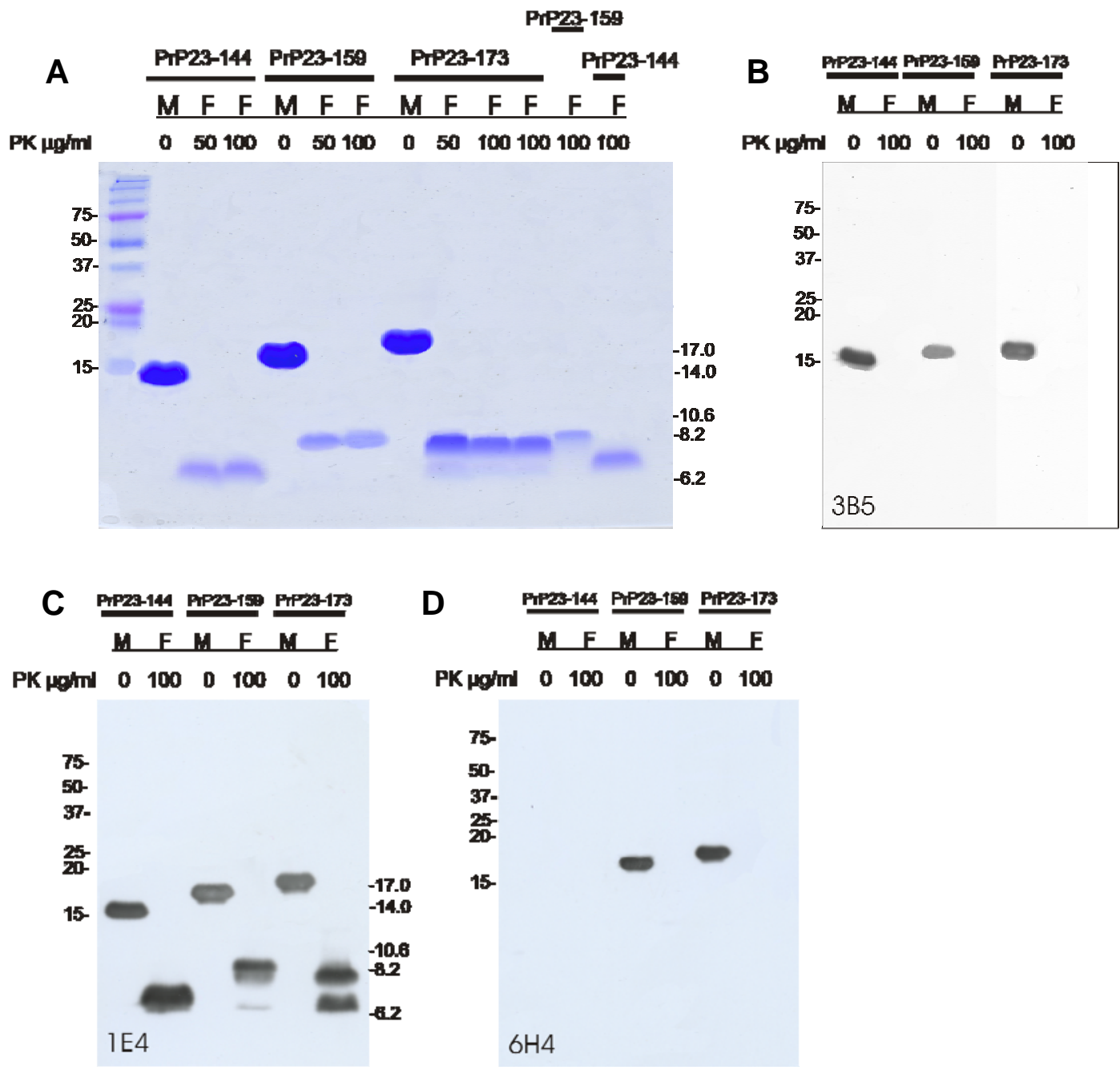

\begin{abstract}
Abb. 24: Überprüfung der Proteinase K Resistenz des $\beta$-Strand S2 und der Helix 1 in fibrillärem humPrP23-173. (A) SDS-PAGE von monomerem (M) und Proteinase K verdautem fibrillärem (Fibrillär) humPrP23-144, humPrP23-159 und humPrP23-173 bei Proteinase K Konzentrationen von $50 \mu \mathrm{g} / \mathrm{ml}$ und 100 $\mu \mathrm{g} / \mathrm{ml}$ in einer speziellen SDS-PAGE, die für die Auftrennung von A $\beta$-Peptiden mit nur einer Aminosäure Unterschied entwickelt wurde (Wiltfang et al., 2001). Die aufgetragenen Proteinmengen pro Spur betrugen je 5 $\mu \mathrm{g}$ der monomeren Proteine und je $30 \mu \mathrm{g}$ der Proteinase K verdauten fibrillären Prionaggregate. (B) Western Blot von monomerem (M) und fibrillärem (F) Proteinase K verdautem (100 $\mu \mathrm{g} / \mathrm{ml}$ Proteinase K, $37{ }^{\circ} \mathrm{C}, 1 \mathrm{~h}$ ) humPrP23-144, humPrP23-159 und humPrP23-173 mit dem Antikörper 3B5 (C) Western Blot von monomerem (M) und fibrillärem (F) Proteinase K verdautem humPrP23-173, humPrP23-159 und humPrP23-144 mit dem Antikörper 1E4. (D) Western Blot von monomerem (M) und fibrillärem (F) Proteinase K verdautem humPrP23144, humPrP23-159 und humPrP23-173 mit dem Antikörper 6H4. Nur monomeres humPrP23-173 und monomeres humPrP23-159 wurden vom 6H4 Antikörper erkannt.
\end{abstract}


Western Blots der Proteinase K verdauten fibrillären Strukturen von humPrP23-173 mit den Antikörpern 3B5 (Motiv 59-89) (Abb. 24 B) und 1E1 (Motiv 98-109) (Abb. 24 C) zeigten, dass die N-terminale Startsequenz des Proteinase K resistenten Fragmentes von humPrP23173 zwischen den Bindungsmotiven der beiden Antikörper 1E4 und 3B5 analog zu humPrP23-159 und humPrP23-144 lag. Ein zum $\mathrm{PrP}^{\mathrm{Sc}}$-Typ 1 analoges Spaltungsmuster konnte auch hier ausgeschlossen werden (Abb. 24 B, C). Das aus der SDS-PAGE (Abb. 24 A) durch Vergleich mit dem Laufverhalten der Markerproteine abschätzbare Molekulargewicht des Proteinase K resistenten Fragmentes von humPrP23-173 schien dem Molekulargewicht von Proteinase K verdautem humPrP23-159 zu entsprechen.

Durch Western Blots mit dem an die Helix 1 Region bindenden Antikörper 6H4 (Motiv 144152) konnte gezeigt werden, dass Proteinase K verdautes fibrilläres humPrP23-173 kein Helix 1-Segment und auch keinen $\beta$-Strand S2 mehr enthält (Abb. 24 D).

Ein Fragment von der Grösse des Segmentes 160-173 (1.8 kDa) konnte in der SDS-PAGE (Abb. 24 A) nicht detektiert werden.

Neben dem qualitativen Nachweis der Helix 1 und des Segmentes 160-173 mit dem $\beta$-Strand S2 in den Proteinase $\mathrm{K}$ verdauten Prionproteinfragmenten wurde auch eine quantitative Analyse der Proteinase K verdauten Fragmente durchgeführt (Abb. 25). Die Annahme bei der Berechnung der Stoffmengenkonzentration war, dass das Proteinase K-resistente Fragment von fibrillärem humPrP23-144 der Region 97-144 und die Proteinase K verdauten Fragmente von fibrillärem humPrP23-159 und humPrP23-173 jeweils der Region 97-146 entsprechen. Nach chromatographischer Aufreinigung der Fragmente ergab eine Proteinkonzentrationsbestimmung aus drei unabhängigen Experimenten ein molares Verhältnis von etwa 5 : 1 : 2.5 für humPrP23-144 : humPrP23-159: humPrP23-173. Es ist anzumerken, dass auch ein hypothetisch Proteinase K-resistenter Bereich der Aminosäuren 97-159 in fibrillärem humPrP23-159 und humPrP23-173 die vorhandene Tendenz nur noch verstärkt hätte. Es würde sich ein molares Verhältnis von etwa 7 : 1 : 2.5 für humPrP23-144 : humPrP23-159 : humPrP23-173 ergeben. Die eingesetzten Stoffmengenkonzentrationen der fibrillären Prionproteinaggregate für den Proteinase K-Verdau waren jeweils identisch. Danach war die Region 97-144 bezogen auf die eingesetzten Proteinmengen das gegen die Proteinase $\mathrm{K}$ deutlich resistenteste Fragment. Eine Verlängerung der Proteinsequenz von humPrP23-144 um das Helix 1-Segment reduzierte die Proteinase K Resistenz der gebildeten fibrillären Aggregate von humPrP23-159 im Vergleich zu fibrillärem humPrP23-144 deutlich. Eine weitere Verlängerung der Proteinsequenz von humPrP23-159 um das Segment 160-173 
mit dem $\beta$-Strand S2 führte dagegen zu einer Erhöhung der Proteinase K Resistenz im Vergleich zu fibrillärem humPrP23-159, ohne jedoch die Resistenz von fibrillärem humPrP23-144 gegenüber proteolytischem Abbau zu erreichen.

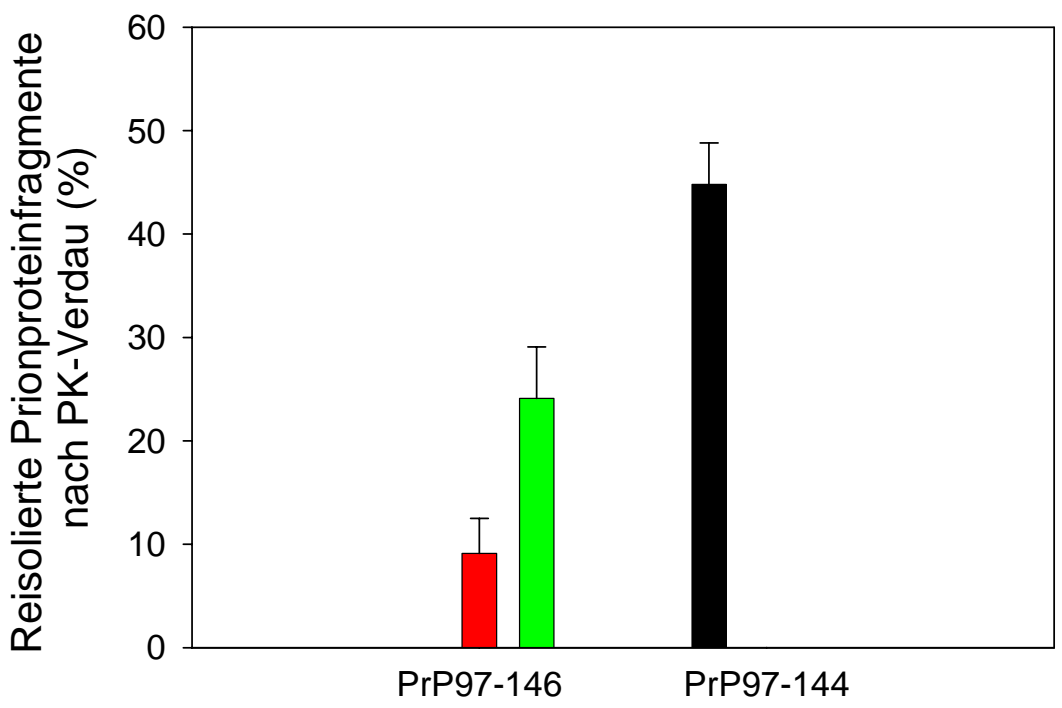

Erwartete Fragmentgrössen nach PK-Verdau

Abb. 25: Quantitative Analyse der Proteinase K (PK)-verdauten fibrillären Prionproteine. Je $0.2 \mu$ mol der fibrillären Prionproteine humPrP23-144 (schwarz), humPrP23-159 (rot) und humPrP23-173 (grün) wurden für je $1 \mathrm{~h}, 37^{\circ} \mathrm{C}$ mit $100 \mu \mathrm{g} / \mathrm{ml}$ Proteinase $\mathrm{K}$ bei $1400 \mathrm{rpm}$ im Eppendorf-Thermoshaker verdaut und anschliessend chromatographisch reisoliert. Die Balken geben die reisolierten Stoffmengenkonzentrationen in Prozent relativ zur eingesetzten Stoffmengenkonzentration an. Die Berechnung der Stoffmengenkonzentration basierte für humPrP23-159 und humPrP23-173 auf einer Fragmentgrösse (PrP97-146), die auf der Edman-Sequenzierung von humPrP23-144 und humPrP23-159 (Abb. 16 B) und einer Grössenabschätzung der Proteinase K verdauten Fragmente aus der SDS-PAGE (Abb. 24 A) beruhte. Die Fragmentgrösse von Proteinase K verdautem humPrP23-173 wurde basierend auf dem N- und C-terminalen Epitop-Mapping bei identischem Laufverhalten als identisch zu Proteinase K verdautem humPrP23-159 angenommen.

Zusammenfassend konnte als Ergebnis des Proteinase K-Verdaus von fibrillärem humPrP23173 gezeigt werden, dass die Proteinase K verdauten Fragmente von fibrillärem humPrP23159 und fibrillärem humPrP23-173 eine wahrscheinlich sehr ähnliche oder identische Proteinsequenz aufweisen. Durch einen Verdau des Helix 1-Segmentes in humPrP23-173 wurde auch die Region 160-173 vom Rest des Moleküls abgespalten. Eine Aussage über die Proteinase K Resistenz des Segmentes 160-173 in humPrP23-173 ist aufgrund der geringen Grösse des Spaltfragmentes und einem Fehlen von spezifischen Antikörpern gegen diese 
Region unsicher. Die Anwesenheit des $\beta$-Strands S2 führte nicht zu einer ähnlich hohen Proteinase K Resistenz der kompletten Region 90-173 wie im pathologischen Prionprotein. Allerdings führte die Existenz der Region 160-173 zu einer Erhöhung der Proteinase K Resistenz der Region 97-146 in humPrP23-173 gegenüber humPrP23-159, womit offensichtlich nicht alle Proteinaggregate trotz gleicher Fragmentlänge eine identische Resistenz gegenüber proteolytischem Verdau aufweisen.

Eine massenspektrometrische Analyse der Proteinase K verdauten Fragmente war aufgrund ihrer Unlöslichkeit unter nicht-denaturierenden Bedingungen nicht möglich. 


\section{Diskussion}

In der vorliegenden Arbeit wurde in einem physiologischen Konversionsassay der Einfluss der Helix 1 und des $\beta$-Faltblattes auf die Aggregation des Prionproteins untersucht. In der folgenden Diskussion werden die Bedeutung physiologischer Bedingungen für die Umfaltung des Prionproteins, der Einfluss des pH-Wertes, der Mechanismus der Umfaltung und die aus den hier erzielten Ergebnissen abgeleitete Struktur des pathologischen Prionproteins dargestellt.

\subsection{In vitro Modell zur Simulation konformativer Änderungen des humanen Prionproteins in seine pathologische Isoform}

Zur Simulation der Konversion des Prionproteins in seine pathologische Isoform wurde in der Vergangenheit fast ausschliesslich unter denaturierenden Bedingungen gearbeitet. Dadurch sollten hohe Aktivierungsenergien bei der Bildung von $\operatorname{PrP}^{\mathrm{Sc}}$-ähnlichen Aggregaten reduziert und die Konversion des Prionproteins in eine $\beta$-Faltblatt-reiche amyloide Struktur beschleunigt werden. Da das Volllängen-Prionprotein unter nativen Bedingungen bisher nicht unter Bildung fibrillärer Strukturen aggregierte, war die Frage, ob eine Umfaltung des Prionproteins unter nativen Bedingungen prinzipiell möglich sei.

Ein generelles Problem beim Arbeiten unter denaturierenden Bedingungen ist die Vergleichbarkeit der Ergebnisse, da die Minderung der Konversionsbarriere für die Umfaltung des Prionproteins auf prinzipiell unterschiedlichen Wegen erreicht werden kann. Nach Morillas et al. (2001) und Swietnicki et al. (2000) wurde ein nativ gefaltetes Prionprotein durch Zugabe von denaturierenden Agenzien partiell entfaltet. Alternativ sollte ausgehend von vollständig denaturiertem Prionprotein eine vergleichbare partielle Faltung durch ein Verdünnen des Denaturierungsmittels erreicht werden (Bocharova et al., 2005b; Breydo et al., 2005). Dabei ist anzumerken, dass der thermodynamische Weg auf dem die partiellen Faltungen erreicht werden, die Stabilität und die Art der Faltungsintermediate jeweils deutlich voneinander abweichen können. Insofern ist auch die Vergleichbarkeit der Endprodukte der Aggregation in Frage zu stellen. 
Ein physiologischer Konversionsassay zur Bestimmung der Aggregationsgeschwindigkeit des Prionproteins wurde von Kundu et al. (2003) entwickelt. Darauf aufbauend konnte in jüngerer Zeit ein Modell zur Entstehung von Speziesbarrieren entwickelt werden (Vanik et al., 2004; Jones et al., 2005), was das enorme Potential physiologischer Bedingungen bei der Untersuchung der Aggregation des humanen Prionproteins andeutete.

In der vorliegenden Arbeit wurde analog zu Kundu et al. (2003) in einem physiologischen, nicht-denaturierenden Aggregationssystem mit humanem Prionprotein aus E.coli gearbeitet, welches die zellulären Bedingungen für die $\operatorname{PrP}^{\mathrm{Sc}}$-Bildung beim Menschen am ehesten simulieren sollte.

\subsection{Einfluss des pH-Wertes auf die Bildung des pathologischen Prionproteins}

Es konnte bislang nicht eindeutig geklärt werden, ob die Konversion des zellulären Prionproteins in einem bestimmten zellulären Kompartiment oder auf der Zelloberfäche erfolgt. Somit kann die Umfaltung des Prionproteins bei $\mathrm{pH}-$ Werten zwischen 4.0-7.4 erfolgen und durch den jeweiligen $\mathrm{pH}-$ Wert wesentlich beeinflusst werden.

Um den Einfluss physiologischer Bedingungen auf die pH-Abhängigkeit der Aggregation zu verstehen, wurde in dieser Arbeit die Aggregation der humanen Prionproteinfragmente humPrP23-112, humPrP23-144 und humPrP23-159 unter nicht-denaturierenden Bedingungen zwischen $\mathrm{pH}$-Werten von 4.0-8.1 untersucht. humPrP23-159 ist das bislang längste Prionproteinfragment, dessen Aggregationsverhalten unter physiologischen Bedingungen untersucht wurde (Watzlawik et al., 2006). Unter physiologischen Bedingungen wurden innerhalb eines $\mathrm{pH}$-Bereiches von 6.2-8.1 fibrilläre Aggregate gebildet, während bei $\mathrm{pH}$ Werten zwischen 4.0-5.0 keine Bildung $\beta$-Faltblatt-reicher Strukturen erfolgte.

Nach Borchelt et al. (1992) erfolgt die Umwandlung des zellulären Prionproteins direkt nach seiner Internalisierung von der Zelloberfläche. Da eine Lagerung von permanent mit $\operatorname{PrP}^{\mathrm{Sc}_{-}}$ infizierten Neuroblastomazellen bei $18{ }^{\circ} \mathrm{C}$ die weitere Bildung des pathologischen Prionproteins reversibel blockierte, wurde ein Transport des Prionproteins in die sauren Endosomen bei der $\mathrm{PrP}^{\mathrm{Sc}}$-Bildung für notwendig erachtet. Die Konversion des Prionproteins 
soll nach Taraboulos et al. (1992) aber vor der Fusion mit den Lysosomen bereits beendet sein. Unterstützend wurde von Morillas et al. (2001) und Swietnicki et al. (2000) angeführt, dass die Bildung $\beta$-Faltblatt-reicher oligomerer und fibrillärer Strukturen aus rekombinantem Prionprotein unter denaturierenden Bedingungen nur zwischen $\mathrm{pH}-$ Werten von 4.0-5.0 zu beobachten sei, während unter neutralen Bedingungen eine stark verlangsamte oder keine Aggregation bzw. Oligomerisierung des Prionproteins erfolgt.

Wenn ein saurer pH-Wert eine derart zentrale Rolle bei der Entstehung des pathologischen Prionproteins einnehmen würde, sollte die Aggregation des Prionproteins in $\beta$-Faltblatt-reiche Strukturen auch in unserem physiologischen System unter sauren pH-Bedingungen zu beobachten sein, was aber nicht der Fall war. Bei der Vermessung der NMR-Strukturen der Volllängen-Prionproteine von Maus und Mensch bzw. des Hamster-Prionproteins ShaPrP90231 wurde unter nicht-denaturierenden Bedingungen bei pH-Werten zwischen 4.5 und 5.2 mit millimolaren Proteinkonzentrationen gearbeitet, ohne dass $\beta$-Faltblatt-reiche Aggregate des Prionproteins detektiert werden konnten (Riek et al., 1997; Zahn et al., 2000; Liu et al., 1999), was auf einen prinzipiell unterschiedlichen Weg der Aggregation des Prionproteins unter sauren denaturierenden Bedingungen im Vergleich zu sauren nicht-denaturierenden Bedingungen hinweist.

Bei pH-Werten von 6.5 konnte dagegen in physiologischen Konversionsassays die Bildung fibrillärer Aggregate des Prionproteins beschrieben werden (Kundu et al., 2003; Jones et al., 2005), was eher für neutrale als saure $\mathrm{pH}-$ Werte bei der $\mathrm{PrP}^{\mathrm{Sc}}$-Bildung spricht.

Die zelluläre Akkumulation des pathologischen Prionproteins soll interessanterweise auch ohne einen Kontakt mit den sauren Lysosomen und Ensosomen im Endoplasmatischen Retikulum (Sernataro et al., 2004; Beranger et al., 2002; Harris, 2003) und im Zytosol (Mironov et al., 2003; Ma et al, 2002; Ma \& Lindquist, 2002; Cohen et al., 2003) erfolgen. Taraboulos et al. (1992) bestätigte, das ein saurer pH-Wert allein für die intrazelluläre Bildung des $\operatorname{PrP}^{\mathrm{Sc}}$ nicht ausreichend ist.

Jüngere Arbeiten konnten auch unter denaturierenden Bedingungen die Bildung fibrillärer Aggregate des Prionproteins oberhalb eines pH-Wertes von 5.5 bestätigen (Breydo et al., 2005; Bocharova et al., 2005a, 2005b), was im direkten Widerspruch zu den Ergebnissen von Morillas et al. (2001) und Swietnicki et al. (2000) steht. Hierbei ist anzumerken, dass die partielle Denaturierung des Prionproteins auf sehr unterschiedlichen Wegen erzeugt wurde 
und eine Vergleichbarkeit der Ergebnisse nicht wahrscheinlich ist (Kapitel 4.1.). Zusätzlich wurde mit Prionproteinen aus zwei unterschiedlichen Spezies gearbeitet, so dass der beobachtete Unterschied auch in einer etwas anderen Proteinsequenz zwischen Maus- und Hamster-Prionprotein begründet sein kann.

Beim Vergleich der pH-Abhängigkeiten von humPrP23-159 mit humPrP23-144 zeigt sich, dass ein neutraler pH-Wert einen stark beschleunigenden Effekt auf die Aggregation von humPrP23-159 ausübte, während ein vergleichbarer Effekt bei humPrP23-144 erst bei einem pH-Wert von 8.1 beobachtet werden konnte. Das impliziert einen Mechanismus, bei dem das Helix 1-Segment und die Region 23-143 einen jeweils eigenen Einfluss auf die pHAbhängigkeit der Umfaltung in humPrP23-159 besitzen (Mechanismus s. Kapitel 4.3.). Die besondere $\mathrm{pH}$-Abhängigkeit der Helix 1-Region im Prionprotein wurde kürzlich durch Elektronenspinresonanz (ESR)-Spektroskopie (ESR) bestätigt. Danach führten pH-WertÄnderungen zwischen pH 5.0-7.4 zu strukturellen Veränderungen innerhalb des Helix 1Segmentes, wobei insbesondere der N-terminale Bereich der Helix 1 mit den Aminosäuren 145-147 betroffen war (Watanabe et al., 2006).

Es soll angemerkt werden, dass ein zusätzlicher Einfluss der Region 174-231 im humanen Prionprotein auf die pH-Abhängigkeit der Aggregation unter physiologischen Bedingungen nicht ausgeschlossen werden kann und einer weiteren Untersuchung bedarf.

Basierend auf den eigenen Ergebnissen scheint die Bildung des pathologischen Prionproteins eher unter neutralen als unter sauren $\mathrm{pH}$-Werten zu erfolgen, was durch andere Arbeiten in physiologischen Aggregationssystemen bestätigt wird. Eine Konversion des Prionproteins unter physiologischen, nicht-denaturierenden Bedingungen konnte bislang nur oberhalb eines pH-Wertes von 6.0 nachgewiesen werden.

\subsection{Einfluss der $\mathbf{N}$-terminalen Domäne, der Helix 1 und des $\beta$-Strands $\mathrm{S} 2$ auf den Mechanismus der Aggregation des humanen Prionproteins}

Das mechanistische Verständnis der Konversion des Prionproteins in seine pathogene Isoform ist für eine mögliche therapeutische Intervention eine Grundvoraussetzung und soll hier deshalb ausführlich diskutiert werden.

In dieser Arbeit konnte gezeigt werden, dass innerhalb eines physiologischen Konversionsassays sowohl die sehr polare Helix 1 als auch die polare Region 160-173 mit 
dem $\beta$-Strand S2 einen stark aggregationsfördernden Effekt auf das Prionprotein ausüben. Der unstrukturierte und sehr flexible N-terminale Bereich 23-112 im Prionprotein zeigte für sich allein dagegen keine Tendenz zur Bildung von $\beta$-Faltblatt-reichen Aggregaten.

Aus diesen Ergebnissen erscheint es evident, dass die Helix 1 und der $\beta$-Strand S2 mechanistisch an der Umfaltung des Prionproteins in eine pathogene Isoform beteiligt sind.

Dies ist umso erstaunlicher als beim $\alpha$-Synuclein und dem Tau-Protein die Trunkierung einer nicht-amyloidogenen Region $\mathrm{zu}$ einer Erhöhung der Aggregationstendenz in dem verbleibenden Fragment führen sollte (Murray et al., 2003; Hoyer et al., 2004; Li et al., 2005; Von Bergen et al., 2002; Barghorn et al., 2000).

Eine Berechnung der Aggregationstendenz der untersuchten Prionproteinfragmente durch das Programm Zygreggator (Pawar et al., 2005) resultierte bei einem pH-Wert von 6.5 in einer Reihenfolge, bei der das Fragment humPrP23-144 den höchsten relativen Aggregationsscore $($ Zagg $=-0.18)$ unter den drei Fragmenten aufwies, gefolgt von humPrP23-159 (Zagg= -0.80) und humPrP23-173 (Zagg= -0.89) mit dem niedrigsten Aggregationsscore, wobei die Reihenfolge den experimentellen Daten entgegengesetzt ist. Einschränkend muss gesagt werden, dass aufgrund einer Limitierung des Programms Zyggregator jeweils nur der Bereich ab Aminosäure 95 für die Berechnung der Aggregationsneigung der Fragmente berücksichtigt werden konnte (PrP95-144, PrP95-159, PrP95-173).

Aus den eigenen Ergebnissen lassen sich zwei verschiedene Mechanismen der Aggregation des Prionproteins ableiten:

\section{Mechanismus A:}

Obwohl der untersuchte N-terminale Bereich 23-112 des Prionproteins selbst nicht zur Aggregation neigte, könnten zwischen der ausschliesslich positiv geladenen und sehr flexiblen, unstrukturierten N-terminalen Domäne und der insgesamt neutral geladenen Helix 1-Region ionische Wechselwirkungen bei neutralem pH-Wert zur Stabilisierung von Aggregat-Aggregat-Interaktionen ausgebildet werden. Durch eine Interaktion des Nterminalen Bereiches mit der Helix 1 (Kopf-Schwanz-Interaktion) zwischen verschiedenen Prionproteinen könnte die schnellere Aggregation von humPrP23-159 gegenüber humPrP23144 erklären werden. Mögliche Salzbrücken könnten durch eine Protonierung der CarboxylatGruppen in den Seitenketten von Aspartaten und Glutamaten mit zunehmend saurer werdendem $\mathrm{pH}-\mathrm{Wert}$ gespalten werden, was die geringe Aggregationstendenz von humPrP23159 bei sauren $\mathrm{pH}-$ Werten erklären würde. 
Da nur die Helix 1-Region negativ geladene Aminosäuren bei neutralem pH-Wert in dem Fragment humPrP23-159 beinhaltet, müsste sie an jeder möglichen Salzbrücke beteiligt sein. Passend dazu soll die Stabilität der Helix 1 entscheidend durch zwei interne Salzbrücken gewährleistet werden (Speare et al., 2003). Insofern könnte z.B. eine Interaktion der Nterminalen Startsequenz (KKRPK...) mit dem Helix 1-Segment anderer Prionproteinmoleküle durch die Ausbildung von ionischen Wechselwirkungen bei neutralem pH-Wert entscheidend zur Aggregation von humPrP23-159 bzw. von allen Prionproteinen mit Helix 1-Motiv und Nterminaler Domäne beitragen.

\section{Mechanismus B:}

Ein alternativer Mechanismus könnte auf der Ausbildung von Salzbrücken zwischen zwei oder mehreren Helix 1-Regionen basieren. Danach könnten zwei stabilisierende intrahelikale Salzbrücken (Asp-Arg) zu intermolekularen Salzbrücken umgeordnet werden, die einen frühen Kontakt zwischen mehreren Prionmolekülen herstellen und so die Aggregation des Prionproteins fördern könnten.

Bestätigend zur möglich Helix-Helix-Interaktion bei der Aggregation des Prionproteins (Mechanismus B) ergaben Proteindatenbankvergleiche des Prionproteins mit anderen Proteinen, dass die Helix 1 des Prionproteins eine der polarsten Helices innerhalb der Protein Data Bank (RCS-PDB) ist (Morissey \& Shakhnovich, 1999). Diese ungewöhnlich hydrophile Helix 1 besitzt nur wenig Kontakt zum Rest des Moleküls (Riek et al., 1996; Korth et al., 1997), während die hydrophoben Helices 2 und 3 ein kompaktes Helix-Bündel ausbilden, dass zusätzlich durch eine Disulfidbrücke stabilisiert wird. Die meisten Ladungen befinden sich auf der Aussenseite der Helix 1, die vom globulären Teil des Proteins abgewandt ist (Morissey \& Shakhnovich, 1999). Energetische Berechnungen zur $\beta$-Aggregation von Helix 1-Peptiden im Prionprotein ergaben nach Morissey \& Shakhnovich (1999), dass die Bildung von Helix-Dimeren durch die Halbierung der möglichen internen Salzbrücken nicht begünstigt ist. Eine Interaktion der dimeren Strukturen mit weiteren Helix 1-Peptiden würde dagegen energetisch favorisiert werden (Morissey \& Shakhnovich, 1999).

Bestätigend zum Einfluss der N-terminalen Domäne auf die Aggregation des Prionproteins wurde von Frankenfield et al. (2005) berichtet (Mechanismus A), dass moPrP23-231 unter neutralen Bedingungen deutlich schneller unter Ausbildung grösserer Aggregatstrukturen als moPrP90-231 aggregiert. Die unterschiedliche Grösse der Proteinaggregate von moPrP23-231 und moPrP90-231 wurde durch einen zweistufigen Aggregationsmechanismus erklärt. In der 
ersten Stufe sollen sowohl moPrP23-231 als auch moPrP90-231 unter Verbrauch von monomerem Prionprotein relativ kleine Proteinaggregate ausbilden. In der zweiten Stufe soll der N-terminale Bereich des Prionproteins 23-89 Aggregat-Aggregat-Interaktionen unter Ausbildung sehr grosser Aggregat-Strkturen vermitteln, die bei moPrP90-231 nicht detektierbar waren. Insofern führt auch hier eine Interaktion der N-terminalen Domäne mit der globulären C-terminalen Domäne zu einer Beschleunigung der Aggregation, die ohne sie nicht möglich wäre. Eine molekulare Erklärung könnte der vorgeschlagene Mechanismus A sein, wobei ionische Wechselwirkungen nicht zwingend zur Helix 1-Region im VolllängenPrionprotein ausgebildet werden müssen.

Der aggregationsbeschleunigende Effekt der N-terminalen Region des Prionproteins könnte die falschen Berechnungen zur $\beta$-Aggregation der untersuchten Prionproteinfragmente durch das Programm Zyggregator nach Pawar et al. (2005) verursacht haben, da der N-terminale Bereich 23-94 zusammen mit den C-terminalen Regionen von humPrP23-144, humPrP23-159 und humPrP23-173 die maximal berechenbare Peptidgrösse von 100 Aminosäuren überstieg. Interessanterweise konnten Parallelen für die ungewöhnliche Aggregationstendenz der Helix 1 in humPrP23-159 im Vergleich $\mathrm{zu}$ humPrP23-144 zu einzelnen Krankheitsberichten gezogen werden. Bei einem Patienten mit einer Q160stop Mutation in der proteincodierenden Region des Prnp-Gens erfolgte das Auftreten der klinischen Symptome etwa 6 Jahre früher als bei einem Patienten mit einer Y145stop Mutation im Prnp-Gen (Ghetti et al., 1996).

Bestätigend zum Einfluss der Helix 1 auf die Aggregation des Prionproteins konnte ein ungewöhnlicher Salzeffekt auf die thermodynamische Stabilität des humanen Prionproteins gezeigt werden. Danach reduzierten alle eingesetzten Salze in Konzentrationen unterhalb von $50 \mathrm{mM}$ signifikant die thermodynamische Stabilität des Prionproteins. Als mögliche Ursache wurde eine Destabilisierung der allein durch ionische Wechselwirkungen stabilisierten Helix 1 angegeben (Apetri et al., 2003), was im Einklang zur Interpretation der eigenen Ergebnissen steht.

Wichtige Arbeiten für die mechanistische Beteiligung der Helix 1 und des $\beta$-Strands S2 stammen aus Infektiositätsstudien in Zellkulturen. Diese Studien basieren auf transienten Transfektionen von stabil mit $\mathrm{PrP}^{\mathrm{Sc}}$-infizierten neuronalen Zelllinien. Bei den transienten Transfektionen der Zellen wurde mit Konstrukten gearbeitet, die eine veränderte Sequenz im für das Prionprotein codierenden Bereich enthalten. Wichtige für spezifische strukturelle Anteile des Prionproteins codierende Sequenzen sind daraus deletiert worden. Ziel der 
Arbeiten war es, eine Übertragbarkeit der Infektiösität auf die transienten, veränderten zellulären Prionproteine aufzuzeigen, was die Bedeutung dieser Regionen bei der $\operatorname{PrP}^{\mathrm{Sc}}$ Bildung aufzeigen könnte. Dabei war zwischen dem stets endogen vorhandenen $\operatorname{PrP}^{\mathrm{C}}$ der neuronalen Zellen und dem transient eingebrachten, veränderten Prionprotein durch spezifische Antikörper $\mathrm{zu}$ unterscheiden, um feststellen $\mathrm{zu}$ können, ob das veränderte Prionprotein auch in eine Proteinase K-resistente Form mit $\operatorname{PrP}^{\mathrm{Sc}}$-ähnlichen Eigenschaften umgewandelt werden kann.

Vorberg et al. (2001) zeigte in $\mathrm{PrP}^{\mathrm{Sc}}$-propagierenden Neuroblastomazellen, dass veränderte Prionproteine, denen entweder die Region 143-153 mit der Helix 1 oder die Region 160-163 mit dem $\beta$-Strand S2 oder die Region 127-130 mit dem $\beta$-Strand S1 fehlte, nicht in Proteinase K-resistente Formen mit $\mathrm{PrP}^{\mathrm{Sc}}$-ähnlichen Eigenschaften überführt werden können, was die Bedeutung der Helix 1 und des $\beta$-Faltblattes bei der Bildung des pathologischen Prionproteins bestätigt. Eine weitere Arbeit konnte die mechanistische Beteiligung der Helix 1 bei der $\mathrm{PrP}^{\mathrm{Sc}}$-Bildung noch weiter konkretisieren. Danach ist die Ladungsverteilung innerhalb der Helix 1 entscheidend für die Propagation der Infektiösität in Zellkulturen. So führte ein Austausch der geladenen Aminosäuren 147-151 gegen ungeladene Aminosäuren oder ein kompletter Austausch aller geladenen Aminosäuren innerhalb der Helix 1-Region gegen solche mit entgegen gesetzter Ladung $\mathrm{zu}$ einer Inhibierung der $\mathrm{PrP}^{\mathrm{Sc}}$-Propagation in Neuroblastoma-Zellen (Norstrom et al., 2006). Damit könnte das Helix 1-Segment zusätzlich zur spontanen Konversion des Prionproteins auch bei erworbenen Prionerkrankungen den Kontakt zum pathologischen Prionprotein über ionische Wechselwirkungen herstellen.

Eine verlängerte Inkubationszeit bei einer tierexperimentellen Übertragung des PrP27-30 ohne N-terminale Region im Vergleich zum $\mathrm{PrP}^{\mathrm{Sc}}$ deutet auch hier auf eine Beteiligung der N-terminalen Region neben Helix 1-Helix 1-Kontakten bei der Bildung des pathologischen Prionproteins hin. Unterstützt wird die Bedeutung der Helix 1 bei der $\operatorname{PrP}^{\mathrm{Sc}}$-Propagation durch verschiedene gegen das Helix 1-Motiv gerichtete Antikörper in Zellkulturexperimenten, die jeweils zu einer Inhibierung der $\operatorname{PrP}^{\mathrm{Sc}}$-Bildung führten (Heppner et al., 2001; Enari et al., 2001).

\section{Mechanismus C:}

Der aggregationsfördernde Effekt des $\beta$-Strands S2 in humPrP23-173 relativ zu humPrP23159 kann prinzipiell mit beiden auf das Helix 1-Motiv bezogenen Aggregationsmechanismen verbunden werden. Obwohl es NMR-spektroskopisch keine Evidenz für die Ausbildung eines $\beta$-Faltblattes in humPrP23-173 gab, wies der $\beta$-Strand S2 die stärkste Tendenz zur 
Ausbildung von $\beta$-Faltblattstruktur innerhalb des Prionproteinfragmentes auf. Zusätzlich zur Helix 1-Helix 1-Interaktion oder zur Interaktion der Helix 1 mit der N-terminalen Region könnte eine Wechselwirkung der $\beta$-Strands S2 zwischen verschiedenen Prionproteinen bei der Aggregation von humPrP23-173 zustande kommen. Anstelle eines intramolekularen $\beta$ Faltblattes würden intermolekulare $\beta$-Faltblätter zwischen den $\beta$-Strands S2 ausgebildet werden, die einer dimeren oder multimeren Struktur aus zwei oder mehreren Prionproteinen zusätzliche Stabilität verleihen würden. Die Bildungsgeschwindigkeit von Helix 1-Helix 1Addukten könnte so deutlich erhöht werden, was der Grund für den zusätzlichen Beschleunigungseffekt des Segmentes 160-173 in humPrP23-173 im Vergleich zu humPrP23159 sein könnte.

Aus den hier erzielten Ergebnissen lassen sich verschiedene Mechanismen für die Aggregation des Prionproteins ableiten, bei denen eine zentrale Helix 1 einen auf ionischen Wechselwirkungen basierenden Kontakt zwischen Prionproteinen bzw. zum $\operatorname{PrP}^{\mathrm{Sc}}$ herstellt, der durch den $\beta$-Strand S2 zusätzlich stabilisiert werden könnte. Ein Fehlen der Helix 1Region und der Region mit dem $\beta$-Strand S2 führte hier zu einer Verminderung der Aggregationsneigung des Prionproteins bzw. in anderen Arbeiten zur Inhibierung der $\mathrm{PrP}^{\mathrm{Sc}}$ Bildung.

\subsection{Struktur des pathologischen Prionproteins}

Die dreidimensionale Struktur des infektiösen Erregers könnte entscheidend zum Verständnis der Prionerkrankungen beitragen und einen Ansatz für therapeutische Interventionen bieten. Bislang konnten klassische NMR-Spektroskopie und Röntgenstrukturanalysen aufgrund der Unlöslichkeit des aggregierten Prionproteins bzw. einer nicht perfekten Kristallstruktur von fibrillärem Prionprotein nicht zur Strukturaufklärung des pathologischen $\operatorname{PrP}^{\mathrm{Sc}}$ und des rekombinanten fibrillären Prionproteins beitragen.

Mit dem bekannt werden der ersten NMR-Struktur des Prionproteins (Riek et al., 1996) wurde die isolierte Helix 1 ohne stabilisierende Tertiätkontakte als wahrscheinlichster Kandidat für eine Umfaltung in ein $\beta$-Faltblatt im $\operatorname{PrP}^{\mathrm{Sc}}$ angesehen. In auf Sekundärstrukturanalysen und elektronenkristallographischen Daten basierenden $\operatorname{PrP}^{\mathrm{Sc}}$ Strukturmodellen wird die Region von Aminosäure 90-175 mit der Helix 1 und dem $\beta$ - 
Faltblatt als alleinige Konversionsregion des Prionproteins angesehen. Die Helices 2 und 3 sollen im $\operatorname{PrP}^{\mathrm{Sc}}$ unverändert vorliegen (Govaerts et al., 2004; Wille et al., 2002).

In dieser Arbeit konnte eine direkte Evidenz durch zwei unabhängige Methoden erbracht werden, dass die Helix 1 trotz eines starken Beschleunigungseffektes auf die Aggregation des humanen Prionproteins selbst nicht in ein $\beta$-Faltblatt umfaltet.

Antikörperbindungsstudien an $\operatorname{PrP}^{\mathrm{C}}$ im Vergleich $\mathrm{zu}^{\mathrm{PrP}} \mathrm{P}^{\mathrm{Sc}}$ zeigten, dass das Helix 1-Motiv in beiden Isoformen durch die Antikörper 6H4 und SAF61 detektiert wird (Korth et al., 1997; Paramithiotis et al., 2003; Perrier et al., 2004; Moroncini et al., 2004). Der Antikörper 6H4 wurde darüber hinaus zur Immunopräzipitation von $\operatorname{PrP}^{\mathrm{C}}$ und $\operatorname{PrP}^{\mathrm{Sc}}$ eingesetzt (Paramithiotis et al., 2003). Daraus ergibt sich, dass das Helix 1-Motiv im $\operatorname{PrP}^{C}$ und $\operatorname{PrP}^{\mathrm{Sc}}$ die gleiche Sekundärstruktur aufweisen sollte und nicht in ein $\beta$-Faltblatt umgewandelt wird.
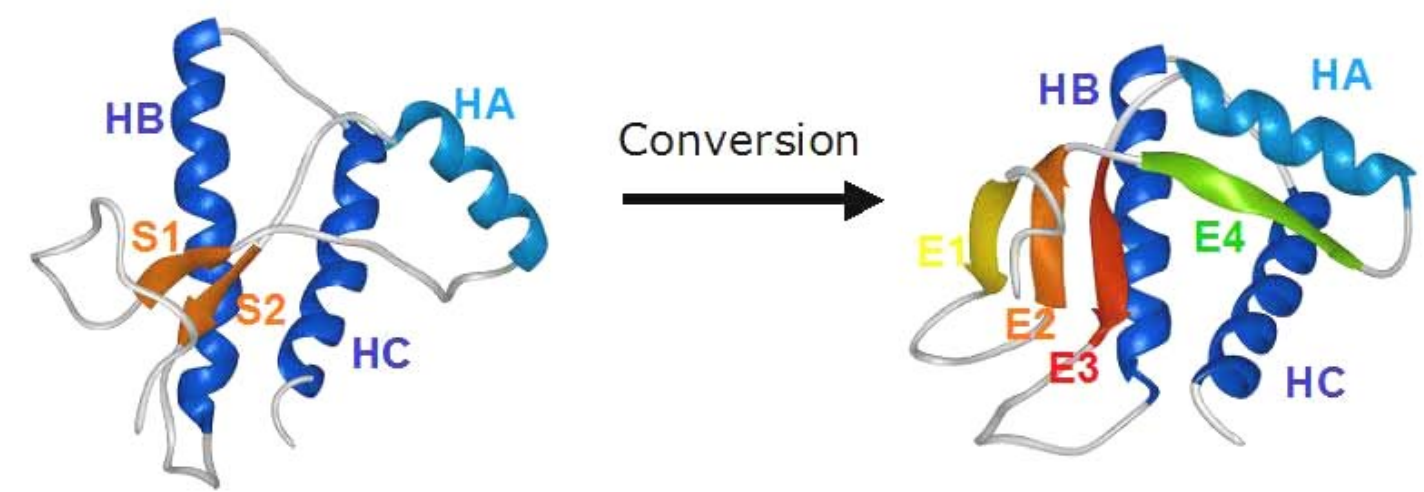

Abb. 26: Alternatives PrP ${ }^{\mathrm{Sc}}$-Strukturmodell (DeMarco und Daggett, 2004). Molekulardynamische (MD) Simulationen der Umfaltung des nativen Prionproteins $\operatorname{PrP}^{\mathrm{C}}$ (Riek et al., 1996, links) führten $\mathrm{zu}$ einem $\mathrm{PrP}^{\mathrm{Sc}}$ Modell, in dem die Region um die $\beta$-Strands S1 und S2 und der Bereich zwischen Helix 2 und Helix 3 im humanen Prionprotein in ein viersträngiges antiparalleles $\beta$-Faltblatt unter Erhalt der Helix 1 umgewandelt wird. HA: Helix 1, HB: Helix 2, HC: Helix 3, S1 und S2: $\beta$-Strands S1 und S2, E1-4: verlängerte $\beta$-Strands 1-4 im $\operatorname{PrP}^{\mathrm{Sc}}$ : E1: 116-119, E2: 129-131, E3: 161-163, E4: 135-140.

In einem auf Molekulardynamischen (MD) Simulationen beruhenden alternativen $\mathrm{PrP}^{\mathrm{Sc}}$ Strukturmodell (DeMarco \& Daggett, 2004) wurde eine Verlängerung der beiden $\beta$-Strands $\mathrm{S} 1$ und $\mathrm{S} 2$ in ein grosses antiparalleles $\beta$-Faltblatt (Abb. 26) als zentrale Einheit der Konversion unter Erhalt der Helix 1 beschrieben. Alle drei $\alpha$-Helices und damit auch die Helix 1 waren in diesem $\operatorname{PrP}^{\mathrm{Sc}}$-Strukturmodell noch existent, wobei insbesondere die Helix 2 in deutlich verkürzter Form vorlag. 
Der $\beta$-Strand S2 führte in dieser Arbeit analog zur Helix 1 zu einer signifikanten Beschleunigung der Aggregation des Prionproteins und erhöhte deutlich die Proteinase KResistenz des Prionproteinfragments humPrP23-173 gegenüber humPrP23-159. Insofern ist anzunehmen, dass zumindest Teile der Region 160-173 um den $\beta$-Strand S2 in ein $\beta$-Faltblatt in fibrillärem humPrP23-173 umgewandeln. Eine quantitative FTIR-Spektroskopie konnte aus zeitlichen Gründen nicht mehr durchgeführt werden, würde aber zu einem wichtigen Aufschluss über die Struktur des Segmentes 160-173 in fibrillärem humPrP23-173 führen. Eine exakte Einschätzung des $\beta$-Faltblattgehaltes der Region 160-173 in fibrillärem PrP23173 konnte deshalb nicht vorgenommen werden.

Kurze Peptide, die neben dem Helix 1-Segment die Proteinsequenz für den $\beta$-Strand S2 umfassten, konnten in $\beta$-Faltblatt-reiche fibrilläre Aggregate umgewandelt werden (Kozin et al., 2001; Jamin et al., 2002), was für die Ausbildung von $\beta$-Faltblattstruktur im Segment 160-173 spricht.

Bei einem Fehlen des $\beta$-Strands S2 konnte verändertes Prionprotein ohne die Aminosäuren 160-163 in Zellkulturexperimenten nicht in $\mathrm{PrP}^{\mathrm{Sc}}$ überführt werden (Vorberg et al. (2001), was die Bedeutung des $\beta$-Faltblattes für die Bildung des pathologischen Prionproteins unterstreicht.

Trunkierte Prionproteine ohne Helix 2 oder Helix 3 zeigten in stabil mit $\operatorname{PrP}^{\mathrm{Sc}}$ transfizierten Neuroblastoma-Zellen keine zum $\operatorname{PrP}^{\mathrm{Sc}}$ vergleichbare Proteinase K-Resistenz (Muramoto et al., 1996), was die eigenen Ergebnisse zur Proteinase K Resistenz von humPrP23-173 direkt bestätigt und für eine Beteiligung der Helices 2 und 3 an der $\mathrm{PrP}^{\mathrm{Sc}}$-Bildung spricht. Bestätigend dazu konnten Helix 2 und Helix 3 umspannende Peptide in $\beta$-Faltblatt-reiche Aggregate umgefaltet werden, während Prionpeptide, die fast nur aus dem sehr polaren Helix 1-Segment bestehen, nicht in fibrilläre Aggregate mit hohem $\beta$-Faltblattanteil umgewandelt werden konnten (Ziegler et al., 2003; Jamin et al., 2002, Sharman et al., 1998). In Versuchen von Tizzano et al. (2005) und Bosques \& Imperiali (2003) wies das kurze Prionpeptid humPrP173-195 mit der Helix 2 bei neutralem pH-Wert eine ausserordentlich hohe Aggregationsneigung auf und konnte auch bei geringer Proteinkonzentration nur für sehr kurze Zeit stabil gehalten werden.

Vergleicht man die hier bestimmten FTIR-spektroskopischen $\beta$-Faltblattanteile von fibrillärem humPrP23-159 und fibrillärem humPrP23-144 mit den $\beta$-Faltblattanteilen im Proteinase $\mathrm{K}$ resistenten $\operatorname{PrP}^{\mathrm{Sc}}$ (Aminosäure 90-231) (Tabelle 1), so ergibt sich, dass jeweils 42 Aminosäuren im aggregierten humPrP23-159 und humPrP23-144 und etwa 67-77 
Aminosäuren im $\operatorname{PrP}^{\mathrm{Sc}}$ in $\beta$-Faltblättern angeordnet sind. Bei einer vergleichbaren Sekundärstruktur der Region 23-159 im $\mathrm{PrP}^{\mathrm{Sc}}$ wie in fibrillärem humPrP23-159 sollten noch 25-35 Aminosäuren ausserhalb der Region 23-159 eine $\beta$-Faltblattstruktur besitzen. Da der vermutete Konversionsbereich im Prionprotein nur den Bereich 90-175 abdecken soll (Govaerts et al., 2004; Wille et al., 2002; DeMarco \& Daggett, 2004), müssen 9-19 Aminosäuren ausserhalb des potentiellen Konversionsbereiches in der Region 176-231 eine $\beta$ Faltblattstruktur aufweisen. Vergleicht man umgekehrt die $\alpha$-helikalen Strukturanteile im $\operatorname{PrP}^{\mathrm{C}}$ mit denen im Proteinase $\mathrm{K}$ verdauten $\mathrm{PrP}^{\mathrm{Sc}}$, müssen bei einer nicht umgefalteten Helix 1 im $\operatorname{PrP}^{\mathrm{Sc}} 27-38$ der 63 Aminosäuren aus $\alpha$-helikalen Segmenten $\operatorname{im} \operatorname{PrP}^{\mathrm{C}}$ in eine andere Struktur im $\mathrm{PrP}^{\mathrm{Sc}}$ umfalten. Selbst wenn die aus 13 Aminosäuren bestehende Helix 1 in random coil umgefaltet würde, was ebenfalls aus den eigenen Ergebnissen abgeleitet werden kann, müssten zusätzlich noch 14-25 Aminosäuren der Helices 2 und 3 ihre Struktur bei der Konversion des Prionproteins verändern (s. Tabelle 1). Die sehr gute Übereinstimmung des Zugewinns an $\beta$-Faltblattstruktur mit dem Verlust an helikaler Struktur in der Region 176231 spricht für die Plausibilität der eigenen Daten und macht eine Beteiligung der Helices 2 und 3 an der Umfaltung des Prionproteins sehr wahrscheinlich.

Kocisco et al konnte im $\operatorname{PrP}^{\mathrm{Sc}}$ zeigen, dass die Helix 1 nicht durch die Proteinase $\mathrm{K}$ abgedaut werden kann (Kocisco et al., 1996). Das resulierende PrP27-30 beinhaltete die Aminosäuren 90-231, in denen auch die Helices 2 und 3 neben der Helix 1 noch intakt waren. Das PrP2730 weist aber noch einen $\alpha$-helikalen Anteil zwischen 18-25\% auf (Tabelle 1, Kapitel 1.3.1.). Ein mangelnder Zugriff der Proteinase $\mathrm{K}$ auf die einzelnen Prionproteine in den $\mathrm{PrP}^{\mathrm{Sc}}$ Aggregaten kann durch eine Abspaltung der N-terminalen Region im $\operatorname{PrP}^{\mathrm{Sc}}$ ausgeschlossen werden (Rogers et al., 1993; Flechsig et al., 2000). Insofern muss die Region 174-231 im $\mathrm{PrP}^{\mathrm{Sc}}$ mit den Helices 2 und 3 direkt vor einem Angriff durch die Proteinase K geschützt sein. Da die Helices 2 und 3 im $\operatorname{PrP}^{\mathrm{C}}$ Proteinase K-sensitiv sind, aber $86 \%$ der Aminosäuren der Region 174-231 ausmachen, die im $\mathrm{PrP}^{\mathrm{Sc}}$ Proteinase K-resistent sind, ist zumindest von Teilbereichen der Helices 2 und 3 eine Umfaltung bei der $\operatorname{PrP}^{\mathrm{Sc}}$-Bildung zu erwarten.

Die Bedeutung der Region 174-231 mit den Helices 2 und 3 für die Infektiösität des Erregers wurde in verschiedenen Tierexperimenten untersucht. Das pathologische Prionprotein aus Patienten mit dem Gerstmann-Sträussler-Scheinker-Syndrom (GSS) ist überwiegend N- und C-terminal trunkiert. Es weist ein Hauptfragment von etwa 7-8 kDa (PrP81/82-144, PrP81/82153) auf, dem die Helix 2 und Helix 3 komplett fehlen (Salmona et al., 2003; Ghetti et al., 2003; Gambetti et al., 2003). Diese trunkierten Prionproteine sind interessanterweise nicht 
mehr infektiös (Chesebro et al., 2005; Tateishi et al., 1996; Brown et al., 1994). Als Ausnahmen seien die mit der GSS assoziierten P102L-Mutation und die OktarepeatInsertionsmutationen im Prnp-Gen anzuführen. Die resultierenden pathologischen Prionproteine werden nicht C-terminal gespalten (Ghetti et al., 2003; Parchi et al., 1998) und stellen die einzigen GSS-assoziierten Prionproteine dar, die sich im Tierexperiment erfolgreich übertragen liessen (Masters et al., 1991; Tateishi et al., 1996; Goldfarb et al., 1992; Hsiao et al., 1992, 1994). Da die Bildung eines infektiösen Prionproteins ohne die Helices 2 und 3 nicht möglich ist, müssen sie an der Konversion des Prionproteins beteiligt sein. Eine komplette Umfaltung der Helices 2 und 3 in $\beta$-Faltblattstruktur im $\operatorname{PrP}^{\mathrm{Sc}}$ wird aber aufgrund der sie stabilisierenden Disulfidbrücke als sehr unwahrscheinlich beurteilt. Welker et al. (2002) konnte in aufgereinigtem und solubilisiertem $\operatorname{PrP}^{\mathrm{Sc}}$ zeigen, dass keine intermolekularen Disulfidbrücken unter Ausbildung dimerer oder multimerer Strukturen existieren (Welker et al., 2002).

Aus der Kristallstruktur des rekombinanten Schaf-Prionproteins PrP123-230 wurde abgeleitet, dass die Region 188-204 mit dem C-terminalen Ende der Helix 2 und dem Turn zwischen Helix 2 und Helix 3 neben den $\beta$-Strands S1 und S2 ein wahrscheinlicher Ausgangspunkt für die Bildung eines grossen $\beta$-Faltblattes sein könnte (Haire et al., 2004). Eine Umfaltung von Teilen der C-terminalen Helices in $\beta$-Faltblattes könnte einen Ansatz für die hohe Proteinase $\mathrm{K}$ Resistenz dieser Regionan liefern und würde im Einklang mit allen strukturellen Anforderungen des $\operatorname{PrP}^{\mathrm{Sc}}$ stehen.

In den $\mathrm{PrP}^{\mathrm{Sc}}$-Strukturmodellen (Govaerts et al., 2004; DeMarco \& Daggett, 2004) wird die Region 90-175 als zentrale Einheit der Konversion ohne Beteiligung der Helices 2 und 3 beschrieben. Gegen das Strukturmodell von Govaerts et al. (2004) sprechen folgende Aspekte: Die Helix 1 wird bei der Konversion des Prionproteins nicht in ein $\beta$-Faltblatt umgefaltet (Watzlawik et al., 2006). Es ist sehr evident, dass die Helices 2 und 3 an der Konversion des Prionproteins beteiligt sind, was in diesem Modell nicht berücksichtigt wird. Darüber hinaus wird die Anwesenheit von $\beta$-Helices in amyloiden Fibrillen als sehr unwahrscheinlich beurteilt (Khurana \& Fink, 2000). Aus dieser Datenlage heraus scheint dieses Modell (Abb. 27) die Struktur des infektiösen $\operatorname{PrP}^{\mathrm{Sc}}$-Erregers nur unvollständig korrekt wiedergeben zu können. 


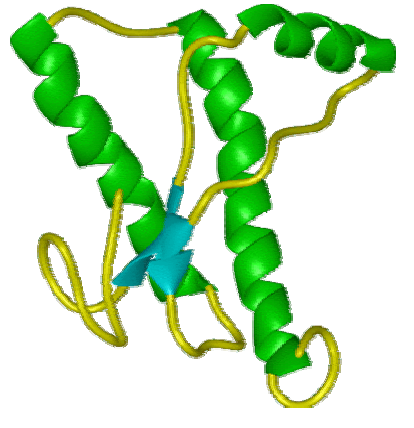

$\operatorname{PrP}^{\mathrm{C}}$ (Riek et al., 1996)

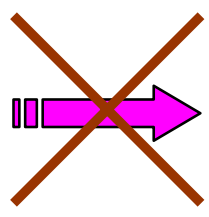

trimere Einheit im $\operatorname{PrP}^{\mathrm{Sc}}$-Modell (Govaerts et al., 2004)

Abb. 27: Beurteilung des aktuellen PrP ${ }^{\mathrm{Sc}}$-Strukturmodells (Govaerts et al., 2004). Die Bildung einer parallelen linksgewundenen trimeren $\beta$-Helix aus nativem $\operatorname{PrP}^{\mathrm{C}}$ (links, Zahn et al., 2000) innerhalb der Region 90-175 im PrP $^{\mathrm{Sc}}$-Modell (rechts, Govaerts et al., 2004)) steht im Widerspruch zur aktuellen Erkenntnislage über die Helix 1 im humanen Prionprotein und der strukturellen Analytik des infektiösen Erregers.

Im $\mathrm{PrP}^{\mathrm{Sc}}$-Strukturmodell von DeMarco \& Daggett (2004) (Abb. 26) wird die Region 90-175 ohne Beteiligung der Helix 1 in ein $\beta$-Faltblatt umgewandelt. Durch eine deutliche Verkürzung der drei Helices und insbesondere der Helix 2 soll der $\alpha$-helikale Gehalt in diesem Modell entsprechend den experimentell bestimmten Werten $\mathrm{im}^{\mathrm{PrP}} \mathrm{P}^{\mathrm{Sc}}$ angepasst werden. Teile der Helices 2 und 3 falten in diesem Modell allergings in random coil und nicht in $\beta$-Faltblatt um. Damit ist auch aus diesem Modell nicht ersichtlich, warum die Helices 2 und 3 für die Infektiösität des Erregers essentiell sind und eine starke Proteinase K Resistenz im $\operatorname{PrP}^{\mathrm{Sc}}$ erzeugen.

Eine Erklärung für die ungewöhnliche Proteinase K-Resistenz des pathologischen Prionprotein trotz $\alpha$-helikalen Charakters könnte in einer starken Zusammenlagerung der kompakten globulären C-terminalen Domänen von mehreren Prionproteinen unter Ausbildung einer Mizellen-ähnlichen Anordnung liegen. Die unstrukturierten und flexiblen N-terminalen Bereiche des Prionproteins würden jeweils nach aussen weisen und proteolytisch angreifbar sein, was die Erklärung für das Fehlen der N-terminalen Region im PrP27-30 sein könnte. Die teilweise umgefalteten Helices 2 und 3 würden sich im Innereren der Strukturen befinden und vor einem Angriff der Proteinase K durch die resistenten Regionen 97-140 geschützt werden, während die Helix 1 umgeben von $\beta$-Faltblattstruktur mehr zur Aussenseite orientiert und den Kontakt zu anderen Prionproteinen herstellen könnte. 


\section{Ausblick}

In dieser Arbeit konnte gezeigt werden, dass die Helix 1 die Aggregation des humanen Prionproteins beschleunigt ohne selbst in ein $\beta$-Faltblatt umzufalten. Strukturelle Analysen des $\operatorname{PrP}^{\mathrm{Sc}}$ machen aber eine Konversion helikaler Bereiche des Prionproteins erforderlich. Wenn die Helix 1 nicht an der Umfaltung des Prionproteins beteiligt ist, müssen zumindest Teile der Helices 2 und 3 ihre Struktur im $\operatorname{PrP}^{\mathrm{Sc}}$ verändern.

Aus dieser Sicht erscheint es sinnvoll, die Aggregation der humanen Prionproteinfragmente humPrP23-194 und humPrP23-199 sowie des Volllängen-Prionproteins zu untersuchen. Durch einen Vergleich der Aggregation dieser Fragmente bzw. des Volllängen-Prionproteins könnte der Einfluss der Helix 2, der Helix 3 und des Turns zwischen Helix 2 und Helix 3 untersucht werden, die als indirektes Resultat dieser Arbeit in die $\operatorname{PrP}^{\mathrm{Sc}}$-Bildung involviert sind. Eine quantitative FTIR-Spektroskopie der fibrillären Prionproteine könnte einen Einblick darüber geben, welche Struktur diese Segmente im aggregiertem Zustand einnehmen. Auf diese Weise könnte ein vertiefender Einblick in den Mechanismus der Aggregation des humanen Prionproteins und seiner Amyloidstruktur gewonnen werden. Zusätzlich könnte eine sehr viel versprechende neuere Methode der Festkörper-NMRStrukturanalyse eingesetzt werden, anhand derer eine definitive Aussage über die Struktur des fibrillären Prionproteins getroffen werden könnte. 


\section{Zusammenfassung}

Bei den Prionerkrankungen wird das $\alpha$-helikale $\operatorname{PrP}^{\mathrm{C}}$ in ein $\beta$-Faltblatt-reiches, Proteinase $\mathrm{K}$ resistentes aggregiertes $\mathrm{PrP}^{\mathrm{Sc}}$ umgewandelt. Obwohl im Gegensatz zur Region 90-145 keine direkten Evidenzen für eine Umfaltung der Region 146-175 bestanden, gingen alle bisherigen $\mathrm{PrP}^{\mathrm{Sc}}$-Strukturmodelle davon aus, dass die Helix 1 (AS 144-156) in $\beta$-Faltblatt umgewandelt wird. Daher wurde erstmals die Aggregation der Prionproteinfragmente humPrP23-159, ein GSS-assoziiertes humanpathogenes Prionprotein, und humPrP23-173 im Vergleich zu humPrP23-144 unter physiologischen Bedingungen untersucht. Trotz einer deutlich schnelleren Aggregation von humPrP23-159 im Vergleich zu humPrP23-144 stellte sich überraschenderweise heraus, dass Helix 1 nicht in $\beta$-Faltblatt konvertiert wird. Dieser Effekt lässt sich nur durch intermolekulare ionische Wechselwirkung zwischen den zu 50 \% geladenen Helix 1 -Segmenten erklären. Der aggregationsbeschleunigende Einfluß des $\beta$-Strand S2 enthaltenden Segmentes 160-173 in humPrP23-173 im Vergleich zu humPrP23-159, sowie die erhöhte Proteinase K-Resistenz des fibrillären humPrP23-173 legt nahe, dass dieser Bereich unter Ausbildung von intermolekularem $\beta$-Faltblatt direkt an der Aggregation beteiligt ist.

Um herauszufinden welchen Einfluß der $\mathrm{pH}-$ Wert auf die spontane Aggregation des Prionproteins während der Endozytose hat, wurde die pH-Abhängigkeit der Aggregation unter physiologischen, nicht-denaturierenden Bedingungen anhand der Prionproteinfragmente humPrP23-144 und humPrP23159 bestimmt. Im Gegensatz zu unter denaturierenden Bedingungen durchgeführten Arbeiten, konnten fibrilläre Strukturen der Prionproteinfragmente nur oberhalb eines pH-Wertes von 6.0 beobachtet werden. Daher ist fraglich, ob die Erniedrigung des $\mathrm{pH}$-Wertes in den endosomalen Kompartimenten während der Endozytose tatsächlich die spontane Aggregation des Prionproteins, wie bisher angenommen, fördert.

Vergleicht man die $\beta$-Faltblattanteile des Proteinase $\mathrm{K}$ resistenten $\operatorname{PrP}^{\mathrm{Sc}}(\sim \mathrm{AS} 90-231)$ mit denen der fibrillären Aggregate von humPrP23-159 und humPrP23-144, sowie die $\alpha$-helikalen Anteile von $\operatorname{PrP}^{\mathrm{Sc}}$ mit denen im $\operatorname{PrP}^{\mathrm{C}}$, so müssten in der Region 145-231 annähernd genau so viele Aminosäuren in $\beta$ Faltblatt umgewandelt werden, wie an $\alpha$-Helix verloren gehen. Da die Helix 1 nicht in $\beta$-Faltblatt umgewandelt wird, müssen die bisher nicht berücksichtigten Helices 2 und 3 an der Umfaltung beteiligt sein. Das würde auch die ungewöhnliche Proteinase K Resistenz der Region 176-231 im $\mathrm{PrP}^{\mathrm{Sc}}$ mit den Helices 2 und $3 \mathrm{im}$ Vergleich zum $\operatorname{PrP}^{\mathrm{C}}$ erklären. Unterstützt wird dies zusätzlich durch die Tatsache, dass die Erzeugung der Infektiösität von der Gegenwart der Helix 2 und 3 abhängig ist. Daher scheint der Mechanismus der spontanen Aggregation des Prionproteins in vivo deutlich anders abzulaufen, als bisher angenommen. 


\section{Literaturverzeichnis}

Alper, T., Haig, D. A., Clarke, M. C. (1966). Biochem. Biophys. Res. Commun. 22, 278-284.

Alper, T., Cramp, W. A., Haig, D. A., Clarke, M. C. (1967). Nature 214, 764-766.

Anfinsen, C. B. (1973). Science 181, 223-30.

Apetri, A. C., Surewicz, W. K. (2003). J. Biol. Chem. 278, 22187-22192.

Arnold, J. E., Tipler, C., Laszlo, L., Hope, J., Landon, M., Mayer, R. J. (1995). J. Pathol. 176, 403-411.

Barghorn, S., Mandelkow, E. (2002). Biochemistry 41, 14885-96.

Baskakov, I. V., Legname, G., Prusiner, S. B., Cohen, F. E. (2001). J. Biol. Chem. 276, 19687-90.

Bax, A., and Grzesiek, S. (1993). Accounts Chem. Res. 26, 131-138.

Beranger, F., Mange, A., Goud, B., Lehmann, S. (2002). J Biol Chem. 277, 38972-7.

Bessen, R. A., Marsh, R. F. (1992). J. Virol. 66, 2096-2101.

Bessen, R. A., Marsh, R. F. (1994). J. Virol. 68, 7859-7868.

Bessen, R. A., Kocisko, D. A., Raymond, G. J., Nandan, S., Lansbury, P. T., Caughey, B. (1995). Nature 375, 698-700.

Bjerrum, O.J. und Nielsen, C. S. (1986). Electrophoresis. VCH Publishers, Deerfield Beach, Fla., 315-327. 
Bocharova, O. V., Breydo, L., Salnikov, V. V., Baskakov, I. V. (2005a). Biochemistry 44, 6776-87.

Bocharova O. V., Breydo, L., Parfenov, A. S., Salnikov, V. V., Baskakov, I. V. (2005b). J Mol Biol. 346, 645-59.

Böhm, G., Muhr, R. \& Jaenicke, R. (1992). Prot. Eng. 5, 191-195.

Borchelt, D. R., Taraboulos, A., Prusiner, S. B. (1992). J. Biol. Chem. 267, 16188-16199.

Bosques, C. J., Imperiali, B. (2003). Proc. Natl. Acad. Sci. USA 100, 7593-8.

Brandner, S., Isenmann, S., Raeber, A., Fischer, M., Sailer, A., Kobayashi, Y., Marino, S., Weissmann, C., Aguzzi, A. (1996a). Nature 379, 339-346.

Brandner, S., Raeber, A., Sailer, A., Blättler, T., Fischer, M., Weissmann, C., Aguzzi, A. (1996b). Proc. Natl. Acad. Sci. USA 93, 13148-13151.

Breydo, L., Bocharova, O. V., Baskakov, I. V. (2005). Anal Biochem. 339, 165-73.

Brown, D. R., Qin, K., Herms, J. W., Madlung, A., Manson, J., Strome, R., Fraser, P. E., Kruck, T., von Bohlen, A., Schulz-Schaeffer, W., Giese, A., Westaway, D., Kretzschmar, H. A. (1997). Nature 390, 684-687.

Brown, D. R. (2001). Brain Res Bull. 55, 165-73.

Brown, P., Gibbs, C. J. Jr., Rodgers-Johnson, P., Asher, D. M., Sulima, M. P., Bacote, A., Goldfarb, L. G., Gajdusek, D. C. (1994). Ann Neurol. 35, 513-29.

Bruce, M. E., McConnell, I., Fraser, H., Dickinson, A. G. (1991). J Gen Virol. 72, 595-603

Bruce, M. E., Chree, A., McConnell, I., Foster, J., Pearson, G., Fraser, H. (1994). Phil. Trans. R. Soc. Lond. B. 343, 405-411. 
Bruce, M. E., Will, R. G., Ironside, J. W., McConnel, I., Drummond, D., Suttie, A., McCardle, L., Chree, A., Hope, J., Birkett, C., Cousens, S., Fraser, H., Bostock, C. J. (1997). Nature 389, 498-501.

Bruce, M. (2003). British Medical Bulletin 66, 99-108.

Büeler, H., Fischer, M., Lang, Y., Bluethmann, H., Lipp, H. P., DeArmond, S. J., Prusiner, S. B., Aguet, M., Weissmann, C. (1992). Nature 356, 577-582.

Büeler, H., Aguzzi, A., Sailer, A., Greiner, R.-A., Autenried, P., Aguet, M. und Weissmann, C. (1993). Cell 73, 1339-1347.

Bullock, W. O., Fernandez, J. M und Short, J. M. (1987). BioTechniques 5, 376-378.

Calzolai, L., Zahn, R. (2003). J Biol Chem. 278, 35592-6.

Caughey, B., Race, R. E., Ernst, D., Buchmeier, M. J., \& Chesebro, B. (1989). J. Virol. 63, 175-181.

Caughey, B. W., Dong, A., Bhat, K. S., Ernst, D., Hayes, S. F., Caughey, W. S. (1991). Biochemistry 30, 7672-7680.

Chesebro, B., Trifilo, M., Race, R., Meade-White, K., Teng, C., LaCasse, R., Raymond, L., Favara, C., Baron, G., Priola, S., Caughey, B., Masliah, E., Oldstone, M.. (2005). Science. 308, 1435-9.

Chiarini, L. B., Freitas, A. R., Zanata, S. M., Brentani, R. R., Martins, V. R., Linden, R. (2002). EMBO J. 21, 3317-26.

Cohen, F.E. (1999). J Mol Biol. 293, 313-20.

Cohen, E. and Taraboulos, A. (2003). EMBO J. 22, 404-417. 
Collinge, J. (2005). J. Neurol. Neurosurg. Psychiatry 76, 906-919.

Cordeiro, Y., Kraineva, J., Gomes, M. P., Lopes, M. H., Martins, V. R., Lima, L. M., Foguel, D., Winter, R., Silva, J. L. (2005). Biophys J. 89, 2667-76.

Creutzfeldt, H. G. (1920). Z. Gesamte Neurol. Psychiatr. 57, 1-18.

Delaglio, F., Grzesiek, S., Vuister, G. W., Zhu, G., Pfeifer, J. and Bax, A. (1995). J. Biom. NMR 6, 277-293.

DeMarco, M.L., Daggett, V. (2004). Proc. Natl. Acad. Sci. USA 101, 2293-2298.

Dickinson, A. G. (1976). Front Biol. 44, 209-41.

Diener, T. O., McKinley, M. P., Prusiner, S. B. (1982). Proc. Natl. Acad. Sci. USA 79, 52205224.

Enari, M., Flechsig, E., Weissmann, C. (2001). Proc. Natl. Acad. Sci. USA 98, 9295-9.

Flechsig, E., Shmerling, D., Hegyi, I., Raeber, A. J., Fischer, M., Cozzio, A., von Mering, C., Aguzzi, A., Weissmann, C. (2000). Neuron 27, 399-408.

Frankenfield, K. N., Powers, E. T., Kelly, J. W. (2005). Protein Sci. 14, 2154-66.

Gajdusek, D. C., Zigas, V. (1959). Am. J. Med. 26, 442-469.

Gambetti, P., Kong, Q., Zou, W., Parchi, P., Chen, S. G. (2003). Br Med Bull. 66, 213-39.

Gasset, M., Baldwin, M. A., Fletterick, R. J., Prusiner, S. B. (1993). Proc. Natl. Acad. Sci. USA 90, 1-5.

Gerstmann, J., Sträussler, E., Scheinker, I. (1936). Z. Neurol. 154, 736-762. 
Ghetti, B., Piccardo, P., Spillantini, M. G., Ichimiya, Y., Porro, M., Perini, F., Kitamoto, T., Tateishi, J., Seiler, C., Frangione, B., Bugiani, O., Giaccone, G., Prelli, F., Goedert, M., Dlouhy, S. R., Tagliavini, F. (1996). Proc. Natl. Acad. Sci. USA 93, 744-8.

Ghetti, B., Tagliavini, F., Takao, M., Bugiani, O., Piccardo, P. (2003). Clin Lab Med. 23, 6585.

Gill, S. C., von Hippel, P. H. (1989). Anal Biochem 182, 319-326.

Glatzel, M., Stoeck, K., Seeger, H., Luhrs, T., Aguzzi, A.(2005). Arch Neurol. 62, 545-552.

Goldfarb, L. G., Petersen, R. B., Tabaton, M., Brown, P., LeBlanc, A. C., Montagna, P., Cortelli, P., Julien, J., Vital, C., Pendelbury, W. W., Haltia, M., Wills, P. R., Hauw, J.-J., McKeever, P. E., Monari, L., Schrank, B., Swergold, G. D., Autilio-Gambetti, L., Gajdusek, D. C., Lugaresi, E., Gambetti, P. (1992). Science 258, 806-808.

Govaerts, C., Wille, H., Prusiner, S.B., Cohen, F.E. (2004). Proc. Natl. Acad. Sci. USA 101, 8342-7.

Griffith, J. S. (1967). Nature 215, 1043-1044.

Haire, L. F., Whyte, S. M., Vasisht, N., Gill, A. C., Verma, C., Dodson, E. J., Dodson, G. G., Bayley, P. M. (2004). J Mol Biol. 336, 1175-83.

Hanahan, D. (1983). Journal of Molecular Biology 166, 557-580.

Harris, D.A. (2003). British Medical Bulletin 66, 71-85.

Heppner, F. L., Musahl, C., Arrighi, I., Klein, M. A., Rulicke, T., Oesch, B., Zinkernagel, R. M., Kalinke, U., Aguzzi, A. (2001). Science 294, 178-82.

Hill, A.F., Desbruslais, M., Joiner, S. (1997) Nature 389, 448-50. 
Hornemann, S., Korth, C., Oesch, B., Riek, R., Wider, G., Wuthrich, K., Glockshuber, R. (1997). FEBS Lett. 413, 277-81

Hornshaw, M. P., McCermott, J. R., Candy, J. M. (1995). Biochem. Biophys. Res. Commun., 207, 621-629.

Hoyer, W., Cherny, D., Subramaniam, V., Jovin, T. M. (2004). Biochemistry 43, 1623316242.

Hsiao, K., Dlouhy, S. R., Farlow, M. R., Cass, C., DaCosta, M., Conneally, P. M., Hodes, M. E., Ghetti, B., Prusiner, S. B.(1992). Nat Genet. 1, 68-71.

Hsiao, K. K., Groth, D. F., Scott, M., Yang, S. L., Serbam, H., Rapp, D., Foster, D., Torchia, M., DeArmond, S. J. und Prusiner, S. B. (1994). Proc. Natl. Acad. Sci. USA 91, 9126-9130.

Huang, Z., Prusiner, S.B., Cohen, F.E. (1996). Fold Des. 1, 13-19.

Ironside, J. W., Ritchie, D. L., Head, M. W. (2005). Neuropathol Appl Neurobiol. 31,565-79.

Jakob, A. (1921). Z. Gesamte Neurol. Psychiatr. 64, 147-228.

Jamin, N., Coic, Y. M., Landon, C., Ovtracht, L., Baleux, F., Neumann, J. M., Sanson, A. (2002). FEBS Lett. 529, 256-60.

Jones, E. M. \& Surewicz, W. K. (2005). Cell 121, 63-72.

Kaneko, K., Zulianello, L., Scott, M., Cooper, C. M., Wallace, A. C., James, T. J., Cohen, F. E., Prusiner, S. B. (1997). Proc. Natl. Acad. Sci. USA 94, 10069-10074.

Kascsak, R. J., Rubenstein, R., Merz, P. A., Tonna-DeMasi, M., Fersko, R., Carp, R. I., Wisniewski, H. M. und Diringer, H. (1987). Journal of Virology 61, 3688-3693. 
Kellings, K., Meyer, N., Mirenda, C., Prusiner, S. B., Riesner, D. (1992a). J. Gen. Virol. 73, 1025-1029.

Kellings, K., Meyer, N., Mirenda, C., Prusiner, S. B., Riesner, D. (1992b). Arch. Virol. Suppl. 7, 215-225.

Khurana, R., Fink, A.L. (2000). Biophys J. 78, 994-1000.

Kocisko, D.A., Lansbury Jr, P.T., Caughey, B. (1996). Biochemistry 35, 13434-42.

Korth, C., Stierli, B., Streit, P., Moser, M., Schaller, O., Fischer, R., Schulz-Schaeffer, W., Kretzschmar, H., Raeber, A., Braun, U., Ehrensperger, F., Hornemann, S., Glockshuber, R., Riek, R., Billeter, M., Wuthrich, K., Oesch, B.(1997). Nature. 390, 74-7.

Kozin, S. A., Bertho, G., Mazur, A. K., Rabesona, H., Girault, J. P., Haertle, T., Takahashi, M., Debey, P., Hoa, G. H. (2001). J Biol Chem. 276, 46364-70.

Kramer, M. L., Kratzin, H. D., Schmidt, B., Römer, A., Windl, O., Liemann, S., Hornemann, S., Kretzschmar, H. (2001). J. Biol. Chem. 276, 16711-16719.

Krasemann, S., Groschup, M. H., Harmeyer, S., Hunsmann, G. und Bodemer, W. (1996). Molecular Medicine 2, 725-734.

Kretzschmar, H. A., Stowring, L. E., Westaway, D., Stubblebine, W. H., Prusiner, S. B., DeArmond S. J. (1986). DNA 5, 315-324.

Kretzschmar, H., Kapitel 26: „Die Pathologie und Genetik der Prionkrankheiten beim Menschen“ aus Hörnlimann, B., Kretzschmar, H., Riesner, D. (Hrsg.) (2001). „Prionen und Prionerkrankungen“, Walter de Gruyter-Verlag, New York, 207-224.

Kundu, B., Maiti, N. R., Jones, E. M., Surewicz, K. A., Vanik, D. L. \& Surewicz, W. K. (2003). Proc. Natl. Acad. Sci. USA 100, 12069-12074. 
Kyhse-Andersen, J. (1984). J. Biochem. Biophys. Meth. 10, 203-209.

Laemmli, U. K. (1970). Nature 227, 680-685.

Lasmézas, C. I., Deslys, J.-P., Demaimey, R., Adjou, K. T., Dormont, D., Robain, O., Ornside, J., Hauw, J.-J. (1996). Nature 381, 743-744.

Lee, K. S., Magalhaes, A. C., Zanata, S. M., Brentani, R. R., Martins, V. R., Prado, M. A. (2001) J Neurochem. 79, 79-87.

Li, W., West, N.; Colla, E., Pletnikova, O., Troncoso, J. C., Marsh, L., Dawson, T. M., Jakala, P., Hartmann, T., Price, D. L., Lee, M. K. (2005). Proc. Natl. Acad. Sci. USA 102, 2162-2167.

Liemann, S., Glockshuber, R. (1999). Biochemistry 38, 3258-67.

Liu, H., Farr-Jones, S., Ulyanov, N. B., Llinas, M., Marqusee, S., Groth, D., Cohen, F. E., Prusiner, S. B., James, T. L. (1999). Biochemistry 38, 5362-77.

Ma, J., Lindquist, S. (2002). Science 298, 1785-8.

Ma, J., Wollmann, R., Lindquist, S.(2002). Science 298, 1781-5.

Mallucci, G. R., Ratte, S., Asante, E. A., Linehan, J., Gowland, I., Jefferys, J. G., Collinge, J. (2002). EMBO J. 21, 202-210.

Mallucci, G., Dickinson, A., Linehan, J., Klohn, P. C., Brandner, S., Collinge, J. (2003). Science 302, 871-874.

Manetto, V., Medori, R., Cortelli, P., Montagna, P., Tinuper, P., Baruzzi, A., Rancurel, G., Hauw, J.-J., Vanderhaeghen, J.-J., Mailleux, P., Bugiani, O., Tagliavini, F., Bouras, C., Rizzuto, N., Lugaresi, E., Gambetti, P. (1992). Neurology 42, 312-319.

Masters, C. L., Gajdusek, D. C. und Gibbs, C. J. (1981). Brain 104, 559-588. 
McKinley, M. P., Taraboulos, A., Kenaga, L., Serban, D., Stieber, A., DeArmond, S. J., Prusiner, S. B., Gonatas, N. (1991). Lab. Invest. 65, 622-630.

Medori, R., Tritschler, H.-J., LeBlanc, A., Villare, F., Manetto, V., Chen, H. Y., Xue, R., Leal, S., Montagna, P., Cortelli, P., Tinuper, P., Avoni, P., Mochi, M., Baruzzi, A., Hauw, J.J., Ott, J., Lugaresi, E., Autilio-Gambetti, L., Gambetti, P. (1992). N. Engl. J. Med. 42, 444449.

Meyer, N. Rosenbaum, V., Schmidt, B., Gilles, K., Mirenda, C., Groth, D., Prusiner, S. B., Riesner, D. (1991). J. Gen. Virol. 72, 37-50.

Mironov, A. Jr., Latawiec, D., Wille, H., Bouzamondo-Bernstein, E., Legname, G., Williamson, R. A., Burton, D., DeArmond, S. J., Prusiner, S. B., Peters, P. J. Jr. (2003). J. Neurosci. 23, 7183-7193

Morillas, M., Vanik, D. L., Surewicz, W.K. (2001). Biochemistry 40, 6982-6987.

Moroncini, G., Kanu, N., Solforosi, L., Abalos, G., Telling, G. C., Head, M., Ironside, J., Brockes, J. P., Burton, D. R., Williamson, R. A. (2004). Proc Natl Acad Sci U S A. 101, 10404-9.

Morrissey, M. P. \& Shakhnovich, E. I. (1999). Proc. Natl. Acad. Sci. USA 96, 11293-8.

Mouillet-Richard, S., Pietri, M., Schneider, B., Vidal, C., Mutel, V., Launay, J. M., Kellermann, O. (2005). J Biol Chem. 280, 4592-601.

Mullis, K. B. und Faloona, F. A. (1987). Meth. Enzymol. 155, 335-350.

Muramoto, T., Scott, M., Cohen, F. E., Prusiner, S. B. (1996). Proc. Natl. Acad. Sci. USA 93, 15457-62.

Murray, I. V., Giasson, B. I., Quinn, S. M., Koppaka, V., Axelsen, P. H., Ischiropoulos, H., Trojanowski, J. Q., Lee, V. M. (2003). Biochemistry 42, 8530-40. 
Nishimura, A., Morita, M., Nishimura, Y. und Sugino, Y. (1990). Nucleic Acids Research 18, 6169.

Norstrom, E. M., Mastrianni, J. A. (2006). J Virol. 80, 8521-9.

Pan, K.-M., Baldwin, M., Nguyen, J., Gasset, M., Servban, A., Groth, D., Mehlhorn, I., Huang, Z., Fletterick, R. J., Cohen, F. E., Prusiner, S. B. (1993). Proc. Natl. Acad. Sci. USA 90, $10962-10966$.

Paramithiotis, E., Pinard, M., Lawton, T., LaBoissiere, S., Leathers, V. L., Zou, W. Q., Estey, L. A., Lamontagne, J., Lehto, M. T., Kondejewski, L. H., Francoeur, G. P., Papadopoulos, M., Haghighat, A., Spatz, S. J., Head, M., Will, R., Ironside, J., O'Rourke, K., Tonelli, Q., Ledebur, H. C., Chakrabartty, A., Cashman, N. R. (2003). Nat. Med. 9, 893-9.

Parchi, P., Chen, S. G., Brown, P., Zou, W., Capellari, S., Budka, H., Hainfellner, J., Reyes, P. F., Golden, G. T., Hauw, J. J., Gajdusek, D. C., Gambetti, P. (1998). Proc Natl Acad Sci U S A. 95, 8322-7.

Parchi, P., Zou, W., Wang, W., Brown, P., Capellari, S., Ghetti, B., Kopp, N., SchulzSchaeffer, W. J., Kretzschmar, H. A., Head, M. W., Ironside, J. W., Gambetti, P., Chen, S. G. (2000). Proc. Natl. Acad. Sci. USA 97, 10168-72.

Pauly, P. C., Harris, D. A. (1998). J Biol Chem. 273, 33107-10.

Pawar, A. P., Dubay, K. F., Zurdo, J., Chiti, F., Vendruscolo, M., Dobson, C. M. (2005). J. Mol. Biol. 350, 379-92.

Peretz, D., Williamson, R. A., Matsunaga, Y., Serban, H., Pinilla, C., Bastidas, R. B., Rozenshteyn, R., James, T. L., Houghten, R. A., Cohen, F. E., Prusiner, S. B., Burton, D. R. (1997). J. Mol. Biol. 273, 614-22.

Perrier, V., Solassol, J., Crozet, C., Frobert, Y., Mourton-Gilles, C., Grassi, J., Lehmann, S. (2004). J. Neurochem. 89, 454-63. 
Peters P. J., Mironov, A., Vey, M., Peretz, D., van Donselaar, E., Leclerc, E., Erpel, S., DeArmond, S. J., Burton, D. R., Williamson, R. A., Prusine, S. B. (2003). J Cell Biol 162, 703-717.

Prado, M. A. et al. (2004). J. Neurochem. 88, 769-781.

Prusiner, S. B. (1982). Science 216, 136-144.

Rezaei, H., Marc, D., Choiset, Y., Takahashi, M., Hui Bon Hoa, G., Haertle, T., Grosclaude, J., Debey, P. (2000). Eur J Biochem. 267, 2833-9.

Riek, R., Hornemann, S., Wider, G., Billeter, M., Glockshuber, R. und Wüthrich, K. (1996). Nature 382, 180-182.

Riek, R., Hornemann, S., Wider, G., Glockshuber, R., Wüthrich, K. (1997). FEBS Lett. 413, 282-288.

Righetti, P. G., Verzola, B. (2001). Electrophoresis 22, 2359-74.

Robinson, A.B., Rudd, C.J. (1974). Curr Top Cell Regul. 8, 247-95.

Rogers, M., Yehiely, F., Scott, M., Prusiner, S. B. (1993). Proc. Natl. Acad. Sci. USA 90, 3182-3186.

Saiki, R. K., Gelfland, D. H., Stoffel, S., Scharf, S. J., Higuchi, R., Horn, G. T., Mullis, K.B. und Erlich, H. A. (1988). Science 239, 487-491.

Salmona, M., Morbin, M., Massignan, T., Colombo, L., Mazzoleni, G., Capobianco, R., Diomede, L., Thaler, F., Mollica, L., Musco, G., Kourie, J. J., Bugiani, O., Sharma, D., Inouye, H., Kirschner, D. A., Forloni, G., Tagliavini, F. (2003). J Biol Chem. 278, 48146-53.

Sambrook, J., Fritsch, E. F. und Maniatis, T. (1989). Molecular cloning: a laboratory manual, 2nd Ed.. Cold Spring Harbor Laboratory, Cold Spring Harbor, New York. 
Sarnataro, D., Campana, V., Paladino, S., Stornaiuolo, M., Nitsch, L., Zurzolo, C. (2004). Mol Biol Cell.15, 4031-42.

Schätzl, H. M., DaCosta, M., Taylor, L., Cohen, F. E., Prusiner, S. B. (1995). J. Mol. Biol. 245, 362-374.

Schmid, F.X. (1989). "Spectral methods of characterizing protein conformation and conformational changes”. In Creighton, T.E., ed. Protein structure, a practical approach. Oxford University Press.

Schwarzinger, S., Kroon, G.J., Foss, T.R., Chung, J., Wright, P.E., Dyson, H.J. (2001). J Am Chem Soc. 123, 2970-2978.

Scott, M. R., Will, R., Ironside, J. W., Nguyen, H.-O. B., Tremblay, P., DeArmond, S. J., Prusiner, S. B. (1999). Proc. Natl. Acad. Sci. USA 96, 15137-15142.

Sharman, G. J., Kenward, N., Williams, H. E., Landon, M., Mayer, R. J., Searle, M. S. (1998). Fold. Des. 3, 313-20.

Sokolowski, F., Modler, A. J., Masuch, R., Zirwer, D., Baier, M., Lutsch, G., Moss, D. A., Gast, K., Naumann, D. (2003). J Biol Chem. 278, 40481-92.

Speare, J., Rush III, T., Bloom, M., Caughey, B. (2003). J. Biol. Chem 278, 12522-12529.

Studier, F. W. und Moffatt, B. A (1986). Journal of Molecular Biology 189, 113-130.

Swietnicki, W., Petersen, R., Gambetti, P., Surewicz W. K. (1997). J Biol Chem. 272, 2751727520.

Swietnicki, W., Petersen, R. B., Gambetti, P., Surewicz, W. K. (1998). J Biol Chem. 273, 31048-52. 
Swietnicki, W., Morillas, M., Chen, S. G., Gambetti, P., Surewicz, W. K. (2000). Biochemistry 39, 424-431.

Taraboulos, A., Raeber, A. J., Borchelt, D. R., Serban, D., Prusiner, S. B. (1992). Mol Biol Cell. 3, 851-63.

Tateishi, J., Kitamoto, T., Hoque, M. Z., Furukawa, H.. (1996). Neurology 46, 532-7.

Tizzano, B., Palladino, P., De Capua, A., Marasco, D., Rossi, F., Benedetti, E., Pedone, C., Ragone, R., Ruvo, M. (2005). Proteins. 59, 72-9.

Tobias, J.W., Shrader, T. E., Rocap, G., Varshavsky, A. (1991). Science 254, 1374-1377.

Torrent, J., Alvarez-Martinez, M. T., Harricane, M. C., Heitz, F., Liautard, J. P., Balny, C., Lange, R.(2004). Biochemistry 43, 7162-70.

Towbin, H., Staehlin, T. und Gordon, J. (1979). Proc. Natl. Acad. Sci. USA 76, 4350-4354.

Towbin, H. und Gordon, J. (1984). J. Immunol. Meth. 72, 313.

Vanik, D. L., Surewicz, K. A. \& Surewicz, W. K. (2004). Mol. Cell 14, 139-45.

Vey, M., Pilkuhn, S., Wille, H., Nixon, R., DeArmond, S. J., Smart, E. J., Anderson, R. G. W, Taraboulos, A., Prusiner, S. B. (1996). Proc. Natl. Acad. Sci. USA 93, 14945-14949.

Viles, J. H., Cohen, F. E. Prusiner, S. B., Goodin, D. B., Wright, P. E., Dyson, H. J. (1999). Proc. Natl. Acad. Sci. USA 96, 2042-2047.

Von Bergen, M., Friedhoff, P., Biernat, J., Heberle, J., Mandelkow, E. M., Mandelkow, E. (2000). Proc. Natl. Acad. Sci. USA 97, 5129-34.

Vorberg, I., Chan, K., Priola, S. A. (2001). J Virol. 75, 10024-32. 
Vorm, O., Mann, M. (1994). J. Am. Soc. Mass. Spectrom. 5, 955-958.

Watanabe, Y., Inanami, O., Horiuchi, M., Hiraoka, W., Shimoyama, Y., Inagaki, F., Kuwabara, M. (2006). Biochem Biophys Res Commun. 350, 549-56.

Watt, N. T., Hooper, N. M. (2003). Trends Biochem Sci. 28, 406-410.

Watzlawik, J., Skora, L., Frense, D., Griesinger, C., Zweckstetter, M., Schulz-Schaeffer, W. J., Kramer, M. L. (2006). J Biol Chem. 281, 30242-50.

Weise, J., Crome, O., Sandau, R., Schulz-Schaeffer, W., Bähr, M., Zerr, I. (2004) Neurosci Lett. 372, 146-50.

Weise, J., Sandau, R., Schwarting, S., Crome, O., Wrede, A., Schulz-Schaeffer, W., Zerr, I., Bähr, M. (2006). Stroke 37, 1296-1300.

Welker, E., Wedemeyer, W. J., Scheraga, H. A. (2001). Proc. Natl. Acad. Sci. USA. 98, 43344336.

Wille, H., Zhang, G.F., Baldwin, M.A., Cohen, F.E., Prusiner, S.B. (1996). J Mol Biol. 259, 608-21.

Wille, H., Michelitsch, M. D., Guenebaut, V., Supattapone, S., Serban, A., Cohen, F. E., Agard, D. A., Prusiner, S. B. (2002). Proc. Natl. Acad. Sci. USA 99, 3563-8.

Wiltfang, J., Arold, N., Neuhoff, V. (1991). Electrophoresis 12, 352-66.

Wishart, D. S., Sykes, B. D. (1994). Methods Enzymol. 239, 363-392.

Wong, B. S., Brown, D. R., Pan, T., Whiteman, M., Liu, T., Bu, X., Li, R., Gambetti, P., Olesik, J, Rubenstein, R., Sy, M. S. (2001). J Neurochem. 79, 689-698. 
Wopfner, F., Weidenhöfer, G., Schneider, R., von Brunn, A., Gilch, S., Schwarz, T. F., Werner, T., Schätzl, H. M. (1999). J. Mol. Biol. 289, 1163-1178.

Wright, H. T. (1991). Protein Eng. 4, 283-294.

Zahn, R., von Schroetter, C., Wuthrich, K. (1997). FEBS Lett. 417, 400-4.

Zahn, R., Liu, A., Lührs, T., Riek, R., von Schroetter, C., Garcia, F. L., Billeter, M., Calzolai, L., Wider, G., Wüthrich, K. (2000) Proc. Natl. Acad. Sci.U. S. A. 97, 145-150.

Zahn, R. (2003). J Mol Biol. 334, 477-88.

Zandomeneghi, G., Krebs, M. R., McCammon, M. G., Fandrich, M. (2004). Protein Sci. 13, 3314-21.

Ziegler, J., Sticht, H., Marx, U. C., Muller, W., Rosch, P., Schwarzinger, S. (2003). J. Biol. Chem. 278, 50175-81. 


\section{Danksagungen}

Herrn PD Dr. Walter Schulz-Schaeffer danke ich für die in jeder Hinsicht gewährte Unterstützung und für das Vertrauen, welches mir ermöglichte meine wissenschaftlichen Ideen zu entwickeln und zu verwirklichen.

Herrn Prof. Dr. Fritz danke ich für die stets interessierte und sehr freundliche Art, mit der er diese externe Arbeit betreut hat

Bei Dr. Michael Kramer bedanke ich mich für die zahlreichen wissenschaftlichen Gespräche, sowie für sein stets vorhandenes Interesse an meiner Arbeit.

Bedanken möchte ich mich auch bei Arne Wrede, Dr. Erik Bahn, Dr. Uwe Hahmann, Dr. Christina Behrens, Wiebke Wemheuer, Nadine Rupprecht, Tatjana Pfander, Manuela Becker und Elke Pralle für das sehr gute Arbeitsklima, den regen Gedankenaustausch und den Spass bei der Arbeit.

Herzlicher Dank gilt auch meinen Eltern, ohne deren Hilfe mein Studium nicht möglich gewesen wäre und die mich in jeder Hinsicht immer unterstützt haben. 


\section{Lebenslauf}

\section{Jens Watzlawik}

03.06.1972

1978-1982

1982-1984

1984-1991

1991

1991

1996-1997

1997

1997-2002

2002

10.2002-12.2006 geboren in Stadthagen

Besuch der Grundschule Lindhorst

Besuch der Orientierungsstufe Lindhorst

Besuch des Ratsgymnasiums in Stadthagen

Abitur

Immatrikulation an der Georg-August-

Universität zu Göttingen im Studienfach

Chemie (Diplom)

Experimentelle Diplomarbeit am Institut

für Organische Chemie der Universität

Göttingen unter der Anleitung von Prof.

Dr. Tietze mit dem Thema „Radikalische

und nichtradikalische Cyclisierungen“

Diplom im Studiengang Chemie

Studium der Biologie (LA/Gymnasien) an

der Georg-August-Universität zu

Göttingen

1. Staatsexamen im Studiengang

LA/Gymnasien in den Fächern Biologie

und Chemie

Beginn der Arbeit zur vorliegenden

Dissertation am Institut für

Neuropathologie der Universität Göttingen

(PD Dr. W. Schulz-Schaeffer) 